\title{
Eutergesundheitsmanagement in Milchviehherden mit sehr niedrigem Herdensammelmilchzellgehalt in Niedersachsen
}

\author{
Dissertation \\ zur Erlangung des Doktorgrades \\ der Fakultät für Agrarwissenschaften \\ der Georg-August-Universität Göttingen
}

Vorgelegt von

Otto Volling

geboren in Soltau

Göttingen, Dezember 2010 
D 7

1. Referentin/Referent: Prof. Dr. Dr. Matthias Gauly

2. Korreferentin/Korreferent: Prof. Dr. Volker Krömker

Tag der mündlichen Prüfung: 17.02.2011 
für meine Milchviehbauern 


\section{Inhaltsverzeichnis}

1 Einleitung 1

2 Literaturübersicht 3

2.1 Mastitis 3

2.1.1 Mastitisdefinition und Inzidenzrate 3

2.1.2 Bedeutung von Mastitiden auf Herdenebene 4

2.1.3 Managementbereiche 6

$\begin{array}{lll}2.1 .3 .1 & \text { Personal } & 6\end{array}$

2.1.3.2 Selektionskriterien bei der Zuchtwahl $\quad 7$

2.1.3.3 Haltung und Fütterung 9

$\begin{array}{lll}\text { 2.1.3.4 Milchentzug } & 15\end{array}$

$\begin{array}{lll}2.1 .3 .5 & \text { Melktechnik } & 20\end{array}$

3 Material und Methoden 23

3.1 Auswahl der Betriebe 23

3.2 Struktur der Betriebe 23

3.3 Datenerhebung 25

3.3.1 Datenerhebung in den Betrieben der Gruppe NZELL 25

3.3.2 Datenerhebung in Herden der Gruppe HZELL 27

$\begin{array}{lll}3.4 & \text { Statistische Auswertung } & 27\end{array}$

4 Ergebnisse $\quad 29$

4.1 Analyse der Cluster der Gruppe NZELL 29

4.1.1 Clusterbildung innerhalb der Gruppe NZELL 29

4.1.2 Analyse der Eutergesundheit in den Betrieben der Gruppe NZELL 29

4.1.3 Analyse der personalbezogenen Managementvariablen der Gruppe NZELL

4.1.4 Analyse der genetische Managementvariablen der Gruppe NZELL 32

4.1.5 Analyse der haltungsbezogenen Managementvariablen der Gruppe NZELL

4.1.6 Analyse der fütterungsbezogenen Managementvariablen der Gruppe

NZELL 
4.1.7 Analyse der melkarbeitsbezogenen Managementvariablen der Gruppe NZELL

4.1.8 Analyse der melktechnischen Managementvariablen der Gruppe NZELL

4.2 Vergleich der Betriebsgruppen HZELL und NZELL

4.2.1 Vergleich der personalbezogenen Managementvariablen

4.2.2 Vergleich der genetischen Managementvariablen

4.2.3 Vergleich der haltungsbedingten Managementvariablen

4.2.4 Vergleich der fütterungsbedingten Managementvariablen

4.2.5 Vergleich der melkarbeitsbezogenen Managementvariablen

4.2.6 Vergleich der melktechnischen Managementvariablen

4.2.7 Ergebnisse der Regressionsanalyse des Vergleichs der Gruppen HZELL und NZELL

5 Diskussion

5.1 Management der Betriebe der Cluster der Gruppe NZELL

5.1.1 Personalbezogene Managementvariablen

5.1.2 Genetische Managementvariablen

5.1.3 Haltungsbezogene Managementvariablen

5.1.4 Fütterungsbezogene Managementvariablen

5.1.5 Melkarbeitsbezogene Managementvariablen

5.1.6 Melktechnische Managementvariablen

5.2 Management der Betriebsgruppen NZELL und HZELL 70

$\begin{array}{lll}5.3 & \text { Methodenkritik } & 73\end{array}$

$\begin{array}{lll}6 & \text { Zusammenfassung } & 75\end{array}$

$\begin{array}{lll}7 & \text { Summary } & 77\end{array}$

$\begin{array}{ll}\text { Literaturverzeichnis } & 79\end{array}$

$\begin{array}{ll}\text { Anhang } & 99\end{array}$

$\begin{array}{ll}\text { Danksagung } & 151\end{array}$

$\begin{array}{ll}\text { Lebenslauf } & 152\end{array}$

$\begin{array}{ll}\text { Selbstständigkeitserklärung } & 153\end{array}$ 


\section{Tabellenverzeichnis}

Tabelle 1: Mastitis-Kategorisierung (DVG, 1994)

Tabelle 2: Personalbezogene Faktoren mit senkendem Einfluss auf die Inzidenzrate von Mastitiden

Tabelle 3: Kriterien der Rinderzucht mit senkendem Einfluss auf die Inzidenzrate von Mastitiden

Tabelle 4: Kriterien des Haltungsmanagements mit senkendem Einfluss auf die Inzidenzrate von Mastitiden

Tabelle 5: Kriterien des Fütterungsmanagements mit senkendem Einfluss auf die Inzidenzrate von Mastitiden

Tabelle 6: Kriterien des Milchentzuges mit senkendem Einfluss auf die Inzidenzrate von Mastitiden

Tabelle 7: Kriterien der Melktechnik mit senkendem Einfluss auf die Inzidenzrate von Mastitiden

Tabelle 8: Strukturdaten der Betriebsgruppen NZELL und HZELL

Tabelle 9: Cluster der Gruppe NZELL im Hinblick auf Therapiehäufigkeit und Nutzungsdauer (Mittelwert +/- Standardabweichung)

Tabelle 10: Neuerkrankungsrate, Mastitisdauer und Heilungsrate anhand des

Zellgehaltes/ml Milch der Cluster der Gruppe NZELL (Mittelwert +/- Standardabweichung)

Tabelle 11: Variablen des Personalmanagements der Cluster der Gruppe NZELL 31

Tabelle 12: Managementvariablen der Genetik der Cluster der Gruppe NZELL

Tabelle 13: Managementvariablen der Gestaltung der Haltungsumwelt der Cluster der Gruppe NZELL

Tabelle 14: Variablen des Fütterungsmanagements der Cluster der Gruppe NZELL 38

Tabelle 15: Managementvariablen der Melkarbeit der Cluster der Gruppe NZELL

Tabelle 16: Variablen der Melktechnik der Cluster der Gruppe NZELL

Tabelle 17: Neuerkrankungsrate, Mastitisdauer und Heilungsrate anhand des

Zellgehaltes/ml Milch der Gruppen HZELL und NZELL (Mittelwert + - Standardabweichung)

Tabelle 18: Variablen des Personalmanagements der Gruppen HZELL und NZELL 46

Tabelle 19: Managementvariablen der Genetik der Gruppen HZELL und NZELL $\quad 47$

Tabelle 20: Managementvariablen der Gestaltung der Haltungsumwelt der Gruppen

HZELL und NZELL 
Tabelle 21: Variablen des Fütterungsmanagements der Gruppen HZELL und NZELL

Tabelle 22: Managementvariablen der Melkarbeit der Gruppen HZELL und NZELL 51

Tabelle 23: Variablen der Melktechnik der Gruppen HZELL und NZELL 52

Tabelle 24: Binäres logistisches Regressionsmodell für die Zuordnung der Betriebe zu den Gruppen HZELL und NZELL anhand von Managementfaktoren 


\section{Abkürzungsverzeichnis}

C. Corynebacterium

CMT California Mastitis Test

d-Phase Druckphase

DVG Deutsche Veterinärmedizinische Gesellschaft

E. Escherichia

HZELL hochzellige Betriebsgruppe (Vergleichsgruppe mit höheren Zellgehalten)

IDF International Dairy Federation

$\mathrm{KbE} \quad$ koloniebildende Einheiten

KNS Koagulase-negativen Staphylokokken

NEL Nettoenergie-Laktation

NZELL niedrigzellige Betriebsgruppe (Vergleichsgruppe mit niedrigen Zellgehalten)

RZG Gesamtzuchtwert

RZS relative Zuchtwert Zellzahl

S. Staphylococcus

Sc. Streptococcus

SCC Gehalt somatischer Zellen

SD Standardabweichung

uTüN unterdurchschnittliche Therapiehäufigkeit, überdurchschnittliche Nutzungsdauer

UTuN unterdurchschnittliche Therapiehäufigkeit, unterdurchschnittliche Nutzungsdauer

üTüN überdurchschnittliche Therapiehäufigkeit, überdurchschnittliche Nutzungsdauer

üTuN überdurchschnittliche Therapiehäufigkeit, unterdurchschnittliche Nutzungsdauer 


\section{Einleitung}

Die Eutergesundheit von Milchkühen gewinnt aufgrund eines steigenden Bewusstseins der Konsumenten in Bezug auf das Wohlergehen der Nutztiere zunehmend an Bedeutung (Rollin, 2004; Napolitano et al., 2008). Außerdem gehören Mastitiden zu den Erkrankungen, die die krankheitsbedingten ökonomischen Verluste in der Milchviehhaltung entscheidend mitbestimmen (Harmon, 1994). Störungen der Eutergesundheit, deren Bedeutung mit steigender Herdenleistung zunimmt, gehören zu den Hauptabgangsgründen von Milchkühen (VIT, 2005). Die Deutsche Veterinärmedizinische Gesellschaft (DVG, 2002) schätzt die mastitisbedingten finanziellen Einbußen auf 300,-€ je gehaltener Kuh und Jahr.

Die Entstehung von Mastitiden stellt ein multifaktorielles Geschehen dar. Dabei interagieren zahlreiche Einflussfaktoren aus den Bereichen Tier, Umwelt und Mensch (Tarabla und Dodd, 1990). Einige Studien belegen mit gesicherter Evidenz die entscheidende Bedeutung des Herdenmanagements für die Eutergesundheit (Barkema et al., 1999b; Barkema et al., 1998b; Faye et al., 1997). Als Variablen, die in Verbindung mit der Abwehrleistung der Kühe stehen, wurden die Fütterung, die Stallumwelt und die maschinelle Milchgewinnung identifiziert (Krömker und Hamann, 1998; Barkema et al., 1999a).

Die Prävalenz von Mastitiden in einem milcherzeugenden Betrieb wird durch zwei Variable determiniert. Nach Dodd (1981) kann die Prävalenz als Produkt der Inzidenzrate und der Dauer einer Mastitis verstanden werden. Somit bestehen zwei grundsätzliche Möglichkeiten, die Eutergesundheitssituation der Herde in einem Milchviehbetrieb zu verbessern. Zum einen kann die Dauer der Infektionen durch Merzung infizierter Tiere, durch erfolgreiche Therapie oder durch Selbstheilung verkürzt werden. Zum anderen kann die Inzidenzrate im Betrieb gesenkt werden, indem eine Verbesserung der Tierumgebung durch Entfernung oder Reduktion der negativen Effekte von Risikofaktoren für die Mastitisentstehung erreicht wird (Østerås, 2006). Die Minimierung dieser Effekte von Risikofaktoren ist die zentrale Aufgabe des landwirtschaftlichen Eutergesundheitsmanagements als Teil des gesamten Tiergesundheitsmanagements eines milchwirtschaftlichen Betriebes.

Niedersächsische Betriebe unterscheiden sich in Bezug auf die Eutergesundheit maßgeblich. So erreichten nur 6\% der 2007 im Rahmen der Milch-Güteverordnung in 
der niedersächsischen Region Weser-Ems untersuchten Herdensammelmilchproben weniger als 125.000 Zellen/ml Milch. 52\% der Proben wiesen zwischen 125.000 und 249.000 Zellen/ml Milch, 38\% zwischen 250.000 und 399.000 Zellen/ml Milch auf und 2,5\% enthielten über 400.000 Zellen/ml Milch (LKV, 2008). Dies macht deutlich, dass mehr als 94\% der Betriebe in ihren Herden Kühe mit gestörter Eutergesundheit hielten.

Ziel der vorliegenden Studie war es, durch eine beschreibende epidemiologische Analyse zu ermitteln, durch welche Managementmaßnahmen norddeutsche Betriebe mit der niedrigsten Herdensammelmilchzellzahl als Indikator für eine sehr gute Eutergesundheit den hohen gesundheitlichen Status ihrer Herde erreichen. Dabei ging es in erster Linie darum, von in der Literatur beschriebenen Faktoren, die wesentlichen für niedersächsische Betriebe zu ermitteln. Zudem sollen die im Rahmen dieser Arbeit ermittelten Daten die Basis für zukünftige vergleichende Studien darstellen. 


\section{Literaturübersicht}

\subsection{Mastitis}

\subsubsection{Mastitisdefinition und Inzidenzrate}

Als Mastitis wird eine entzündliche Reaktion der Milchdrüse mit infektiöser, traumatischer oder toxischer Ursache bezeichnet (IDF, 1987). Zur Kategorisierung der Eutergesundheit werden auf Basis der Vereinbarungen der International Dairy Federation (IDF) und der Deutschen Veterinärmedizinischen Gesellschaft der somatische Zellgehalt der Milch und der Nachweis euterpathogener Mikroorganismen als Parameter herangezogen (DVG, 2002).

Der Gehalt somatischer Zellen (SCC) in der Milch eignet sich dabei als Maßstab für die Abwehrreaktion der Milchdrüse, da er fast ausschließlich durch eine Infektion im Euterviertel beeinflusst wird (Harmon, 2001). Weder das Laktationsstadium noch das Alter der Kühe haben einen nennenswerten Einfluss auf die somatische Zellzahl (Bodoh et al., 1976; Sheldrake et al., 1983; Laevens et al., 1997; Djabri et al., 2002). Nach derzeitigem Kenntnisstand sind Zellzahlen bis zu einem Wert von 100.000 Zellen/ml Milch als physiologischer Normalbereich zu definieren (DVG, 2002). Tabelle 1 zeigt die Kategorisierung der Eutergesundheit nach DVG (1994).

Tabelle 1: Mastitis-Kategorisierung (DVG, 1994)

\begin{tabular}{|c|c|c|}
\hline Beurteilur & $\begin{array}{r}\text { ch-mikrobiologischer B } \\
\text { in Anlehnung }\end{array}$ & er Mastitis-Kategc \\
\hline Zellgehalt & Euterpa & smen \\
\hline pro ml Milch & nicht nachgewiesen & nachgewiesen \\
\hline$<100.000$ & Normale Sekretion & Latente Infektion \\
\hline$>100.000$ & Unspezifische Mastitis & Mastitis \\
\hline
\end{tabular}

Unabhängig von der zytomikrobiologischen Diagnostik auf Euterviertelniveau gibt die Zellzahl auf Einzelgemelksniveau wertvolle Hinweise für die Mastitisbekämpfung. Wenngleich ein einfacher Entzündungsnachweis kein sicherer Infektionsnachweis ist, so ist doch weltweit die Identifikation von infizierten/erkrankten Kühen durch den Einzelgemelkszellgehalt als praxisnahe und praktikable Methode etabliert. Der jeweilig verwandte Grenzwert variiert in Abhängigkeit lokaler Faktoren wie Bezahlung der 
Milch und Untersuchungsfrequenz (Bradley und Green, 2006). In den Beneluxstaaten und den angelsächsischen Ländern wird die Überschreitung des Grenzwertes von 200.000 Zellen/ml Einzelgemelk als Hinweis auf eine Neuinfektion angesehen (Dohoo und Leslie, 1991; Schepers et al., 1997; Bradley et al., 2002). In Deutschland wird aufgrund der größeren Sensitivität der Erkennung von neuerkrankten Tieren eine Verschlechterung der Spezifität (fälschliche Zuordnung nicht erkrankter Tiere zu den erkrankten Tieren - Fehler 1. Art) durch die Verwendung des Grenzwertes von 100.000 Zellen/ml auf Einzeltierniveau in Kauf genommen.

Als Mastitisinzidenzrate wird das Verhältnis zwischen der Anzahl neuer Erkrankungsfälle in einer Population während eines bestimmten Zeitraums und der Summe der Zeiteinheiten aller Tiere in der Population unter Risiko bezeichnet (Henken et al., 2001). Neue Erkrankungsfälle können dabei sowohl subklinisch als auch klinisch sein. Im internationalen Schrifttum werden zur Ermittlung von Neuerkrankungsraten zumeist ausschließlich klinische Mastitisfälle herangezogen. Die Neuerkrankungsrate und die Schwere einer Entzündung des Drüsengewebes werden durch eine Vielzahl von Faktoren, wie die verursachenden Erreger, das Laktationsstadium, das Alter, die Abwehrsituation des Tieres, die Genetik und den Ernährungszustand beeinflusst (Smith et al., 1985a; Hogan und Smith, 1987; Kehrli et al., 1991; Nickerson et al., 1993; Harmon, 1994). So führen Mastitiserreger erst beim Zusammenwirken von endogenen und/oder exogenen Stressoren, die sowohl die systemischen (Gesamtorganismus) als auch die lokalen (Milchdrüse, Zitzengewebe) Abwehrmechanismen beeinträchtigen, zu subklinischen bzw. klinischen Mastitiden (DVG, 2002).

\subsubsection{Bedeutung von Mastitiden auf Herdenebene}

Wirtschaftlich erfolgreiche Betriebe weisen, verglichen mit weniger erfolgreichen, einen höheren Anteil eutergesunder Kühe in ihren Herden auf (Volling et al., 2010). Die DVG (2002) schätzt die mastitisbedingten finanziellen Einbußen auf $300,-€$ je gehaltener Kuh und Jahr. In der Literatur wird die Höhe des mastitisbedingten Milchmengenverlustes mit $375 \mathrm{~kg}$ je klinischem Mastitisfall und $0,5 \mathrm{~kg}$ pro Verdoppelung des Zellgehalts (SCC) über 50.000 Zellen angegeben (Seegers et al., 2003). Zudem ist die Wahrscheinlichkeit des Ausscheidens von Kühen aus dem Betrieb nach einer klinischen bzw. subklinischen Mastitis um 1,5-5-mal höher als bei eutergesunden Tieren (ebenda). 
Die Angaben in der Literatur hinsichtlich der mittleren Inzidenzrate für klinische Mastitiden schwanken zwischen 12,7 und 70 Fällen pro 100 Kuhjahren unter Risiko (Elbers et al., 1998; Barkema et al., 1999a; Beaudeau et al., 2002; Bradley und Green, 2006). Die Unterschiede zwischen den Betrieben sind hierbei beträchtlich. Beispielsweise ermittelten Elbers et al. (1998) in ihrer Untersuchung von 171 Herden eine Inzidenzrate für klinische Mastitiden zwischen 0 und 97 Fällen pro 100 Kuhjahren unter Risiko. Die untersuchten niederländischen Herden hatten jeweils mehr als 30 laktierende Kühe bzw. im Mittel 52,6 laktierende Kühe, die zu 91\% im Laufstall gehalten wurden.

Im Rahmen der ersten systematischen Maßnahmen zur Bekämpfung von Euterentzündungen auf Bestandsebene wurde vor fast 40 Jahren begonnen, den so genannten „5-Point-Plan“ in milcherzeugenden Betrieben heranzuziehen, um insbesondere Infektionen mit Streptococcus (Sc.) agalactiae, aber auch solche, die durch die Erreger Staphylococcus (S.) aureus und Sc. dysgalactiae hervorgerufen werden, zu bekämpfen (Neave et al., 1969). Im „5-Point-Plan“ stand mit den Punkten „sachgerechte Behandlung klinischer Mastitisfälle“, „Merzung chronisch euterkranker Kühe“ und „Anwendung einer regelmäßigen antibiotischen Therapie in der Trockenphase" zunächst die Verkürzung der Erkrankungsdauer im Fokus. Nur zwei der fünf Punkte, „Zitzendesinfektion nach dem Melken“ und „richtige Wartung und Anwendung der Melkmaschine“, dienten der Senkung der Inzidenzrate.

Die so genannten „kuhassoziierten Mastitiserreger“ wie S. aureus und Sc. agalactiae konnten so zwar zurückgedrängt werden, an ihre Stelle traten jedoch vermehrt die so genannten „umweltassoziierten Keime“ als Verursacher von Mastitisproblemen, denen ungleich schwerer zu begegnen ist (Smith, 1982; Schukken et al., 1989; DVG, 2002; Pyorälä, 2002; Ekman und Østerås, 2003). Als mastitisverursachende Umwelterreger kommen zumeist Escherichia (E.) coli und Sc. uberis vor, die aus der direkten Umwelt der Kuh und hier vorwiegend aus der Einstreu zu isolieren sind (Peeler et al., 2000). Eine dritte Erregergruppe stellen die Koagulase-negativen Staphylokokken (KNS) dar, die als opportunistische Hautbesiedler bezeichnet werden und in den letzten Jahren eine zunehmende Bedeutung als Mastitiserreger erlangt haben (DVG, 2002). Insofern musste der Fünf-Punkte-Plan erweitert werden. Beispielhaft mag das 10-Punkte Mastitisbekämpfungsprogramm des „National Mastitis Council“ der USA angeführt werden, welches die vorgenannten fünf Punkte um „ein sauberes und komfortables Umfeld der Kühe“, „Festlegung von Zielen der Eutergesundheit“, „Führen von 
Datenaufzeichnungen“, „regelmäßige Dokumentation der Eutergesundheit“ und „Kontrolle des Programms“ erweitert (NMC, 2001).

\subsubsection{Managementbereiche}

Ziel einer nachhaltigen Mastitisbekämpfung muss es sein, die Ereigniskette „Kontamination - Invasion - Infektion - Inflammation“ zu unterbrechen (DVG, 2002). Die Entstehung von Mastitiden stellt ein multifaktorielles Geschehen dar. Dabei interagieren zahlreiche Einflussfaktoren aus den Bereichen Tier, Umwelt und Mensch (Tarabla und Dodd, 1990), wobei sich die maßgeblichen Risikofaktoren erregerabhängig unterscheiden (Schukken et al., 1991; Lam et al., 1997a; Barkema et al., 1999a).

Die Bedeutung des Managements für die Eutergesundheit ist in mehreren Studien beschrieben worden, wobei unter anderem Zusammenhänge zum Tankmilchzellgehalt (Barkema et al., 1999b), zur Inzidenzrate klinischer Mastitiden (Barkema et al., 1998b) und zum Zellgehalt von Einzelgemelken (Faye et al., 1997) untersucht werden. Die Risikofaktoren für klinische Mastitisfälle und hohe Zellgehalte des Einzeltieres sind im Wesentlichen identisch (ebenda). Die herangezogenen Risikofaktoren für die Inzidenz klinischer Mastitiden können in 3 Kategorien unterteilt werden: 1. Resistenz bzw. Abwehrleistung der Kuh gegenüber intramammären Infektionen, 2. Exposition gegenüber euterpathogenen Keimen, 3. Heilung von intramammären Infektionen oder Entzündungsreaktionen.

\subsubsection{Personal}

Seabrock (1994) konnte in einer Studie zeigen, dass im Zusammenhang mit einer entsprechend umgänglichen Behandlung der Tiere ca. 10\% mehr Milch pro Kuh und Jahr ermolken werden können als bei aversiver Behandlung. Zur Vermeidung von Stresssituationen für die Tiere ist eine kontinuierlich durchgeführte Arbeitsroutine notwendig. Dabei ist besonders wichtig, dass jeder Melker in einem Betrieb immer die gleiche Melkroutine anwendet (Johnson, 2000). In Tabelle 2 werden personalabhängige Faktoren aufgeführt, die Einfluss auf die Mastitisinzidenz nehmen. Der Faktor mit dem stärksten Einfluss auf einen niedrigen mittleren Einzeltierzellgehalt ist nach Barnouin et al. (2004) eine Arbeitsweise, die sich durch Präzision und Sorgfalt auszeichnen sollte. 
Tabelle 2: Personalbezogene Faktoren mit senkendem Einfluss auf die Inzidenzrate von Mastitiden

\begin{tabular}{|c|c|c|c|}
\hline Mensch / Herdenbetreuer & St & $\begin{array}{c}\text { Eutergesundheits- } \\
\text { variable }\end{array}$ & Literaturhinweise \\
\hline Intensive Betreuung der Milchkühe & 1 & METZZ & \multirow[t]{2}{*}{ Barnouin et al., 2004} \\
\hline Arbeitsweise ist sorgfältig, präzise & 2 & METZZ & \\
\hline Konzentration auf die Tätigkeit Melken & 1 & METZZ & Chassagne et al., 2005 \\
\hline $\begin{array}{l}\text { Gute Ausbildung und ständige } \\
\text { Weiterbildung }\end{array}$ & * & ETZZ & Gill et al., 1990 \\
\hline \multicolumn{4}{|l|}{ Einzeltierzellgehalt $=\mathrm{ETZZ}$} \\
\hline \multicolumn{4}{|l|}{ Mittlerer Einzeltierzellgehalt= METZZ } \\
\hline \multicolumn{4}{|c|}{ St $=$ Einflussstärke $(1=$ Odd's Ratio/Risk Ratio $1,1-2,0 ; 2=$ OR/RR $2,1-5,0 ; 3=$ OR/RR $>5,0)$} \\
\hline
\end{tabular}

\subsubsection{Selektionskriterien bei der Zuchtwahl}

Die Auswahl der Rasse hat nur einen sehr begrenzten Einfluss auf die Mastitisinzidenzrate und die Zellgehalte der Milch. Unterschiede im Zellgehalt innerhalb einer Rasse sind zumeist größer als die zwischen unterschiedlichen Rassen (Brolund, 1985).

Die Heritabilität der somatischen Zellzahl der Milch liegt bei 10\% (Shook und Schutz, 1994). Über die Zuchtauswahl kann demzufolge ein positiver Einfluss auf den somatischen Zellgehalt ausgeübt werden (Shook, 2004). Häufig werden Zuchtbullen jedoch nach ihrem Gesamtzuchtwert (RZG) ausgewählt, in dem der relative Zuchtwert Zellzahl (RZS) in der deutschen Holsteinzucht lediglich zu $5 \%$ berücksichtigt wird (Shook, 2004; VIT, 2005). Der Zuchtwert Zellzahl kann herangezogen werden, um die Unterschiede zukünftiger Töchter in der gleichen Herde unter gleichen Bedingungen vorhersagen zu können. In Herden mit niedrigen Zellgehalten können die Nachkommen der schlechtesten Bullen vererbungsbedingt 250.000 statt 125.000 Zellen/ml aufweisen (Shook, 2004).

Als weitere Kriterien im Hinblick auf die Eutergesundheit können bei der Zuchtauswahl die Parameter Spitzenmilchfluss und Zitzenlänge berücksichtigt werden. Diese gelten als Risikofaktoren für das Laufenlassen der Milch (Klaas et al., 2005), wobei dies wiederum in zahlreichen Studien als Risikofaktor für klinische Mastitiden identifiziert werden konnte (Van de Geer et al., 1988; Schukken et al., 1990; Myllys und Rautala, 1995; Waage et al., 1998; Peeler et al., 2000). Mit einer Abnahme der Zitzenlängen 
verringert sich das Risiko der Kontamination von Zitzen- und Euterepithelien mit Mastitiserregern, da die Entfernung der Zitzenspitze zum Boden zunimmt. Andererseits werden mit einer Abnahme der Zitzenlänge die Zitzenkanäle kürzer und weiter, wodurch die Invasion der Erreger erleichtert werden kann (Krömker und Hamann, 1998). In Tabelle 3 sind Einflüsse von Zuchtkriterien auf die Mastitisinzidenzrate aufgeführt. Trotz des begrenzten Einflusses der Rasse treten in Herden der Rasse Holstein-Friesian, deren Tiere geringe Herdensammelmilchzelgehalte aufweisen weniger klinische E. coli-Mastitiden auf als in Herden der Rasse Meuse-Rhine-Yssel, in denen die Kühe ebenfalls niedrige Herdensammelmilchzellgehalte haben (Schukken et al., 1991).

Tabelle 3: Kriterien der Rinderzucht mit senkendem Einfluss auf die Inzidenzrate von Mastitiden

\begin{tabular}{|c|c|c|c|}
\hline Faktoren der Rinderzucht & St & $\begin{array}{l}\text { Eutergesundheits- } \\
\text { variable }\end{array}$ & Literaturhinweise \\
\hline Holstein-Friesian vs. Holstein & 1 & ETZZ & Busato et al., 2000 \\
\hline \multirow[t]{4}{*}{ Holstein-Friesian vs. Meuse-Rhine-Yssel } & 1 & $\begin{array}{c}\text { KM } \\
(\mathrm{HSMZZ}<150.000)\end{array}$ & Schukken et al., 1990 \\
\hline & 1 & KM & Elbers et al., 1998 \\
\hline & 2 & $\begin{array}{c}\text { KM E. coli } \\
(\mathrm{HSMZZ}<150.000)\end{array}$ & Schukken et al., 1991 \\
\hline & 1 & KM S. aureus & Elbers et al., 1998 \\
\hline $\begin{array}{l}\text { Holstein-Friesian x Dutch-Friesian vs. } \\
\text { Holstein-Friesian }\end{array}$ & 1 & KM E. coli & Barkema et al., 1999a \\
\hline $\begin{array}{l}\text { Herden mit überdurchschnittlicher } \\
\text { Milchleistung (7.116 kg/Kuh/Jahr) }\end{array}$ & 1 & $\begin{array}{c}\text { KM } \\
\text { KM S. aureus } \\
(\mathrm{HSMZZ}<150.000)\end{array}$ & Schukken et al., 1990 \\
\hline $\begin{array}{l}\text { Keine überdurchschnittliche } \\
\text { Einzeltierleistung }\end{array}$ & 1 & $\begin{array}{c}\text { KM } \\
\text { KM E. coli } \\
\text { KM Stapyhlococcus } \\
\text { spp. } \\
\text { KM Streptococcus } \\
\text { spp. }\end{array}$ & $\begin{array}{l}\text { Lescourret et al., } 1995 \\
\text { Gröhn et al., } 2004\end{array}$ \\
\hline Überdurchschnittliche Einzeltierleistung & * & $\begin{array}{c}\mathrm{KM} \\
\text { Arcanobacterium } \\
\text { pyogenes }\end{array}$ & Gröhn et al., 2004 \\
\hline
\end{tabular}

Fortsetzung auf der nächsten Seite 
Tabelle 3 (Fortsetzung von vorheriger Seite)

\begin{tabular}{|c|c|c|c|}
\hline Faktoren der Rinderzucht & St & $\begin{array}{l}\text { Eutergesundheits- } \\
\text { variable }\end{array}$ & Literaturhinweise \\
\hline $\begin{array}{l}\text { Einzeltierleistung in Vorlaktation }<4.740 \\
\text { vs. }>5.900 \mathrm{~kg} / \mathrm{Kuh} / \mathrm{Jahr}\end{array}$ & 1 & KM & Gröhn et al., 1990 \\
\hline $\begin{array}{l}\text { Milchleistung der Herde < } 6.705 \text { kg vs. } \\
>7.435 \mathrm{~kg} / \mathrm{Kuh} / \mathrm{Jahr}\end{array}$ & 1 & \begin{tabular}{c|}
$\mathrm{KM}$ \\
$(\bar{x} \mathrm{HSMZZ} 132.000)$
\end{tabular} & Barnouin et al., 2005 \\
\hline $\begin{array}{l}\text { Milchleistung der Herde } 7.397 \text { kg vs. } 7.030 \\
\text { kg/Kuh/Jahr }\end{array}$ & * & METZZ & Chassagne et al., 2005 \\
\hline Zuchtkriterium Zellzahl & * & KM & Rogers et al., 1998 \\
\hline \multirow[t]{2}{*}{ Zuchtkriterium KM } & * & KM & Heringstad et al., 2003 \\
\hline & * & KM & Emanuelson et al., 1988 \\
\hline$<1$ Kuh, die die Milch laufen lässt & 1 & KM & Elbers et al., 1998 \\
\hline $\begin{array}{l}\text { Kühe, die die Milch außerhalb des } \\
\text { Melkstandes laufen lassen }\end{array}$ & 1 & $\begin{array}{c}\text { KM } \\
(\mathrm{HSMZZ}<100.000)\end{array}$ & Peeler et al., 2000 \\
\hline $\begin{array}{l}\text { Sinkender Anteil Kühe, die die Milch laufen } \\
\text { lassen }\end{array}$ & 1 & $\begin{array}{c}\text { KM E. coli } \\
(\mathrm{HSMZZ}<150.000)\end{array}$ & Schukken et al., 1991 \\
\hline Geringerer Spitzenmilchfluss & * & Infektion & Dodd und Neave, 1951 \\
\hline $\begin{array}{l}\text { Spitzenmilchfluss }<0,8 \mathrm{vs} \text {. } \\
>1,6 \mathrm{~kg} / \text { Min./Viertel }\end{array}$ & * & Infektion & Grindal und Hillerton, 1991 \\
\hline Zitzen nicht dicker als Herdenmittel & 1 & KM & Slettbakk et al., 1995 \\
\hline $\begin{array}{l}\text { Abstand Zitzenspitze - Standfläche vorne } \\
>55 \mathrm{~cm} \text { vs. }<52 \mathrm{~cm}\end{array}$ & 1 & KM & \\
\hline \multicolumn{4}{|l|}{ Einzeltierzellgehalt = ETZZ } \\
\hline \multicolumn{4}{|l|}{ Mittlerer Einzeltierzellgehalt= METZZ } \\
\hline \multicolumn{4}{|l|}{ Herdensammelmilchzellgehalt $=$ HSMZZ } \\
\hline \multicolumn{4}{|l|}{ Klinische Mastitis $=\mathrm{KM}$} \\
\hline \multicolumn{4}{|c|}{ St = Einflussstärke (1 = Odd's Ratio/Risk Ratio 1,1-2,0; $2=$ OR/RR 2,1-5,0; $3=\mathrm{OR} / \mathrm{RR}>5,0)$} \\
\hline \multicolumn{4}{|c|}{$\begin{array}{l}\text { * = fehlende Angaben zur Einflussstärke weisen auf signifikante Risikofaktoren hin, für die keine Odd's Ratio oder Risk } \\
\text { Ratio ausgewiesen wurde }\end{array}$} \\
\hline
\end{tabular}

\subsubsection{Haltung und Fütterung}

Zu den wesentlichen Aufgaben des Milchviehhalters zählen die Ausgestaltung der Haltungsumwelt und des Stalles sowie die Versorgung der Tiere. Dies beginnt bei der Planung des Stalles und reicht von der Ausgestaltung der Fress-, Lauf- und Liegebereiche bis hin zur täglichen Hygiene in diesen Bereichen. Die Futterversorgung umfasst die Auswahl der Futtermittel, deren Vorlage und das Anbieten von Tränkwasser (LAVES, 2007). 
Die Ausgestaltung der Haltungsumwelt der Milchkuh übt sowohl einen direkten als auch einen indirekten Einfluss auf das Mastitisgeschehen in der Herde aus. Eine direkte Beziehung besteht zum Erregerdruck, auf den sich durch entsprechende Hygienemaßnahmen einwirken lässt. Einen indirekten Einfluss nimmt das Stallklima, da es vor allem die Immunabwehr der Tiere beeinflusst (Armstrong, 1994). In Tabelle 4 sind evidenzgesicherte Aspekte des Haltungsmanagements aufgeführt, die in Zusammenhang mit dem Gesundheitsstatus der Milchdrüse stehen.

Haltungsbedingte Einflüsse auf die Eutergesundheit stehen vor allem in Bezug zu der hygienischen Situation der Umwelt der Tiere. Zurzeit kann davon ausgegangen werden, dass die Qualität der Einstreu einen wesentlichen Einfluss auf die Eutergesundheit hat. Frische Einstreu sollte häufiger als einmal in der Woche in die Liegeboxen eingebracht werden (Giovannini und Zecconi, 2002). Zudem verringern eine mehrmals tägliche Reinigung der Liegeboxen, das Verwenden von viel Einstreumaterial (Schukken et al., 1991) und die daraus resultierenden sauberen Euter (Giovannini und Zecconi, 2002) die Häufigkeit von klinischen Mastitiden. Als Einstreumaterial eignet sich Sand deutlich besser als Stroh (ebenda). Der Anbindestall ist bei Betrachtung aus eutergesundheitlicher Sicht mit Abstand die schlechteste Stallform (Hultgren, 2002).

Tabelle 4: Kriterien des Haltungsmanagements mit senkendem Einfluss auf die Inzidenzrate von Mastitiden

\begin{tabular}{|c|c|c|c|}
\hline Allgemeine Stallbedingungen & St & $\begin{array}{c}\text { Eutergesundheits- } \\
\text { variable }\end{array}$ & Literaturhinweise \\
\hline Liegeboxenlaufstall vs. Anbindestall & 1 & ETZZ & Hultgren, 2002 \\
\hline Liegeboxenlaufstall vs. Strohlaufstall & 1 & $\begin{array}{c}\text { KM } \\
(H S M Z Z<100.000)\end{array}$ & Peeler et al., 2000 \\
\hline Liegeboxenlaufstall vs. Strohlaufstall & 1 & $\begin{array}{c}\mathrm{KM} \\
(\overline{\mathrm{x}} \mathrm{HSMZZ} 132.000)\end{array}$ & Barnouin et al., 2005 \\
\hline Strohlaufstall vs. Anbindestall & 2 & KM & \multirow[t]{2}{*}{ Hultgren, 2002} \\
\hline Liegeboxenlaufstall vs. Anbindestall & 1 & KM & \\
\hline Laufstall vs. Anbindestall & 1 & KM & Bendixen et al., 1988 \\
\hline Windleitplatten an Trauföffnung & 2 & $\begin{array}{c}\text { KM S. aureus } \\
\text { (HSMZZ <150.000) }\end{array}$ & Schukken et al., 1991 \\
\hline
\end{tabular}

Fortsetzung auf der nächsten Seite 
Tabelle 4 (Fortsetzung von vorheriger Seite)

\begin{tabular}{|c|c|c|c|}
\hline Allgemeine Stallbedingungen & St & $\begin{array}{l}\text { Eutergesundheits- } \\
\text { variable }\end{array}$ & Literaturhinweise \\
\hline Wärmegedämmtes Kuhstalldach & 1 & KM Sc. uberis & \multirow[t]{2}{*}{ Barkema et al., 1999a } \\
\hline Laufflächen als Spaltenboden & 1 & KM E. coli & \\
\hline Nicht rutschiger Wartehof & 1 & $\begin{array}{c}\text { KM } \\
(\bar{x} \text { HSMZZ 132.000) }\end{array}$ & Barnouin et al., 2005 \\
\hline Laufflächen > 1 mal/Tag reinigen & 1 & METZZ & Barnouin et al., 2004 \\
\hline Wartehof 2 mal/Tag reinigen & 1 & $\begin{array}{c}\mathrm{KM} \\
(\mathrm{HSMZZ}<100.000)\end{array}$ & Peeler et al., 2000 \\
\hline Saubere Liegeboxen & 1 & $\begin{array}{c}\mathrm{KM} \\
(\mathrm{HSMZZ}<150.000)\end{array}$ & Schukken et al., 1990 \\
\hline $\begin{array}{l}\text { Häufige tägliche Reinigung der } \\
\text { Liegeboxen }\end{array}$ & 2 & $\begin{array}{c}\text { KM E. coli } \\
(\mathrm{HSMZZ}<150.000)\end{array}$ & Schukken et al., 1991 \\
\hline$>80 \%$ saubere Euter & 2 & KM & Giovannini und Zecconi, \\
\hline $\begin{array}{l}\text { Einstreu > } 1 \mathrm{mal} / \text { Woche in Liegeboxen } \\
\text { nachfüllen }\end{array}$ & 3 & $\mathrm{KM}$ & 2002 \\
\hline $\begin{array}{l}\text { Einstreu in Liegeboxen erneuern: 1/Woche } \\
\text { vs. < 1/Woche }\end{array}$ & 1 & KM S. aureus & Elbers et al., 1998 \\
\hline Größere Einstreumenge in Liegeboxen & 2 & $\begin{array}{c}\text { KM S. aureus } \\
(\mathrm{HSMZZ}<150.000)\end{array}$ & Schukken et al., 1991 \\
\hline $\begin{array}{l}\text { Dünne Schicht Einstreu vs. seltener } \\
\text { gewechselte dicke Schicht }\end{array}$ & 1 & KM E. coli & Elbers et al., 1998 \\
\hline \multirow[t]{2}{*}{ Einstreumaterial: Stroh vs. Sägemehl } & 1 & KM & $\begin{array}{l}\text { Giovannini und Zecconi, } \\
2002\end{array}$ \\
\hline & * & KM Klebsiella spp. & Oz et al., 1985 \\
\hline Einstreumaterial: Sand vs. Stroh & 2 & KM & $\begin{array}{l}\text { Giovannini und Zecconi, } \\
2002\end{array}$ \\
\hline $\begin{array}{l}\text { Geringe Anzahl coliformer } \\
\text { Mikroorganismen in der Einstreu }\end{array}$ & * & KM & Hogan et al., 1989 \\
\hline $\begin{array}{l}\text { Anzahl coliformer Mikroorganismen in } \\
\text { Sägespänen: } 10^{4}-10^{5} \text { vs. } 10^{7} \\
\text { koloniebildende Einheiten/g }\end{array}$ & * & $\begin{array}{l}\text { Infektion mit } \\
\text { coliformen } \\
\text { Mikroorganismen }\end{array}$ & Bramley und Neave, 1975 \\
\hline Anbindestall mit Weide vs. Anbindestall & 1 & KM & Bendixen et al., 1988 \\
\hline Ermöglichung von Nachtweide & $\begin{array}{l}1 \\
1\end{array}$ & $\begin{array}{c}\text { KM } \\
\text { KM E. coli }\end{array}$ & Barkema et al., 1999a \\
\hline
\end{tabular}


Tabelle 4 (Fortsetzung von vorheriger Seite)

\begin{tabular}{|c|c|c|c|}
\hline Allgemeine Stallbedingungen & St & $\begin{array}{l}\text { Eutergesundheits- } \\
\text { variable }\end{array}$ & Literaturhinweise \\
\hline $\begin{array}{l}\text { Kein freier Zugang zur Weide bei } \\
\text { schlechtem Wetter }\end{array}$ & 1 & METZZ, & \multirow[t]{2}{*}{ Barnouin et al., 2004} \\
\hline Nutzung eines Abkalbebereiches & 1 & METZZ & \\
\hline $\begin{array}{l}\text { Abkalbe- und Krankenstall sind von } \\
\text { einander getrennt }\end{array}$ & 1 & KM E. coli & \multirow[t]{5}{*}{ Barkema et al., 1999a } \\
\hline $\begin{array}{l}\text { Stroh im Abkalbebereich nicht nach jeder } \\
\text { Kalbung wechseln }\end{array}$ & 1 & KM & \\
\hline \multirow{3}{*}{$\begin{array}{l}\text { Höhe der trockenen Einstreu im } \\
\text { Abkalbebereich }>5 \mathrm{~cm}\end{array}$} & 1 & KM & \\
\hline & 1 & KM Sc. dysgalactiae & \\
\hline & 1 & KM S. aureus & \\
\hline Gummimatten im Abkalbebereich & 1 & $\begin{array}{c}\text { KM E. coli } \\
(\mathrm{HSMZZ}<150.000)\end{array}$ & Schukken et al., 1991 \\
\hline $\begin{array}{l}\text { Reinigung des Abkalbebereiches } \\
>1 \text { mal/Monat }\end{array}$ & 1 & $\begin{array}{c}\mathrm{KM} \\
(\mathrm{HSMZZ}<100.000)\end{array}$ & Peeler et al., 2000 \\
\hline $\begin{array}{l}\text { Desinfektion des Abkalbebereiches: } \\
\text { manchmal vs. niemals }\end{array}$ & 1 & $\frac{\mathrm{KM}}{\mathrm{KM} \text { E. coli }}$ & Elbers et al., 1998 \\
\hline
\end{tabular}

Einzeltierzellgehalt $=\mathrm{ETZZ}$

Mittlerer Einzeltierzellgehalt= METZZ

Herdensammelmilchzellgehalt $=\mathrm{HSMZZ}$

Klinische Mastitis $=\mathrm{KM}$

St = Einflussstärke (1 = Odd's Ratio/Risk Ratio 1,1-2,0; 2 = OR/RR 2,1-5,0; 3 = OR/RR >5,0)

* = fehlende Angaben zur Einflussstärke weisen auf signifikante Risikofaktoren hin, für die keine Odd's Ratio oder Risk

Ratio ausgewiesen wurde

Die Ernährung bzw. Fütterung stellt im vielschichtigen Ursachenkomplex für Störungen der Eutergesundheit als Faktorenerkrankung einen wesentlichen Bereich dar (DVG, 2002). Die Körperfunktionen von Hochleistungskühen werden durch die Milchsynthese stärker bestimmt als durch die Aufrechterhaltung der Funktionsfähigkeit des eigenen Organismus. Das Immunsystem ist, auch durch die höhere Stoffwechselaktivität der Abwehrzellen, somit besonders belastet (Hamann und Krömker, 1999). Zusammenhänge zwischen der Fütterung und der Mastitisinzidenzrate werden in Tabelle 5 dargestellt.

Gerade hinsichtlich klinischer S. aureus-Mastitiden scheint die Tränkewasserqualität entscheidend zu sein. Das Tränkewasser sollte weder aus einem eigenen Brunnen noch aus einem Bach stammen (Schukken et al., 1991). In Betrieben, in denen mehr 
als $10 \%$ der Kühe mit $S$. aureus infiziert sind, kann dieser Erreger auch im Tränkewasser nachgewiesen werden (Roberson et al., 1994).

Ebenso von großer Bedeutung für die Eutergesundheit ist die ausreichende Versorgung der Milchkühe mit Selen (Le Blanc et al., 2004). Selen zählt zu den essentiellen Spurenelementen. Selenabhängige Proteine können antioxidativ wirken. Für einige Enzymsysteme, die an der Zellteilung und Immunabwehr beteiligt sind, ist Selen zur Erzielung der funktionellen Eigenschaften notwendig (Kirchgeßner et al., 2008).

Tabelle 5: Kriterien des Fütterungsmanagements mit senkendem Einfluss auf die Inzidenzrate von Mastitiden

\begin{tabular}{|c|c|c|c|}
\hline Fütterungsmanagement & St & $\begin{array}{l}\text { Eutergesundheits- } \\
\text { variable }\end{array}$ & Literaturhinweise \\
\hline Fressplätze $>0,8<1,1$ vs. $\leq 0,8$ & 1 & KM E. coli & Barkema et al., 1999a \\
\hline \multirow{2}{*}{$\begin{array}{l}\text { Kühe stehen nach dem Melken im } \\
\text { Fressgitter: fixieren, frisches Futter } \\
\text { vorlegen }\end{array}$} & 1 & $\begin{array}{c}\mathrm{KM} \\
(\mathrm{HSMZZ}<100.000)\end{array}$ & Peeler et al., 2000 \\
\hline & 1 & KM Sc. uberis & Barkema et al., 1999a \\
\hline $\begin{array}{l}\text { Grundration der Kühe mit ausgeglichenem } \\
\text { Kraftfutter }\end{array}$ & 1 & $\begin{array}{c}\text { KM } \\
(\bar{x} \text { HSMZZ 132.000) }\end{array}$ & Barnouin et al., 2005 \\
\hline Kein Energiemangel post partum & * & ETZZ & Lotthammer et al., 1988 \\
\hline Tränkewasser: Leitung vs. Brunnen & 1 & KM & Barkema et al., 1999a \\
\hline $\begin{array}{l}\text { Tränkewasser: Leitung vs. Bach oder } \\
\text { Brunnen }\end{array}$ & 1 & $\begin{array}{c}\mathrm{KM} \\
(\mathrm{HSMZZ}<150.000)\end{array}$ & Schukken et al., 1990 \\
\hline Tränkewasser: Leitung vs. Bach & 3 & $\begin{array}{c}\text { KM S. aureus } \\
(\text { HSMZZ <150.000) }\end{array}$ & Schukken et al., 1991 \\
\hline Tränkewasser: Leitung vs. Brunnen & 2 & $\begin{array}{c}\text { KM S. aureus } \\
(\mathrm{HSMZZ}<150.000)\end{array}$ & \\
\hline $\begin{array}{l}\text { Tränkewasser im Sommer: Leitung vs. } \\
\text { Brunnen }\end{array}$ & 1 & KM E. coli & Barkema et al., 1999a \\
\hline $\begin{array}{l}\text { Keine Rübennassschnitzel an laktierende } \\
\text { Kühe füttern }\end{array}$ & 1 & $\begin{array}{c}\mathrm{KM} \\
(\mathrm{HSMZZ}<150.000)\end{array}$ & Schukken et al., 1990 \\
\hline Maissilage an laktierende Kühe füttern & 1 & KM außer E. coli & Barkema et al., 1999a \\
\hline Mineralstoffe ganzjährig ergänzen & 1 & $\begin{array}{c}\text { KM Sc. dysgalactiae } \\
\text { KM Sc. uberis }\end{array}$ & \\
\hline
\end{tabular}

Fortsetzung auf der nächsten Seite

Tabelle 5 (Fortsetzung von vorheriger Seite) 


\begin{tabular}{|c|c|c|c|}
\hline Fütterungsmanagement & St & $\begin{array}{l}\text { Eutergesundheits- } \\
\text { variable }\end{array}$ & Literaturhinweise \\
\hline $\mathrm{NaCl}$ ergänzen & * & METZZ & Barnouin et al., 2004 \\
\hline MgO ergänzen & * & HSMZZ & Skrzypek et al., 2004 \\
\hline Selen ergänzen & $*$ & KM & Smith et al., 1984 \\
\hline \multirow[t]{3}{*}{ Selengehalt $\geq 150$ vs. $<150 \mu \mathrm{g} / \mathrm{l}$ Blut } & 2 & KM & Le Blanc et al., 2004 \\
\hline & * & $\begin{array}{l}\text { Infektion mit „major } \\
\text { pathogens“ }\end{array}$ & Erskine et al., 1987 \\
\hline & * & $\begin{array}{c}\text { Infektion mit } \\
\text { Koagulase- } \\
\text { negativen } \\
\text { Staphylokokken, } \\
\text { A. pyogenes, } \\
\text { Corynebacterium } \\
\text { (C.) spp., S. aureus }\end{array}$ & Jukola et al., 1996 \\
\hline Selen und Vitamin E ergänzen & * & KM & Smith et al., 1984 \\
\hline \multirow{2}{*}{$\begin{array}{l}\text { Höhere Vitamin A- und ß-Karotin-Gehalte } \\
\text { im Blut }\end{array}$} & \multirow[t]{2}{*}{ * } & ETZZ & Chew et al., 1982 \\
\hline & & ETZZ & Batra et al., 1992 \\
\hline $\begin{array}{l}300 \text { mg ß-Karotin/Tag ergänzen vom } \\
\text { 3. - 98. Tag post partum: ja vs. nein }\end{array}$ & * & KM & Wang et al., 1988 \\
\hline Vitamin E ergänzen: ja vs. nein & * & KM & Smith et al., 1984 \\
\hline \multirow{3}{*}{$\begin{array}{l}\text { Vitamin E ergänzen: } \\
4.000 \text { vs. } 1.000 \text { vs. } 100 \text { IU/Tag }\end{array}$} & \multirow[t]{3}{*}{ * } & KM & \multirow[t]{4}{*}{ Weiss et al., 1997} \\
\hline & & Infektion & \\
\hline & & $\begin{array}{l}\text { Infektion mit } \\
\text { S. aureus }\end{array}$ & \\
\hline $\begin{array}{l}\text { Vitamin E ergänzen: } \\
4.000 \text { vs. } 1.000 \text { IU/Tag }\end{array}$ & * & $\begin{array}{l}\text { Infektion mit nicht } \\
\text { Staphylokokken }\end{array}$ & \\
\hline Vitamin A, D, E ergänzen & * & $\mathrm{KM}$ & $\begin{array}{l}\text { Barnouin und Chassagne, } \\
1998\end{array}$ \\
\hline \multicolumn{4}{|l|}{ IU = International Units } \\
\hline \multicolumn{4}{|l|}{ Einzeltierzellgehalt $=\mathrm{ETZZ}$} \\
\hline \multicolumn{4}{|l|}{ Mittlerer Einzeltierzellgehalt= METZZ } \\
\hline \multicolumn{4}{|l|}{ Herdensammelmilchzellgehalt $=\mathrm{HSMZZ}$} \\
\hline \multicolumn{4}{|l|}{ Klinische Mastitis $=\mathrm{KM}$} \\
\hline \multicolumn{4}{|c|}{ St $=$ Einflussstärke (1 = Odd's Ratio/Risk Ratio 1,1-2,0; 2 = OR/RR 2,1-5,0; $3=$ OR/RR >5,0) } \\
\hline \multicolumn{4}{|c|}{$\begin{array}{l}*=\text { fehlende Angaben zur Einflussstärke weisen auf signifikante Risikofaktoren hin, für die keine Odd's Ratio oder Risk } \\
\text { Ratio ausgewiesen wurde }\end{array}$} \\
\hline
\end{tabular}




\subsubsection{Milchentzug}

Dem Milchentzug kommt eine besondere Bedeutung in Bezug auf Mastitiden zu, die durch kuhassoziierte Erreger (S. aureus, Sc. agalactiae) und Sc. dysgalactiae verursacht werden (Harmon, 1994). Jedoch können auch Umwelterreger beim Melken übertragen werden (Hogan und Smith, 1987). Sowohl die Tankmilchzellgehalte als auch das Risiko einer Infektion mit euterpathogenen Erregern sinken, wenn die Hygiene im Melkstand gut ist (Köster et al., 2006). Eine gute Melkhygiene sollte als Maßnahmen das Tragen von Gummihandschuhen beim Melken (Philpot, 1979; DVG, 2002), die Reinigung der Euter mit einem sauberen und trockenen Tuch pro Tier (Faye et al., 1997; DVG, 2002) sowie eine Zwischendesinfektion der Melkbecher nach jedem einzelnen Milchentzug (DVG, 2002) umfassen. Das Desinfizieren der Zitzen unmittelbar nach Beendigung des Milchentzuges mit einem entsprechenden Dippmittel (DVG, 2002; Ekman und Østerås, 2003; Hillerton und Berry, 2003) ist bei kuhassoziierten Erregern erforderlich, kann aber das Auftreten von E. coli-Mastitiden begünstigen (Schukken et al., 1990; Lam et al., 1997a; Elbers et al., 1998; Barkema et al., 1999b).

Um eine Übertragung von Erregern von infizierten auf nicht infizierte Tiere ausschließen zu können, sollten Milchkühe in einer ihrem Gesundheitsstatus entsprechenden Reihenfolge gemolken werden (zuerst Kühe mit niedrigen Zellgehalten, am Schluss Tiere mit klinischen Infektionen) (Ekman und Østerås, 2003).

Das Vormelken führt zu kürzeren maschinellen Melkzeiten (Svennersten-Sjaunja, 2004) und somit zu einem euterschonenderen Milchentzug. Als optimal für HolsteinFriesian-Kühe hat sich, unabhängig vom Laktationsstadium, eine Stimulation von Hand für eine Zeit von 10 bis 20 Sekunden herausgestellt (Reneau, 2001). Dabei sollte die Zeit von der ersten Berührung der Zitze bis zum Ansetzen des Melkzeuges möglichst 60 bis 90 Sekunden, optimalerweise 80 Sekunden betragen (Reneau, 2001; Svennersten-Sjaunja, 2004). In Tabelle 6 werden Faktoren dargestellt, die im Rahmen des Milchentzuges die Mastitisinzidenzrate beeinflussen.

Das Vormelken von Hand scheint insbesondere klinische S. aureus-Mastitiden zu begünstigen (Schukken et al., 1991). Verschiedene Arbeiten zeigen, dass Epithelien der menschlichen Hand durch kuh- und euterpathogene S. aureus besiedelt werden 
können (Shoop und Myres, 1984; Saperstein et al., 1988; Roberson et al., 1994); diese Stämme können durch das Vormelken auf die Zitzen- und Euterepithelien gelangen. Um eine Übertragung von S. aureus über menschliche Hände als Vektoren zu verhindern, sollten Einweghandschuhe getragen werden (DVG, 2002).

Giovannini und Zecconi (2002) stellten fest, dass sich gutes Anrüsten der Kühe (Vormelken und/oder Reinigen der Euter) vorteilhaft in Bezug auf die Häufigkeit von klinischen Mastitiden auswirkt. Die optimale Anrüstzeit ist abhängig vom Laktationsstadium der Milchkühe. Bis zum 90. Laktationstag sollte sie weniger als 30 Sekunden und ab dem 150. Laktationstag mehr als 60 Sekunden betragen (ebenda). Die Zeitdauer, die das Melkzeug am Euter haftet, sollte möglichst gering sein, Blindmelken sollte vermieden werden. Daher wird empfohlen, nicht mechanisch nachzumelken und eine Abnahmeautomatik zu verwenden (ebenda).

In verschiedenen Arbeiten wurde festgestellt, dass die mittleren Einzeltierzellgehalte in Herden geringer waren, in denen ein Zitzendesinfektionsmittel sprühend und nicht tauchend appliziert wurde (Barnouin et al., 2004; Chassagne et al., 2005). Barnouin et al. (2004) kommen zu dem Schluss, dass zwischen Zitzentauchen und Zitzensprühen kein Unterschied bestehen muss. Voraussetzung für ein wirkungsvolles Zitzentauchen ist die Verwendung eines starken Desinfektionsmittels und die regelmäßige Reinigung der Dippbecher. Beim Zitzensprühen ist sicherzustellen, dass die gesamte Zitzenhaut benetzt wird (Barnouin et al., 2004).

Tabelle 6: Kriterien des Milchentzuges mit senkendem Einfluss auf die Inzidenzrate von Mastitiden

\begin{tabular}{|l|c|c|l|}
\hline Faktoren des Milchentzuges & St & $\begin{array}{c}\text { Eutergesundheits- } \\
\text { variable }\end{array}$ & Literaturhinweise \\
\hline $\begin{array}{l}\text { Kühe nach dem Melken nicht auf den } \\
\text { Laufhof sperren }\end{array}$ & 1 & $\begin{array}{c}\text { KM } \\
(\text { HSMZZ <100.000) }\end{array}$ & Peeler et al., 2000 \\
\hline $\begin{array}{l}\text { Gute und mittlere Hygiene im Melkstand } \\
\text { und Wartehof }\end{array}$ & $*$ & METZZ & Köster et al., 2006 \\
\hline $\begin{array}{l}\text { Scheren der Euter: ja vs. nein } \\
\text { Kühe mit subklinischer oder klinischer } \\
\text { Mastitis am Schluss melken }\end{array}$ & 1 & METZZ & Barnouin et al., 2004 \\
\hline $\begin{array}{l}\text { Kühe mit Infektion mit S. aureus am } \\
\text { Schluss melken }\end{array}$ & $*$ & $\begin{array}{c}\text { Infektion mit } \\
\text { S. aureus }\end{array}$ & Wilson et al., 1995 \\
\hline
\end{tabular}

Fortsetzung auf der nächsten Seite 
Tabelle 6 (Fortsetzung von vorheriger Seite)

\begin{tabular}{|c|c|c|c|}
\hline Faktoren des Milchentzuges & St & $\begin{array}{l}\text { Eutergesundheits- } \\
\text { variable }\end{array}$ & Literaturhinweise \\
\hline 3 mal vs. 2 mal melken/Tag & * & METZZ & Smith et al., 2002 \\
\hline \multirow[t]{2}{*}{ Zitzentauchen vor dem Melken } & $*$ & Infektion & \multirow{2}{*}{$\begin{array}{l}\text { Pankey und Drechsler, } \\
1993\end{array}$} \\
\hline & & $\begin{array}{c}\text { Infektion mit "major } \\
\text { pathogens“ }\end{array}$ & \\
\hline \multirow[t]{2}{*}{$\begin{array}{l}\text { Zitzentauchen vor dem Melken mit } \\
\text { lodophor: } 0,1 \% \text { oder } 0,25 \% \text { vs. nicht }\end{array}$} & * & $\begin{array}{l}\text { Infektion mit „major } \\
\text { pathogens“ }\end{array}$ & \multirow[t]{2}{*}{ Pankey et al., 1987} \\
\hline & & $\begin{array}{l}\text { Infektion mit } \\
\text { umweltassoziierten } \\
\text { Mikroorganismen }\end{array}$ & \\
\hline \multirow[t]{2}{*}{ Euter trocken reinigen } & 1 & $\begin{array}{c}\text { KM E. coli } \\
(\mathrm{HSMZZ}<150.000)\end{array}$ & Schukken et al., 1991 \\
\hline & 1 & KM Sc. dysgalactiae & \multirow[t]{2}{*}{ Barkema et al., 1999a } \\
\hline $\begin{array}{l}\text { Euter nicht mit einem Lappen aus einem } \\
\text { Eimer waschen }\end{array}$ & 1 & KM E. coli & \\
\hline $\begin{array}{l}\text { Nach dem Euterwaschen dies mit } \\
\text { Zeitungspapier trocknen, 1/Tier }\end{array}$ & * & ETZZ & Gill et al., 1990 \\
\hline Anrüstzeit 60 Sekunden & $*$ & ETZZ & Kawai et al., 2005 \\
\hline $\begin{array}{l}\text { Anrüstzeit bis zum 90. Laktationstag } \\
<30 \text { Sekunden }\end{array}$ & 2 & KM & \multirow[t]{2}{*}{$\begin{array}{l}\text { Giovannini und Zecconi, } \\
2002\end{array}$} \\
\hline $\begin{array}{l}\text { Anrüstzeit ab 150. Laktationstag } \\
>60 \text { Sekunden }\end{array}$ & 2 & KM & \\
\hline Vormelken in Vormelkbecher & * & ETZZ & Gill et al., 1990 \\
\hline \multirow[t]{5}{*}{ Kein Vormelken von Hand } & 1 & $\begin{array}{c}\mathrm{KM} \\
(\mathrm{HSMZZ}<100.000)\end{array}$ & Peeler et al., 2000 \\
\hline & 1 & KM S. aureus & Barkema et al., 1999a \\
\hline & 1 & KM S. aureus & Elbers et al., 1998 \\
\hline & 3 & $\begin{array}{c}\text { KM S. aureus } \\
(\mathrm{HSMZZ}<150.000)\end{array}$ & Schukken et al., 1991 \\
\hline & 1 & KM E. coli & Elbers et al., 1998 \\
\hline $\begin{array}{l}\text { Kein Lufteinlassen beim Ansetzten der } \\
\text { Zitzenbecher }\end{array}$ & 1 & METZZ & Chassagne et al., 2005 \\
\hline Abnahmeautomatik & 2 & KM & $\begin{array}{l}\text { Giovannini und Zecconi, } \\
2002\end{array}$ \\
\hline Keine Abnahmeautomatik & 1 & KM E. coli & Barkema et al., 1999a \\
\hline
\end{tabular}


Tabelle 6 (Fortsetzung von vorheriger Seite)

\begin{tabular}{|c|c|c|c|}
\hline Faktoren des Milchentzuges & St & $\begin{array}{l}\text { Eutergesundheits- } \\
\text { variable }\end{array}$ & Literaturhinweise \\
\hline $\begin{array}{l}\text { Halbautomatische Abnahme Duovac (Fa. } \\
\text { Alfa Laval Agri AB, Tumba, Schweden) }\end{array}$ & 1 & $\mathrm{KM}$ & Barkema et al., 1999a \\
\hline Kein mechanisches Nachmelken & 2 & $\mathrm{KM}$ & $\begin{array}{l}\text { Giovannini und Zecconi, } \\
2002\end{array}$ \\
\hline Kein Blindmelken & * & ETZZ & Kawai et al., 2005 \\
\hline $\begin{array}{l}\text { Kein Spülen der Melkzeuge nach dem } \\
\text { Melken einer Kuh mit hoher ETZZ (Wasser } \\
\text { oder Spüllösung) }\end{array}$ & 1 & $\begin{array}{c}\text { KM } \\
(\bar{x} \text { HSMZZ 132.000) }\end{array}$ & Barnouin et al., 2005 \\
\hline $\begin{array}{l}\text { Zwischendesinfektion mit Wasser, } 85^{\circ} \mathrm{C} \text { für } \\
\text { mind. } 5 \mathrm{Sec} \text {. }\end{array}$ & * & Neuinfektion & Neave et al., 1969 \\
\hline Zwischendesinfektion mit Jod & * & Infektion C. bovis & Smith et al., 1985c \\
\hline \multirow[t]{6}{*}{ Keine Zitzendesinfektion nach dem Melken } & 1 & $\mathrm{KM}$ & Elbers et al., 1998 \\
\hline & 1 & $\begin{array}{c}\text { KM } \\
(\mathrm{HSMZZ}<100.000)\end{array}$ & Peeler et al., 2000 \\
\hline & 1 & $\begin{array}{c}\text { KM } \\
(\mathrm{HSMZZ}<150.000)\end{array}$ & Schukken et al., 1990 \\
\hline & 2 & KM E. coli & Elbers et al., 1998 \\
\hline & 2 & $\begin{array}{c}\text { KM E. coli } \\
(\mathrm{HSMZZ}<150.000)\end{array}$ & Schukken et al., 1991 \\
\hline & * & $\begin{array}{l}\text { Infektion mit } \\
\text { coliformen } \\
\text { Mikroorganismen }\end{array}$ & \multirow[t]{4}{*}{ Hogan et al., 1987} \\
\hline \multirow[t]{2}{*}{ Zitzendesinfektion nach dem Melken } & * & $\begin{array}{l}\text { Infektion mit KNS, } \\
\text { S. aureus und Sc. } \\
\text { agalactiae }\end{array}$ & \\
\hline & & $\begin{array}{l}\text { Infektion mit } \\
\text { S. epidermidis }\end{array}$ & \\
\hline $\begin{array}{l}\text { Zitzentauchen mit lodophor vs. } \\
\text { Benzylsulfonsäure }\end{array}$ & * & $\begin{array}{l}\text { Infektion mit } \\
\text { nicht-S. aureus- } \\
\text { Staphylokokken }\end{array}$ & \\
\hline $\begin{array}{l}\text { Zitzentauchen mit lodophor mit 1\% } \\
\text { verfügbarem Jod vs. kein Tauchen }\end{array}$ & * & $\begin{array}{c}\text { KM } \\
\text { KM nicht-Sc. } \\
\text { agalactiae- } \\
\text { Streptokokken }\end{array}$ & Eberhart et al., 1983 \\
\hline
\end{tabular}


Tabelle 6 (Fortsetzung von vorheriger Seite)

\begin{tabular}{|c|c|c|c|}
\hline Faktoren des Milchentzuges & St & $\begin{array}{l}\text { Eutergesundheits- } \\
\text { variable }\end{array}$ & Literaturhinweise \\
\hline $\begin{array}{l}\text { Zitzentauchen mit lodophor vs. kein } \\
\text { Tauchen }\end{array}$ & * & $\begin{array}{l}\text { Infektion mit } \\
\text { nicht-S. aureus- } \\
\text { Staphylokokken }\end{array}$ & Hogan et al., 1987 \\
\hline Kein Zitzentauchen vs. mit 0,5\% Jod & * & $\begin{array}{c}\text { KM mit E. coli, } \\
(\mathrm{HSMZZ}<150.000)\end{array}$ & Lam et al., 1997a \\
\hline Kein Zitzentauchen vs. mit 0,5\% Jod & * & $\begin{array}{l}\text { Infektion mit E. coli, } \\
(\mathrm{HSMZZ}<150.000)\end{array}$ & \multirow[t]{3}{*}{ Lam et al., 1997b } \\
\hline $\begin{array}{l}\text { Zitzentauchen mit 0,5\% Jod vs. kein } \\
\text { Tauchen }\end{array}$ & * & $\begin{array}{c}\text { Infektion mit } \\
\text { S. aureus } \\
(\text { HSMZZ }<150.000)\end{array}$ & \\
\hline $\begin{array}{l}\text { Zitzentauchen mit 0,5\% Jod vs. kein } \\
\text { Tauchen }\end{array}$ & * & $\begin{array}{l}\text { Infektion mit „minor } \\
\text { pathogens“ } \\
(\mathrm{HSMZZ}<150.000)\end{array}$ & \\
\hline $\begin{array}{l}\text { Zitzentauchen von spröden Zitzen mit } 1 \% \\
\text { Jod und } 10 \% \text { Glycerin vs. } 10 \% \text { Glycerin } \\
\text { oder kein Tauchen }\end{array}$ & * & $\begin{array}{l}\text { Infektion mit } \\
\text { S. aureus }\end{array}$ & Fox, et al., 1991 \\
\hline Zitzentauchen mit anderen Mitteln vs. & 1 & KM S. aureus & \multirow[t]{3}{*}{ Barkema et al., 1999a } \\
\hline Chlorhexidine & 1 & KM Sc. dysgalactiae & \\
\hline Kein Zitzentauchen vs. Chlorhexidine & 1 & KM Sc. dysgalactiae & \\
\hline $\begin{array}{l}\text { Zitzentauchen mit Chlorhexidine vs. } \\
\text { lodophor }\end{array}$ & * & Infektion S. hyicus & Hogan et al., 1987 \\
\hline $\begin{array}{l}\text { Barriere-Dippmittel (Latex) vs. kein } \\
\text { Tauchen }\end{array}$ & * & $\begin{array}{c}\text { Infektion mit } \\
\text { S. aureus } \\
\text { Infektion mit } \\
\text { S. epidermidis } \\
\text { Infektion mit } \\
\text { coliformen } \\
\text { Mikroorganismen }\end{array}$ & Farnsworth et al., 1980 \\
\hline Dippbecher nach jedem Melken reinigen & * & METZZ & Barnouin et al., 2004 \\
\hline Zitzendesinfektion sprühen vs. tauchen & $\begin{array}{l}2 \\
2\end{array}$ & $\begin{array}{l}\text { METZZ } \\
\text { METZZ }\end{array}$ & $\begin{array}{l}\text { Chassagne et al., } 2005 \\
\text { Barnouin et al., } 2004\end{array}$ \\
\hline
\end{tabular}

Einzeltierzellgehalt $=\mathrm{ETZZ}$

Mittlerer Einzeltierzellgehalt= METZZ

Herdensammelmilchzellgehalt $=\mathrm{HSMZZ}$

Klinische Mastitis $=\mathrm{KM}$

St $=$ Einflussstärke (1 = Odd's Ratio/Risk Ratio 1,1-2,0; 2 = OR/RR 2,1-5,0; 3 = OR/RR >5,0) 


\subsubsection{Melktechnik}

Mein et al. (2004) nehmen an, dass die Melkmaschine zu 10\% direkt (durch den Transport von Bakterien, Kreuz-Kontamination sowie "impacts") und zu weiteren 10\% indirekt (durch Effekte auf die Gesundheit des Zitzenkanals, des Zitzengewebes und der Zitzenhaut) zur Entstehung von neuen Infektionen beiträgt.

Um mögliche negative Einflüsse der Zitzengummis auf das Gewebe gering zu halten, sollten diese immer in neuem Zustand eingebaut und entsprechend den Herstellerangaben gewechselt werden. Die Alterung der Zitzengummis und ein damit einhergehendes schlechteres Melkverhalten stellen einen kontinuierlichen Prozess dar. Die ersten signifikanten Änderungen im Melkverhalten (sinkender Milchfluss, Zunahme der Zitzengewebsbelastung) lassen sich nach 3.000 Melkungen feststellen (Hillerton et al., 2003)

Vakuumschwankungen in der Milchleitung, die unter anderem durch rutschende und dabei Nebenluft ziehende oder herunterfallende Melkzeuge verursacht werden können, sollten vermieden werden (Bramley und Neave, 1975).

Zitzen- und Zitzenhautläsionen begünstigen zum einen die Besiedlung mit Erregern und beeinträchtigen zum anderen den Melkvorgang und damit die Blutversorgung der Zitze (Krömker und Hamann, 1998). Zirkulationsstörungen, die mit einer deutlich reduzierten Infektionsabwehr der Zitze einhergehen, werden zudem durch lange Melkdauer, unzureichende Pulsierung und hohe Melkvakua hervorgerufen (Jasper et al., 1975; Mahle et al., 1982; Krömker und Hamann, 1998). In Tabelle 7 sind melktechnische Faktoren mit Einfluss auf die Mastitisinzidenz dargestellt.

Zur Verhinderung von Infektionen mit E. coli soll die Druckphase (d-Phase) nicht unter 150 ms lang sein (Barkema et al., 1999a). Eine kurze Druckphase führt vermehrt zu Zitzenspitzenverletzungen (Mein, 1990) und ist mit einer erhöhten Prävalenz von Infektionen, die durch Sc. dysgalactiae oder S. aureus verursacht werden (Reitsma, 1981; Zadoks et al., 2001) und höheren Einzeltierzell- (Mahle et al., 1982) sowie Herdensammelmilchzellgehalten (Østeras, 1995) verbunden. Für die Praxis wird eine Länge der d-Phase von 200-300 ms empfohlen (Krömker, 2007). 
Tabelle 7: Kriterien der Melktechnik mit senkendem Einfluss auf die Inzidenzrate von Mastitiden

\begin{tabular}{|c|c|c|c|}
\hline Melktechnik & St & $\begin{array}{l}\text { Eutergesundheits- } \\
\text { variable }\end{array}$ & Literaturhinweise \\
\hline Melkmaschine überprüft & 1 & $\begin{array}{c}\text { KM S. aureus } \\
(\mathrm{HSMZZ}<150.000)\end{array}$ & Schukken et al., 1991 \\
\hline $\begin{array}{l}\text { Anzahl Melkzeuge }>8 \text { vs. } \leq 8 \text { (bei } \\
75 \text { Kühe/Herde +/- 21,1 Kühe/Herde }\end{array}$ & 1 & KM E. coli & Barkema et al., 1999a \\
\hline Zitzengummiwechsel > 6.000 Melkungen & 1 & $\begin{array}{l}\text { KM (HSMZZ } \\
<100.000)\end{array}$ & Peeler et al., 2000 \\
\hline $\begin{array}{l}\text { Kein Blindmelken mit Störungen der } \\
\text { Pulsierung }\end{array}$ & * & Infektion & Mein et al., 1986 \\
\hline Keine Impacts beim Melken erzeugen & * & Infektion mit E. coli & Bramley und Neave, 1975 \\
\hline $\begin{array}{l}\text { Bei starken zyklischen } \\
\text { Vakuumschwankungen keine } \\
\text { unregelmäßigen Vakuumschwankungen } \\
\text { erzeugen }\end{array}$ & * & $\begin{array}{l}\text { Infektion mit } \\
\text { Sc. agalactiae und } \\
\text { Sc. dysgalactiae }\end{array}$ & Thiel et al., 1973 \\
\hline $\begin{array}{l}\text { Minimales Vakuum im kleinen } \\
\text { Milchschlauch bei einem Milchfluss von } \\
2 \text { kg/min: } 34,6 \text { vs. } 32,1 \mathrm{kPa}\end{array}$ & * & HSMZZ & Barkema et al., 1998a \\
\hline $\begin{array}{l}\text { Minimales Vakuum im kurzen } \\
\text { Milchschlauch während der dynamischen } \\
\text { Messung: } \leq 32 \text { vs. > } 32 \mathrm{kPa}\end{array}$ & 1 & KM & Barkema et al., 1999a \\
\hline $\begin{array}{l}\text { Minimales Vakuum im kurzen } \\
\text { Milchschlauch während eines Milchflusses } \\
\text { von } 4 \mathrm{~kg} / \mathrm{min}: \geq 25 \text { vs. }<25 \mathrm{kPa}\end{array}$ & 1 & KM E. coli & \\
\hline $\begin{array}{l}\text { Mittleres maximales Vakuum im kurzen } \\
\text { Milchschlauch: } \leq 43.5 \text { vs. }>43.5 \mathrm{kPa}\end{array}$ & 1 & KM Sc. dysgalactiae & \\
\hline $\begin{array}{l}\text { Maximales Vakuum im kurzen } \\
\text { Milchschlauch bei einem Fluss von } \\
3 \mathrm{~kg} / \mathrm{min}: \leq 40 \text { vs. }>40 \mathrm{kPa}\end{array}$ & 1 & KM Sc. uberis & \\
\hline $\begin{array}{l}\text { Hohe Vakuum-Reserve in der } \\
\text { Vakuumpumpe }\end{array}$ & * & HSMZZ & Nyhan und Cowhig, 1967 \\
\hline Vakuumhöhe 50 vs. $41,6 \mathrm{kPa}$ & * & ETZZ & Mahle et al., 1982 \\
\hline Elektronischer Pulsator & 1 & KM E. coli & Barkema et al., 1999a \\
\hline Pulsation $70: 30$ vs. $60: 40$ & * & ETZZ & Mahle et al., 1982 \\
\hline
\end{tabular}

Fortsetzung auf der nächsten Seite 
Tabelle 7 (Fortsetzung von vorheriger Seite)

\begin{tabular}{|c|c|c|c|}
\hline Melktechnik & St & $\begin{array}{l}\text { Eutergesundheits- } \\
\text { variable }\end{array}$ & Literaturhinweise \\
\hline d-Phase des Pulszyklus nicht $<150$ ms & 3 & KM E. coli & Barkema et al., 1999a \\
\hline $\begin{array}{l}\text { Keine Nebenlufteinträge in den } \\
\text { Zitzenbecher während des Melkens }\end{array}$ & * & Infektion & Cousins et al., 1973 \\
\hline $\begin{array}{l}\text { Kein tiefes Eindringen der Zitzen in den } \\
\text { Zitzenbecher zum Ende des Melkens }\end{array}$ & * & KM & $\begin{array}{l}\text { Rønningen und Reitan, } \\
1990\end{array}$ \\
\hline $\begin{array}{l}\text { Schwächere Hyperkeratosen (weniger } \\
\text { stark ausgeprägte Ringe) }\end{array}$ & * & KM (außer E. coli) & Neijenhuis et al., 2001 \\
\hline $\begin{array}{l}\text { Schwächere Hyperkeratosen: weniger } \\
\text { stark ausgeprägte Ringe vs. extrem } \\
\text { ausgebildet Ringe }\end{array}$ & * & $\begin{array}{l}\text { Infektion mit } \\
\text { S. aureus }\end{array}$ & Zadoks et al., 2001 \\
\hline \multicolumn{4}{|l|}{ Einzeltierzellgehalt $=$ ETZZ } \\
\hline \multicolumn{4}{|l|}{ Herdensammelmilchzellgehalt $=\mathrm{HSMZZ}$} \\
\hline \multicolumn{4}{|l|}{ Klinische Mastitis $=\mathrm{KM}$} \\
\hline \multicolumn{4}{|c|}{ St $=$ Einflussstärke (1 = Odd's Ratio/Risk Ratio 1,1-2,0; 2 = OR/RR 2,1-5,0; $3=$ OR/RR >5,0) } \\
\hline
\end{tabular}




\section{Material und Methoden}

\subsection{Auswahl der Betriebe}

Zunächst erfolgte die Identifikation der niedersächsischen Milchviehherden mit den niedrigsten Herdensammelmilchzellzahlen als Indikator für eine sehr gute Eutergesundheit durch die Landeskontrollverbände. Als Startanalysekriterium wurde der Zellzahljahresmittelwert der Herdensammelmilch des Milchkontrolljahres vom 01.10.2004 bis 30.09.2005 zu Grunde gelegt. Es wurden diejenigen Herden ermittelt, die sich über einen Zeitraum von 12 Monaten durch eine hohe Persistenz des Zellzahlmittels auf niedrigem Niveau auszeichneten, also solche, die im gewichteten Monatsmittel am häufigsten Werte unter 100.000 Zellen $/ \mathrm{ml}$ erreichten. Bei Übereinstimmung mehrerer Betriebe hinsichtlich dieses Kriteriums wurde der Betrieb mit der höheren Kuhzahl ausgewählt. Betriebe mit weniger als sechs melkenden Kühen im Durchschnitt des Jahres wurden nicht berücksichtigt.

Um eine gleichmäßige örtliche Verteilung der Betriebe zu gewährleisten, wurde Niedersachsen räumlich unterteilt. Je 14.000 Milchkühe in einer Region wurde ein Betrieb in die Versuchsgruppe aufgenommen. Für fünf Betriebe, die aus persönlichen Gründen nicht an der Studie teilnehmen wollten, wurde gemäß den oben aufgeführten Kriterien je ein Ersatzbetrieb ermittelt.

In einem zweiten Schritt wurde eine Vergleichsgruppe von Milchviehbetrieben mit Problemen im Bereich der Eutergesundheit zusammengestellt. Diese hatten sich aufgrund von Eutergesundheitsproblemen an den Eutergesundheitsdienst der Landwirtschaftskammer Hannover gewandt. Zu jedem Betrieb der Gruppe mit den sehr niedrigen Herdensammelmilchzellzahlen wurde ein in Bezug auf die regionale Lage und die Betriebsgröße vergleichbarer Betrieb ermittelt.

\subsection{Struktur der Betriebe}

Insgesamt wurden 44 Betriebe mit niedrigen Zellgehalten in der Herdensammelmilch (NZELL) in die vorliegende Studie einbezogen. Im Mittel des Kontrolljahres hielten diese Betriebe 41 Milchkühe (Tabelle 8), die ein mittleres Alter von 4,8 Jahren und eine mittlere 305-Tageleistung von $9.086 \mathrm{~kg}(+/-1.199 \mathrm{~kg})$ Milch bei 4,2\% (+/- 0,25\%) Fett und 3,4\% (+/- 0,08\%) Eiweiß aufwiesen. Im Mittel der elf monatlichen Milchkontrollen konnte für die Betriebe ein Zellgehalt von 88.000 Zellen/ml Milch 
(Minimum: 49.000 Zellen/ml; Maximum: 134.000 Zellen/ml) bestimmt werden. Die Spannweite der monatlichen Ergebnisse je Betrieb betrug 43.000 bis 440.000 Zellen/ml Milch. Die Zwischenkalbezeit lag bei im Mittel 405 (+/- 19) Tagen bei einem Besamungsindex von 1,9 (+/- 0,4) und einer Non-Return-Rate von 64\% $(+/-13 \%)$.

Von den 44 aufgenommenen Vergleichsbetrieben mit Eutergesundheitsproblemen (HZELL) standen nicht alle Daten zur Verfügung. Da diese Betriebe im Rahmen der Problemberatung aufgesucht wurden, konnte nur eine eingeschränkte Analyse der Managementdaten erfolgen. Die Betriebe der Gruppe HZELL hielten im Mittel 45 Milchkühe, die ein mittleres Alter von 4,7 Jahren und eine mittlere $305-$ Tageleistung von $8.215 \mathrm{~kg}(+/-1.212 \mathrm{~kg})$ Milch bei 4,15\% (+/- 0,33\%) Fett und $3,27 \%$ (+/- 0,08\%) Eiweiß hatten. Im Mittel der elf monatlichen Milchkontrollen wiesen die Betriebe 312.000 Zellen/ml Milch (Minimum: 166.000 Zellen/ml; Maximum: 552.000 Zellen/ml) Milch auf. Die Zwischenkalbezeit betrug im Mittel 416 Tage (+/- 25 Tage) (Tabelle 8).

Tabelle 8: Strukturdaten der Betriebsgruppen NZELL und HZELL

\begin{tabular}{|l|c|c|c|c|c|c|}
\hline & \multicolumn{3}{|c|}{ NZELL } & \multicolumn{3}{c|}{ HZELL } \\
& Mittelwert (SD) & Min & Max & Mittelwert (SD) & Min & Max \\
\hline Anzahl Kühe & $41(+/-24)$ & 6 & 116 & $45(+/-27)$ & 15 & 125 \\
\hline Alter, Jahre & $4,8(+/-0,5)$ & 3,7 & 5,9 & $4,7(+/-0,6)$ & 3,6 & 6,0 \\
\hline $\begin{array}{l}\text { Nutzungsdauer, } \\
\text { Monate (Herde) }\end{array}$ & $28(+/-6)$ & 16,7 & 41,5 & $27(+/-4)$ & 16,5 & 37,0 \\
\hline Laktationen (Herde) & $2,2(+/-0,4)$ & 1,4 & 3,2 & $2,1(+/-0,5)$ & 1,2 & 3,3 \\
\hline $\begin{array}{l}\text { Gesamtleistung, } \\
\text { kg Milch (Herde) }\end{array}$ & $21.135(+/-5.082)$ & 11.967 & 31.495 & & & \\
\hline $\begin{array}{l}\text { Nutzungsdauer, } \\
\text { Monate (Merzungen) }\end{array}$ & $39,7(+/-13,1)$ & 16,8 & 74,4 & & & \\
\hline Laktationen (Merzungen) & $3,1(+/-1)$ & 1,4 & 6,1 & & & \\
\hline $\begin{array}{l}\text { Gesamtleistung, } \\
\text { kg Milch (Merzungen) }\end{array}$ & 28.635 & 13.693 & 59.063 & & & \\
\hline 305-Tage Leistung, kg & $(+/-10401)$ & & & & & \\
\hline Fettgehalt, \% & $9.086(+/-1.199)$ & 6.073 & 12.001 & $8.215(+/-1.212)$ & 4.755 & 11.622 \\
\hline Fettmenge, kg & $4,19(+/-0,25)$ & 3,41 & 4,72 & $4,15(+/-0,33)$ & 3,16 & 4,78 \\
\hline Eiweißgehalt, \% & $379(+/-40)$ & 271 & 453 & & & \\
\hline
\end{tabular}


Tabelle 8 (Fortsetzung von vorheriger Seite)

\begin{tabular}{|l|c|c|c|c|c|c|}
\hline & \multicolumn{3}{|c|}{ NZELL } & \multicolumn{3}{c|}{ HZELL } \\
\hline Fett-Eiweißmenge, kg & $686(+/-81)$ & 471 & 843 & & & \\
\hline Zellgehalt, 1.000 Zellen/ml & $88(+/-34)$ & 49 & 134 & $312(+/-32)$ & 166 & 552 \\
\hline Zwischenkalbezeit, Tage & $405(+/-19)$ & 361 & 448 & $416(+/-25)$ & 363 & 474 \\
\hline Abkalberate, \% & $80(+/-8)$ & 59 & 95 & & & \\
\hline Besamungsindex (Kühe) & $1,9(+/-0)$ & 1,3 & 3,4 & & & \\
\hline Besamungsindex (Färsen) & $1,6(+/-0)$ & 1,0 & 3,0 & & & \\
\hline Non-Return-Rate, \% (Kühe) & $64(+/-13)$ & 33 & 100 & & & \\
\hline Non-Return-Rate, \% (Färsen) & $72(+/-21)$ & 0 & 100 & & & 34 \\
\hline Erstkalbealter Färsen, Monate & $29(+/-2)$ & 25 & 35 & $29(+/-3)$ & 23 & 34 \\
\hline
\end{tabular}

\subsection{Datenerhebung}

\subsubsection{Datenerhebung in den Betrieben der Gruppe NZELL}

Die Datengrundlage bildeten die Ergebnisse der monatlichen Milchleistungsprüfungen im Milchkontrolljahr 2004-2005 sowie die auf den Betrieben erhobenen Daten. Diese wurden in Microsoft Excel erfasst. Zur Erhebung der Daten wurden die Betriebe mit den niedrigen Herdensammelmilchzellgehalten von November 2005 bis Januar 2006 besucht. Das Interview wurde mit Hilfe eines standardisierten Fragebogens durchgeführt. Die eigenen Messungen und Beobachtungen erfolgten an Hand einer Checkliste.

Der Fragebogen bzw. die Checkliste wurden auf Basis aktueller Literatur (Schukken et al., 1990; Faye, 1997; Barkema et al., 1999a; Busato et al., 2000; Peeler et al., 2000; Barnouin et al., 2004; Chassagne et al., 2005) und in Rücksprache mit Experten erstellt. Der Fragebogen umfasste 303 überwiegend geschlossene Fragen. Diese werden im Anhang aufgeführt. $\mathrm{Zu}$ jedem Managementbereich wurde eine offene Frage gestellt, mittels welcher der Landwirt nach seiner Meinung zu wesentlichen Aspekten gefragt wurde. Die Interviews dauerten zwischen zwei und vier Stunden. Ausgewertet wurden nur solche Aspekte, die bereits in der Literatur genannt wurden.

Während einer Melkzeit wurden die Euter- und Zitzenform, die Melkarbeit, die Positionierung der Melkzeuge sowie die akute und chronische Zitzenkondition nach Melkzeugabnahme (Neijenhuis et al., 2000, Mein et al., 2001) erfasst. Weiterhin wurden Daten zum Verhalten der Kühe während des Melkens und zur Sauberkeit der Tiere (Euter, Klauen, hinteres Bein, Schwanz) mit Hilfe von Benotungssystemen 
erhoben. Die wesentlichen Daten der Melktechnik (Melkzeug, Milchschlauch, Milchleitung, Vakuumpumpe, Regelventil, Vakuum laut Vakuummeter) wurden aufgenommen, außerdem erfolgten folgende Messungen:

- Milchflusskurven mit dem Lactocorder®

- Dynamische Vakuummessung im kurzen Milchschlauch mit PULSOTESTmini (Westfalia)

- Dynamische Messung der Pulsation mit PULSOTESTmini (Westfalia)

Zur Beschreibung der Haltungsumwelt wurden das Angebot und die Hygiene der Tränken, die Abmessungen und die Gestaltung der Laufgänge und der Fress- und Liegeplätze sowie die Weichheit und die Hygiene der Liegeplätze erfasst (Zube, 2005). Des Weiteren wurde die Körperkondition der Tiere (Edmonson et al., 1989) beurteilt. Die Krankheitsinzidenzen wurden dem Behandlungsbuch entnommen. Es erfolgte eine Sinnesprüfung der Silagen (DLG, 2004), außerdem wurden Proben der frischen, noch nicht benutzten Einstreu entnommen, um deren Keimgehalt zu bestimmen (Krömker et al., 2010).

Die Auswertung der Einzelgemelkszellgehalte erfolgte in Anlehnung an die von Valde et al. (2005) beschriebene Methode. Abweichend von dieser Arbeit wurde in der vorliegenden Studie gemäß der Klassifizierung durch die DVG (1994) ein somatischer Zellgehalt von 100.000 Zellen/ml Milch als Grenzwert für Störungen der Eutergesundheit berücksichtigt. Als Neuerkrankung wurde ein Anstieg des Einzeltierzellgehaltes von unter 100.000 Zellen/ml Milch auf über 100.000 Zellen/ml Milch zwischen zwei aufeinander folgenden Untersuchungszeitpunkten definiert. Als Heilung wurde ein Absinken des Zellgehaltes von über 100.000 Zellen/ml Milch auf unter $\quad 100.000$ Zellen/ml Milch zwischen zwei aufeinander folgenden Untersuchungszeitpunkten definiert. Die Erhöhungsrate wurde als prozentualer Anteil der Einzelgemelksproben mit auf über 100.000 Zellen/ml angestiegenem Zellgehalt an der Gesamtzahl der Einzelgemelksproben im Untersuchungszeitraum berechnet. Die Neuerkrankungsrate wurde als prozentualer Anteil neu infizierter Tiere an der Gesamtzahl der Tiere berechnet. Mit Hilfe der Daten der letzten Milchleistungsprüfung vor dem Trockenstellen sowie die Daten der ersten Milchleistungsprüfung nach dem Abkalben wurde in Anlehnung an Krömker (2008) die Eutergesundheitsentwicklung (Neuerkrankungsraten, Heilungsraten) in der Trockenperiode abgeschätzt. Zellgehalte 
der Erstkalbinnen von über 100.000 Zellen am ersten Untersuchungstag wurden ebenfalls als Neuerkrankungen (Färsenmastitis) eingestuft.

Als mittlerer Erkrankungsgrad wurde der prozentuale Anteil der Einzelgemelke mit Einzelgemelkszellgehalten von über 100.000 Zellen/ml Milch an der Gesamtzahl der untersuchten Einzelgemelke herangezogen. Die Dauer einer Erkrankung wurde mittels des Zeitraums in Monaten von der ersten Erhöhung des Zellgehaltes auf über 100.000 Zellen/ml Milch bis zur Abnahme des Zellgehaltes auf unter 100.000 Zellen/ml Milch beschrieben. Die mittlere Dauer der Erkrankung wurde aus dem mittleren Erkrankungsgrad geteilt durch die Neuerkrankungsrate multipliziert mit 100 errechnet. Die so errechnete Prozentzahl wurde in Monate umgerechnet (Valde et al., 2005).

\subsubsection{Datenerhebung in Herden der Gruppe HZELL}

Die Daten der Herden mit den Eutergesundheitsproblemen wurden von Prof. Dr. Krömker im Rahmen der eutergesundheitsdienstlichen Bestandsbesuche von 2002 bis 2004 erhoben. Diese Dienstleistung können Milchviehbetriebe anfordern, um Entscheidungshilfen zur Verbesserung der Eutergesundheit ihrer Herden zu erlangen. Die Datenerhebung entsprach grundsätzlich dem in den Betrieben mit niedrigen Herdensammelmilchzellgehalten praktizierten Vorgehen, jedoch wurden weniger Parameter zu den einzelnen Bereichen aufgenommen.

\subsection{Statistische Auswertung}

Die Daten wurden unter Verwendung von Excel, Access 2000 (Microsoft Corporation) und SPSS (SPSS 13.0, Chicago USA) gesammelt und analysiert. Die Daten wurden auf Ausreißer und Plausibilität geprüft. Aus diesen Gründen wurden keine Datensätze entfernt. Die statistische Einheit war die Milchviehherde. In der Betriebsgruppe der Betriebe mit den niedrigen Zellgehalten wurde nach weiter differenzierenden Variablen mit Hilfe einer Clusteranalyse gesucht (Anderberg, 1973). Als Lagemaße wurden arithmetische Mittelwerte oder Mediane angegeben und als Streuungsmaße wurden Standardabweichung (SD) oder Minimum und Maximum berechnet. Die statistische Signifikanzgrenze wurde mit $\mathrm{P} \leq 0,05$ festgelegt. In Abhängigkeit der Variablentypen (metrisch (normalverteilt oder nicht), ordinal, nominal) wurden unterschiedliche Testverfahren zur Untersuchung von Assoziationen und Zusammenhängen zwischen den Variablen gewählt. Zunächst wurden stets univariate 
Testverfahren verwandt. Statistische Unterschiede zwischen Verhältnissen wurden mit dem Chi-Quadrat-Test oder mit dem Fisher Exact Test errechnet, für Mittelwertsunterschiede normalverteilter metrischer Variablen wurde der T-Test nach Student oder die einfaktorielle Varianzanalysen verwandt. Ansonsten wurde der ChiQuadrat-Test gewählt. Nach Durchführung der univariaten Analysen erfolgten multivariate Untersuchungen. Hierbei wurden logistische Regressionen (binäre, ordinale, nominale) und mehrfaktorielle varianzanalytische Modelle berücksichtigt (Urban, 1993). Diese Testverfahren wurden sowohl für den Vergleich zwischen niedrigzelligen (NZELL) und hochzelligen (HZELL) Betrieben als auch für den Vergleich der verschiedenen Gruppen der niedrigzelligen Betriebe verwendet. 


\section{Ergebnisse}

\subsection{Analyse der Cluster der Gruppe NZELL}

\subsubsection{Clusterbildung innerhalb der Gruppe NZELL}

In Bezug auf die Minimierung von Risikofaktoren erfolgreiche Betriebe zeichnen sich einerseits durch einen geringen Therapieaufwand und andererseits durch eine hohe Nutzungsdauer aus. Die Betriebe wurden mit Hilfe der durchschnittlichen niedersächsischen Nutzungsdauer im Kontrolljahr 2004-2005 von 29,04 Monaten (VIT, 2005) und der durchschnittlichen Therapiehäufigkeit von 0,5 Fällen/Kuh und Jahr (Krömker, 2007) im Rahmen einer Clusteranalyse gruppiert, um unter Berücksichtigung dieser Variablen die Betriebsgruppe identifizieren zu können, die sich durch eine hervorragende Eutergesundheit auszeichnete, ohne dabei eine nur sehr kurze Nutzungsdauer oder/und eine hohe Behandlungsintensität zu erreichen. 37 Betriebe zeichneten sich durch eine unterdurchschnittliche Therapiehäufigkeit (uT...) aus, wovon 13 Betriebe eine überdurchschnittliche Nutzungsdauer (uTüN) und 24 Betriebe eine unterdurchschnittliche Nutzungsdauer (uTuN) aufwiesen. Sieben Betriebe zeigten eine überdurchschnittliche Therapiehäufigkeit (üT...), sechs davon hatten eine überdurchschnittliche Nutzungsdauer (üTüN). Lediglich einer der Betriebe, der im Weiteren nicht näher betrachtet werden soll, wies bei überdurchschnittlicher Therapiehäufigkeit eine unterdurchschnittliche Nutzungsdauer (üTuN) auf.

\subsubsection{Analyse der Eutergesundheit in den Betrieben der Gruppe NZELL}

Die Betriebe mit unterdurchschnittlicher Therapiehäufigkeit führten im Mittel 0,22 Mastitistherapien je Kuh und Jahr durch. Solche mit einer überdurchschnittlichen Nutzungsdauer erreichten eine mittlere Nutzungsdauer von 34 Monaten. Als Indikator für den langfristigen Erfolg wurde der Anteil der mittleren Zellgehalte je Monat mit Werten unter 100.000 Zellen/ml im Zeitraum von Oktober 2002 bis September 2005 herangezogen. Die Betriebe erreichten diese Zellzahl in $22 \%$ bis $100 \%$ der Monate. Der Mittelwert je Gruppe lag zwischen 47\% (uTüN) und 86\% (üTuN). Die Ergebnisse sind in Tabelle 9 dargestellt. 
Tabelle 9: Cluster der Gruppe NZELL im Hinblick auf Therapiehäufigkeit und Nutzungsdauer (Mittelwert + l- Standardabweichung)

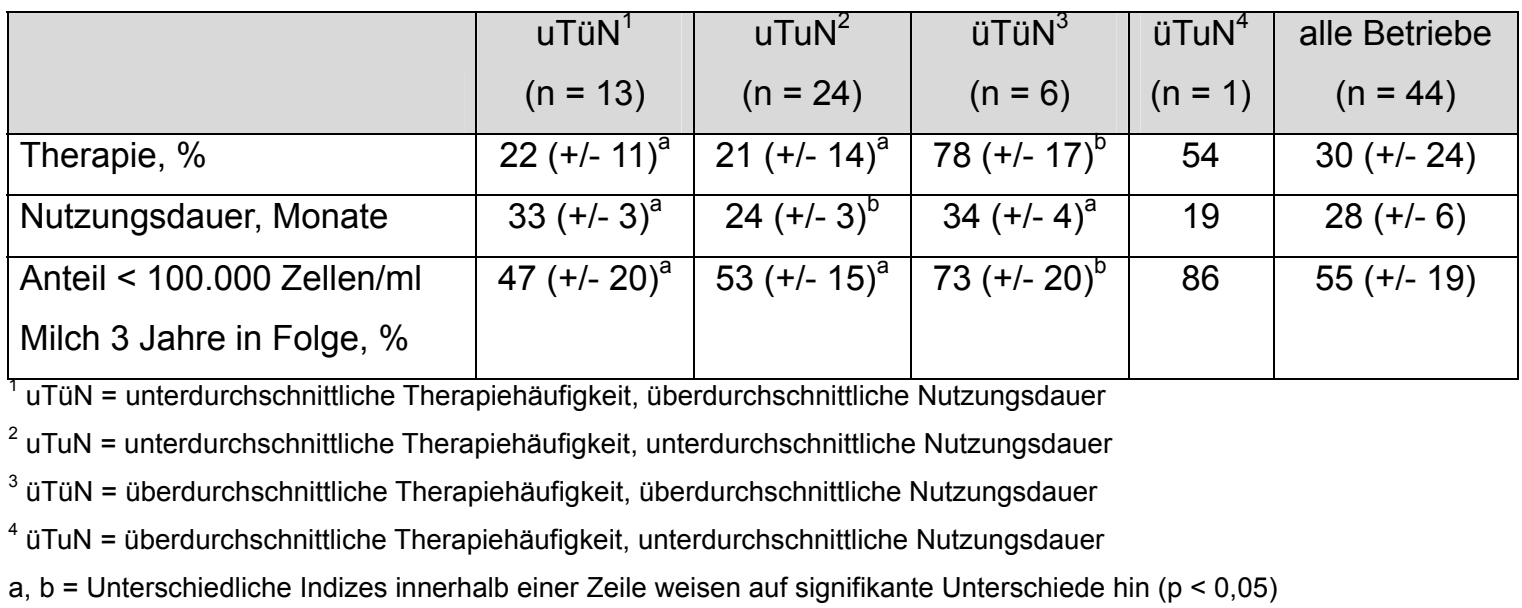

Die subklinische Eutergesundheit in den Versuchsbetrieben lässt sich auf Basis der somatischen Zellgehalte, die im Rahmen der Milchleistungsprüfung ermittelt wurden, beschreiben (Tabelle 10). Im Mittel der Betriebe wiesen 24\% (+/- 6\%) der Kühe einen Zellgehalt im Einzelgemelk von über 100.000 Zellen/ml Milch auf. Die Erhöhungsrate betrug im Mittel der Betriebe 9\% (+/- 2\%) und die Neuerkrankungsrate lag im Durchschnitt der Betriebe bei $97 \%$ (+/- 2\%). Im Mittel betrug die Dauer einer Erkrankung 3,0 (+/- 0,6) Monate. In der Trockenperiode betrugen die Neuerkrankungsrate $16 \%(+/-13 \%)$ und die Heilungsrate $77 \%$ (+/- 18\%). Die Färsenmastitisrate lag bei $18 \%$ (+/- 13\%) der Erstkalbinnen.

Tabelle 10: Neuerkrankungsrate, Mastitisdauer und Heilungsrate anhand des Zellgehaltes/ml Milch der Cluster der Gruppe NZELL (Mittelwert +/- Standardabweichung)

\begin{tabular}{|l|c|c|c|c|}
\hline & $\begin{array}{c}\text { uTüN }^{1} \\
(\mathrm{n}=13)\end{array}$ & $\begin{array}{c}\mathrm{uTuN}^{2} \\
(\mathrm{n}=24)\end{array}$ & $\begin{array}{c}\text { üTüN } \\
(\mathrm{n}=6)\end{array}$ & $\begin{array}{c}\text { alle Betriebe } \\
(\mathrm{n}=44)\end{array}$ \\
\hline Erkrankungsgrad, \% & $26(+/-8)$ & $24(+/-5)$ & $20(+/-5)$ & $24(+/-6)$ \\
\hline Erhöhungsrate, \% & $9(+/-2)$ & $9(+/-2)$ & $8(+/-1)$ & $9(+/-2)$ \\
\hline Neuerkrankungsrate, \% & $94(+/-2)$ & $99(+/-2)$ & $94(+/-1)$ & $97(+/-2)$ \\
\hline $\begin{array}{l}\text { Mittlere Dauer der Erkrankung, } \\
\text { Monate }\end{array}$ & $3,2(+/-0,7)$ & $2,9(+/-0,6)$ & $2,6(+/-0,5)$ & $3,0(+/-0,6)$ \\
\hline $\begin{array}{l}\text { Neuerkrankungsrate in der } \\
\text { Trockenperiode, \% }\end{array}$ & $15(+/-13)$ & $14(+/-13)$ & $24(+/-11)$ & $16(+/-13)$ \\
\hline $\begin{array}{l}\text { Heilungsrate in der Trockenperiode, } \\
\%\end{array}$ & $78(+/-18)$ & $77(+/-21)$ & $76(+/-8)$ & $77(+/-18)$ \\
\hline Färsenmastitisrate, \% & $18(+/-12)$ & $17(+/-14)$ & $21(+/-15)$ & $18(+/-13)$ \\
\hline
\end{tabular}




\subsubsection{Analyse der personalbezogenen Managementvariablen der Gruppe NZELL}

In der Gruppe uTüN gaben die Betriebsleiter häufiger an, regelmäßig einen California Mastitis Test (CMT) durchzuführen. Zudem konnten diese Betriebsleiter eine höher qualifizierte Ausbildung vorweisen. Die Kühe schienen, gemessen an der Häufigkeit des Kotabsetzens, während des Melkens weniger Stress zu haben. Weiterhin konnte festgestellt werden, dass in der Gruppe uTüN häufiger wechselndes Personal am Melkvorgang beteiligt war. Die überprüften Managementfaktoren aus dem Bereich Personal sind in Tabelle 11 zusammengefasst.

Tabelle 11: Variablen des Personalmanagements der Cluster der Gruppe NZELL

\begin{tabular}{|c|c|c|c|c|c|c|c|c|c|c|c|c|}
\hline & \multicolumn{3}{|c|}{$\mathrm{uTüN}^{1}$} & \multicolumn{3}{|c|}{$\mathrm{uTuN}^{2}$} & \multicolumn{3}{|c|}{ üTüN ${ }^{3}$} & \multicolumn{3}{|c|}{ Alle Betriebe } \\
\hline $\begin{array}{l}\text { Regelmäßiger CMT, } \\
\%\end{array}$ & 62 & \multicolumn{2}{|c|}{$(8 / 13)$} & 50 & \multicolumn{2}{|c|}{$(12 / 24)$} & 50 & \multicolumn{2}{|c|}{$(3 / 6)$} & 53 & \multicolumn{2}{|c|}{$(23 / 43)$} \\
\hline $\begin{array}{l}\text { Durchgängig eine } \\
\text { Person im } \\
\text { Melkstand, \% }\end{array}$ & $54^{\mathrm{a}}$ & \multicolumn{2}{|c|}{$(7 / 13)$} & $67^{a}$ & \multicolumn{2}{|c|}{$(16 / 24)$} & $17^{\mathrm{b}}$ & \multicolumn{2}{|c|}{$(1 / 6)$} & 56 & \multicolumn{2}{|c|}{$(24 / 43)$} \\
\hline $\begin{array}{l}\text { Landwirt hat } \\
\text { zweijährige } \\
\text { Fachschule oder } \\
\text { Meister, \% }\end{array}$ & $77^{\mathrm{a}}$ & \multicolumn{2}{|c|}{$(10 / 13)$} & $42^{b}$ & \multicolumn{2}{|c|}{$(10 / 24)$} & $67^{\mathrm{a}}$ & \multicolumn{2}{|c|}{$(4 / 6)$} & 56 & \multicolumn{2}{|c|}{$(24 / 43)$} \\
\hline Regelmäßige & 77 & \multicolumn{2}{|c|}{$(10 / 13)$} & 88 & \multicolumn{2}{|c|}{$(21 / 24)$} & 83 & \multicolumn{2}{|c|}{$(5 / 6)$} & 84 & \multicolumn{2}{|c|}{$(36 / 43)$} \\
\hline & $\begin{array}{l}\text { Mittel- } \\
\text { wert }\end{array}$ & SD & $n$ & $\begin{array}{l}\text { Mittel- } \\
\text { wert }\end{array}$ & SD & $n$ & $\begin{array}{c}\text { Mittel- } \\
\text { wert }\end{array}$ & SD & $\mathrm{n}$ & $\begin{array}{l}\text { Mittel- } \\
\text { wert }\end{array}$ & SD & $\mathrm{n}$ \\
\hline $\begin{array}{l}\text { Melkgeschwindig- } \\
\text { keit, Kühe/h }\end{array}$ & 31 & 16 & 13 & 28 & 17 & 24 & 36 & 7 & 6 & 30 & 16 & 43 \\
\hline $\begin{array}{l}\text { Fortbildungen, } \\
\text { Anzahl/Jahr }\end{array}$ & 6 & 5 & 13 & 5 & 4 & 24 & 6 & 5 & 6 & 5 & 4 & 43 \\
\hline $\begin{array}{l}\text { Alter des Landwirts, } \\
\text { Jahre }\end{array}$ & $39^{a}$ & 9 & 13 & $46^{b}$ & 11 & 24 & $33^{a}$ & 4 & 6 & 42 & 11 & 43 \\
\hline $\begin{array}{l}\text { Zeit als Landwirt } \\
\text { tätig, Jahre }\end{array}$ & $20^{a}$ & 11 & 13 & $28^{b}$ & 12 & 24 & $15^{\mathrm{a}}$ & 5 & 6 & 24 & 12 & 43 \\
\hline
\end{tabular}


Tabelle 11 (Fortsetzung von vorheriger Seite)

\begin{tabular}{|c|c|c|c|c|c|c|c|c|c|c|c|c|}
\hline & \multicolumn{3}{|c|}{$\mathrm{uTüN}^{1}$} & \multicolumn{3}{|c|}{$\mathrm{uTuN}^{2}$} & \multicolumn{3}{|c|}{ üTüN ${ }^{3}$} & \multicolumn{3}{|c|}{ Alle Betriebe } \\
\hline & $\begin{array}{c}\text { Mittel- } \\
\text { wert }\end{array}$ & SD & $n$ & $\begin{array}{c}\text { Mittel- } \\
\text { wert }\end{array}$ & SD & $\mathrm{n}$ & $\begin{array}{l}\text { Mittel- } \\
\text { wert }\end{array}$ & SD & $\mathrm{n}$ & $\begin{array}{c}\text { Mittel- } \\
\text { wert }\end{array}$ & SD & $\mathrm{n}$ \\
\hline $\begin{array}{l}\text { Zeit als } \\
\text { Hauptverantwortlich, } \\
\text { Jahre }\end{array}$ & $10^{a}$ & 10 & 13 & $17^{\mathrm{b}}$ & 11 & 24 & $6^{a}$ & 3 & 6 & 13 & 11 & 43 \\
\hline $\begin{array}{l}\text { Kotabsetzen beim } \\
\text { Melken, \% }\end{array}$ & 1 & 1 & 13 & 4 & 8 & 24 & 3 & 3 & 6 & 3 & 6 & 43 \\
\hline $\begin{array}{l}\text { Melkzeiten von } \\
\text { Hauptmelker } \\
\text { gemolken, \% }\end{array}$ & $64^{\mathrm{a}}$ & 20 & 13 & $84^{b}$ & 21 & 24 & $86^{b}$ & 19 & 6 & 78 & 22 & 43 \\
\hline
\end{tabular}

uTüN = unterdurchschnittliche Therapiehäufigkeit, überdurchschnittliche Nutzungsdauer

${ }^{2}$ uTuN = unterdurchschnittliche Therapiehäufigkeit, unterdurchschnittliche Nutzungsdauer

${ }^{3}$ üTüN = überdurchschnittliche Therapiehäufigkeit, überdurchschnittliche Nutzungsdauer

$a, b=$ Unterschiedliche Indizes innerhalb einer Zeile weisen auf signifikante Unterschiede hin $(p<0,05)$

\subsubsection{Analyse der genetische Managementvariablen der Gruppe NZELL}

In allen ausgewerteten Betrieben wurden Kühe der Rasse Deutsch Holstein schwarzbunt oder rotbunt gehalten. Es konnte festgestellt werden, dass die Betriebsleiter der Gruppe uTüN im Vergleich zu den anderen Gruppen bei der Auswahl der Bullen häufiger auf das Zuchtkriterium Zellzahl bzw. bei der Auswahl von Färsen auf den Zellgehalt der Muttertiere achteten.

Der durchschnittliche Spitzenmilchfluss wies mit 3,2 bis $3,7 \mathrm{~kg} / \mathrm{min}$ in allen drei Gruppen ähnliche Werte auf. Auch hinsichtlich des mittleren Zitzendurchmessers von 26 bis $27 \mathrm{~mm}$ unterschieden sich die Gruppen nicht wesentlich. Tabelle 12 gibt einen Überblick über die ermittelten Zuchtfaktoren.

Tabelle 12: Managementvariablen der Genetik der Cluster der Gruppe NZELL

\begin{tabular}{|l|c|c|c|c|c|c|c|c|}
\hline & \multicolumn{2}{|c|}{ UTüN $^{1}$} & \multicolumn{2}{c|}{ uTuN $^{2}$} & \multicolumn{2}{c|}{ üTüN $^{3}$} & \multicolumn{2}{c|}{ Alle Betriebe } \\
\hline $\begin{array}{l}\text { Rasse Deutsche } \\
\text { Holstein schwarz- u. } \\
\text { rotbunt, \% }\end{array}$ & 100 & $(13 / 13)$ & 100 & $(24 / 24)$ & 100 & $(6 / 6)$ & 100 & $(43 / 43)$ \\
\hline $\begin{array}{l}\text { Zuchtkriterium } \\
\text { Bullenwahl Zellzahl, } \\
\%\end{array}$ & 38 & $(5 / 13)$ & 21 & $(5 / 24)$ & 0 & $(0 / 6)$ & 23 & $(10 / 43)$ \\
\hline \begin{tabular}{l} 
Fortsetzung auf der nächsten Seite \\
\hline
\end{tabular} & & & & & & & & \\
\hline
\end{tabular}


Tabelle 12 (Fortsetzung von vorheriger Seite)

\begin{tabular}{|c|c|c|c|c|c|c|c|c|c|c|c|c|}
\hline & \multicolumn{3}{|c|}{ uTüN ${ }^{1}$} & \multicolumn{3}{|c|}{$\mathrm{uTuN}^{2}$} & \multicolumn{3}{|c|}{ üTüN ${ }^{3}$} & \multicolumn{3}{|c|}{ Alle Betriebe } \\
\hline $\begin{array}{l}\text { Zuchtkriterium } \\
\text { Färsenauswahl } \\
\text { Zellzahl Mutter, \% }\end{array}$ & $23^{a}$ & \multicolumn{2}{|c|}{$(3 / 13)$} & $4^{b}$ & \multicolumn{2}{|c|}{$(1 / 24)$} & $0^{c}$ & \multicolumn{2}{|c|}{$(0 / 6)$} & 9 & \multicolumn{2}{|c|}{$(4 / 43)$} \\
\hline \multirow{2}{*}{\begin{tabular}{|l|} 
Mittlere \\
Herdenleistung \\
$<8.293 \mathrm{~kg} / \mathrm{Kuh}$ \\
(niedersächsisches \\
Mittel), \%
\end{tabular}} & 8 & \multicolumn{2}{|c|}{$(1 / 13)$} & 29 & \multicolumn{2}{|c|}{$(7 / 24)$} & 0 & \multicolumn{2}{|c|}{$(0 / 6)$} & 19 & \multicolumn{2}{|c|}{$(8 / 43)$} \\
\hline & $\begin{array}{c}\text { Mittel- } \\
\text { wert }\end{array}$ & SD & $n$ & $\begin{array}{l}\text { Mittel- } \\
\text { wert }\end{array}$ & SD & $n$ & $\begin{array}{c}\text { Mittel- } \\
\text { wert }\end{array}$ & SD & $\mathrm{n}$ & $\begin{array}{c}\text { Mittel- } \\
\text { wert }\end{array}$ & SD & $n$ \\
\hline $\begin{array}{l}\text { Milchleistung, } \\
\text { kg/Kuh u. Jahr }\end{array}$ & 9.253 & 691 & 13 & 8.839 & 1.472 & 24 & 9.635 & 691 & 6 & 9.075 & 1.211 & 43 \\
\hline $\begin{array}{l}\text { Durchschnittlicher } \\
\text { Spitzenmilchfluss, } \\
\text { kg/min }\end{array}$ & 3,4 & 0,6 & 13 & 3,2 & 0,6 & 23 & 3,7 & 0,4 & 6 & 3,3 & 0,6 & 42 \\
\hline $\begin{array}{l}\text { Spitzenmilchfluss } \\
\leq 3,2 \mathrm{~kg} / \mathrm{min}, \%\end{array}$ & 43 & 28 & 13 & 52 & 24 & 23 & 38 & 16 & 6 & 47 & 25 & 42 \\
\hline $\begin{array}{l}\text { Euter höher als } \\
\text { Sprunggelenk, \% }\end{array}$ & 91 & 12 & 13 & 94 & 6 & 24 & 88 & 9 & 6 & 92 & 9 & 43 \\
\hline $\begin{array}{l}\text { Mittlerer Zitzen- } \\
\text { durchmesser, mm }\end{array}$ & 26 & 1 & 13 & 26 & 2 & 24 & 27 & 1 & 6 & 26 & 2 & 43 \\
\hline $\begin{array}{l}\text { Schwankung Zitzen- } \\
\text { durchmesser, mm }\end{array}$ & 5,4 & 1,5 & 13 & 4,4 & 2,4 & 23 & 5,2 & 1,7 & 6 & 4,8 & 2,1 & 42 \\
\hline
\end{tabular}

\subsubsection{Analyse der haltungsbezogenen Managementvariablen der Gruppe} NZELL

Der überwiegende Teil der Betriebe hielt die Kühe in einem Liegeboxenlaufstall, dessen Laufflächen aus Spalten bestanden, die zum Großteil regelmäßig gereinigt wurden. Die Laufflächen wurden im Mittel aller Betriebe einmal täglich gereinigt.

Die Liegeflächen im Euterbereich waren in den meisten Betrieben trocken, jedoch wiesen lediglich die Kühe der beiden Gruppen uTüN und UTuN überwiegend saubere Euter auf. In 20\% der Betriebe mit Liegeboxen wurde die Weichheit der Liegeflächen 
mit 1 benotet (Skala von $1=$ sehr weich bis $3=$ sehr hart). In den Anbindeställen wurde eine so gute Bewertung nicht vergeben. $68 \%$ der Betriebe mit überdurchschnittlicher Nutzungsdauer (alle Betriebe der Gruppe uTüN und üTüN) erzielten einen Grad von 1 oder 2 für die Weichheit der Liegeflächen. In mehr als der Hälfte der Betriebe wurde Stroh eingestreut. Lediglich in der Gruppe uTüN wiesen alle Betriebe eingestreute Liegeflächen auf. Die Keimbelastung der Einstreu wurde in über der Hälfte der Betriebe als risikofrei (Gesamtkeimzahl: Stroh $<7 \times 10^{8} \mathrm{KbE}$; Späne $<1 \times 10^{6} \mathrm{KbE}$; coliforme Keime $<10^{6} \mathrm{KbE} / \mathrm{g}$; Krömker und Grabowski, 2002; Kristula et al., 2005) eingestuft. Die Pflege der Liegeflächen erfolgte häufiger als zweimal täglich. Tabelle 13 fasst die überprüften haltungsbezogenen Managementfaktoren zusammen.

Tabelle 13: Managementvariablen der Gestaltung der Haltungsumwelt der Cluster der Gruppe NZELL

\begin{tabular}{|c|c|c|c|c|c|c|c|c|}
\hline & \multicolumn{2}{|c|}{ uTüN $N^{1}$} & \multicolumn{2}{|c|}{$\mathrm{uTuN}^{2}$} & \multicolumn{2}{|c|}{ üTüN ${ }^{3}$} & \multicolumn{2}{|c|}{ Alle Betriebe } \\
\hline $\begin{array}{l}\text { Liegeboxenlaufstall, } \\
\%\end{array}$ & 77 & $(10 / 13)$ & 67 & $(16 / 24)$ & 100 & $(6 / 6)$ & 74 & $(32 / 43)$ \\
\hline $\begin{array}{l}\text { Ganz oder teilweise } \\
\text { wärmegedämmtes } \\
\text { Kuhstalldach, \% }\end{array}$ & $50^{a}$ & $(6 / 12)$ & $42^{a}$ & $(10 / 24)$ & $17^{b}$ & $(1 / 6)$ & 40 & $(17 / 42)$ \\
\hline $\begin{array}{l}\text { Laufflächen als } \\
\text { Spaltenboden } \\
\text { (Liegeboxenlauf- } \\
\text { stall), \% }\end{array}$ & 80 & $(8 / 10)$ & 81 & $(13 / 16)$ & 83 & $(5 / 6)$ & 81 & $(26 / 32)$ \\
\hline $\begin{array}{l}\text { Regelmäßige } \\
\text { Reinigung der } \\
\text { Laufflächen } \\
\text { (Liegeboxenlaufstall } \\
\text { mit Spalten), \% }\end{array}$ & 75 & $(6 / 8)$ & 85 & $(11 / 13)$ & 80 & $(4 / 5)$ & 81 & $(21 / 26)$ \\
\hline $\begin{array}{l}\text { Laufflächen } \\
>1 \text { mal/Tag reinigen } \\
\text { (Liegeboxenlaufstall } \\
\text { mit Spalten), \% }\end{array}$ & 63 & $(5 / 8)$ & 85 & $(11 / 13)$ & 60 & $(3 / 5)$ & 73 & $(19 / 26)$ \\
\hline $\begin{array}{l}\text { Trockene } \\
\text { Liegefläche im } \\
\text { Euterbereich, \% }\end{array}$ & 77 & $(10 / 13)$ & 79 & $(19 / 24)$ & 83 & $(5 / 6)$ & 79 & $(34 / 43)$ \\
\hline
\end{tabular}


Ergebnisse

Tabelle 13 (Fortsetzung von vorheriger Seite)

\begin{tabular}{|c|c|c|c|c|c|c|c|c|}
\hline & \multicolumn{2}{|c|}{ uTüN ${ }^{1}$} & \multicolumn{2}{|c|}{$\mathrm{UTuN}^{2}$} & \multicolumn{2}{|c|}{ üTüN ${ }^{3}$} & \multicolumn{2}{|c|}{ Alle Betriebe } \\
\hline $\begin{array}{l}\text { Tägliche Pflege der } \\
\text { Liegeflächen, \% }\end{array}$ & 100 & $(13 / 13)$ & 100 & $(24 / 24)$ & 100 & $(6 / 6)$ & 100 & $(43 / 43)$ \\
\hline $\begin{array}{l}\text { Euter sind sauber } \\
\text { bis sehr sauber, }{ }^{4}{ }^{4}\end{array}$ & $77^{\mathrm{a}}$ & $(10 / 13)$ & $67^{a}$ & $(16 / 24)$ & $33^{b}$ & $(2 / 6)$ & 65 & $(28 / 43)$ \\
\hline $\begin{array}{l}\text { Sehr weiche } \\
\text { Liegefläche (Liege- } \\
\text { boxenlaufstall), } \%^{5}\end{array}$ & 20 & $(2 / 10)$ & 19 & $(3 / 16)$ & 17 & $(1 / 6)$ & 19 & $(6 / 32)$ \\
\hline $\begin{array}{l}\text { Weiche - sehr } \\
\text { weiche Liegefläche } \\
\text { (Liegeboxenlauf- } \\
\text { stall), } \%^{5}\end{array}$ & 70 & $(7 / 10)$ & 50 & $(8 / 16)$ & 100 & $(6 / 6)$ & 66 & $(21 / 32)$ \\
\hline $\begin{array}{l}\text { Weiche - sehr } \\
\text { weiche Liegefläche } \\
\text { (Anbindestall), } \%^{5}\end{array}$ & 0 & $(0 / 3)$ & 13 & $(1 / 8)$ & & $(0 / 0)$ & 9 & $(1 / 11)$ \\
\hline $\begin{array}{l}\text { Weiche - sehr } \\
\text { weiche Liegefläche } \\
\text { (alle Betriebe), } \%^{5}\end{array}$ & 54 & $(7 / 13)$ & 38 & $(9 / 24)$ & 100 & $(6 / 6)$ & 51 & $(22 / 43)$ \\
\hline $\begin{array}{l}\text { Stroh als Einstreu, } \\
\%\end{array}$ & 62 & $(8 / 13)$ & 50 & $(12 / 24)$ & 67 & $(4 / 6)$ & 56 & $(24 / 43)$ \\
\hline $\begin{array}{l}\text { Kalk als Zusatz in } \\
\text { Einstreu, \% }\end{array}$ & 46 & $(6 / 13)$ & 25 & $(6 / 24)$ & $67 \%$ & $(4 / 6)$ & 37 & $(16 / 43)$ \\
\hline $\begin{array}{l}\text { Anbindestall mit } \\
\text { Weide, } \%\end{array}$ & 100 & $(3 / 3)$ & 88 & $(7 / 8)$ & & $(0 / 0)$ & 91 & $(10 / 11)$ \\
\hline $\begin{array}{l}\text { Ermöglichung von } \\
\text { Nachtweide (alle } \\
\text { Betriebe), \% }\end{array}$ & $38^{a}$ & $(5 / 13)$ & $46^{b}$ & $(11 / 24)$ & 50 & $(3 / 6)$ & 44 & $(19 / 43)$ \\
\hline $\begin{array}{l}\text { Einstreu in } \\
\text { Liegfläche (alle), \% }\end{array}$ & 100 & $(13 / 13)$ & 88 & $(21 / 24)$ & 83 & $(5 / 6)$ & 91 & $(39 / 43)$ \\
\hline $\begin{array}{l}\text { Einstreu } \\
>1 \text { mal/Woche in } \\
\text { Liegeboxen } \\
\text { nachfüllen } \\
\text { (Liegeboxenlaufstall } \\
\text { mit Einstreu), \% }\end{array}$ & 40 & $(4 / 10)$ & 64 & $(9 / 14)$ & 60 & $(3 / 5)$ & 55 & $(16 / 29)$ \\
\hline
\end{tabular}

Fortsetzung auf der nächsten Seite 
Tabelle 13 (Fortsetzung von vorheriger Seite)

\begin{tabular}{|c|c|c|c|c|c|c|c|c|c|c|c|c|}
\hline & \multicolumn{3}{|c|}{ uTüN ${ }^{1}$} & \multicolumn{3}{|c|}{$\mathrm{UTuN}^{2}$} & \multicolumn{3}{|c|}{ üTüN ${ }^{3}$} & \multicolumn{3}{|c|}{ Alle Betriebe } \\
\hline $\begin{array}{l}\text { Einstreu } \\
>1 \text { mal/Woche in } \\
\text { Liegeboxen } \\
\text { nachfüllen } \\
\text { (Anbindestall mit } \\
\text { Einstreu), \% }\end{array}$ & 100 & \multicolumn{2}{|c|}{$(3 / 3)$} & 100 & \multicolumn{2}{|c|}{$(7 / 7)$} & & \multicolumn{2}{|c|}{$(0 / 0)$} & 100 & \multicolumn{2}{|c|}{$(10 / 10)$} \\
\hline $\begin{array}{l}\text { Keime in Einstreu } \\
\text { gering (Gesamt- } \\
\text { keimzahl: Stroh } \\
<7 \times 10^{8} \mathrm{KbE} / \mathrm{g} ; \\
\text { Späne } \\
<1 \times 10^{6} \mathrm{KbE} / \mathrm{g} \text { ), \% }\end{array}$ & 62 & \multicolumn{2}{|c|}{$(8 / 13)$} & 71 & \multicolumn{2}{|c|}{$(17 / 24)$} & 50 & \multicolumn{2}{|c|}{$(3 / 6)$} & 65 & \multicolumn{2}{|c|}{$(28 / 43)$} \\
\hline Gehalt an & 69 & \multicolumn{2}{|c|}{$(9 / 13)$} & 50 & \multicolumn{2}{|c|}{$(12 / 24)$} & 50 & \multicolumn{2}{|c|}{$(3 / 6)$} & 56 & \multicolumn{2}{|c|}{$(24 / 43)$} \\
\hline & $\begin{array}{l}\text { Mittel } \\
\text { wert }\end{array}$ & SD & $\mathrm{n}$ & $\begin{array}{l}\text { Mittel- } \\
\text { wert }\end{array}$ & SD & $\mathrm{n}$ & $\begin{array}{l}\text { Mittel- } \\
\text { wert }\end{array}$ & SD & $\mathrm{n}$ & $\begin{array}{l}\text { Mittel- } \\
\text { wert }\end{array}$ & SD & $\mathrm{n}$ \\
\hline $\begin{array}{l}\text { Höhe der Einsteu, } \\
\mathrm{cm}\end{array}$ & 3,2 & 5,2 & 13 & 2,0 & 3,5 & 24 & 3,1 & 3,4 & 6 & 2,5 & 4,9 & 43 \\
\hline $\begin{array}{l}\text { Rutschfestigkeit } \\
\text { Lauffläche (Liege- } \\
\text { boxenlaufstall) }^{6}\end{array}$ & 4,1 & 1,7 & 10 & 3,3 & 1,9 & 16 & 2,8 & 1,6 & 6 & 3,4 & 1,8 & 32 \\
\hline $\begin{array}{l}\text { Anzahl Reinigung } \\
\text { Lauffläche } \\
\text { (Liegeboxenlaufstall } \\
\text { mit Spalten) je Tag }\end{array}$ & 1,1 & 1,0 & 10 & 1,5 & 1,2 & 16 & 1,2 & 1,3 & 6 & 1,3 & 1,1 & 32 \\
\hline $\begin{array}{l}\text { Anzahl Reinigung / } \\
\text { Pflege der } \\
\text { Liegeflächen je Tag }\end{array}$ & 2,4 & 1,0 & 13 & 2,2 & 0,6 & 24 & 2,3 & 0,6 & 6 & 2,3 & 0,7 & 43 \\
\hline Sauberkeit Euter4 & 1,9 & 0,6 & 13 & 2,2 & 0,7 & 24 & 2,6 & 1,4 & 6 & 2,1 & 0,8 & 43 \\
\hline $\begin{array}{l}\text { Strohlagerung im } \\
\text { Kopfraum (Liege- } \\
\text { boxenlaufstall), Tage }\end{array}$ & 10 & 10 & 10 & 4,0 & 4,8 & 14 & 3,8 & 3,6 & 5 & 6,1 & 7,4 & 29 \\
\hline
\end{tabular}

Fortsetzung auf der nächsten Seite 
Tabelle 13 (Fortsetzung von vorheriger Seite)

\begin{tabular}{|c|c|c|c|c|c|c|c|c|c|c|c|c|}
\hline & \multicolumn{3}{|c|}{ uTüN } & \multicolumn{3}{|c|}{$\mathrm{uTuN}^{2}$} & \multicolumn{3}{|c|}{ üTüN ${ }^{3}$} & \multicolumn{3}{|c|}{ Alle Betriebe } \\
\hline & $\begin{array}{c}\text { Mittel- } \\
\text { wert }\end{array}$ & SD & $\mathrm{n}$ & $\begin{array}{l}\text { Mittel- } \\
\text { wert }\end{array}$ & SD & $\mathrm{n}$ & $\begin{array}{l}\text { Mittel- } \\
\text { wert }\end{array}$ & SD & $\mathrm{n}$ & $\begin{array}{l}\text { Mittel- } \\
\text { wert }\end{array}$ & SD & $\mathrm{n}$ \\
\hline $\begin{array}{l}\text { Verwendung von } \\
\text { Kalk je Tag }\end{array}$ & 0,3 & 0,6 & 13 & 0,1 & 0,2 & 24 & 0,8 & 0,9 & 6 & 0,2 & 0,5 & 43 \\
\hline Kuhkomfortindex, \% & 75 & 19 & 13 & 79 & 15 & 19 & 73 & 12 & 6 & 77 & 16 & 38 \\
\hline
\end{tabular}

uTüN = unterdurchschnittliche Therapiehäufigkeit, überdurchschnittliche Nutzungsdauer

${ }^{2}$ uTuN = unterdurchschnittliche Therapiehäufigkeit, unterdurchschnittliche Nutzungsdauer

${ }^{3}$ üTüN = überdurchschnittliche Therapiehäufigkeit, überdurchschnittliche Nutzungsdauer

${ }^{4}$ Verschmutzung Euter: 1 = sehr sauber, 6 = sehr stark verschmutzt

${ }^{5}$ Weichheit der Liegefläche: 1 = sehr weich, 3 = hart

${ }^{6}$ Rutschfestigkeit Laufgänge: 1 = rutschfest, 6 = sehr glatt

$a, b=$ Unterschiedliche Indizes innerhalb einer Zeile weisen auf signifikante Unterschiede hin $(p<0,05)$

\subsubsection{Analyse der fütterungsbezogenen Managementvariablen der Gruppe} NZELL

Im Mittel aller Betriebe standen jeder Kuh 1,1 Fressplätze zur Verfügung. Durch Fixieren der Tiere oder durch die Vorlage von frischem Futter wurde überwiegend (70\% der Betriebe) dafür gesorgt, dass sich die Kühe nicht unmittelbar nach dem Melken ablegen. 40\% der Betriebe setzte zum Tränken im Stall Trinkwasser ein. Über die Hälfte der Betriebsleiter gaben an, dass das Tränkewasser im Stall Trinkwasserqualität aufwies. Das auf der Weide zur Verfügung stehende Wasser hatte in deutlich weniger Fällen Trinkwasserqualität.

In nahezu allen Betrieben wurde Maissilage gefüttert, Rübennassschnitzel wurden in keinem Betrieb eingesetzt. 93\% der Betriebe ergänzten die Ration ganzjährig mit Mineralstoffen, wobei in allen Betrieben $\mathrm{NaCl}, \mathrm{MgO}$, Selen, Vitamin A, Vitamin $\mathrm{E}$ und Vitamin D3 substituiert wurde. 79\% der Betriebsleiter boten den Kühen nach der Kalbung Wasser, teilweise mit Zusatzstoffen, an und verabreichten Einzeltieren Propylenglykol.

Ein Verdacht auf subklinische Ketosen (Fett-Eiweiß-Quotient $>1,5$ ) in der Frühlaktation bestand im Mittel der Betriebe bei 15\% der Kühe und ein Verdacht auf Pansenfermentationsstörungen (Fett-Eiweiß-Quotient < 1,0) in der Laktation bei 10\% der Kühe. Tabelle 14 stellt die ermittelten fütterungsbezogenen Managementfaktoren dar. 
Ergebnisse

Tabelle 14: Variablen des Fütterungsmanagements der Cluster der Gruppe NZELL

\begin{tabular}{|c|c|c|c|c|c|c|c|c|}
\hline & \multicolumn{2}{|c|}{ uTüN ${ }^{1}$} & \multicolumn{2}{|c|}{$\mathrm{UTuN}^{2}$} & \multicolumn{2}{|c|}{ üTüN ${ }^{3}$} & \multicolumn{2}{|c|}{ Alle Betriebe } \\
\hline $\begin{array}{l}\text { Fressplätze }>0,8 \text { je } \\
\text { Kuh, \% }\end{array}$ & 90 & $(9 / 10)$ & $94^{a}$ & $(15 / 16)$ & $67^{b}$ & $(4 / 6)$ & 88 & $(28 / 32)$ \\
\hline $\begin{array}{l}\text { Kühe nach dem } \\
\text { Melken fixieren } \\
\text { (Liegeboxenlauf- } \\
\text { stall), \% }\end{array}$ & $20^{a}$ & $(2 / 10)$ & $57^{b}$ & $(8 / 14)$ & 50 & $(3 / 6)$ & 43 & $(13 / 30)$ \\
\hline $\begin{array}{l}\text { Fixieren oder } \\
\text { frisches Futter } \\
\text { vorlegen nach dem } \\
\text { Melken, \% }\end{array}$ & 69 & $(9 / 13)$ & $75^{\mathrm{a}}$ & $(18 / 24)$ & $50^{b}$ & $(3 / 6)$ & 70 & $(30 / 43)$ \\
\hline $\begin{array}{l}\text { Trinkwasser als } \\
\text { Tränkwasser (Stall), } \\
\%\end{array}$ & 46 & $(6 / 13)$ & 38 & $(9 / 24)$ & 33 & $(2 / 6)$ & 40 & $(17 / 43)$ \\
\hline $\begin{array}{l}\text { Tränkwasser hat } \\
\text { Trinkwasserqualität } \\
\text { (Stall), \% }\end{array}$ & $54^{\mathrm{a}}$ & $(7 / 13)$ & $79^{b}$ & $(19 / 24)$ & $50^{a}$ & $(3 / 6)$ & 67 & $(29 / 43)$ \\
\hline $\begin{array}{l}\text { Trinkwasser als } \\
\text { Tränkwasser } \\
\text { (Weide), \% }\end{array}$ & $8^{a}$ & $(1 / 12)$ & $14^{\mathrm{a}}$ & $(3 / 21)$ & $50^{b}$ & $(3 / 6)$ & 18 & $(7 / 39)$ \\
\hline $\begin{array}{l}\text { Rationsberechnung, } \\
\%\end{array}$ & 69 & $(9 / 13)$ & 67 & $(16 / 24)$ & 100 & $(6 / 6)$ & 72 & $(31 / 43)$ \\
\hline $\begin{array}{l}\text { Futtervorlage } \\
\text { gemischt, \% }\end{array}$ & 77 & $(10 / 13)$ & 38 & $(9 / 24)$ & 100 & $(6 / 6)$ & 58 & $(25 / 43)$ \\
\hline $\begin{array}{l}\text { Keine Rübenschnit- } \\
\text { zel an laktierende } \\
\text { Kühe füttern, \% }\end{array}$ & 100 & $(13 / 13)$ & 100 & $(24 / 24)$ & 100 & $(6 / 6)$ & 100 & $(43 / 43)$ \\
\hline $\begin{array}{l}\text { Maissilage an } \\
\text { laktierende Kühe } \\
\text { füttern, \% }\end{array}$ & 92 & $(12 / 13)$ & 88 & $(21 / 24)$ & 100 & $(6 / 6)$ & 91 & $(39 / 43)$ \\
\hline $\begin{array}{l}\text { Mineralstoffe } \\
\text { ganzjährig } \\
\text { ergänzen, \% }\end{array}$ & 85 & $(11 / 13)$ & 96 & $(23 / 24)$ & 100 & $(6 / 6)$ & 93 & $(40 / 43)$ \\
\hline Kraftfutter füttern, \% & 100 & $(13 / 13)$ & 100 & $(24 / 24)$ & 100 & $(6 / 6)$ & 100 & $(43 / 43)$ \\
\hline $\mathrm{NaCl}$ ergänzen, \% & 100 & $(13 / 13)$ & 100 & $(24 / 24)$ & 100 & $(6 / 6)$ & 100 & $(43 / 43)$ \\
\hline MgO ergänzen, \% & 100 & $(13 / 13)$ & 100 & $(24 / 24)$ & 100 & $(6 / 6)$ & 100 & $(43 / 43)$ \\
\hline Selen ergänzen, \% & 100 & $(13 / 13)$ & 100 & $(24 / 24)$ & 100 & $(6 / 6)$ & 100 & $(43 / 43)$ \\
\hline
\end{tabular}

Fortsetzung auf der nächsten Seite 
Ergebnisse

Tabelle 14 (Fortsetzung von vorheriger Seite)

\begin{tabular}{|c|c|c|c|c|c|c|c|c|c|c|c|c|}
\hline & \multicolumn{3}{|c|}{ uTüN ${ }^{1}$} & \multicolumn{3}{|c|}{$\mathrm{uTuN}^{2}$} & \multicolumn{3}{|c|}{ üTüN ${ }^{3}$} & \multicolumn{3}{|c|}{ Alle Betriebe } \\
\hline $\begin{array}{l}\text { Vitamin A, D3, E } \\
\text { ergänzen, \% }\end{array}$ & 100 & \multicolumn{2}{|c|}{$(13 / 13)$} & 100 & \multicolumn{2}{|c|}{$(24 / 24)$} & 100 & \multicolumn{2}{|c|}{$(6 / 6)$} & 100 & \multicolumn{2}{|c|}{$(43 / 43)$} \\
\hline $\begin{array}{l}\text { Propylenglycol bei } \\
\text { Kühen zu Beginn } \\
\text { der Laktation, \% }\end{array}$ & 77 & \multicolumn{2}{|c|}{$(10 / 13)$} & 50 & \multicolumn{2}{|c|}{$(12 / 24)$} & 67 & \multicolumn{2}{|c|}{$(4 / 6)$} & 60 & \multicolumn{2}{|c|}{$(26 / 43)$} \\
\hline Wasser, & 85 & \multicolumn{2}{|c|}{$(11 / 13)$} & 71 & \multicolumn{2}{|c|}{$(17 / 24)$} & 100 & \multicolumn{2}{|c|}{$(6 / 6)$} & 79 & \multicolumn{2}{|c|}{ (34/43) } \\
\hline & $\begin{array}{c}\text { Mittel- } \\
\text { wert }\end{array}$ & SD & $\mathrm{n}$ & $\begin{array}{c}\text { Mittel- } \\
\text { wert }\end{array}$ & SD & $n$ & $\begin{array}{l}\text { Mittel- } \\
\text { wert }\end{array}$ & $\mathrm{SD}$ & $\mathrm{n}$ & $\begin{array}{l}\text { Mittel- } \\
\text { wert }\end{array}$ & SD & $\mathrm{n}$ \\
\hline $\begin{array}{l}\text { Fressplätze je Kuh } \\
\text { (alle) }\end{array}$ & 1,1 & 0,2 & 13 & 1,1 & 0,2 & 24 & 1,0 & 0,2 & 6 & 1,1 & 0,2 & 43 \\
\hline $\begin{array}{l}\text { Vorlage von } \\
\text { frischem Futter oder } \\
\text { Nachschieben, } \\
\text { Anzahl }\end{array}$ & 5,3 & 1,4 & 13 & 4,5 & 1,7 & 24 & 4,6 & 2,2 & 6 & 4,8 & 1,7 & 43 \\
\hline $\begin{array}{l}\text { Reinigung des } \\
\text { Futtertisches je Tag, } \\
\text { Anzahl }\end{array}$ & 1,2 & 0,7 & 13 & 1,5 & 0,9 & 24 & 1,3 & 0,4 & 6 & 1,4 & 0,8 & 43 \\
\hline $\begin{array}{l}\text { Bewertung der } \\
\text { Grassilage }^{4}\end{array}$ & 3,2 & 1,5 & 13 & 4,2 & 3,7 & 24 & 3,0 & 2,1 & 6 & 3,8 & 3,1 & 43 \\
\hline $\begin{array}{l}\text { Maximale Kraft- } \\
\text { futtermenge, } \mathrm{kg} / \mathrm{Tag}\end{array}$ & 11,4 & 1,6 & 13 & 11,3 & 2,9 & 24 & 12,1 & 1,1 & 6 & 11,5 & 2,3 & 43 \\
\hline $\begin{array}{l}\text { Fett-Eiweiß-Quotient } \\
>1,5 \text { bei Laktations- } \\
\text { tage }<100, \%\end{array}$ & 15 & 5 & 13 & 17 & 10 & 24 & 10 & 3 & 6 & 15 & 8 & 43 \\
\hline $\begin{array}{l}\text { Fett-Eiweiß-Quotient } \\
<1 \text { bei Laktations- } \\
\text { tage }<300, \%\end{array}$ & 9 & 7 & 13 & 9 & 12 & 24 & 12 & 14 & 6 & 10 & 11 & 43 \\
\hline $\begin{array}{l}\text { Wiederkauindex vor } \\
\text { oder nach dem } \\
\text { Melken, \% }\end{array}$ & 59 & 12 & 13 & 59 & 19 & 21 & 62 & 13 & 6 & 59 & 16 & 40 \\
\hline
\end{tabular}

Fortsetzung auf der nächsten Seite 
Tabelle 14 (Fortsetzung von vorheriger Seite)

\begin{tabular}{|c|c|c|c|c|c|c|c|c|c|c|c|c|}
\hline & \multicolumn{3}{|c|}{ uTüN ${ }^{1}$} & \multicolumn{3}{|c|}{$\mathrm{uTuN}^{2}$} & \multicolumn{3}{|c|}{ üTüN ${ }^{3}$} & \multicolumn{3}{|c|}{ Alle Betriebe } \\
\hline & $\begin{array}{c}\text { Mittel- } \\
\text { wert }\end{array}$ & SD & $\mathrm{n}$ & $\begin{array}{l}\text { Mittel- } \\
\text { wert }\end{array}$ & SD & $n$ & $\begin{array}{c}\text { Mittel- } \\
\text { wert }\end{array}$ & SD & $\mathrm{n}$ & $\begin{array}{c}\text { Mittel- } \\
\text { wert }\end{array}$ & SD & $\mathrm{n}$ \\
\hline $\begin{array}{l}\text { Zeit in der Euter } \\
\text { nach dem Kalben } \\
\text { geschwollen ist, } \\
\text { Tage }\end{array}$ & 10 & 5 & 13 & 13 & 7 & 23 & 13 & 6 & 6 & 12 & 6 & 42 \\
\hline $\begin{array}{l}\text { Dauer Trocken- } \\
\text { periode, Wochen }\end{array}$ & 7,3 & 1,2 & 13 & 7,3 & 0,9 & 24 & 7,4 & 0,8 & 6 & 7,3 & 1,0 & 43 \\
\hline $\begin{array}{l}\text { Mittlere Milchmenge } \\
\text { beim Trockenstellen, } \\
\text { kg }\end{array}$ & 17 & 4,7 & 13 & 16 & 5,3 & 24 & 14 & 2,5 & 6 & 16 & 4,8 & 43 \\
\hline $\begin{array}{l}\text { Anteil Kühe, die } \\
\text { nach dem Trocken- } \\
\text { stellen die Milch } \\
\text { laufen lassen, \% }\end{array}$ & 19 & 14 & 13 & 11 & 13 & 22 & 21 & 18 & 5 & 15 & 14 & 40 \\
\hline TM Grassilage, \% & 30 & 3,7 & 10 & 35 & 10 & 17 & 31 & 7,8 & 6 & 33 & 8,4 & 33 \\
\hline XF Grassilage, \% & 25 & 2 & 10 & 26 & 1,9 & 17 & 25 & 1,8 & 6 & 26 & 1,9 & 33 \\
\hline XP Grassilage, \% & 18 & 2,3 & 10 & 17 & 2,3 & 16 & 17 & 1,9 & 6 & 17 & 2,3 & 32 \\
\hline $\begin{array}{l}\text { Energie Grassilage, } \\
\text { NEL }\end{array}$ & 6,2 & 0,2 & 10 & 6 & 0,4 & 17 & 6,1 & 0,5 & 6 & 6,1 & 0,4 & 33 \\
\hline RNB Grassilage & 7,5 & 3 & 10 & 5,0 & 2,8 & 17 & 5,4 & 2,4 & 6 & 5,9 & 2,9 & 33 \\
\hline
\end{tabular}

${ }^{1}$ uTüN = unterdurchschnittliche Therapiehäufigkeit, überdurchschnittliche Nutzungsdauer

${ }^{2}$ uTuN = unterdurchschnittliche Therapiehäufigkeit, unterdurchschnittliche Nutzungsdauer

${ }^{3}$ üTüN = überdurchschnittliche Therapiehäufigkeit, überdurchschnittliche Nutzungsdauer

${ }^{4}$ Bewertung der Grassilage nach dem DLG-Schlüssel (DLG, 2004)

$a, b=$ Unterschiedliche Indizes innerhalb einer Zeile weisen auf signifikante Unterschiede hin $(p<0,05)$

4.1.7 Analyse der melkarbeitsbezogenen Managementvariablen der Gruppe NZELL

Die Hygiene im Melkstand oder Anbindestand wurde in allen Betrieben als mittelmäßig oder besser ( $<=3$, Skala von $1=$ sehr sauber bis $6=$ stark verschmutzt) beurteilt. Die Euter wurden in $51 \%$ der Betriebe geschoren.

In der Gruppe uTüN wurden subklinisch oder klinisch an Mastitis erkrankte Kühe häufiger am Schluss gemolken oder die Melkzeuge mit Wasser gespült als in den anderen Gruppen. Die Euter wurden in $60 \%$ der Betriebe trocken und in $28 \%$ der Betriebe gar nicht gereinigt. 
Etwa ein Drittel (30\%) der Betriebe erreichte eine Anrüstzeit von 60 bis 90 Sekunden. In den meisten Betrieben wurde von Hand vorgemolken. In der Regel wurde kein Vormelkbecher genutzt, auch wurden häufig keine Gummihandschuhe getragen. In $89 \%$ der Betriebe wurden die Zitzen nach dem Melken getaucht (63\%) oder besprüht (26\%). Hierzu wurde von der Hälfte der Betriebe ein jodhaltiges Mittel eingesetzt, jedoch in der Gruppe uTüN deutlich seltener als in den übrigen Gruppen. Eine Nachmelkautomatik war in zwei Melkanlagen vorhandenen. In Tabelle 15 sind die überprüften melkarbeitsbezogenen Managementfaktoren aufgeführt.

Tabelle 15: Managementvariablen der Melkarbeit der Cluster der Gruppe NZELL

\begin{tabular}{|c|c|c|c|c|c|c|c|c|}
\hline & \multicolumn{2}{|c|}{ uTüN ${ }^{1}$} & \multicolumn{2}{|c|}{ uTuN $^{2}$} & \multicolumn{2}{|c|}{ üTüN ${ }^{3}$} & \multicolumn{2}{|c|}{ Alle Betriebe } \\
\hline $\begin{array}{l}\text { Kühe nach dem } \\
\text { Melken nicht auf } \\
\text { den Laufhof } \\
\text { sperren, \% }\end{array}$ & 100 & $(13 / 13)$ & 100 & $(24 / 24)$ & 100 & $(6 / 6)$ & 100 & $(43 / 43)$ \\
\hline $\begin{array}{l}\text { Gute und sehr gute } \\
\text { Hygiene im } \\
\text { Melkraum, } \%{ }^{4}\end{array}$ & $62^{a}$ & $(8 / 13)$ & $88^{b}$ & $(21 / 24)$ & $67^{a}$ & $(4 / 6)$ & 77 & $(33 / 43)$ \\
\hline $\begin{array}{l}\text { Scheren der } \\
\text { Euterhaare \% }\end{array}$ & 62 & $(8 / 13)$ & 42 & $(10 / 24)$ & 67 & $(4 / 6)$ & 51 & $(22 / 43)$ \\
\hline $\begin{array}{l}\text { Kühe mit } \\
\text { subklinischer oder } \\
\text { klinischer Mastitis } \\
\text { am Schluss melken }\end{array}$ & 46 & $(6 / 13)$ & 33 & $(8 / 24)$ & 33 & $(2 / 6)$ & 37 & $(16 / 43)$ \\
\hline $\begin{array}{l}\text { Kühe mit } \\
\text { subklinischer oder } \\
\text { klinischer Mastitis } \\
\text { am Schluss melken } \\
\text { oder mit Wasser } \\
\text { nachspülen, \% }\end{array}$ & $85^{a}$ & $(11 / 13)$ & $50^{b}$ & $(12 / 24)$ & 67 & $(4 / 6)$ & 63 & $(27 / 43)$ \\
\hline $\begin{array}{l}\text { Gummihandschuhe } \\
\text { beim Melken immer } \\
\text { tragen, \% }\end{array}$ & $31^{a}$ & $(4 / 13)$ & $30^{\mathrm{a}}$ & $(7 / 23)$ & $67^{b}$ & $(4 / 6)$ & 36 & $(15 / 42)$ \\
\hline $\begin{array}{l}\text { Euter trocken } \\
\text { reinigen, \% }\end{array}$ & 62 & $(8 / 13)$ & 54 & $(13 / 24)$ & 80 & $(4 / 5)$ & 60 & $(25 / 42)$ \\
\hline
\end{tabular}

Fortsetzung auf der nächsten Seite 
Ergebnisse

Tabelle 15 (Fortsetzung von vorheriger Seite)

\begin{tabular}{|c|c|c|c|c|c|c|c|c|}
\hline & \multicolumn{2}{|c|}{ uTüN ${ }^{1}$} & \multicolumn{2}{|c|}{$\mathrm{uTuN}^{2}$} & \multicolumn{2}{|c|}{ üTüN ${ }^{3}$} & \multicolumn{2}{|c|}{ Alle Betriebe } \\
\hline $\begin{array}{l}\text { Euter nicht reinigen, } \\
\%\end{array}$ & $38^{a}$ & $(5 / 13)$ & 25 & $(6 / 24)$ & $17^{b}$ & $(1 / 6)$ & 28 & $(12 / 43)$ \\
\hline $\begin{array}{l}\text { Euter nicht mit } \\
\text { einem Lappen aus } \\
\text { einem Eimer } \\
\text { waschen, \% }\end{array}$ & 100 & $(13 / 13)$ & 92 & $(22 / 24)$ & 100 & $(6 / 6)$ & 95 & $(41 / 43)$ \\
\hline $\begin{array}{l}\text { Anrüstzeit 60-90 } \\
\text { Sekunden, \% }\end{array}$ & 31 & $(4 / 13)$ & $33^{a}$ & $(8 / 24)$ & $17^{\mathrm{b}}$ & $(1 / 6)$ & 30 & $(13 / 43)$ \\
\hline $\begin{array}{l}\text { Vormelken in } \\
\text { Vormelkbecher } \\
\text { (Melkstand), \% }\end{array}$ & 0 & $(0 / 10)$ & $6^{a}$ & $(1 / 16)$ & $33^{b}$ & $(2 / 6)$ & 9 & $(3 / 32)$ \\
\hline $\begin{array}{l}\text { Vormelken in } \\
\text { Vormelkbecher } \\
\text { (Anbindung), \% }\end{array}$ & 0 & $(0 / 3)$ & 13 & $(1 / 8)$ & & $(0 / 0)$ & 9 & $(1 / 11)$ \\
\hline $\begin{array}{l}\text { Kein Vormelken von } \\
\text { Hand, \% }\end{array}$ & 15 & $(2 / 13)$ & 13 & $(3 / 24)$ & 0 & $(0 / 6)$ & 12 & $(5 / 43)$ \\
\hline $\begin{array}{l}\text { Kein Lufteinlassen } \\
\text { beim Ansetzten der } \\
\text { Zitzenbecher, \% }\end{array}$ & 46 & $(6 / 13)$ & 63 & $(15 / 24)$ & 67 & $(4 / 6)$ & 58 & $(25 / 43)$ \\
\hline $\begin{array}{l}\text { Abnahmeautomatik } \\
\text { (Melkstand), \% }\end{array}$ & $40^{\mathrm{a}}$ & $(4 / 10)$ & $44^{\mathrm{a}}$ & $(7 / 16)$ & $83^{b}$ & $(5 / 6)$ & 50 & $(16 / 32)$ \\
\hline $\begin{array}{l}\text { Abschalt- oder } \\
\text { Abnahmeautomatik } \\
\text { (Alle), \% }\end{array}$ & $54^{\mathrm{a}}$ & $(7 / 13)$ & $38^{\mathrm{a}}$ & $(9 / 24)$ & $83^{b}$ & $(5 / 6)$ & 49 & $(21 / 43)$ \\
\hline $\begin{array}{l}\text { Kein mechanisches } \\
\text { Nachmelken, \% }\end{array}$ & 92 & $(12 / 13)$ & 100 & $(24 / 24)$ & 83 & $(5 / 6)$ & 95 & $(41 / 43)$ \\
\hline $\begin{array}{l}\text { Kein Runterdrücken } \\
\text { der Melkzeugen } \\
\text { zum Ende (wenn } \\
\text { keine Abnahme- } \\
\text { automatik), \% }\end{array}$ & $44^{\mathrm{a}}$ & $(4 / 9)$ & $19^{\mathrm{b}}$ & $(3 / 16)$ & 0 & $(0 / 1)$ & 27 & $(7 / 26)$ \\
\hline $\begin{array}{l}\text { Zitzentauchmittel } \\
\text { sprühen, \% }\end{array}$ & 31 & $(4 / 13)$ & 25 & $(6 / 24)$ & 17 & $(1 / 6)$ & 26 & $(11 / 43)$ \\
\hline $\begin{array}{l}\text { Zitzentauchmittel } \\
\text { tauchen, \% }\end{array}$ & $62^{\mathrm{a}}$ & $(8 / 13)$ & $58^{\mathrm{a}}$ & $(14 / 24)$ & $83^{b}$ & $(5 / 6)$ & 63 & $(27 / 43)$ \\
\hline
\end{tabular}

Fortsetzung auf der nächsten Seite 
Tabelle 15 (Fortsetzung von vorheriger Seite)

\begin{tabular}{|c|c|c|c|c|c|c|c|c|c|c|c|c|}
\hline & \multicolumn{3}{|c|}{ uTüN ${ }^{1}$} & \multicolumn{3}{|c|}{$\mathrm{UTuN}^{2}$} & \multicolumn{3}{|c|}{ üTüN ${ }^{3}$} & \multicolumn{3}{|c|}{ Alle Betriebe } \\
\hline $\begin{array}{l}\text { Zitzentauchmittel mit } \\
\text { Zulassung als } \\
\text { Tierarzneimittel, \% }\end{array}$ & $8^{a}$ & \multicolumn{2}{|c|}{$(1 / 13)$} & $21^{a}$ & \multicolumn{2}{|c|}{$(5 / 24)$} & $67^{\mathrm{b}}$ & \multicolumn{2}{|c|}{$(4 / 6)$} & 23 & \multicolumn{2}{|c|}{$(10 / 43)$} \\
\hline $\begin{array}{l}\text { Zitzentauchen mit } \\
\text { Jod, \% }\end{array}$ & $31^{a}$ & \multicolumn{2}{|c|}{$(4 / 13)$} & 54 & \multicolumn{2}{|c|}{$(13 / 24)$} & $83^{b}$ & \multicolumn{2}{|c|}{$(5 / 6)$} & 51 & \multicolumn{2}{|c|}{$(22 / 43)$} \\
\hline $\begin{array}{l}\text { Zitzentauchen mit } \\
\text { Chlor, \% }\end{array}$ & 31 & \multicolumn{2}{|c|}{$(4 / 13)$} & 17 & \multicolumn{2}{|c|}{$(4 / 24)$} & 17 & \multicolumn{2}{|c|}{$(1 / 6)$} & 21 & \multicolumn{2}{|c|}{$(9 / 43)$} \\
\hline Zweimal täglicher & 85 & \multicolumn{2}{|c|}{$(11 / 13)$} & 77 & \multicolumn{2}{|c|}{$(16 / 24)$} & 83 & \multicolumn{2}{|c|}{$(5 / 6)$} & 74 & \multicolumn{2}{|c|}{$(32 / 43$} \\
\hline & $\begin{array}{l}\text { Mittel } \\
\text { wert }\end{array}$ & SD & $n$ & $\begin{array}{l}\text { Mittel } \\
\text { wert }\end{array}$ & SD & $\mathrm{n}$ & $\begin{array}{c}\text { Mittelw } \\
\text { ert }\end{array}$ & SD & $\mathrm{n}$ & $\begin{array}{l}\text { Mittel } \\
\text { wert }\end{array}$ & SD & $\mathrm{n}$ \\
\hline $\begin{array}{l}\text { Hygienebewertung } \\
\text { Melkraum }^{4}\end{array}$ & 2,0 & 0,9 & 13 & 1,7 & 0,6 & 24 & 1,8 & 1,0 & 6 & 1,8 & 0,7 & 43 \\
\hline $\begin{array}{l}\text { Anrüstzeit, } \\
\text { Sekunden }\end{array}$ & 48 & 44 & 13 & 59 & 44 & 24 & 92 & 59 & 6 & 60 & 47 & 43 \\
\hline $\begin{array}{l}\text { Milchfluss }<0,2 \\
\mathrm{~kg} / \mathrm{min}, \text { Minuten }\end{array}$ & 1,1 & 0,6 & 13 & 1,2 & 0,7 & 23 & 1,1 & 0,4 & 6 & 1,1 & 0,6 & 42 \\
\hline $\begin{array}{l}\text { Milchfluss }<0,2 \\
\mathrm{~kg} / \mathrm{min}, \geq 1 \mathrm{~min}, \%\end{array}$ & 39 & 24 & 13 & 45 & 27 & 23 & 66 & 35 & 6 & 46 & 28 & 42 \\
\hline
\end{tabular}

\subsubsection{Analyse der melktechnischen Managementvariablen der Gruppe NZELL}

Die Funktionsfähigkeit der Melkanlagen wurde in nahezu allen Betrieben jährlich von einem Fachmann überprüft. Die Zitzengummis wurden durchschnittlich nach 3.500 Melkungen gewechselt. Der Anteil luftziehender Melkzeuge während des maschinellen Milchentzuges lag im Mittel bei $4 \%$. Es fielen beinahe keine Melkzeuge ab, auch wurden nahezu keine Melkzeuge abgetreten. Im Mittel wiesen mehr als die Hälfte aller Zitzenkanalöffnungen keinerlei Veränderungen wie Verfärbungen, Schwellungen oder Hyperkeratosen auf. Tabelle 16 zeigt die beurteilten melktechnikbezogenen Managementfaktoren. 
Ergebnisse

Tabelle 16: Variablen der Melktechnik der Cluster der Gruppe NZELL

\begin{tabular}{|c|c|c|c|c|c|c|c|c|}
\hline & \multicolumn{2}{|c|}{ uTüN ${ }^{1}$} & \multicolumn{2}{|c|}{$\mathrm{uTuN}^{2}$} & \multicolumn{2}{|c|}{ üTüN ${ }^{3}$} & \multicolumn{2}{|c|}{ Alle Betriebe } \\
\hline $\begin{array}{l}\text { Melkmaschine } \\
\text { mindestens jährlich } \\
\text { durch Fachmann } \\
\text { überprüft, \% }\end{array}$ & 85 & $(11 / 13)$ & 67 & $(16 / 24)$ & 100 & $(6 / 6)$ & 77 & $(33 / 43)$ \\
\hline $\begin{array}{l}\text { Weniger als } \\
\text { 9,3 Kühe je } \\
\text { Melkzeug (Liege- } \\
\text { boxenlaufstall), \% }\end{array}$ & 100 & $(10 / 10)$ & 100 & $(16 / 16)$ & 83 & $(5 / 6)$ & 97 & $(31 / 32)$ \\
\hline $\begin{array}{l}\text { Anteil slippender } \\
\text { Melkzeuge }<5 \%, \%\end{array}$ & 77 & $(10 / 13)$ & 63 & $(15 / 24)$ & 67 & $(4 / 6)$ & 67 & $(29 / 43)$ \\
\hline $\begin{array}{l}\text { Zitzengummiwechse } \\
\text { I Gummi < } 6.000 \\
\text { Melkungen } \\
\text { (Melkstand, } \\
\text { schwarz), \% }\end{array}$ & 89 & $(8 / 9)$ & 86 & $(12 / 14)$ & 80 & $(4 / 5)$ & 86 & $(24 / 28)$ \\
\hline $\begin{array}{l}\text { Minimales Vakuum } \\
\text { im kurzen Milch- } \\
\text { schlauch während } \\
\text { der dynamischen } \\
\text { Messung: } \leq 32 \mathrm{kPa} \text {, } \\
\%\end{array}$ & 23 & $(3 / 13)$ & 26 & $(5 / 19)$ & 0 & $(0 / 6)$ & 21 & $(8 / 38)$ \\
\hline $\begin{array}{l}\text { Hohe Vakuum- } \\
\text { Reserve in der } \\
\text { Vakuumpumpe } \\
\text { (> 10\% Leistung), \% }\end{array}$ & 23 & $(3 / 13)$ & 13 & $(3 / 21)$ & 100 & $(6 / 6)$ & 30 & $(12 / 40)$ \\
\hline $\begin{array}{l}\text { Vakuumhöhe } \\
<42 \mathrm{kPa}, \%\end{array}$ & 100 & $(10 / 10)$ & 63 & $(10 / 16)$ & 83 & $(5 / 6)$ & 78 & $(25 / 32)$ \\
\hline $\begin{array}{l}\text { Elektronischer } \\
\text { Pulsator, \% }\end{array}$ & 92 & $(12 / 13)$ & 71 & $(17 / 24)$ & 100 & $(6 / 6)$ & 81 & $(35 / 43)$ \\
\hline $\begin{array}{l}\text { Pulsation 60:40 - } \\
65: 35, \%\end{array}$ & 100 & $(13 / 13)$ & 88 & $(21 / 24)$ & 100 & $(6 / 6)$ & 93 & $(40 / 43)$ \\
\hline $\begin{array}{l}\text { D-Phase des } \\
\text { Pulszyklus nicht } \\
<150 \mathrm{~ms}, \%\end{array}$ & 100 & $(13 / 13)$ & 100 & $(24 / 24)$ & 100 & $(6 / 6)$ & 100 & $(43 / 43)$ \\
\hline
\end{tabular}

Fortsetzung auf der nächsten Seite 
Tabelle 16 (Fortsetzung von vorheriger Seite)

\begin{tabular}{|c|c|c|c|c|c|c|c|c|c|c|c|c|}
\hline & \multicolumn{3}{|c|}{ uTüN ${ }^{1}$} & \multicolumn{3}{|c|}{$\mathrm{uTuN}^{2}$} & \multicolumn{3}{|c|}{ üTüN ${ }^{3}$} & \multicolumn{3}{|c|}{ Alle Betriebe } \\
\hline & $\begin{array}{c}\text { Mittel- } \\
\text { wert }\end{array}$ & SD & $\mathrm{n}$ & $\begin{array}{c}\text { Mittel- } \\
\text { wert }\end{array}$ & SD & $\mathrm{n}$ & $\begin{array}{l}\text { Mittel- } \\
\text { wert }\end{array}$ & SD & $\mathrm{n}$ & $\begin{array}{l}\text { Mittel- } \\
\text { wert }\end{array}$ & SD & $\mathrm{n}$ \\
\hline $\begin{array}{l}\text { Anzahl Kühe je } \\
\text { Melkzeug } \\
\text { (Liegeboxenlaufstall) }\end{array}$ & 5,5 & 2,3 & 10 & 4,9 & 1,4 & 16 & 5,7 & 2,3 & 6 & 5,2 & 1,9 & 32 \\
\hline $\begin{array}{l}\text { Zitzengummiwech- } \\
\text { sel (Gummi, Liege- } \\
\text { boxenlaufstall), } \\
\text { Melkungen }\end{array}$ & 3.838 & 2.238 & 9 & 3.333 & 1.775 & 14 & 3.631 & 1.778 & 5 & 3.549 & 1877 & 28 \\
\hline $\begin{array}{l}\text { Anteil luftziehender } \\
\text { Melkzeuge, \% }\end{array}$ & 4 & 3 & 13 & 4 & 4 & 24 & 7 & 7 & 6 & 4 & 4 & 43 \\
\hline $\begin{array}{l}\text { Abfallende } \\
\text { Melkzeuge, \% }\end{array}$ & $0^{a}$ & 0 & 13 & $0^{a}$ & 0 & 23 & $1^{b}$ & 1 & 6 & 0 & 0 & 42 \\
\hline $\begin{array}{l}\text { Abgetretene } \\
\text { Melkzeuge, \% }\end{array}$ & 0,5 & 1 & 13 & 0 & 1 & 23 & 1 & 1 & 6 & 0 & 1 & 42 \\
\hline $\begin{array}{l}\text { Hyperkeratosen } \\
\text { keine Veränderung } \\
\text { oder kleiner weißer } \\
\text { Ring, \% }\end{array}$ & 53 & 21 & 13 & 56 & 21 & 24 & 69 & 24 & 6 & 57 & 22 & 43 \\
\hline
\end{tabular}

'uTüN = unterdurchschnittliche Therapiehäufigkeit, überdurchschnittliche Nutzungsdauer

${ }^{2}$ uTuN = unterdurchschnittliche Therapiehäufigkeit, unterdurchschnittliche Nutzungsdauer

${ }^{3}$ üTüN = überdurchschnittliche Therapiehäufigkeit, überdurchschnittliche Nutzungsdauer

$a, b=$ Unterschiedliche Indizes innerhalb einer Zeile weisen auf signifikante Unterschiede hin $(p<0,05)$

\subsection{Vergleich der Betriebsgruppen HZELL und NZELL}

Zur Identifikation von Managementfaktoren, die - gemessen an der mittleren Zellzahl der Milchleistungsprüfungen - Einfluss auf die Eutergesundheit auf Herdenebene nehmen, wurden die identifizierten besten Betriebe mit Milchviehbetrieben verglichen, die in Größe und regionaler Zuordnung den „besten Betrieben“ entsprachen jedoch aufgrund von aufgetretenen Eutergesundheitsproblemen freiwillig den Eutergesundheitsdienst konsultierten. Die betrieblichen Daten entstammen Betriebsprotokollen, die während der Besuche des Eutergesundheitsdienstes angefertigt wurden.

Die beiden Gruppen unterschieden sich signifikant in Bezug auf die Erkrankungsrate, die Neuerkrankungs- und die Heilungsrate in der Trockenperiode wie auch hinsichtlich 
der Färsenmastitisrate. Die Erkrankungsrate in der Gruppe HZELL lag um Faktor 2,25 höher als die der Gruppe NZELL. In der Trockenperiode war die Neuerkrankungsrate in der Gruppe HZELL um den Faktor 1,4 höher und die Heilungsrate um den Faktor 0,62 geringer als in der Gruppe NZELL. Die Färsenmastitisrate in der Gruppe HZELL lag um den Faktor 2,33 höher als die der Gruppe NZELL (Tabelle 17).

Tabelle 17: Neuerkrankungsrate, Mastitisdauer und Heilungsrate anhand des Zellgehaltes/ml Milch der Gruppen HZELL und NZELL (Mittelwert +l- Standardabweichung)

\begin{tabular}{|l|c|c|}
\hline & HZELL $(\mathrm{n}=44)$ & NZELL $(\mathrm{n}=44)$ \\
\hline Erkrankungsgrad, \% & $54(+/-13)^{\mathrm{a}}$ & $24(+/-6)^{\mathrm{b}}$ \\
\hline Neuerkrankungsrate in der Trockenperiode, \% & $23(+/-13)^{\mathrm{a}}$ & $16(+/-13)^{\mathrm{b}}$ \\
\hline Heilungsrate in der Trockenperiode, \% & $48(+/-14)^{\mathrm{a}}$ & $77(+/-18)^{\mathrm{b}}$ \\
\hline Färsenmastitisrate, \% & $42(+/-15)^{\mathrm{a}}$ & $18(+/-13)^{\mathrm{b}}$ \\
\hline $\mathrm{a}, \mathrm{b}=$ Unterschiedliche Indizes innerhalb einer Zeile weisen auf signifikante Unterschiede hin $(\mathrm{p}<0,05)$
\end{tabular}

\subsubsection{Vergleich der personalbezogenen Managementvariablen}

In 2,4-mal mehr Betrieben der Gruppe NZELL wurde ein CMT durchgeführt als in der Gruppe HZELL. Zudem nahmen 84\% der Landwirte der Gruppe NZELL und 61\% der Gruppe HZELL regelmäßig an Fortbildungen teil (Tabelle 18).

Tabelle 18: Variablen des Personalmanagements der Gruppen HZELL und NZELL

\begin{tabular}{|l|c|c|c|c|}
\hline & \multicolumn{2}{|c|}{ HZELL } & \multicolumn{2}{c|}{ NZELL } \\
\hline Regelmäßiger CMT, \% & $22^{\mathrm{a}}$ & $(10 / 44)$ & $53^{\mathrm{b}}$ & $(23 / 43)$ \\
\hline Durchgängig eine Person im Melkstand, \% & 43 & $(19 / 44)$ & 56 & $(24 / 43)$ \\
\hline Regelmäßige Teilnahme an Fortbildungen, \% & $61^{\mathrm{a}}$ & $(27 / 44)$ & $84^{\mathrm{b}}$ & $(36 / 43)$ \\
\hline
\end{tabular}

$a, b=$ Unterschiedliche Indizes innerhalb einer Zeile weisen auf signifikante Unterschiede hin $(p<0,05)$

\subsubsection{Vergleich der genetischen Managementvariablen}

In beiden untersuchten Betriebsgruppen wurden ausschließlich Kühe der Rasse Deutsche Holstein gehalten. Jedoch war die durchschnittliche Einzeltierleistung in den Betrieben der Gruppe NZELL um 860 kg Milch höher als in der Gruppe HZELL. Die Betriebe der Gruppe HZELL hatten im Vergleich zu den Betrieben der Gruppe NZELL im Mittel einen höheren Spitzenmilchfluss und einen geringeren Zitzendurchmesser. Die Ergebnisse der Managementfaktoren zur Zucht sind in Tabelle 19 zusammengefasst. 
Tabelle 19: Managementvariablen der Genetik der Gruppen HZELL und NZELL

\begin{tabular}{|l|c|c|c|c|c|c|}
\hline & \multicolumn{2}{|c|}{ HZELL } & \multicolumn{3}{c|}{ NZELL } \\
\hline $\begin{array}{l}\text { Rasse Deutsche Holstein schwarz- + rotbunt, } \\
\%\end{array}$ & 100 & $(44 / 44)$ & 100 & \multicolumn{2}{c|}{$(43 / 43)$} \\
\hline Zuchtkriterium Bullenwahl Zellzahl, \% & 16 & $(7 / 44)$ & 23 & $(10 / 43)$ \\
\hline $\begin{array}{l}\text { Zuchtkriterium bei Färsenauswahl Zellzahl } \\
\text { Mutter, \% }\end{array}$ & 5 & $(2 / 44)$ & 9 & $(4 / 43)$ \\
\hline $\begin{array}{l}\text { Mittlere Herdenleistung < 8.293 kg/Kuh } \\
\text { (niedersächsisches Mittel), \% }\end{array}$ & $48^{\mathrm{a}}$ & $(21 / 44)$ & $199^{\mathrm{b}}$ & \multicolumn{2}{|c|}{$(8 / 43)$} \\
\hline & Mittel- & SD & $\mathrm{n}$ & Mittel- & SD & $\mathrm{n}$ \\
& wert & & & wert & \multicolumn{2}{|c|}{} \\
\hline Milchleistung, kg/Kuh u. Jahr & $8.215^{\mathrm{a}}$ & 1.212 & 44 & $9.075^{\mathrm{b}}$ & 1.211 & 43 \\
\hline Durchschnittlicher Spitzenmilchfluss, kg/min & $3,6^{\mathrm{a}}$ & 0,8 & 44 & $3,3^{\mathrm{b}}$ & 0,6 & 42 \\
\hline Spitzenmilchfluss <= 3,2 kg/min, \% & 41 & 23 & 44 & 47 & 25 & 42 \\
\hline Mittlerer Zitzendurchmesser, mm & $24^{\mathrm{a}}$ & 2 & 44 & $26^{\mathrm{b}}$ & 2 & 43 \\
\hline
\end{tabular}

a, b = Unterschiedliche Indizes innerhalb einer Zeile weisen auf signifikante Unterschiede hin $(p<0,05)$

\subsubsection{Vergleich der haltungsbedingten Managementvariablen}

Der Aufwand, der zum Erreichen einer guten Hygiene im Milchviehstall betrieben wurde, war in den Betrieben der Gruppe NZELL deutlich höher als in der Gruppe HZELL (Tabelle 20). So reinigten $81 \%$ der Betriebe der Gruppe NZELL (18\% in der Gruppe HZELL) regelmäßig die Laufgänge und 73\% der Gruppe NZELL (11\% in der Gruppe HZELL) schoben diese mehr als einmal täglich ab. In der Gruppe NZELL wurden eine trockene Liegefläche in 79\% der Betriebe der Gruppe (66\% in der Gruppe HZELL) und saubere Euter bei $65 \%$ der Kühe (30\% in der Gruppe HZELL) festgestellt. Zudem waren die Liegeflächen in den Betrieben der Gruppe NZELL weicher als die der Gruppe HZELL. In der Gruppe NZELL gab es vermehrt eingestreute Liegeflächen, wurde häufiger zusätzlich Kalk eingestreut, die Einstreu hatte seltener erhöhte Keimgehalte und es wurde teilweise Nachtweide angeboten. Die Betriebe der Gruppe NZELL pflegten die Liegeflächen 2,3-mal täglich, während die Betriebe der Gruppe HZELL dies 1,4-mal täglich taten, so dass die Tiere entsprechend stärker verschmutzte Euter hatten. Der Kuhkomfortindex in den Betrieben der Gruppe NZELL (77\%) war höher als in der Gruppe HZELL (68\%). 
Tabelle 20: Managementvariablen der Gestaltung der Haltungsumwelt der Gruppen HZELL und NZELL

\begin{tabular}{|c|c|c|c|c|}
\hline & \multicolumn{2}{|c|}{ HZELL } & \multicolumn{2}{|c|}{ NZELL } \\
\hline Liegeboxenlaufstall, \% & 73 & $(32 / 44)$ & 74 & $(32 / 43)$ \\
\hline $\begin{array}{l}\text { Laufflächen als Spaltenboden } \\
\text { (Liegeboxenlaufstall), \% }\end{array}$ & 88 & $(28 / 32)$ & 81 & $(26 / 32)$ \\
\hline $\begin{array}{l}\text { Regelmäßige Reinigung der Laufflächen } \\
\text { (Liegeboxenlaufstall mit Spalten), \% }\end{array}$ & $18^{\mathrm{a}}$ & $(5 / 28)$ & $81^{b}$ & $(21 / 26)$ \\
\hline $\begin{array}{l}\text { Laufflächen > } 1 \text { mal/Tag reinigen } \\
\text { (Liegeboxenlaufstall mit Spalten), \% }\end{array}$ & $11^{a}$ & $(3 / 28)$ & $73^{b}$ & $(19 / 26)$ \\
\hline Trockene Liegefläche im Euterbereich, \% & $66^{a}$ & $(29 / 44)$ & $79^{b}$ & $(34 / 43)$ \\
\hline Tägliche Pflege der Liegeflächen, \% & 73 & $(32 / 44)$ & 100 & $(43 / 43)$ \\
\hline Euter sind sauber bis sehr sauber, $\%^{1}$ & $30^{\mathrm{a}}$ & $(13 / 44)$ & $65^{b}$ & $(28 / 43)$ \\
\hline $\begin{array}{l}\text { Sehr weiche Liegefläche } \\
\text { (Liegeboxenlaufstall), } \%{ }^{2}\end{array}$ & 13 & $(4 / 32)$ & 19 & $(6 / 32)$ \\
\hline $\begin{array}{l}\text { Weiche - sehr weiche Liegefläche } \\
\text { (Liegeboxenlaufstall), } \%^{2}\end{array}$ & $34^{\mathrm{a}}$ & $(11 / 32)$ & $66^{b}$ & $(21 / 32)$ \\
\hline $\begin{array}{l}\text { Weiche - sehr weiche Liegefläche } \\
\text { (Anbindestall), } \%^{2}\end{array}$ & 0 & $(0 / 6)$ & 9 & $(1 / 11)$ \\
\hline $\begin{array}{l}\text { Weiche - sehr weiche Liegefläche (alle } \\
\text { Betriebe), } \%^{2}\end{array}$ & $25^{a}$ & $(11 / 44)$ & $51^{b}$ & $(22 / 43)$ \\
\hline Stroh als Einstreu, \% & 64 & $(28 / 44)$ & 56 & $(24 / 43)$ \\
\hline Kalk als Zusatz im Einstreu, \% & $16^{\mathrm{a}}$ & $(7 / 44)$ & $37^{b}$ & $(16 / 43)$ \\
\hline Anbindestall mit Weide, \% & 8 & $(5 / 6)$ & 91 & $(10 / 11)$ \\
\hline $\begin{array}{l}\text { Ermöglichung von Nachtweide } \\
\text { (alle Betriebe), \% }\end{array}$ & $0^{a}$ & $(0 / 44)$ & $44^{\mathrm{b}}$ & $(19 / 43)$ \\
\hline Einstreu in Liegfläche (alle), \% & $80^{a}$ & $(35 / 44)$ & $91^{b}$ & $(39 / 43)$ \\
\hline $\begin{array}{l}\text { Einstreu > } 1 \mathrm{mal} / \text { Woche in Liegeboxen } \\
\text { nachfüllen (Liegeboxenlaufstall mit Einstreu), } \\
\%\end{array}$ & 56 & $(14 / 25)$ & 55 & $(16 / 29)$ \\
\hline $\begin{array}{l}\text { Einstreu > } 1 \text { mal/Woche in Liegeboxen } \\
\text { nachfüllen (Anbindestall mit Einstreu), \% }\end{array}$ & 0 & $(0 / 0)$ & 100 & $(10 / 10)$ \\
\hline $\begin{array}{l}\text { Keime in Einstreu gering (Gesamtkeimzahl: } \\
\text { Stroh }<7 \times 10^{8} \mathrm{KbE} / \mathrm{g} \text {; Späne }<1 \times 10^{6} \mathrm{KbE} / \mathrm{g} \text { ), \% }\end{array}$ & $43^{a}$ & $(15 / 35)$ & $65^{b}$ & $(28 / 43)$ \\
\hline Gehalt an coliformen Keimen $<10^{6} \mathrm{KbE} / \mathrm{g}, \%$ & 40 & $(14 / 35)$ & 56 & $(24 / 43)$ \\
\hline
\end{tabular}

Fortsetzung auf der nächsten Seite 
Tabelle 20 (Fortsetzung von vorheriger Seite)

\begin{tabular}{|l|c|c|c|c|c|c|}
\hline & \multicolumn{2}{|c|}{ HZELL } & \multicolumn{3}{|c|}{ NZELL } \\
& $\begin{array}{c}\text { Mittel- } \\
\text { wert }\end{array}$ & SD & $\mathrm{n}$ & $\begin{array}{c}\text { Mittel- } \\
\text { wert }\end{array}$ & SD & $\mathrm{n}$ \\
\hline $\begin{array}{l}\text { Anzahl Reinigung Lauffläche } \\
\text { (Liegeboxenlaufstall mit Spalten) je Tag }\end{array}$ & $0,4^{\mathrm{a}}$ & 1,3 & 32 & $1,3^{\mathrm{b}}$ & 1,1 & 32 \\
\hline $\begin{array}{l}\text { Anzahl Reinigung / Pflege der Liegeflächen je } \\
\text { Tag }\end{array}$ & $1,4^{\mathrm{a}}$ & 0,6 & 44 & $2,3^{\mathrm{b}}$ & 0,7 & 43 \\
\hline Sauberkeit Euter & & & & & & \\
\hline $\begin{array}{l}\text { Strohlagerung im Kopfraum } \\
\text { (Liegeboxenlaufstall), Tage }\end{array}$ & $8,3^{\mathrm{a}}$ & 1,3 & 44 & $2,1^{\mathrm{b}}$ & 0,8 & 43 \\
\hline Kuhkomfortindex, \% & 6,8 & 28 & 6,1 & 7,4 & 29 \\
\hline
\end{tabular}

Verschmutzung Euter: 1 = sehr sauber, 6 = sehr stark verschmutzt

${ }^{2}$ Weichheit der Liegefläche: 1 = sehr weich, 3 = hart

$a, b=$ Unterschiedliche Indizes innerhalb einer Zeile weisen auf signifikante Unterschiede hin $(p<0,05)$

\subsubsection{Vergleich der fütterungsbedingten Managementvariablen}

Im Bereich des Fütterungsmanagements leisteten die Betriebe der Gruppe NZELL einen größeren Aufwand, als die Betriebe der Gruppe HZELL. In der Gruppe NZELL gab es mehr Fressplätze je Kuh, das Tränkwasser hatte häufiger Trinkwasserqualität und es wurde regelmäßiger Rationsberechnungen durchgeführt. Die Betriebe in der Gruppe NZELL fütterten häufiger Maissilage, ergänzten die Ration häufiger mit Mineralstoffen und verabreichten den Kühen direkt nach der Kalbung häufiger Wasser oder einen Energietrunk. Die Betriebe der Gruppe NZELL legten 1,4-mal häufiger Grundfutter vor und fütterten gleichzeitig eine geringere maximale Kraftfuttergabe je Kuh und Tag. Ein Verdacht auf Ketose bzw. Acidose lag in den Betrieben der Gruppe NZELL seltener vor. In der Gruppe NZELL wurden die Kühe für fast eine Woche länger trockengestellt, gaben zum Zeitpunkt des Trockenstellens weniger Milch und ließen nach dem Trockenstellen seltener die Milch laufen. Die fütterungsbezogenen Daten sind in Tabelle 21 abgebildet. 
Tabelle 21: Variablen des Fütterungsmanagements der Gruppen HZELL und NZELL

\begin{tabular}{|c|c|c|c|c|c|c|}
\hline & \multicolumn{3}{|c|}{ HZELL } & \multicolumn{3}{|c|}{ NZELL } \\
\hline Fressplätze $>0,8$ je Kuh, $\%$ & $59^{a}$ & \multicolumn{2}{|c|}{$(22 / 37)$} & $88^{b}$ & \multicolumn{2}{|c|}{$(28 / 32)$} \\
\hline $\begin{array}{l}\text { Kühe nach dem Melken fixieren } \\
\text { (Liegeboxenlaufstall), \% }\end{array}$ & 28 & \multicolumn{2}{|c|}{$(9 / 32)$} & 43 & \multicolumn{2}{|c|}{$(13 / 30)$} \\
\hline $\begin{array}{l}\text { Fixieren oder frisches Futter vorlegen nach } \\
\text { dem Melken, \% }\end{array}$ & 59 & \multicolumn{2}{|c|}{$(26 / 44)$} & 70 & \multicolumn{2}{|c|}{$(30 / 43)$} \\
\hline Tränkwasser hat Trinkwasserqualität, \% & $43^{\mathrm{a}}$ & \multicolumn{2}{|c|}{$(19 / 44)$} & $67^{b}$ & \multicolumn{2}{|c|}{$(29 / 43)$} \\
\hline Rationsberechnung, \% & $50^{a}$ & \multicolumn{2}{|c|}{$(22 / 44)$} & $72^{b}$ & \multicolumn{2}{|c|}{$(31 / 43)$} \\
\hline Futtervorlage gemischt, \% & 52 & \multicolumn{2}{|c|}{$(23 / 44)$} & 58 & \multicolumn{2}{|c|}{$(25 / 43)$} \\
\hline $\begin{array}{l}\text { Keine Rübennassschnitzel an laktierende } \\
\text { Kühe füttern, \% }\end{array}$ & 77 & \multicolumn{2}{|c|}{$(34 / 44)$} & 100 & \multicolumn{2}{|c|}{$(43 / 43)$} \\
\hline Maissilage an laktierende Kühe füttern, \% & $82^{\mathrm{a}}$ & \multicolumn{2}{|c|}{$(36 / 44)$} & $91^{b}$ & \multicolumn{2}{|c|}{$(39 / 43)$} \\
\hline Mineralstoffe ganzjährig ergänzen, \% & $64^{\mathrm{a}}$ & \multicolumn{2}{|c|}{$(28 / 44)$} & $93^{\mathrm{b}}$ & \multicolumn{2}{|c|}{$(40 / 43)$} \\
\hline $\mathrm{NaCl}$ ergänzen, \% & 84 & \multicolumn{2}{|c|}{$(37 / 44)$} & 100 & \multicolumn{2}{|c|}{$(43 / 43)$} \\
\hline Selen ergänzen, \% & 57 & \multicolumn{2}{|c|}{$(25 / 44)$} & 100 & \multicolumn{2}{|c|}{$(43 / 43)$} \\
\hline Vitamin A, D3, E ergänzen, \% & 66 & \multicolumn{2}{|c|}{$(29 / 44)$} & 100 & \multicolumn{2}{|c|}{$(43 / 43)$} \\
\hline $\begin{array}{l}\text { Propylenglycol bei Kühen zu Beginn der } \\
\text { Laktation, \% }\end{array}$ & 61 & \multicolumn{2}{|c|}{$(27 / 44)$} & 60 & \multicolumn{2}{|c|}{$(26 / 43)$} \\
\hline Wasser, Energietrunk an alle Kühe direkt nach & $32^{a}$ & \multicolumn{2}{|c|}{$(14 / 44)$} & $79^{b}$ & \multicolumn{2}{|c|}{$(34 / 43)$} \\
\hline & $\begin{array}{c}\text { Mittel- } \\
\text { wert }\end{array}$ & SD & $\mathrm{n}$ & $\begin{array}{c}\text { Mittel- } \\
\text { wert }\end{array}$ & SD & $\mathrm{n}$ \\
\hline Fressplätze je Kuh (alle) & $0,8^{\mathrm{a}}$ & 0,2 & 44 & $1,1^{\mathrm{b}}$ & 0,2 & 43 \\
\hline $\begin{array}{l}\text { Vorlage von frischem Futter oder } \\
\text { Nachschieben, Anzahl }\end{array}$ & $3,4^{a}$ & 2,0 & 44 & $4,8^{b}$ & 1,7 & 43 \\
\hline Reinigung des Futtertisches je Tag, Anzahl & 1,2 & 0,7 & 44 & 1,4 & 0,8 & 43 \\
\hline Maximale Kraftfuttermenge, $\mathrm{kg} / \mathrm{Tag}$ & $13,4^{\mathrm{a}}$ & 1,7 & 44 & $11,5^{b}$ & 2,3 & 43 \\
\hline $\begin{array}{l}\text { Fett-Eiweiß-Quotient }>1,5 \text { bei } \\
\text { Laktationstage }<100, \%\end{array}$ & $18 a$ & 6 & 44 & $15 \mathrm{~b}$ & 8 & 43 \\
\hline $\begin{array}{l}\text { Fett-Eiweiß-Quotient }<1 \text { bei } \\
\text { Laktationstage }<300, \%\end{array}$ & $29^{a}$ & 12 & 44 & $10^{\mathrm{b}}$ & 11 & 43 \\
\hline Dauer Trockenperiode, Wochen & $6,4^{\mathrm{a}}$ & 0,9 & 44 & $7,3^{b}$ & 1,0 & 43 \\
\hline Mittlere Milchmenge beim Trockenstellen, kg & $18^{\mathrm{a}}$ & 4,5 & 44 & $16^{b}$ & 4,8 & 43 \\
\hline $\begin{array}{l}\text { Anteil Kühe, die nach dem Trockenstellen die } \\
\text { Milchlaufen lassen, } \%\end{array}$ & $21^{\mathrm{a}}$ & 13 & 44 & $15^{\mathrm{b}}$ & 14 & 40 \\
\hline
\end{tabular}

$a, b=$ Unterschiedliche Indizes innerhalb einer Zeile weisen auf signifikante Unterschiede hin $(p<0,05)$ 


\subsubsection{Vergleich der melkarbeitsbezogenen Managementvariablen}

Hinsichtlich der Melkarbeit unterschieden sich die beiden Betriebsgruppen HZELL und NZELL in zahlreichen Punkten signifikant. Die Wahrscheinlichkeit für einen Betrieb, zur Gruppe NZELL zu gehören, war größer, wenn der Melkraum sauberer war, die Euterhaare geschoren wurden, beim Melken das Tragen von Gummihandschuhen erfolgte, Kühe mit Mastitiden entweder zum Schluss gemolken oder die Melkzeuge nach dem Melken mit Wasser nachgespült wurden, das Reinigen der Euter nicht mit nassen Tüchern aus einem Eimer erfolgte, die Anrüstzeit 60 - 90 Sekunden betrug, die Kühe von Hand vorgemolken wurden, es keine Abnahme-, Abschalt-, Nachmelkautomatik gab, die Zitzen nach dem Milchentzug getaucht wurden, als Zitzentauchmittel kein Chlor verwandt wurde und der Melkrhythmus vor dem Trockenstellen geändert wurde (Tabelle 22).

Tabelle 22: Managementvariablen der Melkarbeit der Gruppen HZELL und NZELL

\begin{tabular}{|l|c|c|c|c|}
\hline & \multicolumn{2}{|c|}{ HZELL } & \multicolumn{2}{c|}{ NZELL } \\
\hline Gute und sehr gute Hygiene im Melkraum, \% & 59 & $(26 / 44)$ & 77 & $(33 / 43)$ \\
\hline Scheren der Euterhaare \% & $32^{\mathrm{a}}$ & $(14 / 44)$ & $51^{\mathrm{b}}$ & $(22 / 43)$ \\
\hline $\begin{array}{l}\text { Kühe mit subklinischer oder klinischer Mastitis } \\
\text { am Schluss melken }\end{array}$ & $11^{\mathrm{a}}$ & $(5 / 44)$ & $37^{\mathrm{b}}$ & $(16 / 43)$ \\
\hline $\begin{array}{l}\text { Kühe mit subklinischer oder klinischer Mastitis } \\
\text { am Schluss melken oder mit Wasser } \\
\text { nachspülen, \% }\end{array}$ & $25^{\mathrm{a}}$ & $(11 / 44)$ & $63^{\mathrm{b}}$ & $(27 / 43)$ \\
\hline $\begin{array}{l}\text { Gummihandschuhe beim Melken immer } \\
\text { tragen, \% }\end{array}$ & $20^{\mathrm{a}}$ & $(9 / 44)$ & $36^{\mathrm{b}}$ & $(15 / 42)$ \\
\hline Euter trocken reinigen, \% & 45 & $(20 / 44)$ & 60 & $(25 / 42)$ \\
\hline Euter nicht reinigen, \% & 39 & $(17 / 44)$ & 28 & $(12 / 43)$ \\
\hline $\begin{array}{l}\text { Euter nicht mit einem Lappen aus einem Eimer } \\
\text { waschen, \% }\end{array}$ & $84^{\mathrm{a}}$ & $(37 / 44)$ & $95^{\mathrm{b}}$ & $(41 / 43)$ \\
\hline Anrüstzeit 60-90 Sekunden, \% & $16^{\mathrm{a}}$ & $(7 / 44)$ & $30^{\mathrm{b}}$ & $(13 / 43)$ \\
\hline Vormelken in Vormelkbecher (Melkstand), \% & 5 & $(2 / 38)$ & 9 & $(3 / 32)$ \\
\hline Vormelken in Vormelkbecher (Anbindung), \% & 0 & $(0 / 6)$ & 9 & $(1 / 11)$ \\
\hline Kein Vormelken von Hand, \% & $39^{\mathrm{a}}$ & $(17 / 44)$ & $12^{\mathrm{b}}$ & $(5 / 43)$ \\
\hline $\begin{array}{l}\text { Kein Lufteinlassen beim Ansetzten der } \\
\text { Zitzenbecher, \% }\end{array}$ & 48 & $(21 / 44)$ & 58 & $(25 / 43)$ \\
\hline Abnahmeautomatik (Melkstand), \% & $68^{\mathrm{a}}$ & $(26 / 38)$ & $50^{\mathrm{b}}$ & $(16 / 32)$ \\
\hline Abschalt- oder Abnahmeautomatik (Alle), \% & $70^{\mathrm{a}}$ & $(31 / 44)$ & $49^{\mathrm{b}}$ & $(21 / 43)$ \\
\hline Forsetzun auf der ächsen Sise & & & \\
\hline
\end{tabular}

Fortsetzung auf der nächsten Seite 
Tabelle 22 (Fortsetzung von vorheriger Seite)

\begin{tabular}{|c|c|c|c|c|c|c|}
\hline & \multicolumn{3}{|c|}{ HZELL } & \multicolumn{3}{|c|}{ NZELL } \\
\hline Kein mechanisches Nachmelken, \% & $80^{a}$ & \multicolumn{2}{|c|}{$(35 / 44)$} & $95^{\mathrm{b}}$ & \multicolumn{2}{|c|}{$(41 / 43)$} \\
\hline $\begin{array}{l}\text { Kein Runterdrücken der Melkzeugen zum } \\
\text { Ende (wenn keine Abnahmeautomatik), \% }\end{array}$ & 25 & \multicolumn{2}{|c|}{$(3 / 12)$} & 27 & \multicolumn{2}{|c|}{$(7 / 26)$} \\
\hline Zitzentauchmittel sprühen, \% & 18 & \multicolumn{2}{|c|}{$(8 / 44)$} & 26 & \multicolumn{2}{|c|}{$(11 / 43)$} \\
\hline Zitzentauchmittel tauchen, \% & $48^{a}$ & \multicolumn{2}{|c|}{$(21 / 44)$} & $63^{b}$ & \multicolumn{2}{|c|}{$(27 / 43)$} \\
\hline $\begin{array}{l}\text { Zitzentauchmittel mit Zulassung als } \\
\text { Tierarzneimittel, \% }\end{array}$ & 25 & \multicolumn{2}{|c|}{$(11 / 44)$} & 23 & \multicolumn{2}{|c|}{$(10 / 43)$} \\
\hline Zitzentauchen mit Jod, \% & 59 & \multicolumn{2}{|c|}{$(17 / 29)$} & 51 & \multicolumn{2}{|c|}{$(22 / 43)$} \\
\hline Zitzentauchen mit Chlor, \% & $41^{a}$ & \multicolumn{2}{|c|}{$(12 / 29)$} & $21^{\mathrm{b}}$ & \multicolumn{2}{|c|}{$(9 / 43)$} \\
\hline Zweimal täglicher Milchentzug bis zum & $89^{a}$ & \multicolumn{2}{|c|}{$(39 / 44)$} & $74^{\mathrm{b}}$ & \multicolumn{2}{|c|}{$(32 / 43)$} \\
\hline & $\begin{array}{l}\text { Mittel- } \\
\text { wert }\end{array}$ & SD & $\mathrm{n}$ & $\begin{array}{l}\text { Mittel- } \\
\text { wert }\end{array}$ & SD & $\mathrm{n}$ \\
\hline Hygienebewertung Melkraum $^{1}$ & $2,8^{\mathrm{a}}$ & 1,1 & 44 & $1,8^{\mathrm{b}}$ & 0,7 & 43 \\
\hline Anrüstzeit, Sekunden & $42^{\mathrm{a}}$ & 35 & 44 & $60^{b}$ & 47 & 43 \\
\hline
\end{tabular}

Hygienebewertung im Melkraum: 1 = sehr sauber, 6 = stark verschmutzt

$a, b=$ Unterschiedliche Indizes innerhalb einer Zeile weisen auf signifikante Unterschiede hin $(p<0,05)$

\subsubsection{Vergleich der melktechnischen Managementvariablen}

In den Betrieben der Gruppe NZELL traten weniger luftsaugende Melkzeuge während des Melkens auf, die Zitzengummis wurden häufiger gewechselt, das minimale Vakuum im kurzen Milchschlauch betrug seltener $\leq 32 \mathrm{kPa}$ und es konnten seltener Hyperkeratosen an der Zitzenöffnung beobachtet werden (Tabelle 23).

Tabelle 23: Variablen der Melktechnik der Gruppen HZELL und NZELL

\begin{tabular}{|l|c|c|c|c|}
\hline & \multicolumn{2}{|c|}{ HZELL } & \multicolumn{2}{c|}{ NZELL } \\
\hline $\begin{array}{l}\text { Melkmaschine mindestens jährlich durch } \\
\text { Fachmann überprüft, \% }\end{array}$ & 77 & $(34 / 44)$ & 77 & $(33 / 43)$ \\
\hline $\begin{array}{l}\text { Weniger als 9,3 Kühe je Melkzeug } \\
\text { (Melkstände), \% }\end{array}$ & 95 & $(36 / 38)$ & 97 & $(31 / 32)$ \\
\hline Anteil luftsaugender Melkzeuge <5\%,\% & $32^{\mathrm{a}}$ & $(14 / 44)$ & $67^{\mathrm{b}}$ & $(29 / 43)$ \\
\hline $\begin{array}{l}\text { Zitzengummiwechsel Gummi <6.000 } \\
\text { Melkungen (Melkstand, schwarz), \% }\end{array}$ & $48^{\mathrm{a}}$ & $(21 / 44)$ & $86^{\mathrm{b}}$ & $(24 / 28)$ \\
\hline
\end{tabular}

Fortsetzung auf der nächsten Seite 
Tabelle 23 (Fortsetzung von vorheriger Seite)

\begin{tabular}{|c|c|c|c|c|c|c|}
\hline & \multicolumn{3}{|c|}{ HZELL } & \multicolumn{3}{|c|}{ NZELL } \\
\hline $\begin{array}{l}\text { Minimales Vakuum im kurzen Milchschlauch } \\
\text { während der dynamischen Messung: } \leq 32 \mathrm{kPa} \text {, } \\
\%\end{array}$ & $40^{\mathrm{a}}$ & \multicolumn{2}{|c|}{$(15 / 38)$} & $21^{b}$ & \multicolumn{2}{|c|}{$(8 / 38)$} \\
\hline $\begin{array}{l}\text { Hohe Vakuum-Reserve in der Vakuumpumpe } \\
\text { (> 10\% Leistung), } \%\end{array}$ & 32 & \multicolumn{2}{|c|}{$(14 / 44)$} & 30 & \multicolumn{2}{|c|}{$(12 / 40)$} \\
\hline Vakuumhöhe $<42 \mathrm{kPa}, \%$ & 90 & \multicolumn{2}{|c|}{$(34 / 38)$} & 78 & \multicolumn{2}{|c|}{$(25 / 32)$} \\
\hline Elektronischer Pulsator, \% & 84 & \multicolumn{2}{|c|}{$(37 / 44)$} & 81 & \multicolumn{2}{|c|}{$(35 / 43)$} \\
\hline Pulsation 60:40-65:35, \% & 86 & \multicolumn{2}{|c|}{$(38 / 44)$} & 93 & \multicolumn{2}{|c|}{$(40 / 43)$} \\
\hline D-Phase des Pulszyklus nicht $<150 \mathrm{~ms}, \%$ & 100 & \multicolumn{2}{|c|}{$(44 / 44)$} & 100 & \multicolumn{2}{|c|}{$(43 / 43)$} \\
\hline & $\begin{array}{l}\text { Mittel- } \\
\text { wert }\end{array}$ & SD & $\mathrm{n}$ & $\begin{array}{l}\text { Mittel- } \\
\text { wert }\end{array}$ & SD & $\mathrm{n}$ \\
\hline Anzahl Kühe je Melkzeug (Melkstand) & 4,9 & 1,8 & 38 & 5,2 & 1,9 & 32 \\
\hline Anteil luftsaugender Melkzeuge, $\%$ & 6 & 7 & 44 & 4 & 4 & 43 \\
\hline Abfallende Melkzeuge, $\%$ & 2 & 4 & 44 & 0 & 0 & 42 \\
\hline Abgetretene Melkzeuge, $\%$ & $2^{a}$ & 2 & 44 & $0^{b}$ & 1 & 42 \\
\hline $\begin{array}{l}\text { Hyperkeratosen: keine Veränderung oder } \\
\text { kleiner weißer Ring, \% }\end{array}$ & $33^{a}$ & 14 & 44 & $57^{b}$ & 22 & 43 \\
\hline
\end{tabular}

\subsubsection{Ergebnisse der Regressionsanalyse des Vergleichs der Gruppen HZELL und NZELL}

Mit Hilfe der 45 Managementfaktoren, in denen sich die Betriebe der Gruppen NZELL und HZELL signifikant $(P<0,05)$ unterschieden, wurde eine logistische Regression durchgeführt. Drei Managementfaktoren konnten in der multivariaten Analyse als wesentliche Einflussfaktoren im Hinblick auf die Zuordnung der Betriebe zu den Gruppen NZELL und HZELL identifiziert werden. So wurde als sehr unwahrscheinlich identifiziert, dass Betriebe, in denen die Laufflächen nicht mehr als einmal täglich gereinigt wurden, der Gruppe NZELL angehörten. Die Wahrscheinlichkeit, dass Betriebe, in denen subklinisch oder klinisch erkrankte Tiere zum Schluss gemolken oder nach dem Melken betroffener Tiere die Melkzeuge mit Wasser gespült wurden, der Gruppe HZELL zuzuordnen waren, war hingegen sehr gering. Mit einem steigenden Anteil an Tieren mit einen Fett-Eiweiß-Quotienten $<1,0$ in einer Herde nahm die Wahrscheinlichkeit zu, dass der Betrieb der Gruppe HZELL angehörte. Die Ergebnisse der binären logistischen Regression stellt Tabelle 24 dar. 
Tabelle 24: Binäres logistisches Regressionsmodell für die Zuordnung der Betriebe zu den Gruppen HZELL und NZELL anhand von Managementfaktoren

\begin{tabular}{|l|c|c|c|c|}
\hline & B & S.E. & Sig. & Exp(B) \\
\hline Laufflächenreinigung $>1$ mal/Tag & & & 0,095 & \\
\hline nein & 3,993 & 1,913 & 0,037 & 54,203 \\
\hline ja & 1,064 & 2,503 & 0,671 & 2,898 \\
\hline Melkreihenfolge o. Wasserspülung & $-3,920$ & 1,831 & 0,032 & 0,020 \\
\hline Fett-Eiweiß-Quotient <1,0 & 0,195 & 0,074 & 0,008 & 1,216 \\
\hline Konstante & $-23,579$ & 40192,99 & 1,000 & 0,000 \\
\hline
\end{tabular}

$89,7 \%$ korrekt klassifiziert. Hosmer und Lemeshow Goodness of fit $=0,892$ 


\section{Diskussion}

\subsection{Management der Betriebe der Cluster der Gruppe NZELL}

In Niedersachsen wurden im Milchkontrolljahr 2004-2005 im Mittel 50 Milchkühe je Betrieb gehalten (VIT, 2005). Die im Rahmen dieser Studie ermittelten eutergesündesten Betriebe hielten durchschnittlich 41 Milchkühe, wobei 16\% der Betriebe (Mittelwert Niedersachsen: 16\%) 5 bis 19 Kühe, 48\% (27\%) 20 bis 39 Kühe, $18 \%(24 \%) 40$ bis 59 Kühe, 14\% (17\%) 60 bis 79 Kühe, $5 \%(8 \%) 80$ bis 99 Kühe und kein Betrieb (7\%) mehr als 100 Kühe hielten. Die untersuchten Betriebe erreichten mit 4,8 Jahren je Kuh ein dem niedersächsischen Durchschnitt von 4,9 Jahren entsprechendes mittleres Alter (VIT, 2005). Die 305-Tageleistung lag bei vergleichbaren Inhaltsstoffen mit $9.086 \mathrm{~kg} / \mathrm{Kuh}$ (4,19\% Fett, 3,38\% Eiweiß) etwa $800 \mathrm{~kg}$ über dem niedersächsischem Mittel von $8.293 \mathrm{~kg} / \mathrm{Kuh}$ (4,16\% Fett, 3,41\% Eiweiß) (VIT, 2005).

Die Ergebnisse entsprechen denen anderer Untersuchungen, die zeigten, dass Betriebe mit niedrigeren Zellgehalten in der Milch in der Regel weniger Kühe halten, jedoch überdurchschnittliche mittlere Herdenleistungen erbringen (Brown und White, 1972; Barkema et al., 1998a). Betriebliches Wachstum und der Bau eines neuen Laufstalls gehen häufig mit sinkender Milchleistung, steigenden Kosten für Tierarzt und Medikamente und schlechterer Eutergesundheit einher, auch wenn, langfristig betrachtet, die Eutergesundheit nach dem Wechsel vom Anbinde- in den Laufstall eine Verbesserung erfährt (Hultgren, 2002; Walter et al., 2005). Aufgrund der geringen mittleren Größe der in die vorliegende Studie einbezogenen Herden von 41 Tieren ist davon auszugehen, dass ein betriebliches Wachstum der ausgewählten Betriebe unmittelbar vor der Datenerhebung nicht oder nur eingeschränkt stattgefunden hat. Bei erfolgendem Betriebswachstum ist nach Waage et al. (1998) sicherzustellen, dass der Stress für die Tiere möglichst gering bleibt, das Tiergesundheitsmanagement nicht vernachlässigt wird und der Zukauf von Tieren möglichst unterbleibt.

Brolund (1985) stellte fest, dass mit zunehmendem Alter der Kühe die Zellgehalte in der Milch ansteigen. Dies konnte im Rahmen der vorliegenden Studie nicht bestätigt werden; die durchschnittliche Nutzungsdauer der Milchkühe in der Gruppe uTüN lag mit 33 Monaten 12\% über dem niedersächsischen Mittelwert. Dies deckt sich auch mit 
den Erkenntnissen anderer Arbeiten, in denen kein signifikanter Einfluss des Alters auf den Zellgehalt festgestellt wurde (Bodoh et al., 1976, Sheldrake et al., 1983, Laevens et al., 1997). Als Hauptabgangsgründe für Holstein Kühe mit einer Leistung von über $8.500 \mathrm{~kg}$ Milch je Kuh und Jahr werden Unfruchtbarkeit (18\% der Abgänge) gefolgt von Euterkrankheiten (17\%) und Verkäufen zur Zucht (17\%) angegeben (VIT, 2005). Die Betriebe dieser Studie wiesen mit 28\% einen höheren Anteil an Abgängen aufgrund von Unfruchtbarkeit auf. Im Hinblick auf den Anteil an Abgängen aufgrund von Euterkrankheiten entsprachen die ermittelten Werte dem Durchschnitt der Holstein Kühe. Abgänge zur Zucht hatten einen Anteil von nur 11\%.

Verschiedene Autoren konnten Inzidenzraten klinischer Mastitiden in Herden mit niedrigen Zellgehalten von 17,9 (0-80) Fällen je 100 Kühe und Jahr (Schukken et al., 1989) bzw. 22,8 (0,6-147) Fällen je 100 Kühe und Jahr (Peeler et al., 2000) ermitteln. In der vorliegenden Studie wurden 30 Behandlungen je 100 Kühe (24 Erstbehandlungen je 100 Kühe) aufgrund von Mastitiden durchgeführt. Betriebe der Gruppe uTüN führten 22 Mastitistherapien je 100 Kühe und Jahr durch. Das entsprach etwa der Inzidenzrate klinischer Mastitiden in den Herden mit den niedrigsten Zellgehalten in Frankreich (20\%) (Barnouin et al., 2005) und England $(22,8 \%)$ (Peeler et al., 2000).

Der mittlere Erkrankungsgrad in den untersuchten Herden betrug 24\% (+/- 6\%), während Volling et al. (2010) in 25 niedersächsischen Milchviehbetrieben einen mittleren Erkrankungsgrad von $62 \%$ ermittelten. Damit konnte in der vorliegenden Studie gezeigt werden, dass die in die Auswertung einbezogenen 43 Betriebe einen im Vergleich dazu niedrigeren Erkrankungsgrad aufwiesen. In der Untersuchung von Green et al. (2006) wurden 33 Herden in England und Wales mit leicht überdurchschnittlichen Herdensammelmilchzellgehalten von April 2003 bis März 2004 betrachtet. Für diese Betriebe wurde eine Erhöhungsrate von 13,3\% bestimmt (Green et al., 2006). Färsenmastitiden wurden dabei nicht erfasst. Für die in diese Studie einbezogenen Betriebe konnte eine um 33\% geringere Erhöhungsrate (9\% inklusive Färsenmastitiden) berechnet werden. Dabei muss beachtet werden, dass in den untersuchten Herden bei mehr Tieren eine Erhöhung des Zellgehaltes möglich gewesen wäre, denn der mittlere Herdensammelmilchzellgehalt lag in der vorliegenden Untersuchung bei 87.000 Zellen/ml und in der Untersuchung von Green et al. (2006) bei 200.000 Zellen/ml. Die Neuerkrankungsrate betrug im Mittel $97 \%$ bei einer Therapiehäufigkeit von 0,3 Mastitistherapien je Kuh und Jahr. Damit wird 
deutlich, dass in den untersuchten Betrieben nicht jedes Tier, das einen erhöhten Zellgehalt von über 100.000 Zellen/ml aufwies, therapiert wurde.

In verschiedenen Studien wurden Neuerkrankungsraten für die Trockenstehzeit von $26 \%$ bis 33\% bezogen auf die Euter (Ekman und Østerås, 2003; Volling et al., 2010) bzw. von $50 \%$ bezogen auf die Euterviertel (Klocke et al., 2010) ermittelt. Die mittlere Neuerkrankungsrate, die in der vorliegenden Arbeit berechnet wurde, war dagegen mit 16\% deutlich niedriger. Die Gründe hierfür könnten die sehr guten Hygienebedingungen (Green et al., 2007) und der Einsatz von antibiotischen Trockenstellern sein (Smith et al., 1985b; Schukken et al., 1993; Robert et al., 2006).

In der Literatur werden Heilungsraten für die Trockenstehzeit von 34\% der Euterviertel (Klocke et al., 2010) bzw. 38\% bis 46\% der Euter (Ekman und Østerås, 2003; Volling et al., 2010) beschrieben. Die durch Volling et al. (2010) untersuchten Betriebe setzten zu 14\% antibiotische Trockensteller (unveröffentlichte Daten) ein. Ekman und Østerås (2003) führen geringe Heilungsraten auf eine hohe Anzahl chronisch infizierter Euterviertel und einen geringen Einsatz antibiotischer Trockensteller in den Herden zurück. Lediglich in der Studie von Klocke et al. (2010) wurden alle Euterviertel mit antibiotischen Trockenstellern behandelt. In der vorliegenden Arbeit wurden in $95 \%$ der Betriebe alle Kühe mit antibiotischen Trockenstellern behandelt, wobei eine Heilungsrate von $77 \%$ in der Trockenstehzeit erzielt wurde. Diese hohe Heilungsrate ist zum einen auf den intensiven Einsatz von antibiotischen Trockenstellern und zum anderen auf die gute Hygiene zurückzuführen, denn es ist möglich, dass Euterviertel während der Trockenperiode zunächst heilen und anschließend wieder erkranken. Solche Fälle werden bei der Ermittlung der Neuerkrankungsrate anhand der Entwicklung der Zellgehalte nicht berücksichtigt. Die Wahrscheinlichkeit einer Erkrankung ist bei guter Hygiene jedoch geringer.

\subsubsection{Personalbezogene Managementvariablen}

Barnouin et al. (2005) stellten fest, dass sich eine intensivere Betreuung der Milchkühe sowie eine sorgfältige Arbeitsweise positiv auf die Eutergesundheit auswirken. Die uTüN-Gruppe zeichnete sich im Vergleich zu den beiden anderen Gruppen durch einen größeren Anteil an Betrieben aus, die regelmäßig einen CMT durchführten. Dies kann als Indikator einer besonderen Aufmerksamkeit der verantwortlichen Personen für die Eutergesundheit betracht werden, was auch die Ergebnisse von Chassagne et al. (2005) und Busato et al. (2000) bestätigen. 
Die ständige Beaufsichtigung des Melkvorganges erwies sich als vorteilhaft für die Eutergesundheit. Chassagne et al. (2005) zeigten, dass sich ein Verlassen des Melkstandes während der Melkzeit, beispielsweise zum Kälberfüttern, negativ auf die Eutergesundheit auswirkt. In den Betrieben mit einer unterdurchschnittlichen Therapiehäufigkeit (uTüN und uTuN) wurde häufiger unter ständiger Anwesenheit von Landwirt bzw. Melkpersonal gemolken (54\% und 67\%) als in solchen mit einer überdurchschnittlichen Therapiehäufigkeit (17\%). Daher kann davon ausgegangen werden, dass durch die ständige Beaufsichtigung des Melkprozesses die nicht erwünschten Effekte von Vakuumschwankungen in der Milchleitung (Impacts, Rückspray), die vor allem aus luftsaugenden, abgetretenen oder abgefallenen Melkzeugen resultieren, weitestgehend vermieden werden können. Die Beaufsichtigung des Melkprozesses scheint daher mit einer verbesserten Kontrolle des Milchentzugs einherzugehen.

Gill et al. (1990) fanden in ihrer Untersuchung heraus, dass in Herden mit unterschiedlichen Melkern die Herdensammelmilchzellgehalte tendenziell höher waren. Jedoch waren sie geringer, wenn das Melken häufiger von Fremdarbeitskräften durchgeführt wurde (Gill et al., 1990). Dies steht im Widerspruch zu den Ergebnissen von Bartelt et al. (1992), die feststellten, dass in Herden, in denen das Melken durch Fremdarbeitskräfte durchgeführt wird, mehr durch Sc. agalactiae hervorgerufene Infektionen auftreten. Wichtig für die Eutergesundheit scheint also nicht die melkende Person, sondern die Qualität der Melkarbeit zu sein (Barkema et al., 1999a; Barnouin et al., 2004). In der vorliegenden Arbeit kann die große Bedeutung der Arbeitsroutine bestätigt werden, da in den Betrieben der Gruppe uTüN die Melkarbeit signifikant seltener (64\%) vom Hauptmelker durchgeführt wurde als in den beiden anderen Gruppen (84\% in UTuN, 86\% in üTuN). Den Untersuchungen von Chassagne et al. (2005) zufolge ist in kleinen Herden die benötigte Arbeitszeit für das Melken geringer und die Arbeit der Melker sorgfältiger, was auch für die vorliegend untersuchten Betriebe zutrifft.

Zahlreiche Studien zeigen, dass sich gute Ausbildung und ständige Weiterbildung der Landwirte positiv auf das Mastitisgeschehen im Betrieb auswirken (Huton et al., 1989; Gill et al., 1990; Barkema et al., 1999b). Von den Betriebsleitern der uTüN-Gruppe absolvierten $77 \%$ wenigstens die zweijährige Fachschule, in den übrigen Gruppen waren es nur 42\% (uTuN) bzw. 67\% (üTüN). 84\% der Betriebsleiter gaben an, 
regelmäßig an Weiterbildungen teilzunehmen. Ein signifikanter Unterschied zwischen den Gruppen konnte hierbei jedoch nicht festgestellt werden.

Ein Alter der Landwirte über 42 bzw. 40 Jahre wird in einigen Studien in Zusammenhang mit höheren Zellgehalten gebracht (Gill et al., 1990; Barkema et al., 1999b). In dieser Studie waren $48 \%$ der Betriebsleiter über 40 Jahre alt. Ein Zusammenhang zwischen dem Alter der Landwirte und der Eutergesundheitssituation der Herde konnte im Rahmen dieser Studie damit nicht bestätigt werden.

Eine schlechte Hygiene im Melkstand steht laut Barkema et al. (1999b) in Beziehung zu hohen Tankmilchzellgehalten. Die Hygiene im Melkstand in den untersuchten Betrieben wurde im Mittel als gut bewertet. Zudem hat die Häufigkeit des Abkotens von Kühen im Melkstand, was als Anzeichen für Stress eingestuft wird (Munksgard et al., 1997), einen Einfluss auf die hygienischen Bedingungen während des Melkens. Weniger als $5 \%$ aller Kühe (1\% der uTüN-Kühe) setzten während der Melkzeit Kot ab. Geringes Abkoten während des Melkens verbessert die hygienischen Bedingungen im Melkstand und kann als Ausdruck der Entspannung der Tiere gedeutet werden. Das Vermeiden von Stress wirkt sich positiv auf die Leistung und die Gesundheit der Tiere aus (Seabrock, 1994; DVG, 2002).

\subsubsection{Genetische Managementvariablen}

Alle untersuchten Betriebe setzten die Rasse Deutsch Holstein in den Farben schwarzbunt oder rotbunt ein. In Niedersachsen gehören 97\% der der Milchkontrolle angeschlossenen Milchkühe (VIT, 2010) der Rasse Deutsch Holstein an. Verschiedene Arbeiten konnten zeigen, dass Tiere der Rasse Holstein-Friesian im Vergleich zu anderen Rassen geringere Einzeltierzellgehalte und weniger klinische Mastitiden aufweisen (Schukken et al., 1990; Schukken et al., 1991; Elbers et al., 1998; Barkema et al., 1999a; Busato et al., 2000).

Über die Zuchtauswahl mit dem Kriterium „Zuchtwert Zellzahl“ kann ein positiver Einfluss auf den somatischen Zellgehalt der folgenden Generation genommen werden (Shook und Schutz, 1994; Rogers et al., 1998; Shook, 2004). Die Betriebsleiter der Gruppe uTüN gaben zu $38 \%$ an, den Zuchtwert Zellzahl bei der Bullenwahl zu berücksichtigen. 23\% der Betriebsleiter dieser Gruppe nutzten zudem den Zellgehalt der Mutter bei der Auswahl von Färsen. Dies unterschied sich signifikant von den beiden anderen Betriebsgruppen (Beachtung Zellgehalt Muttertier: 4\% uTuN und 0\% 
üTüN). Demnach hat bei der Auswahl der Zuchttiere die Berücksichtigung sowohl des Zuchtwertes Zellzahl bei den Vätern als auch der Verlauf der Eutergesundheit der Mütter einen positiven Effekt auf die Zellzahl der Nachkommen.

Herden mit höheren Leistungen haben geringere mittlere Einzeltierzellgehalte (Wilson et al., 1997; Chassagne et al., 2005; Volling et al., 2010). Diese Aussage konnte durch die vorliegende Studie bestätigt werden. Die einbezogenen Betriebe erreichten eine im Mittel höhere Leistung als das niedersächsische Mittel. Anderen Untersuchungen zufolge steigt für Tiere mit höheren Leistungen jedoch das Risiko, an einer klinischen Mastitis zu erkranken (Lescourret et al., 1995; Gröhn et al., 2004; Oltenacu und Ekesbo, 1994). Nach Kellog et al. (2001) nimmt die Herdenleistung in Folge der Verbesserung des Managements zu. Auch durch das Merzen chronisch infizierter Kühe kann die Herdenleistung ansteigen, da diese Tiere häufig hohe somatische Zellgehalte in der Milch bei gleichzeitig geringer Milchleistung aufweisen (Bennedsgaard et al., 2003; Whist et al., 2009). Tiere mit hohen Einzeltierleistungen in Hochleistungsherden leiden jedoch häufiger unter Stoffwechselstörungen, die eine Schwächung der Immunabwehr und ein erhöhtes Erkrankungsrisiko zur Folge haben (Lotthammer et al., 1988; Heuer et al., 1999). In der Gruppe uTuN wiesen 29\% der Betriebe eine unterdurchschnittliche Leistung auf, was vermutlich auf den höheren Anteil von Erstkalbinnen zurückgeführt werden kann.

Dodd und Neave (1951) beschrieben, dass Kühe mit einem geringen Spitzenmilchfluss eine geringere Erkrankungsrate aufweisen. Grindal und Hillerton (1991) stellten fest, dass bei Kühen mit geringem Spitzenmilchfluss seltener Infektionen auftraten ( $<0,8$ vs. $>1,6 \mathrm{~kg} / \mathrm{min} /$ Euterviertel). Ein hoher Spitzenmilchfluss geht mit einem weiten Zitzenkanal einher, was die Funktion des Zitzenkanals als mechanische Barriere für eine mikrobielle Invasion beeinträchtigt (McDonald, 1975). Im Mittel der untersuchten Betriebe hatten $48 \%$ der Kühe in den Herden uTüN und uTuN einen Milchfluss von weniger als $3,2 \mathrm{~kg} / \mathrm{min} /$ Euter (entspricht $0,8 \mathrm{~kg} / \mathrm{min} /$ Euterviertel). Keines der untersuchten Tiere in der Studie hatte einen Spitzenmilchfluss von über 6,4 kg/Min/Euter (entspricht 1,6 kg/min/Euterviertel).

Slettbakk et al. (1995) fanden heraus, dass Kühe mit überdurchschnittlich dicken Zitzen ein erhöhtes Risiko für klinische Mastitiden aufweisen. Ein Einfluss des Zitzendurchmessers auf den Zellgehalt ließ sich im Rahmen der vorliegenden Studie nicht feststellen. Zum einen war die Schwankungsbreite des Zitzendurchmessers 
innerhalb der Herden im Mittel mit 4,8 mm geringer als in anderen Herden, in denen die Standardabweichung bereits $+/-3,5 \mathrm{~mm}$ betrug (Paduch et al., 2010), zum anderen waren die Zitzendurchmesser in den untersuchten Herden ähnlich. Die diesbezüglichen Einzeltierrisiken innerhalb einer Herde wurden nicht beurteilt.

Viertel, deren Zitzen mehr als $55 \mathrm{~cm}$ Abstand zum Boden haben, weisen ein geringeres Infektionsrisiko auf (Slettbakk et al., 1995). Nach Grommers et al. (1971) steigt das Risiko für Verletzungen bei Zitzen, die einen geringen Abstand zum Boden haben. Dies wiederum erhöht das Risiko für klinische Mastitiden (Van de Geer et al., 1988, Gröhn et al., 1990). Bodennahe Zitzen können verstärkt verschmutzen. In den untersuchten Herden hatten die Kühe in der Regel eine gute Euteraufhängung, im Mittel der Herden war bei 92\% der Kühe der Euterboden höher als das Sprunggelenk.

\subsubsection{Haltungsbezogene Managementvariablen}

Zahlreiche Studien belegen, dass der Liegeboxenlaufstall in Bezug auf die Eutergesundheit im Vergleich zum Strohlaufstall oder zum Anbindestall zu bevorzugen ist (Bendixen et al., 1988; Peeler et al., 2000; Hultgren, 2002; Barnouin et al., 2005). Die Vorteile bestehen darin, dass die Liegeplätze sauberer sind und sich die Kühe weniger Zitzenverletzungen zufügen (Hultgren, 2002). Die Ergebnisse der vorliegenden Untersuchung zeigen, dass auch im Anbindestall Herden mit geringen Zellgehalten gehalten werden können, denn nur $73 \%$ der untersuchten Betriebe hielten die laktierenden Kühe in Boxenlaufställen, jedoch keiner in Laufställen mit freier Liegefläche.

Ein wesentliches Ziel im Rahmen des Haltungsmanagements von Milchkühen sind saubere Euter der Tiere (Giovannini und Zecconi, 2002). Dies konnte in $77 \%$ der Betriebe der Gruppe uTüN erreicht werden. Voraussetzung hierfür sind saubere Laufund Liegeflächen (Schukken et al., 1990; Barnouin et al., 2004). Bei einer mehrmals täglichen Reinigung des Spaltenbodens durch Abschieben (12-mal zwischen den Liegeboxen und 7-mal am Futtertisch) wurden 30\% weniger Kotreste im euternahen Liegeboxenbereich nachgewiesen (Magnusson et al., 2008). Dies hatte eine geringere Verschmutzung der Euter und der Zitzen zur Folge, was wiederum das Infektionsrisiko mit umweltassoziierten Mastitiserregern verringert (Magnusson et al., 2008; Schreiner und Ruegg, 2003, Reneau et al., 2005). Dass sich eine häufige Reinigung der Spaltenböden positiv auf die Eutergesundheit auswirkt, konnte mit der vorliegenden Arbeit bestätigt werden. Im Mittel der Betriebe wurden die Spalten 1,3-mal täglich 
ganz oder teilweise gereinigt. In mehr als $80 \%$ der untersuchten Betriebe waren die Laufflächen im Boxenlaufstall als Spaltenboden ausgestaltet. Dies führt Barkema et al. (1999a) zufolge zu einer geringeren Mastitisrate.

Zur Erhaltung einer guten Eutergesundheit sollen die Liegeflächen sauber, trocken und gut eingestreut sein sowie mehrmals täglich gereinigt werden (Schukken et al., 1990; Schukken et al., 1991; Elbers et al., 1998, Kelly et al., 2009). Diese Anforderungen wurden zum Großteil von den teilnehmenden Betrieben erfüllt. In 91\% der Betriebe wurden die Liegeflächen eingestreut, in allen Betrieben täglich gepflegt und in $73 \%$ der Betriebe mit Boxenlaufstall wurden sie mehrmals täglich gereinigt. Daraus resultierte, dass in $79 \%$ der Betriebe eine trockene Liegefläche im euternahen Bereich vorhanden war. Alle Betriebe der Gruppe uTüN streuten die Liegeflächen ein (Liegeboxenlauf- und Anbindestall). Die Euter in der Gruppe uTüN wurden im Mittel mit einem Sauberkeitsscore von 1,8 beurteilt und waren somit signifikant sauberer als die der Gruppe üTüN $(2,6)$.

Neben der regelmäßigen Pflege der Liegeflächen haben auch das Einstreumaterial und dessen Management einen Einfluss auf die Eutergesundheit. Giovannini und Zecconi (2002) stellten fest, dass bei Verwendung von Sand als Einstreumaterial am seltensten klinische Mastitiden auftraten, gefolgt von Stroh und Sägemehl (Oz et al., 1985). In den vorliegend untersuchten Betrieben wurde kein Sand, in 56\% der Fälle Stroh und in 34\% der Betriebe Sägespäne verwendet. Neben der Art des Einstreumaterials ist dessen Keimbelastung für die Eutergesundheit von Bedeutung (Bramley und Neave, 1975; Hogan et al., 1989). Über die Hälfte der Betriebe unterschritt die im Hinblick auf das Risiko für die Entstehung von Mastitiden in der Literatur beschriebenen Keimzahl-Grenzwerte für Einstreumaterialien (Gesamtkeimzahl: $\quad$ Stroh $<7 \times 10^{8} \mathrm{KbE} ; \quad$ Späne $<1 \times 10^{6} \mathrm{KbE}$; coliforme Keime $<10^{6} \mathrm{KbE} / \mathrm{g}$ ) (Krömker und Grabowski, 2002; Kristula et al., 2005). Das Einstreumaterial sollte trocken beschafft und gelagert sowie häufig frisch in die Liegeboxen verbracht werden. Feuchtigkeit (Regen, Urin, Luftfeuchtigkeit) fördert das mikrobielle Wachstum in der Einstreu (Krömker et al., 2010). Studien belegen, dass sich mehrfach in der Woche frisch eingestreute Liegeboxen positiv auf die Eutergesundheit auswirken (Elbers et al., 1998; Giovannini und Zecconi, 2002). Alle untersuchten Betriebe mit Anbindeställen, aber nur die Hälfte der Laufstallbetriebe mit eingestreuten Liegeflächen führten dies durch. $67 \%$ aller Betriebe lagerten das 
Einstreumaterial unter Dach, 21\% unter Folie und 12\% im Freien. In der Gruppe uTüN lagerte nur 1 Betrieb das Langstroh im Freien, holte es aber täglich in den Stall.

Bis auf eine Ausnahme wurde den Kühen in allen Betrieben Weidegang gewährt. Dieses ist als positiv für die Eutergesundheitssituation zu bewerten, da mit Weidegang kombinierte Haltungsverfahren mit einem geringeren Risiko für das Auftreten klinischer Mastitiden einhergehen (Bendixen et al., 1988, Schukken et al., 1988). Nach Cook (2002) kann der Eregerdruck bei Weidegang geringer sein als bei der Haltung im Stall. Im Gegensatz dazu fanden Olde Riekering et al. (2007) heraus, dass der Herdensammelmilchzellgehalt im Sommer am höchsten war, jedoch die Inzidenzrate von Infektionen mit E. coli geringer und mit Sc. uberis höher als in den Wintermonaten. Der hohe Zellgehalt im Sommer lässt sich überwiegend durch die neu auftretenden Infektionen erklären, da Tiere ohne Infektion des Drüsengewebes auf den Weidegang nicht mit einem Anstieg des Zellgehaltes reagieren (Oliver et al., 1956; Hamann und Reichmuth, 1990). Hitze oder Regen können jedoch als klimatische Stressoren eine Zunahme des Zellgehaltes bei Weidegang bewirken (Faye, 1997; Barkema et al., 1999a). Die Entstehung von Störungen der Eutergesundheit kann durch starke Niederschläge und in Folge hohen Erregerdruckes sowie des Zustands der Liegeflächen und Treibwege beeinflusst werden (Barnouin et al., 2004; Kelly et al., 2009).

In Betrieben, die den Kühen im Sommer Nachtweide anbieten, treten nach Barkema et al. (1999a) weniger durch E. coli verursachte klinische Mastitiden auf. Die Autoren führten dies auf eine geringere Belastung mit Umwelterregern auf der Weide zurück. 43\% der im Rahmen der vorliegenden Arbeit untersuchten Betriebe ermöglichten den Kühen im Sommer Nachtweide, in der Gruppe uTüN waren es jedoch lediglich $38 \%$. Demnach scheint Nachtweide als keimdruckreduzierende Maßnahme bei sehr guten hygienischen Bedingungen nicht erforderlich zu sein.

Barkema et al. (1999a) stellten fest, dass sich ein wärmegedämmtes Kuhstalldach positiv auf die Eutergesundheit auswirkt. In der vorliegenden Studie wiesen weniger als die Hälfte der Betriebe ein solches Dach auf. Die Betriebe uTüN und uTuN hatten zu $44 \%$ und die Betriebe üTüN zu 17\% ein isoliertes Dach. Ein isoliertes Dach bietet im Sommer besseren Wärmeschutz als ein unisoliertes. Dies führt zu einer Verringerung des Hitzestresses und damit zu einer besseren Immunabwehr (Armstrong, 1994). 


\subsubsection{Fütterungsbezogene Managementvariablen}

Eine Reduzierung der den Tieren zur Verfügung stehenden Länge des Futtertisches auf 0,2 m je Kuh bzw. der Anzahl der Fressplätze auf 0,25 je Kuh führt nicht zu einer Verringerung der Futteraufnahme, sondern zu einer Zunahme der Verdrängungen am Futtertisch und zu reduzierten Fresszeiten (Friend et al., 1976, Olofsson, 1999). Olofsson (1999) konnte hierdurch keinen Einfluss auf die Leistung und die Gesundheit der untersuchten Milchkühe feststellen, die Versuche dauerten jedoch nur 7 Tage an. Langfristig scheint sich das Tier-Fressplatz-Verhältnis auf die Tiergesundheit auszuwirken, denn Barkema et al. (1999a) stellten fest, dass Betriebe mit mehr als 0,8 Fressplätzen je laktierender Kuh eine bessere Eutergesundheit aufwiesen. Diese Ergebnisse können in dieser Arbeit bestätigt werden, da im Mittel der Betriebe 1,1 Fressplätze je Kuh zur Verfügung standen. 90\% der Betriebe uTüN (94\% UTuN und $67 \%$ üTüN) boten mehr als 0,8 Fressplätze je Kuh an.

Durch das Verhindern des Ablegens der Kühe unmittelbar nach dem Melken, also in einem Zeitraum, in dem der Zitzenkanal noch geöffnet ist, kann die klinische Mastitisrate gesenkt werden (Barkema et al., 1999a; Peeler et al., 2000). Dies kann durch die vorliegende Studie bestätigt werden, denn $69 \%$ der Betriebe in den Gruppen mit unterdurchschnittlicher Therapiehäufigkeit (UTüN und UTuN) und nur $50 \%$ in der Gruppe üTuN sorgten dafür, dass ein Hinlegen der Tiere nach Beendigung des Melkens unterblieb.

Auch die Qualität des Tränkwassers wird in Zusammenhang mit der Eutergesundheit einer Herde gebracht. So wurde in mehreren Untersuchungen gezeigt, dass die klinische Mastitisrate beim Vertränken von Trinkwasser geringer ist als bei Verwendung von Brunnen- oder Bachwasser (Schukken et al., 1990; Schukken et al., 1991; Barkema et al., 1999a). Die Autoren gehen davon aus, dass beim Saufen aus einem Brunnen oder Bach die Kuh vermehrt dem Einfluss von Schmutz und damit einem erhöhten Erregerdruck ausgesetzt ist. Zudem wäre es möglich, dass Wasser aus Brunnen oder Bächen hohe Gehalte an Schwermetallen oder Nitrat und Nitrit enthält bzw. hohe Eisengehalte die Aufnahme anderer Spurenelemente behindern (BMELV, 2007). In Niedersachsen untersuchtes Tränkwasser wird zu 39\% aufgrund zu hoher Eisengehalte und zu 1,4\% aufgrund zu hoher Nitrat- bzw. Nitritgehalte als unbrauchbar eingestuft (LUFA, 2004). In der vorliegenden Studie vertränkten 40\% der 
Betriebe Trinkwasser im Stall. 67\% der Betriebe gaben an, dass das Wasser im Stall Trinkwasserqualität aufweise.

Nur wenige Studien stellen einen Zusammenhang zwischen einzelnen Futtermitteln und der Eutergesundheit dar. So stellten Schukken et al. (1990) fest, dass das Verfüttern von Rübennassschnitzeln in negativer Beziehung zur klinischen Mastitisrate steht. Dies kann in der vorliegenden Arbeit nicht bestätigt werden, da keiner der untersuchten Betriebe Rübennassschnitzel einsetzte. Barkema et al. (1999a) ermittelten, dass beim Verfüttern von Maissilage an laktierende Kühe seltener klinische Mastitiden auftreten, diese aber häufiger durch $E$. coli hervorgerufen wurden. Im Rahmen der vorliegenden Studie konnte ein durch das Verfüttern von Maissilage hervorgerufener negativer Effekt nicht bestätigt werden. 89\% der Betriebe verfütterten Maissilage an die laktierenden Tiere. Die übrigen Betriebe bauten aufgrund reiner Grünlandstandorte keinen Mais an. Zudem wird in der Literatur beschrieben, dass das Verfüttern von Silomais zur besseren Energieversorgung in der Frühlaktation beitragen kann und dies in positiver Korrelation zum Einzeltierzellgehalt steht (Lotthammer et al., 1988).

Ein Fett-Eiweiß-Quotient > 1,5 ist als Hinweis auf eine subklinische Ketose zu werten (De Kruif et al., 1998). In Milchviehbetrieben mit einer mittleren Leistung von 6.266 kg je Kuh wurde für Tiere mit Verdacht auf subklinische Ketosen (Fett-EiweißQuotient > 1,5 in den ersten 100 Laktationstagen) ein Anteil von 15\% ermittelt (Volling et al., 2010). Das entspricht dem Anteil entsprechender Stoffwechselstörungen in den untersuchten Betrieben, die jedoch eine deutlich höhere Milchleistung aufwiesen. Daher kann die Energieversorgung in den betrachteten Betrieben zu Beginn der Laktation als gut bezeichnet werden.

Ein Fett-Eiweiß-Quotient < 1,0 gilt als Hinweis auf Pansenfermentationsstörungen (De Kruif et al., 1998). In der Untersuchung von Volling et al. (2010) hatten im Mittel 7\% der Kühe einen Fett-Eiweiß-Quotienten $\leq 1,0$. Dies war im Mittel der untersuchten Betriebe bei $10 \%$ der Tiere der Fall, was in Anbetracht der hohen Milchleistung und der damit einhergehenden höheren Kraftfuttermenge als gutes Ergebnis zu werten ist, auch wenn Krömker und Grabowski (2002) feststellten, dass das Risiko für Mastitiden steigt, wenn mehr als 5\% der Tiere einen Fett-Eiweiß-Quotienten $<1,0$ aufweisen.

Die Wasser- und Energieversorgung direkt nach der Kalbung ist besonders wichtig, um das postpartale Erkrankungsrisiko zu senken (Rossow, 2004; Rothert, 2000). Dies 
konnte in dieser Studie bestätigt werden. $79 \%$ der Betriebe boten allen Kühen nach der Kalbung zusätzlich Wasser, teilweise mit energiereichen Zusätzen, an. In 60\% der Betriebe erhielten einzelne Kühe Propylenglycol zu Beginn der Laktation, um eine ausreichende Energieversorgung der Tiere sicherzustellen (Emery et al., 1964).

Verschiedenen Studien zu Folge hat das Ergänzen von Mineralstoffen wie Natrium, Magnesium, Selen sowie den Vitaminen A, D und E einen positiven Einfluss auf das klinische und subklinische Mastitisgeschehen im Betrieb (Chew et al., 1982; Smith et al., 1984; Erskine et al., 1987; Wang et al., 1988; Batra et al., 1992; Weiss et al., 1997; Jukola et al., 1996; Barnouin und Chassange, 1998; Barkema et al., 1999a; Barnouin et al., 2004; Skrzypek et al., 2004; Le Blanc et al., 2004). In allen untersuchten Betrieben wurden die oben genannten Mineralstoffe und Vitamine ergänzt, in 93\% der Betriebe ganzjährig.

Eine zweimal tägliche Futtervorlage und ein gutes Futtertischmanagement mit dem Ziel, den Kühen ständig frisches Futter anzubieten, sind wesentliche Voraussetzungen für eine maximale Futteraufnahme (Grant und Albright, 1995; De Vries et al., 2005). In den untersuchten Betrieben gab es im Mittel 4,8 Futterbewegungen am Tag. Dies beinhaltete sowohl das Nachschieben wie auch das Vorlegen von frischem Futter. Zudem wurde der Futtertisch 1,4-mal täglich gereinigt.

Grassilage stellte in den Betrieben die wichtigste Futterkomponente in Bezug auf die Trockenmasseaufnahme dar. Im Mittel der Betriebe enthielt diese 33\% (+/- 8,4\%) Trockenmasse mit 26\% (+/- 1,9\%) Rohfaser. Die Energiekonzentration betrug 6,1 MJ NEL (+/- 0,4 MJ NEL), der Rohproteingehalt lag bei 17\% (+/- 2,3\%) und die RNB bei 5,9 (+/- 2,9). Damit lag die Energiekonzentration leicht über den Ergebnissen der niedersächsischen Grassilagen (6,0 MJ NEL im 1. Schnitt) bei 1,6\% höheren Rohfasergehalten und 0,6\% höheren Rohproteingehalten (AG FUKO, 2005).

\subsubsection{Melkarbeitsbezogene Managementvariablen}

Smith et al. (2002) beschrieben, dass das dreimalige anstelle des zweimal täglichen Melkens den mittleren Einzeltierzellgehalt verringert. Keiner der Studienbetriebe führte einen dreimal täglichen Milchentzug durch.

Um einen möglichst kurzen und damit euterschonenden Milchentzug zu ermöglichen, sollten Holstein-Friesian Kühe 10 bis 20 Sekunden von Hand stimuliert werden 
(Reneau, 2001; Svennerstein-Sjaunja, 2004). Dabei sollte die Zeit von der ersten Berührung der Zitze bis zum Ansetzen des Melkzeuges möglichst 60 bis 90 Sekunden, optimalerweise 80 Sekunden, betragen (Reneau, 2001; SvennersteinSjaunja, 2004). Die Anrüstzeit in den untersuchten Betrieben betrug im Mittel 60 Sekunden je Kuh, jedoch lag die Anrüstzeit nur in 30\% der Betriebe im optimalen Bereich von 60 - 90 Sekunden. Wagner und Ruegg (2002) untersuchten den Einfluss der Stimulation bei Kühen mit sehr hoher Milchleistung und konnten keinen signifikanten Effekt auf den Milchfluss oder die Melkzeit dieser Tiere feststellen. Daraus lässt sich ableiten, dass in den untersuchten Herden, die eine überdurchschnittliche Milchleistung aufwiesen, die optimale Stimulation der Tiere an Bedeutung verliert.

Nach Köster et al. (2006) nimmt die Hygiene im Melkstand einen Einfluss auf die Eutergesundheit. Melkhygienische Maßnahmen umfassen die Sauberkeit im Melkstand, das Tragen von Gummihandschuhen beim Melken, das Scheren der Euterhaare, das Reinigen der Euter vor dem Melken und die Desinfektion der Melkbecher nach jedem Milchentzug (Köster et al., 2006; Philpot, 1979; DVG, 2002; Schukken et al., 1991; Faye et al., 1997; Barkema et al., 1998a; Barkema et al., 1999a). Die Hygiene im Melkraum der untersuchten Betriebe war gut und wurde auf einer Skala von 1 bis 6 mindestens mit 3 und in $77 \%$ der Betriebe mit 2 oder besser bewertet. Gummihandschuhe wurden beim Melken in 51\% der Betriebe immer (37\%) oder teilweise (14\%) getragen. In 51\% der Herden wurden die Euter geschoren. $60 \%$ der Betriebe reinigten die Euter trocken vor $(41 \%$ mit einem trockenen Tuch oder Lappen, $13 \%$ mit Desinfektionslösung getränkten Tüchern, $6 \%$ mit schleudertrockenen Lappen). 28\% der Betriebe reinigten gar nicht vor, $7 \%$ mit nassen Lappen und 5\% mit Wasser. In der Gruppe uTüN reinigten $62 \%$ der Betriebe trocken und $8 \%$ mit in Desinfektionslösung getränkten Tüchern vor. 38\% der Betriebe der Gruppe uTüN führten keine Vorreinigung durch. Letztere wiesen jedoch vor dem Melken insgesamt sehr saubere Euter auf (Note 1,4). Daraus lässt sich ableiten, dass die empfohlenen Hygienemaßnahmen während des Melkens die Eutergesundheit grundsätzlich unterstützen, in Herden mit sehr geringen Herdensammelmilchzellgehalten und gutem Hygienestatus jedoch ohne Nachteile darauf verzichtet werden kann (Munoz et al., 2008).

Nach Aussage einiger Autoren verringert das Desinfizieren der Zitzen vor dem Melken die Neuinfektionsrate (Pankey et al., 1987; Pankey und Drechsler, 1993). Die Wirkung 
der Zitzendesinfektion nach dem Melken wirkt sich vor allem positiv auf die Eutergesundheit aus, wenn in der Herde kuhassoziierte Erreger vorherrschen (Eberhart et al., 1983; Hogan et al., 1987; Barkema et al., 1999a; DVG, 2002; Ekman und Østerås, 2003; Hillerton und Berry, 2003; Kelly et al., 2009). Die Desinfektion der Zitzenepithelien kann jedoch auch das Auftreten von E. coli-Mastitiden begünstigen (Schukken et al., 1990; Lam et al., 1997a; Elbers et al., 1998; Barkema et al., 1999b). Nur einer der untersuchten Betriebe führte eine Zitzendesinfektion vor dem Melken durch. Jedoch setzten von den untersuchten Betrieben $88 \%$ ein Zitzentauchmittel unmittelbar nach Beendigung des Milchentzuges ein. In 51\% der Betriebe wurde ein jodhaltiges Zitzentauchmittel eingesetzt, allerdings wurde nur in 23\% der Betriebe ein als Tierarzneimittel zugelassenes Präparat verwendet. In der Gruppe uTüN setzten $8 \%$ ein als Tierarzneimittel zugelassenes Zitzentauchmittel ein.

Eine Übertragung von Erregern von infizierten auf nicht infizierte Tiere kann ausgeschlossen werden, indem die Milchkühe in einer ihrem Gesundheitsstatus entsprechenden Reihenfolge gemolken werden (zuerst Kühe mit niedrigen Zellgehalten, Tiere mit klinischen Infektionen am Schluss) (Wilson et al., 1995; Ekman und Østerås, 2003; Barnouin et al., 2004). 46\% der Betriebe uTüN hielten eine entsprechende Melkreihenfolge ein und weitere 38\% reinigten die Melkzeuge nach dem Melken erkrankter Tiere mit Wasser. Das Durchspülen mit $85^{\circ} \mathrm{C}$ warmem Wasser für 5 Sekunden stellt eine sehr effektive Methode dar, um die Übertragung von Erregern durch die Melkbecher zu verhindern (Dodd et al., 1966). Im Widerspruch dazu steht, dass bei Untersuchungen von Sheran et al. (1994) durch die Melkzeugreinigung mit Hilfe eines Druckluft-Wasser-Gemisches nur eine geringe Erregerreduzierung erreicht werden konnte.

Um eine Ausbreitung von kontagiösen Erregern zu vermeiden, werden in der Literatur Maßnahmen wie das Desinfizieren der Zitzen nach dem Milchentzug, die Verwendung eines separaten Reinigungstuches je Tier und das Tragen von Handschuhen genannt (Neave et al., 1969; DVG, 2002). Sehr geringe Herdensammelmilchzellgehalte lassen die Vermutung zu, dass lediglich eine geringe Anzahl der Tiere mit kuhassoziierten Mastitiserregern infiziert ist (Erskine et al., 1988; Watts und Owens, 1989) und deshalb auf einen Teil dieser Maßnahmen verzichtet werden könnte, ohne die Eutergesundheit negativ zu beeinflussen. Mit zunehmender Herdengröße wird es jedoch schwieriger, Infektionen mit kuhassoziierten Erregern zu vermeiden (Keefe, 1997). Zum einen werden in größeren Herden häufiger Tiere zugekauft, ohne dabei 
auf ausreichende Quarantänemaßnahmen zu achten (Faye et al., 1997; Wille, 2009). Zum anderen steigt die Wahrscheinlichkeit, dass infizierte Tiere nicht identifiziert werden oder neue Erregerreservoire zur Entstehung neuer Infektionen beitragen (Roberson et al., 1994; Keefe, 1997; Zecconi, 2006).

Gill et al. (1990) stellten fest, dass das Vormelken in einen Vormelkbecher in Bezug auf die Einzeltierzellgehalte als positiv zu bewerten ist, was im Rahmen der vorliegenden Studie nicht bestätigt werden konnte.

Beim Ansetzen der Melkzeuge sollte möglichst keine Luft eingelassen werden (Chassagne et al., 2005). Insgesamt setzten 58\% der untersuchten Betriebe die Melkzeuge ohne Lufteinlassen an, in der Gruppe uTüN waren es nur 46\%. Dies könnte darauf hinweisen, dass der Effekt des Luftziehens beim Ansetzen des Melkzeuges bei sehr guter Melkhygiene von nur geringer Bedeutung für die Eutergesundheit ist.

Lange Blindmelkzeiten (Zeiten mit Milchfluss $<200 \mathrm{~g} / \mathrm{min}$ ) haben nach Kawai et al. (2005) einen negativen Einfluss auf die Zellgehalte in der Milch. Zur Vermeidung des Blindmelkens wird der Einsatz einer Abschalt- oder Abnahmeautomatik empfohlen (Barkema et al., 1999a; Giovannini und Zecconi, 2002). 50\% der untersuchten Betriebe setzten eine derartige Technik ein. Trotzdem traten in 39\% der Betriebe mit Abschaltautomatik bzw. 58\% der Betriebe mit Abnahmeautomatik Blindmelkzeiten auf (in Betrieben ohne technische Hilfsmittel: 50\% der Betriebe). Die durchschnittliche Dauer des Milchflusses unter $200 \mathrm{~g} / \mathrm{min}$ (Blindmelken) betrug bei der Verwendung einer Abnahmeautomatik 0,88 min, bei der Nutzung einer Abschaltautomatik 2,13 min und ohne die Anwendung technischer Hilfsmittel 1,16 min. Dies macht deutlich, dass mit Hilfe einer Abnahmeautomatik die kürzesten Blindmelkzeiten erreicht werden, ohne sie jedoch gänzlich zu verhindern. Als Grund hierfür kommt zum einen die Einstellung der Schaltwerte in Frage, zum anderen ein nicht konsequentes Einsetzen der Technik. Für Einzeltiere wurde die Abnahmeautomatik teilweise ausgeschaltet. Blindmelkzeiten bei Melkeinheiten mit Abschaltautomatik sind weniger schädlich für das Zitzengewebe, da hierbei das Vakuum abgesenkt wird. Dennoch sollte Blindmelken vermieden bzw. die Blindmelkdauer reduziert werden. 


\subsubsection{Melktechnische Managementvariablen}

Eine technisch korrekte Funktionsfähigkeit der Melkanlage nimmt wesentlichen Einfluss auf den Erhalt der Eutergesundheit. Mindestens einmal im Jahr sollte eine technische Überprüfung der Melkanlage von einem Fachmann durchgeführt werden (Schukken et al., 1991). In 79\% der Betriebe wurde diese Prüfung durchgeführt. Zitzengummis sollten nur neu eingebaut und entsprechend den Herstellerangaben gewechselt werden. Die Rate klinischer Mastitiden war in solchen Betrieben geringer, die nach mehr als 6.000 Melkungen die Zitzengummis wechselten. Jedoch, war dies auf ein häufigeres Wechseln der Zitzengummis in den Betrieben mit Störungen der Eutergesundheit zurückzuführen (Peeler et al., 2000). Im Mittel der Betriebe wurden die Zitzengummis alle 3.500 Melkungen gewechselt, $86 \%$ der Betriebe tauschten häufiger als alle 6.000 Melkungen die Zitzengummis aus.

Weiterhin sollen Vakuumschwankungen in der Milchleitung, die unter anderem durch rutschende und luftziehende oder herunterfallende Melkzeuge verursacht werden können, vermieden werden (Cousins et al., 1973). Luftziehende Melkzeuge traten nur sehr selten auf (4\% der Melkzeuge) und abfallende oder abgetretene Melkzeuge wurden gar nicht beobachtet.

Ausgeprägte Hyperkeratosen als Folge des Milchentzugs stellen nach Neijenhuis et al. (2001) und Zadoks et al. (2001) ein Risiko für die Entstehung von Mastitiden dar. In den untersuchten Betrieben wiesen 44\% der Kühe Veränderungen auf, die über einen „kleinen weißen Ring“ hinausgingen und bei $17 \%$ der Kühe wurde ein „fransiger Ring“ beobachtet.

\subsection{Management der Betriebsgruppen NZELL und HZELL}

Die Betriebe der Gruppe NZELL hielten im Mittel 41 Kühe und die Betriebe der Gruppe HZELL 45 Kühe bei vergleichbaren Nutzungsdauern (NZELL = 28 Monate, HZELL = 27 Monate). Die Milchleistung in der Gruppe NZELL war um $870 \mathrm{~kg}$ höher als die der Gruppe HZELL. Dies entspricht den Ergebnissen anderer Untersuchungen, die zeigten, dass Herden mit geringerer Leistung häufiger erhöhte Zellgehalte haben (Wilson et al., 1997; Barkema et al., 1998a; Chassagne et al., 2005; Volling et al., 2010). In der Trockenstehphase traten bei den Kühen in den Betrieben der Gruppe HZELL häufiger Neuerkrankungen auf, die Heilungsrate war geringer und die 
Färsenmastitisrate höher als in den Betrieben der Gruppe NZELL. Dies deckt sich mit Beobachtungen anderer Autoren (Ekman und Østerås, 2003; Klocke et al., 2010; Volling et al., 2010).

Auch in dieser Studie konnte für den Bereich Personalmanagement bestätigt werden, dass die Betriebe mit geringen Zellgehalten häufiger einen California Mastitis Test durchführen (Busato et al., 2000; Chassagne et al., 2005) und die Betriebsleiter regelmäßiger an Weiterbildungen teilnehmen (Huton et al., 1989; Gill et al., 1990; Barkema et al., 1999b).

Die züchterischen Maßnahmen, die die Gruppen NZELL und HZELL unterschieden, betrafen in den Betrieben der Gruppe NZELL eine höhere Milchleistung, einen geringeren Spitzenmilchfluss und einen größeren Zitzendurchmesser. Ein Einfluss des Spitzenmilchflusses wurde auch in der Arbeit von Grindal und Hillerton (1991) festgestellt. Ein hoher Milchfluss (Göft, 1991) steht im züchterischen Zusammenhang mit einer hohen Milchleistung. Daraus lässt sich ableiten, dass das genetische Potenzial in den Betrieben HZELL sogar über dem in den Betrieben NZELL liegen könnte, die Betriebe dies aber managementbedingt nicht ausschöpfen können.

Bei den haltungsbezogenen Managementfaktoren unterschieden sich die Betriebe der Gruppen in den Punkten Reinigung der Laufflächen, Trockenheit der Liegeflächen, Einstreuen der Liegeflächen, Gesamtkeimzahlen in der Einstreu, Anbieten von Nachtweide und der Sauberkeit der Euter. Diese Ergebnisse bestätigen die Resultate aus anderen Untersuchungen (Bramley und Neave, 1975; Hogan et al., 1989; Schukken et al., 1990; Barkema et al., 1999a; Giovannini und Zecconi, 2002; Barnouin et al., 2004). In der Gruppe NZELL wurde häufiger Kalk als Zusatz zur Einstreu verwand, was zu einer Reduzierung der Keimgehalte in der Einstreu beiträgt (Bey et al., 2002).

Bezüglich der fütterungsbezogenen Managementfaktoren unterschieden sich die Gruppen HZELL und NZELL in der Anzahl der Fressplätze je Kuh, der Trinkwasserqualität, der Verfütterung von Maissilage an die laktierenden Kühe, der ganzjährigen Ergänzung von Mineralfutter und der Gabe von Wasser oder Energietrunk nach der Kalbung. Diese Beziehungen konnten auch in anderen Arbeiten festgestellt werden (Smith et al., 1984; Lotthammer et al., 1988; Schukken et al., 1990; Schukken et al., 1991; Barkema et al., 1999a; Barnouin et al., 2004; Skrzypek et al., 2004). Des Weiteren führten mehr Betriebe der Gruppe NZELL 
Rationsberechnungen durch, und es wurde häufiger Futter vorgelegt. Beide Maßnahmen tragen zu einer Verbesserung der Energieversorgung der Kühe bei und wirken sich somit positiv auf die Eutergesundheit aus (Lotthammer et al., 1988). Zudem waren in dieser Gruppe die maximale Kraftfuttermenge je Kuh und Tag sowie auch der Anteil Tiere mit einem Fett-Eiweiß-Quotient $<1,0$ geringer, was das Risiko für Mastitiden verringert (Krömker und Grabowski, 2002). Die Betriebe der Gruppe NZELL wiesen eine um eine Woche längere Trockenperiode auf, die Kühe gaben vor dem Trockenstellen weniger Milch und ließen nach dem Trockenstellen weniger Milch laufen. Auch dies bestätigt die Erkenntnisse anderer Studien (Oliver et al., 1956; Schukken et al., 1993; Envoldsen und Sørensen, 1991; Kuhn et al., 2006).

Bei der Melkarbeit unterschieden sich die Gruppen darin, dass die Betriebe NZELL häufiger die Euterhaare scherten und an Mastitis erkrankte Tiere am Schluss melkten oder die Melkzeuge mit Wasser nachspülten. Die Melker dieser Betriebe trugen beim Melken häufiger Handschuhe, reinigten die Euter nicht nass vor, rüsteten die Kühe optimal an und melkten von Hand vor. Außerdem wurden seltener Abnahme- oder Abschaltautomatiken eingesetzt und die Zitzen nach dem Melken häufiger getaucht. Diese Ergebnisse entsprechen denen andere Arbeiten (Hogan et al., 1987; Wilson et al., 1995; Barkema et al., 1998a; Barkema et al., 1999a; Barnouin et al., 2004; Kawai et al., 2005).

Die Betriebe der Gruppe NZELL hatten weniger slippende Melkzeuge, wechselten regelmäßiger die Zitzengummis und hielten weniger Tiere, die Hyperkeratosen an den Zitzenkanalöffnungen aufwiesen. Dies bestätigt die Ergebnisse anderer Studien (Cousins et al., 1973; Peeler et al., 2000; Neijenhuis et al., 2001; Zadoks et al., 2001).

Es ist davon auszugehen, dass die einseitig signifikanten Managementfaktoren teilweise voneinander abhängen und sich gegenseitig beeinflussen. Um dieses auszuschließen, wurde eine logistische Regression gerechnet. Die drei verbleibenden Managementfaktoren, in denen sich die Betriebe der Gruppen NZELL und HZELL unterschieden, stammen aus den Bereichen Haltungsumwelt, Fütterung und Melkarbeit.

Im Bereich der Haltungsumwelt erwies sich als besonders wichtig, dass als Spaltenböden gestaltete Laufgänge mehr als einmal täglich abgeschoben werden. Saubere Laufgänge führen zu weniger Kotresten auf den Liegeflächen (Magnusson et al., 2008), dies hat saubere Euter zur Folge (Magnusson et al., 2008; Schreiner und 
Ruegg, 2003, Reneau et al., 2005), was sich positiv auf die Eutergesundheit auswirkt (Schukken et al., 1990; Giovannini und Zecconi, 2002; Barnouin et al., 2004).

Für eine funktionierende Immunabwehr ist eine optimale Versorgung der Kühe mit Nährstoffen genauso wichtig wie das Aufrechterhalten der Pansenfunktion (DVG, 2002; Krömker und Grabowski, 2002). Der Anteil der Kühe mit einem Fett-EiweißQuotienten < 1,0 gibt einen Hinweis auf die Pansenfunktion in der Herde (Kruif et al., 1998). In der Gruppe NZELL war dieser Anteil signifikant geringer als in der Gruppe HZELL.

Die Übertragung von Mastitiserregern von Kuh zu Kuh beim Melken verhinderten die Betriebe der Gruppe NZELL häufiger, indem Tiere mit subklinischen oder klinischen Mastitiden entweder zum Schluss gemolken wurden oder nach dem Melken erkrankter Tiere ein Spülen der Melkzeuge mit Wasser erfolgte. Während die keimreduzierende Wirkung des Spülens der Melkzeuge mit Wasser nicht eindeutig belegt ist (Dodd et al., 1966; Sheran et al., 1994), stellt das Beachten der Melkreihenfolge eine sichere Maßnahme zur Verhinderung von Neuinfektionen dar (Wilson et al., 1995; Ekman und Østerås, 2003; Barnouin et al., 2004).

\subsection{Methodenkritik}

Es wurden ausschließlich Betriebe in die Studie einbezogen, die sich über einen Zeitraum von 12 Monaten hinweg durch sehr niedrige Zellzahlgehalte (Gruppe NZELL) oder aber durch Eutergesundheitsprobleme (HZELL) auszeichneten. Für die Gruppe NZELL wäre eventuell eine Einbeziehung von Betrieben sinnvoll gewesen, die eine mehrjährig niedrige Herdensammelmilchzellzahl aufwiesen. Die für diese Arbeit erfassten Daten wurden zum Teil durch den Autor bzw. den Eutergesundheitsdienst erfasst. Ein Teil der Daten entstammte jedoch den Dokumentationen der jeweiligen Landwirte. Aufgrund der somit in gewissem Rahmen uneinheitlichen Datenerhebung kann nicht ausgeschlossen werden, dass einzelne Angaben aus Unachtsamkeit oder Unaufrichtigkeit nicht den tatsächlichen Gegebenheiten entsprachen bzw. eine Dokumentation einzelner Daten nicht erfolgte. Es ist jedoch davon auszugehen, dass die zur Teilnahme an der Studie bereiten Landwirte der Gruppe NZELL die Daten nach bestem Wissen und Gewissen zur Verfügung stellten.

Da im Rahmen der Datenerhebung zwei Interviewern an der Studie teilnahmen, erfolgte im Vorfeld eine Abstimmung der Datenerfassung sowie der Fragen. 
Zusätzlich wurden vor Studienbeginn zwei Betriebsbesuche gemeinsam durchgeführt, um ein standardisiertes Vorgehen der Interviewer im Studienzeitraum gewährleisten zu können.

Um sicherzustellen, dass alle wesentlichen Parameter erfasst wurden, wurde vor der Erstellung des Fragebogens und der Checklisten eine ausführliche Literaturstudie durchgeführt. Ergänzend wurden Gespräche mit Experten im Bereich des Eutergesundheitsmanagements geführt. $\mathrm{Da}$ die Fragebögen ausschließlich zusammen mit einem Interviewer ausgefüllt wurden, kann eine unterschiedliche Interpretation der Fragen ausgeschlossen werden. 


\section{Zusammenfassung}

Störungen der Eutergesundheit senken die Erlöse, erhöhen die Produktionskosten und verschlechtern die Milchqualität. Ihre Bekämpfung erfordert präventive und therapeutische Maßnahmen. Insbesondere präventive Maßnahmen, die innerbetriebliche Risiken für Neuinfektionen der Milchdrüsen reduzieren, liegen in der Hand der die Tiere betreuenden Landwirte. In der vorliegenden Studie wurde die Durchführung von Managementmaßnahmen, die in der wissenschaftlichen Literatur als positiv für die Eutergesundheit der Herden empfohlen werden, evaluiert.

Als Datenbasis dienten die niedersächsischen Betriebe mit der niedrigsten Herdensammelmilchzellzahl (NZELL) und Betriebe, die freiwillig die Beratung des Eutergesundheitsdienstes (HZELL) anforderten. Aufgrund einer räumlichen Zuordnung von jeweils einem NZELL- und einem HZELL-Betrieb pro Region mit 14.000 gehaltenen Kühen in Niedersachsen wurden pro Gruppe 44 Milchviehbetriebe ausgewählt. Die Betriebe wurden zur Durchführung eines fragebogengestützten Interviews sowie eigener Untersuchungen einmalig besucht.

Alle Betriebe hielten Milchkühe der Rasse Deutsche Holstein (NZELL = 41 Kühe, HZELL = 45 Kühe (Mittelwert)). Die durchschnittliche 305-Tageleistung betrug in der Gruppe NZELL $9.086 \mathrm{~kg}$ (HZELL $8.215 \mathrm{~kg}$ ) Milch mit 4,2\% (HZELL 4,15\%) Fett und 3,4\% (HZELL 3,27\%) Eiweiß und einem Zellgehalt von 87.000 Zellen/ml (HZELL 312.000 Zellen/ml) in der Herdensammelmilch.

Die Betriebe der Gruppe NZELL unterschieden sich in 45 Managementfaktoren signifikant von der Gruppe HZELL. Nach Berechnung der logistischen Regression verblieben drei Managementfaktoren. Die Wahrscheinlichkeit, dass ein Betrieb zu der Gruppe NZELL gehörten war höher, wenn:

- Laufgänge mit Spaltenboden mehr als einmal täglich abgeschoben wurden

- Pansenfermentationsstörungen selten auftraten (Fett-Eiweiß-Quotienten < 1,0)

- Tiere mit subklinischen oder klinischen Mastitiden zum Ende der Melkzeit gemolken oder die Melkzeuge nach dem Melken erkrankter Tiere mit Wasser gespült wurden

Damit wird deutlich, dass zur Verbesserung der Eutergesundheit nicht nur Maßnahmen in einem Bereich genügen, sondern an unterschiedlichen Punkten 
Veränderungen erfolgen müssen. Dazu zählen Maßnahmen zur Verringerung des Keimdruckes, wie die Verbesserung der Hygiene in der Haltungsumwelt und das Verhindern einer Übertragung von Mastitiserregern während der Melkzeit genauso wie eine Optimierung der Fütterung zur Stabilisierung der Immunabwehr der Kühe.

In einem weiteren Schritt wurde analysiert, in welchen Managementvariablen sich die Betriebe mit den niedrigsten Herdensammelmilchzellgehalten (NZELL) unterschieden. Hierfür wurden die Betriebe der Gruppe NZELL mit einer Clusteranalyse anhand ihres therapeutischen Aufwands (im Mittel 30 Fälle je 100 Kühe) sowie der Nutzungsdauer der Milchkühe (im Mittel 28 Monate) in vier Betriebsgruppen unterteilt (uTüN = unterdurchschnittliche Therapiehäufigkeit und überdurchschnittliche Nutzungsdauer; uTuN unterdurchschnittliche Therapiehäufigkeit und unterdurchschnittliche Nutzungsdauer; üTüN = überdurchschnittliche Therapiehäufigkeit und überdurchschnittliche Nutzungsdauer; üTuN = überdurchschnittliche Therapiehäufigkeit und unterdurchschnittliche Nutzungsdauer; üTuN wurde nicht hier betrachtet). Die Betriebe mit unterdurchschnittlicher Therapiehäufigkeit und überdurchschnittliche Nutzungsdauer (UTüN) unterschieden sich signifikant von den anderen Untergruppen der Gruppe NZELL in folgenden Punkten:

- Hauptverantwortlicher melkt seltener (UTüN 64\%, uTuN 84\%, üTüN 86\%)

- Nutzung des Zellgehaltes des Muttertieres als Zuchtkriterium (UTüN 23\%, UTuN $4 \%$, üTüN 0\%)

Die Daten weisen darauf hin, dass eine niedrige Mastitisprävalenz in niedersächsischen Milchviehherden über verschiedene innerbetriebliche Managementstrategien erreicht werden kann. Hierzu gehören die vermehrte Remontierung euterkranker Tiere oder/und die vermehrte Therapie erkrankter Tiere. Die Milchviehbetriebe der NZELL-Untergruppe mit unterdurchschnittlichem Therapiehäufigkeit und überdurchschnittliche Nutzungsdauer (uTüN) zeigen jedoch, dass auch mit Verzicht auf diese Strategien eine hervorragende Eutergesundheit möglich ist. Voraussetzung dafür ist, dass alle notwendigen Arbeiten sehr definiert durchgeführt werden, die innerbetriebliche Hygiene ein sehr hohes Niveau erreicht hat, die genetischen Möglichkeiten genutzt werden und die verantwortliche Person des Betriebes über ein hohes Ausbildungsniveau verfügt. 


\section{Summary}

Mastitis causes a reduction in financial return, increases production costs and decreases milk quality. To combat mastitis it is necessary to use prevention as well as therapy. The main method of prevention is reducing farm related risk factors that cause new infection of the mammary gland, and this is the responsibility of the livestock farmer. The work presented here evaluates management practices recommended in agricultural extension for reducing mastitis incidence on farm level.

The data used comprises the dairy farms in Lower Saxony with the lowest somatic cell counts in bulk milk ("NZELL") and dairy farms which have consulted the udder health service for advice ("HZELL"). Within the area of Lower Saxony, regions were defined with 14,000 dairy cows in each region. From every region, one farm for each group (NZELL and HZELL) was included, forming a total of 44 farms per group. Each farm was visited once to complete a questionnaire based interview and asses own measurements.

All farms kept black pied or red pied German Holstein-Friesian (mean herd size: NZELL $=41$ cows, HZELL = 45 cows). The average milk yield in 305 days in the group NZELL was 9,086 kg (HZELL 8,215 kg) milk containing 4.2\% (HZELL 4.15\%) milk fat and 3.4\% (HZELL 3.27\%) milk protein and a bulk milk somatic cell count of 87,000 cells/ml (HZELL 312,000 cells/ml).

45 management factors were distinguished in which the farms of the group "NZELL" differed significantly from the group "HZELL". After applying multiple regressions three management practices remained. The probability for a farm belonging to the group "NZELL" was associated with:

- Slatted floors were cleaned more than once a day

- Acidosis was rare (fat-protein-ratio < 1.0)

- Cows suffering from subclinical or clinical mastitis were milked after all other cows or clusters were rinsed with water after milking

These findings show that in order to advance udder health there is not just one aspect to be aware of but various areas that need to be ameliorated. These include action to minimize bacterial concentration e.g. by improving hygiene in livestock housing and 
preventing the transmission of mastitis causing bacteria during milking. Furthermore it is necessary to stabilise the immune system of the cows by optimising the nutrition.

In addition the discriminating management variables for four subgroups of the farms with the lowest somatic cell counts in bulk milk (NZELL) were identified. For this purpose the farms of the group NZELL were divided into four subgroups using a cluster analysis with the two variables: quantity of therapeutic treatments (average: 30 cases per 100 cows) and life span after first calving (average: 28 month). The group with below-average quantity of therapeutic treatments and above-average life span after first calving was named "uTüN"; the group with below-average quantity of therapeutic treatments and below-average life span after first calving was named "uTuN"; the group with above-average therapeutic treatments and above-average life span after first calving was named "üTüN". The fourth group consisted of only one farm and was not considered for evaluation. The farms with below-average quantity of therapeutic treatments and above-average life span after first calving (uTüN) differed significantly from the other NZELL-subgroups in the following aspects:

- Farm manager less often carries out milking himself (uTüN 64\%, uTuN 84\%, üTüN 86\%)

- Somatic cell count of the mother is used as a breeding criterion (UTüN 23\%, uTuN 4\%, üTüN 0\%)

- Livestock is less often kept on pasture during night time (UTüN 38\%, uTuN 46\%, üTüN 50\%)

The results indicate different farm management strategies inducing low mastitis prevalence in Lower Saxony dairy farms. These include increased replacement of infected animals and/or augmentation of therapeutic treatments. However, it is possible to attain outstanding udder health without these strategies as the findings of the "NZELL-subgroup" with below-average quantity of therapeutic treatments and above-average life span after first calving show. The preconditions are: all necessary tasks are accurately done, hygiene on the farm is up to a very high standard, the genetic potential is used and the person in charge on the farm is highly qualified. 


\section{Literaturverzeichnis}

AG FUKO - Arbeitsgemeinschaft Futterbau und Futterkonservierung (2005):

Grundfutter - Grassilagen 2005 teilweise mit Qualitätsreserven. Grünland- und Futterbauinfo 4/05.

Anderberg, M.R. (1973): Cluster analysis for applications. Academic Press, New York, NY.

Armstrong, D.V. (1994): Heat stress interactions with shade and cooling. J. Dairy Sci. 77:2044-2050.

Barkema, H.W., Schukken, Y.H., Lam, T.J.G.M., Beiboer, M.L., Benedictus, G., Brand, A. (1998a): Management practices associated with low, medium, and high somatic cell counts in bulk milk. J. Dairy Sci. 81:1917-1927.

Barkema, H.W., Schukken, Y.H., Lam, T.J.G.M., Beiboers, M.L., Wilmink, H., Benedictus, G., Brand, A. (1998b): Incidence of clinical mastitis in dairy herds grouped in three categories by bulk milk somatic cell counts. J. Dairy Sci. 81:411-419.

Barkema, H.W., Schukken, Y.H., Lam, T.J.G.M., Beiboer, M.L., Benedictus, G., Brand, A. (1999a): Management practices associated with the incidence rate of clinical mastitis. J. Dairy Sci. 82:1643-1654.

Barkema, H.W., van der Ploeg, J.D., Schukken, Y.H. (1999b): Management style and its association with bulk milk somatic cell count and incidence rate of clinical mastitis. J. Dairy Sci. 82:1655-1663.

Barnouin, J., Chassagne, M. (1998): Factors associated with clinical mastitis incidence in French dairy herds during late gestation and early lactation. Vet. Res. 29:159-171.

Barnouin, J., Chassagne, M., Bazin, S., Boichard, D. (2004): Management practices from questionnaire surveys in herds with very low somatic cell score through a national mastitis program in France. J. Dairy Sci. 87:3989-3999. 
Barnouin, J., Bord, S., Bazin, S., Chassagne, M. (2005): Dairy management practices associated with incidence rate of clinical mastitis in low somatic cell score herds in France. J. Dairy Sci. 88:3700-3709.

Bartlett, P.C., Miller, G.Y., Lance, S.E., Heider, L.E. (1992): Managerial determinants of intramammary coliform and environmental streptococci infections in Ohio dairy herds, J. Dairy Sci. 75:1241-1252.

Batra, T.R., Singh, K., Ho, S.K., Hidiroglou, M. (1992): Concentration of plasma and milk vitamin $\mathrm{E}$ and plasma ß-carotene of mastitis and healthy cows. Int. J. Vit. Nutr. Res. 62:233-237.

Beaudeau, F., Fourichon, C., Seegers, H., Bareille, N. (2002): Risk of clinical mastitis in dairy herds with a high proportion of low individual milk somatic-cell counts. Prev. Vet. Med. 53:43-54.

Bendixen, P.H., Vilson, B., Ekesbo, I., Astrand, D.B. (1988): Disease frequencies in dairy cows in Sweden. V. Mastitis. Prev. Vet. Med. 5:263-274.

Bennedsgaard, T.W., Enevoldsen, C., Thamsborg, S.M., Vaarst, M. (2003): Effect of mastitis treatment and somatic cell counts on milk yield in Danish organic dairy cows. J. Dairy Sci. 86:3174-3178.

Bey, R.F., Reneau, J.K., Farnsorth, R.J. (2002): The role of bedding management in udder health. Proc. National Mastitis Council Annual Meeting, 9, 45-55.

Blanc, le S.J., Herdt, T.H., Seymour, W.M., Duffield, T.F., Leslie, K.E. (2004): Peripartum serum vitamin E, retinol, and $ß$-carotene in dairy cattle and their associations with disease. J. Dairy Sci. 87:609-619.

Bodoh, G.W., Battista, W.J., Schultz, L.H., Johnston, R.P. (1976): Variation in somatic cell counts in dairy herd improvement milk samples. J. Dairy Sci. 59:1119-1123.

Bramley, A.J., Neave, F.K. (1975): Studies on the control of coliform mastitis in dairy cows. Br. Vet. J. 131:160-169. 
Bradley, A., Green, M. (2006): An approach to the analysis and monitoring of clinical and sub clinical mastitis data. Proc. XXIVth World Buiatrics Congress, Nice, France, 15.-19.10.2006, id 505.

Bradley, A.J., Green M.J., Huxley, J.N. (2002): Making better use of milk samples: Monitoring and investigating herd mastitis. Cattle Pract 10:105-112.

Brolund, L. (1985): Individual cow somatic cell counting: diagnostic significance and applicability. Kieler Milchwirtschaftlicher Forschungsbericht 37:286-297.

Brown, C.A., White, J.M. (1972): Management factors associated with herd average milk yield and income over feed cost in Guernsey, Holstein, and Jersey Herds. J. Dairy Sci., 56:789-798.

BMELV - Bundesministerium für Ernährung, Landwirtschaft und Verbraucherschutz (2007): Hygienische Qualität von Tränkwasser. Orientierungsrahmen zur futtermittelrechtlichen Beurteilung. http://www.bmelv.de/cln_044/nn_753016/DE/07SchutzderTiere/Futtermittelsicherheit/OrientierungsrahmenTraenkewasser,templateld=renderPrint.html (1.10.2009).

Busato, A., Trachsel, P., Schällibaum, M., Blum, J.W. (2000): Udder health and risk factors for subclinical mastitis in organic dairy farms in Switzerland. Prev. Vet. Med. 44:205-220.

Chassagne, M., Barnouin, J., le Guenic, M. (2005): Expert assessment study of milking and hygiene practices characterizing very low somatic cell score herds in France. J. Dairy Sci. 88:1909-1916.

Chew, B.P., Hollen, L.L., Hillers, J.K., Herlugson, M.L. (1982): Relationship between vitamin $A$ and $ß$-carotene in blood plasma and milk and mastitis in Holsteins. J. Dairy Sci. 65:2111-2118. 
Cook, C. (2002): Teat preparation - remove the dirt, reduce the risk. British Mastitis Conference, Brockworth, Proceedings, p. 51-57 in Redetzky, R., Hamann, J. (2003): Mastitisprophylaxe - Trockenperiode und Hygienemanagement. DVG, Arbeitskreis "Eutergesundheit" - Diagnostik, Prävention und Therapie boviner Mastitiden vor dem Hintergrund neuer legislativer Regelungen, 3.+4.4. Kiel, 91109.

Cousins, C.L., Thiel, C.C., Westgarth, D.R., Higgs, T.M. (1973): Further short-term studies of the influence of the milking machine on the rate of new infections. J. Dairy Res. 40:289-292.

Djabri, B., Bareille, N., Beaudeau, H.S. (2002): Quarter milk somatic cell count in infected dairy cows: a meta-analysis. J. Dairy Res. 33:335-357.

DLG - Deutsche Landwirtschafts-Gesellschaft e.V. (Hrsg.) (2004): Grobfutter Bewertung - Teil A:DLG - Schlüssel zur Bewertung von Grünfutter, Silagen und Heu mit Hilfe der Sinnbewertung. DLG, Frankfurt a. M..

Dodd, F.H., Neave, F.K. (1951): Machine milking rate and mastitis. J. Dairy Res. 18:240-245.

Dodd, F.H. (1981): Mastitis control. In Bramley, A.J., Dodd, F.H., Griffin, T.K. (Hrsg) Mastitis control and herd management. Technical Bulletin 4, National Institute for Research in Dairying, Reading, England, 11-23.

Dodd, F.H., Neave, F.K., Kingwell, R.G., Thiel, C.C., Westgarth, D.R. (1966): The importance of hygiene in the control of udder disease. Proc. Int. Dairy Congress, München, A383.

Dohoo I.R., Leslie K.E. (1991): Evaluation of changes in somatic cell counts as indicators of new intramammary infections. Prev. Vet. Med. 10:225-237.

DVG - Deutsche Veterinärmedizinische Gesellschaft (Hrsg.) (1994): Leitlinien zur Bekämpfung der Mastitis des Rindes als Bestandsproblem. In: Sachverständigenausschuss:,Subklinische Mastitis“. DVG, Gießen. 
DVG - Deutsche Veterinärmedizinische Gesellschaft (Hrsg.) (2002): Leitlinien zur Bekämpfung der Mastitis des Rindes als Herdenproblem. In: Sachverständigenausschuss: „Subklinische Mastitis“. DVG, Gießen.

Eberhart, R.J., le Van, P.L., Griel, L.C., Kesler, E.M. (1983): Germicidal teat dip in a herd with low prevalence of Streptococcus agalactiae and Staphylococcus aureus mastitis. J. Dairy Sci. 66:1390-1395.

Edmonson, A.J., Lean, I.J., Weaver, L.D., Farver, T., Webster, G. (1989): A body condition scoring chart for Holstein dairy cows. J. Dairy Sci. 72:68-78.

Ekman, T., Østerås, O. (2003): Mastitis control and dry cow therapy in the nordic countries. National Mastitis Council Anual Meeting Proceedings, 18-30.

Elbers, A.R.W., Miltenburg, J.D., de Lange, D., Crauwels, A.P.P., Barkema, H.W., Schukken, Y.H. (1998): Risk factors for clinical mastitis in a random sample of dairy herds from the southern part of the Netherlands. J. Dairy Sci. 81:420426.

Emanuelson, U., Danell, B., Philipsson, J. (1988): Genetic parameters for clinical mastitis, somatic cell counts, and milk production estimated by Multiple-Trait restricted maximum likelihood. J. Dairy Sci. 71:467-476.

Emery, R.S., Burg, N., Brown, L.D., Blank, G.N. (1964): Detection, occurrence, and prophylactic treatment of borderline ketosis with propylene glycol feeding. J. Dairy Sci. 47:1074-1079.

Envoldsen, C., Sørensen, J.T. (1991): Effects of dry period length on clinical mastitis and other major clinical health disorders. J. Dairy Sci. 75:1007-1014.

Erskine, R.J., Eberhart, R.J., Hutchinson, L.J., Scholz, R.W. (1987): Blood selenium concentrations and glutathione peroxidase activities in dairy herds with high and low somatic cell counts. J. Am. Vet. Med. A. 190:1417-1421.

Erskine, R.J., Eberhart, R.J., Hutchinson, L.J., Spencer, S.B., Campbell, M.A. (1988): Incidence and types of clinical mastitis in dairy herds with high and low somatic cell count. J. Am. Vet. Med. Assoc. 192: 761-765. 
Farnsworth, R.J., Wyman, L., Hawkinson, R. (1980): Use of teat sealer for prevention of intramammary infections in lactating cows. J. Am. Vet. Med. A. 177:441-444.

Faye, B., Lescourret, F., Dorr, N., Tillard, E., MacDermott, B., McDermott, J. (1997): Interrelationships between herd management practices and udder health status using canonical correspondence analysis. Prev. Vet. Med. 32:171-192.

Fox, L.K., Nagy, J.A., Hillers, J.K., Cronrath, J.D., Ratkowsky, D.A. (1991): Effects of postmilking treatment on the colonization of Staphylococcus aureus on chapped teat skin. Am. J. Vet. Res. 52:799-802.

Friend, T.H., Polan, C.E., McGilliard, M.L. (1976): Free stall and feed bunk requirements relative to behavior, production and individual feed intake in dairy cows. J. Dairy Sci. 60:108-116.

Geer, van de D., Schukken, Y.H., Grommers, F.J., Brand, A. (1988): A matched casecontrol study on clinical mastitis in Holstein-Frisian dairy cows. 6th Int. Congr. Anim. Hygiene, Skara, Sweden, 14.-17.06.1988, 60-64.

Gill, R., Howard, W.H., Leslie, K.E., Lissemore, K. (1990): Economics of mastitis control. J. Dairy Sci. 73:3340-3348.

Giovannini, G., Zecconi, A. (2002): Field study on epidemiology of clinical mastitis in five Italian dairy herds. Milchwissenschaft 57:3-6.

Grant, R.J., Albright, J.L. (1995): Feeding behaviour and management factors during the transition period in dairy cattle. J. Anim. Sci. 73:2791-2803.

Green, M.J., Bradley, A.J., Newton, H., Browne, W.J. (2006): Seasonal variation of bulk milk somatic cell counts in UK dairy herds: investigations of the summer rise. Prev. Vet. Med. 74: 293-308.

Green, M.J., Bradley, A.J., Medley, G.F., Browne, W.J. (2007): Cow, farm, and management factors during the dry period that determine the rate of clinical mastitis after calving. J. Dairy Sci. 90:3764-3776. 
Grindal, R.J., Hillerton, J.E. (1991): Influence of milk flow rate on new intramammary infection in dairy cows. J. Dairy Res. 58:263-268.

Gröhn, Y.T., Erb, H.N., McCulloch, C.E., Saloniemi, H.S. (1990): Epidemiology of mammary gland disorders in multiparous Finnish Ayrshire cows. Prev. Vet. Med. 8:241-252.

Gröhn, Y.T., Wilson, D.J., Gonzalez, R.N., Hertl, J.A., Schulte, H., Bennett, G., Schukken, Y.H. (2004): Effect of pathogen-specific clinical mastitis on milk yield in dairy cows. J. Dairy Sci. 87:3358-3374.

Grommers, F.J., van de Braak, A.E., Antonisse, H.W. (1971): Direct trauma of the mammary gland disorders in cattle. I. Variations in incidence due to animal variables. Br. Vet. J. 127:271-282.

Hamann, J., Reichmuth, J. (1990): Exogene Einflüsse auf den Zellgehalt der Milch unter Berücksichtigung des Gesundheitszustandes der Milchdrüse. Milchwissenschaft 45: 286-290.

Hamann, J., Krömker, V. (1999): Mastitistherapie - Hilfe zur Selbsthilfe. Prakt. Tierarzt coll. vet. $X X I X: 38-42$.

Harmon R.J. (1994): Physiology of mastitis and factors affecting somatic cell counts. J. Dairy Sci. 77:2103-2112.

Harmon, R.J. (2001): Somatic cell counts: A primer. National Mastitis Council Anual Meeting Proceedings, 3-9.

Henken, A.M., Graat, E.A.M., Casal, J. (2001): Measurement of disease frequency. Application of quantitative methods in veterinary epidemiology. Wageningen Press ISBN: 9074134890.

Heringstad, B., Klemetsdal, G., Steine, T. (2003): Selection responses for clinical mastitis and protein yield in two Norwegian dairy cattle selection experiments. J. Dairy Sci. 86:2990-2999. 
Heuer, C., Schukken, Y.H., Dobbelaar, P. (1999): Postpartum body condition score and results from the first test day milk as predictors of disease, fertility, yield, and culling in commercial dairy herds. J. Dairy Sci. 82:295-304.

Hillerton, J.E., Berry, E.A. (2003): The management and treatment of environmental streptococcal mastitis. Vet. Clin. N. Am.-Food A. 19:157-169.

Hillerton, J.E., Boast, D., Davies, D., Ohnstad, I., Middleton, N. (2003): Changes in milking liner performance with age. National Mastitis Council Annual Meeting Proceedings, 239- 250.

Hogan, J.S., Smith, K.L. (1987): A practical look at environmental mastitis. Comp. Cont. Educ. Pract. 9, F341.

Hogan, J.S., White, D.G., Pankey, J.W. (1987): Effects of teat dipping on intramammary infections by Staphylococci other than Staphylococcus aureus. J. Dairy Sci. 70:873-879.

Hogan, J.S., Smith, K.L., Hoblet, K.H., Todhunter, D.A., Schönberger, P.S., Hueston, W.D., Pritchard, D.E., Bowman, G.L., Heider, L.E., Brockett, B.L., Conrad, H.R. (1989): Bacterial counts in bedding materials used on nine commercial dairies. J. Dairy Sci. 72:250-258.

Hultgren, J. (2002): Foot/leg and udder health in relation to housing changes in Swedish dairy herds. Prev. Vet. Med. 53:167-189.

Huton, C., Fox, L.K., Hancock, D.D. (1989): Mastitis control practices: differences between herds with high and low milk somatic cell counts. J. Dairy Sci. 73:1135-1143.

IDF - International Dairy Federation (1987): Bovine Mastitis - Definition and guidelines for diagnosis. Behr's Verlag, Hamburg.

Jasper, D.E., Dellinger, J.B., Bushnell, R.B. (1975): Herd studies on coliform mastitis. J. Am. Vet. Med. A. 166:778-780. 
Johnson, A.P. (2000): A proper milking routine: The key to quality milk, National Mastitis Council Annual Meeting Proceedings, 2000:123. Internet, http://www.nmconline.org/articles/keyqlty.htm, 1.6.2007.

Jukola, E., Hakka Rainen, J., Saloniemi, H., Sankari, S. (1996): Blood selenium, vitamin $E$, vitamin $A$ and $B$-Carotene. Concentration and udder health, fertility treatments and fertility. J. Dairy Sci. 79:838-845.

Kawai, K., Kurosawa, S., Nagahata, H., Rosenberg, J. (2005): Evaluation of dairy management practices on Japanese dairy farms: relationships to bulk tank SCC and individual linear scores. National Mastitis Council Annual Meeting, 2005:285-286.

Keefe, G.P. (1997): Streptococcus agalactiae mastitis: a review. Can. Vet. J. 38:429437.

Kehrli, M.E., Weigel, K.A., Freeman, A.E., Thurston, J.R., Kelley, D.H. (1991): Bovine sire effects on daughter's in vitro blood neutrophil functions, lymphocyte blastogenesis, serum complement, and conglutinin levels. Vet. Immunol. Immunop. 27:303-319.

Kelly P.T., O’Sullivan, K., Berry, D.P., More, S.J., Meaney, W.J., O’Callaghan, E.J., O'Brien, B. (2009): Farm management factors associated with bulk tank somatic cell count in Irish dairy herds. Irish V. J. 62:45-51.

Kellogg, D.W., Pennington, J.A., Johnson, Z.B., Panivavit, R. (2001): Survey of management practices used for the highest producing $\mathrm{DHI}$ herds in the United States. J. Dairy Sci. 84:E120-E127.

Kirchgeßner, M., Roth, F.X., Schwarz, F.J., Stangl, G.I. (2008): Tierernährung, Leitfaden für Studium, Beratung und Praxis. 12., neu überarbeitete Auflage, DLG-Verlag-GmbH, Frankfurt a. M..

Klaas, I.C., Enevoldsen, C., Ersbøll, A.K., Tölle , U. (2005): Cow-related risk factors for milk leakage. J. Dairy Sci. 88:128-136. 
Klocke, D., Haverkamp, H., Zinke, C., Paduch, J.H., Abograra, I., Krömker, v. (2010): Zur Wirksamkeit der Langzeitantibiotika Nafpenzal T und Benestermycin in der Trockenperiode von Milchkühen - eine Feldstudie. Tierärztl. Umschau, 65:331335.

Köster, G., Tenhagen, B.A., Heuwieser, W. (2006): Factors associated with high milk test day somatic cell counts in large dairy herds in Brandenburg. I. Housing conditions. J. Vet. Med. A. Physiol. Pathol. Clin. Med. 53:134-139.

Kristula, M.A., Rogers R., Hogan, J.S., Sabo, M. (2005): Comparison of bacteria populations in clean and recycled sand used for bedding in dairy facilities. J. Dairy Sci. 88:4317-4325.

Krömker, V., Hamann, J. (1998): Diagnostik des Mastitisrisikos: Tierindividuelle Merkmale. Prakt. Tierarzt coll. vet. XXVIII:70-75.

Krömker, V., Hamann, J. (1999): Nichtantibiotische Mastitistherapie - Einordnung und Beurteilung. Prakt. Tierarzt coll. vet. XXIX:48-51.

Krömker, V., Grabowski, N.T. (2002): Risk factor analysis for mastitis caused by environmental pathogens in the environment of dairy herds. XXII World Buiatrics Congress, Hannover, 18.-23.08.2002.

Krömker, V. (Hrsg.) (2007): Kurzes Lehrbuch Milchkunde und Milchhygiene. ISBN 38304-4155-X, Parey, Stuttgart.

Krömker, V. (2008): Mastitis risk analysis in dairy herds. Large Animal Review. 14:1519.

Krömker, V., Paduch, J.-H., Bormann, A., Friedrich, J., Zinke, C. (2010): Nachweisverfahren zur Beurteilung der Keimbelastung in Einstreumaterialien und des daraus resultierenden Mastitisrisikos. Tierärztl. Prax. Großtiere 2:7378.

Kruif, A. de, Mansfeld, R., Hoedemaker, M. (1998): Tierärztliche Bestandsbetreuung beim Milchrind. 1. Aufl. Verlag Enke, Stuttgart. 
Kuhn, M.T., Hutchison, J.L., Norman, H.D. (2006): Effects of length of dry period on yields of milk fat and protein fertility and milk somatic cell score in the subsequent lactation of dairy cows. J. Dairy Res. 73:154-162.

Laevens, H., de Luyker, H., Schukken, Y.H., de Meulemeester, L., van der Meersch, R., de Muelenaere, E., de Kruif, A. (1997): Influence of parity and stage of lactation on the somatic cell count in bacteriologically negative dairy cows. J. Dairy Sci. 80:3219-3226.

Lam, T.J., van Vliet, J.H., Schukken, Y.H., Grommers, F.J., van Velden-Russcher, A., Barkema, H.W., Brand, A. (1997a): The effect of discontinuation of postmilking teat disinfection in low somatic cell count herds. I. Incidence of clinical mastitis. Vet. Quart. 19:41-47.

Lam, T.J.G.M., van Vliet, J.H., Schukken, Y.H., Grommers, F.J., van Velden-Russcher, A., Barkema, H.W., Brand, A. (1997b): The effect of discontinuation of postmilking teat disinfection in low somatic cell count herds. II. Dynamics of intramammary infections. Vet. Quart. 19:47-53.

LKV - Landeskontrollverband Weser-Ems (2008): Milchproben je Zellzahlstufe in Weser- Ems im Rahmen der Milch-Güteverordnung. Internet, http://www.Ikvwe.de/Zellgehalt.html, 1.6.2008.

LAVES - Landesamt für Lebensmittelsicherheit und Verbraucherschutz (2007):

Tierschutzleitlinie für die Milchkuhhaltung. Oldenburg.

Lescourret, F., Coulon, J.B., Faye, B. (1995): Predictive model of mastitis occurrence in the dairy cow. J. Dairy Sci. 78:2167-2177.

Lotthammer, K.-H., Boehnke, H.-J., Morawietz, M. (1988): Beziehungen zwischen verschiedenen Blutparametern als Kriterium für Stoffwechselstörungen und dem Milchzellgehalt bei Milchrindern. Deut. tierärztl. Woch. 95:379-384.

LUFA - Landwirtschaftliche Untersuchungs- und Forschungsanstalt (2004):

Tränkwasseruntersuchung 2001 - 2004. http://www.lufa-nordwest.de/lufa2/downloads/pdf/traenkwasser.pdf. 
Madouasse, A., Huxley, J.N., Browne, W.J., Bradley, A.J., Green, M.J. (2010): Somatic cell count dynamics in a large sample of dairy herds in England and Wales. Prev. Vet. Med. 96:56-64.

Magnusson, M., Herlin, A.H., Ventorp, M. (2008): Short Communication: Effect of alley floor cleanliness on free-stall and udder hygiene. J. Dairy Sci. 91:3927-3930.

Mahle, D.E., Galton, D.M., Adkinson, R.W. (1982): Effects of vacuum and pulsation ratio on udder health. J. Dairy Sci. 65:1252-1257.

McDonald, J.S. (1975): Radiographic method for anatomic study of the teat canal: characteristics related to resistance to new intramammary infection during lactation and the early dry period. Cornell Vet. 65:492-499.

Mein, G.A., Brown, M.R., Williams, D.M. (1986): Effects of mastitis on overmilking in conjunctions with pulsation failure. J. Dairy Sci. 53:17-22.

Mein, G. A. (1990): Milking machine factors related to mastitis. 2-15. In: Proc. Sem. Machine Milking Mastitis, Koldkaergaard, Aarhus, Denmark. Natl. Inst. Anim. Sci., Foulum, DK-8830 Tjele, Denmark.

Mein, G.A., Neijenhuis, F., Morgan, W.F., Reinemann, D.J., Hillerton, J.E., Baines, J.R., Ohnstad, I., Rasmussen, M.D., Timms, L., Britt, J.S., Farnsworth, R., Cook, N., Hemling, T. (2001): Evaluation of bovine teat condition in commercial dairy herds: 1. Non-infectious factors. NMC-AABP International Symposium on Mastitis and Milk Quality, Vancouver, BC, Canada, 347-351.

Mein, G., Reineman, D., Schuring, N., Ohnstad, I. (2004): Milking machines and mastitis risk: A storm in a teat cup. National Mastitis Council Annual Meeting Proceedings, 2004, 176-188.

Munksgard, L., de Passilé, A.M., Rushen, J., Thodberg, K., Jensen, M.B. (1997): Discrimination of people by dairy cows based on handling. J. Dairy Sci. 80:1106-1112. 
Munoz, M.A., Bennett, G.J., Ahlström, C., Griffiths, H.M., Schukken, Y.H., Zadoks, R.N. (2008): Cleanliness scores as indicator of Klebsiella exposure in dairy cows. J. Dairy Sci. 91:3908-3916.

Myllys, V., Rautala, H. (1995): Characterisation of clinical mastitis in primiparous heifers. J. Dairy Sci. 78:538-545.

Napolitano, F., Pacelli, C., Girolami, A., Braghieri, A. (2008): Effect of information about animal welfare on consumer willingness to pay for yogurt. J. Dairy Sci. 91:910-917.

Neave, F.K., Dodd, F.H., Kingwell, R.G., Westgarth, D.R. (1969): Control of mastitis in the dairy herd by hygiene and management. J. Dairy Sci. 52:696-707.

Neijenhuis, F., Barkema, H. W., Hogeveen, H., Noordhuizen, J.P.T.M. (2000): Classification and longitudinal examination of callused teat ends in dairy cows. J. Dairy Sci. 83:2795-2804.

Neijenhuis, F., Barkema, H.W., Hoegeveen, H., Noordhuizen, J.P.T.M. (2001):

Relationship between teat-end callosity and occurrence of clinical mastitis. J. Dairy Sci. 84:2664-2672.

Nickerson, S.C., Owens, W.E., Boddie, R.L. (1993): Effect of a Staphylococcus aureus bacterin on serum antibody, new infection, and mammary histology in nonlactating dairy cows. J. Dairy Sci. 76:1290-1297.

NMC - A global organization for mastitis control and milk quality (2001):

Recommended mastitis control program. www.nmconline.org/docs/NMC10steps.pdf.

Nyhan, J.F., Cowhig, M.J. (1967): Inadequate milking machine reserve and mastitis. Vet. Rec. 81:122-124.

Olde Riekerink, R.G.M., Barkema, H.W., Stryhn, H. (2007): The effect of season on somatic cell count and the incidence of clinical mastitis. J. Dairy Sci. 90:17041715. 
Oliver, J., Dodd, F. H., Neave, F. K., Bailey, G. L. (1956): Variations in the incidence of udder infection and mastitis with stage of lactation, age, and season of the year. J. Dairy Res. 23:181-193.

Olofsson, J. (1999): Competition for total mixed diets fed for ad libitum intake using one or four cows per feeding station. J. Dairy Sci. 82:69-79.

Oltenacu, P.A., Ekesbo, I. (1994): Epidemiological study of clinical mastitis in dairy cattle. Vet. Res. 25:208-12.

Østerås, O., Rønningen O., Sandvik L., Waage.S. (1995): Field studies show associations between pulsator characteristics and udder health. J. Dairy Res. 62:1-13.

Østerås, O. (2006): Mastitis Epidemiology - Practical approaches and applications. Proc. XXIV World Buiatrics Congress, Nice, France, 15.-19.10.2006, 203-215.

Oz, H.H., Farnsworth, R.J., Larson, V.L. (1985): Environmental mastitis. Veterinary Bulletin, London 55:829-840.

Paduch, J.-H., Haverkamp, H., Klocke, D., Abogara, I., Zinke, C., Krömker, V. (2010): Zitzenform, Zitzenmaße und Zitzenkonditionen in nord- und mitteldeutschen Milchviehherden. 8. Berlin-Brandenburgischer Rindertag, 07.-09.10.2010, Berlin.

Pankey, J.W., Wildman, E.E., Drechsler, P.A., Hogan, J.S. (1987): Field trial evaluation of premilking teat disinfection. J. Dairy Sci. 70:867-872.

Pankey, J.W., Drechsler, P.A. (1993): Evolution of udder hygiene. Premilking teat sanitation. Vet. Clin. N. Am.-Food A. 9:519-530.

Peeler, E.J., Green, M.J., Fitzpatrick, J.L., Morgan, K.L., Green, L.E. (2000): Risk factors associated with clinical mastitis in low somatic cell count British dairy herds. J. Dairy Sci. 83:2464-2472.

Philpot, W.N. (1979): Control of mastitis by hygiene and therapy. J. Dairy Sci. 62:168176. 
Pyörälä, S. (2002): New strategies to prevent mastitis. Reprod. Domest. Anim. 37:211216.

Rasmussen, M.D. (2004): Overmilking and teat condition, National Mastitis Council Annual Meeting Proceedings, 2004, 170-175.

Reitsma, S.Y., Cant, E.J., Grindal, R.J., Westgarth, D.R., Bramley, A.J. (1981): Effect of duration of teat cup liner closure per pulsation cycle on bovine mastitis. J. Dairy Sci. 64:2240-2245.

Reneau, J.K. (2001): Prepping cows: who needs it? National Mastitis Council -PDPW Milk Quality Conference, 2001, S. 33-42. Internet, http://www.nmconline.org/articles/prepping.pdf, 1.6.2007.

Reneau, J.K., Seykora, A.J., Heins, B.J., Endres, M.I., Farnsworth, R.J., Bey, R.F. (2005): Association between hygiene scores and somatic cell scores in dairy cattle, J. am. Vet. Med, Assoc. 227:1297-1301.

Robert, A., Seegers, H., Bareille, N. (2006): Incidence of intramamary infections during the dry period without with antibiotic treatment in dairy cows-a quantitative analysis of published data. Vet. Res. 37:25-48.

Roberson, J.R., Fox, L.K., Hancock, J.M., Gay, J.M. (1994): Ecology of Staphylococcus aureus isolated from various sites on dairy farms. J. Dairy Sci. 77:3354-3361.

Rodrigues, A.C.O., Caraviello, D.Z., Ruegg, P.L. (2005): Management of Wisconsin dairy herds enrolled in milk quality teams. J. Dairy Sci. 88:2660-2671.

Rogers, G.W., Banos, G., Sander Nielsen, U., Philipsson, J. (1998): Genetic correlations among somatic cell scores, productive life, and type traits from the United States and udder health measures from Denmark and Sweden. J. Dairy Sci. 81:1445-1453.

Rollin, B.E. (2004): Annual meeting keynote address: Animal agriculture and emerging social ethics for animals. J. Animal Sci. 82:955-964. 
Rønningen, O., Reitan, A.D. (1990): Influence of static and dynamic teat characteristics and milking time on udder health in Norwegian Red Cattle. J. Dairy Res. 57:171-177.

Rossow, N. (2004): Allgemeine Grundlagen des Fettstoffwechsels der Hochleistungskuh. Großtierpraxis 05:6-13.

Rothert, J. (2000): Drenchen: Kühe mit warmem Wasser fit machen. topagrar10:R14-R15.

Saperstein, G., Hinckley, L.S., Post, J.E. (1988): Taking the team approach to solving staphylococcal mastitis infection. Vet. Med. 83:939-947.

Schepers, A.J., Lam, T.J., Schukken, Y.H., Wilmink, J.B., Hanekamp, W.J. (1997): Estimation of variance components for somatic cell counts to determine thresholds for uninfected quarters. J. Dairy Sci. 80:1833-1840.

Schreiner, D.A., Ruegg, P.L. (2003): Relationship between udder and leg hygiene scores and subclinical mastitis. J. Dairy Sci. 86:3460-3465.

Schukken, Y.H., Erb, H.N, Sears, P.M., Smith, R.D. (1988): Ecologic study of the risk factors for environmental mastitis in cows. Am. J. Vet. Res. 49:766-769

Schukken, Y.H., Grommers, F.J., van de Geer, D., Brand, A. (1989): Incidence of clinical mastitis on farms with low somatic cell counts in bulk milk. Vet. Res. 125:60-62.

Schukken, Y.H., Grommers, F.J., van de Geer, D., Ere, H.N., Brand, A. (1990): Risk factors for clinical mastitis in herds with a low bulk milk somatic cell count. 1. Data and risk factors for all cases. J. Dairy Sci. 73:3463-3471.

Schukken, Y.H., Grommers, F.J., van de Geer, D., Ere, H.N., Brand, A. (1991): Risk factors for clinical mastitis in herds with a low bulk milk somatic cell count. 2. Risk factors for Escherichia coli and Staphylococcus aureus. J. Dairy Sci. 74:826-832. 
Schukken, Y.H., van Vliet, J., van de Geer, D., Grommers, F.J. (1993): A randomized blind trial on dry cow antibiotic infusion in a low somatic cell count herd. J. Dairy Sci. 76:2925-30.

Seabrock, M. (1994): Psychological interaction between the milker and the dairy cow. National Mastitis Council 33rd Annual Meeting, Orlando, Florida, 1994, 163174.

Seegers, H., Fourichon, C., Beaudeau, F. (2003): Production effects related to mastitis and mastitis economics in dairy cattle herds. Vet. Res. 34:475-491.

Sheldrake, R.F., Hoare, R.J.T., McGregor, G.D. (1983): Lactation stage, parity, and infection affecting somatic cells, electrical conductivity, and serum albumin in milk. J. Dairy Sci. 66:542-547.

Sheran, M.F.H, Morgan, J.H., Hillerton, J.E. (1994): Reduction of bacterial contamination of teatcup liners by an entrained wash system. Veterinary Record 134:450.

Shook, G.E., Schutz, M.M. (1994): Selection on somatic cell score to improve resistance to mastitis in the United States. J. Dairy Sci. 77:648-658.

Shook, G. (2004): Breeding, selection and somatic cell counts. Internet, http://www.uwex.edu/MilkQuality/PDF/MQ_Web_Article_PTA-SCS_2004.pdf, 1.6.2007.

Shoop, D.S., Myers, L.L. (1984): Serologic analysis of isolates of Pasteurella haemolytica and Staphylococcus aureus from mastitic ewes. Am. J. Vet. Res. 45:1944-1946.

Skrzypek, R., Wojtowski, J., Fahr, R.D. (2004): Factors affecting somatic cell count in cow bulk tank milk - a case study from Poland. J. Vet. Med. A. Physiol. Pathol. Clin. Med. 51:127-131.

Slettbakk, T., Jørstad, A., Farver, T.B., Holmes, J.C. (1995): Impact of milking characteristics and morphology of udder and teats on clinical mastitis in firstand second-lactation Norwegian cattle. Prev. Vet. Med. 24:235-244. 
Smith, J.W., Ely, L.O., Graves, W.M., Gilson, W.D. (2002): Effect of milking frequency on DHI performance measures. J. Dairy Sci. 85:3526-3533.

Smith, K. L. (1982): Mastitis control: A discussion. J. Dairy Sci. 66:1790-1794.

Smith, K.L., Harrison J.H., Hancock D.A., Todhunter, A.A., Conrad, H.R. (1984): Effect of vitamin $E$ and selenium supplementation on incidence of clinical mastitis and duration of clinical symptoms. J. Dairy Sci. 67:1293-1300.

Smith, K.L., Todhunter, D.A., Schoenberger, P.S. (1985a): Environmental mastitis: Cause, prevalence and prevention. J. Dairy Sci. 68:1531-1553.

Smith, K.L., Todhunter, A.A., Schoenberger, P.S. (1985b): Environmental pathogens and intramammary infection during the dry period. J. Dairy Sci. 68:402.

Smith, T.W., Eberhart, R.J., Spencer, S.B., Kesler, E.M., Hargrove, G.L., Wilson, R.W., Heald, C.W. (1985c): Effect of automatic backflushing on number of new intramammary infections, bacteria on teatcup liners, and milk iodine. J. Dairy Sci. 68:424-432.

Svennersten-Sjaunja, K. (2004): The science behind milk ejection. National Mastitis Council Annual Meeting, 2004.

Tarabla, H.D., Dodd, K. (1990): Associations between farmer's personal characteristics, management practices and farm performance. Br. Vet. J. 146:157-164.

Thiel, C.C., Cousins, C.L., Westgarth, D.R., Neave, F.K. (1973): The influence of some physical characteristics of the milking machine on the rate of new mastitis infections. J. Dairy Res. 40:117-129.

Urban, D. (1993): Logit-Analyse. Gustav Fischer Verlag, Stuttgart, Jena, New York.

Valde, J. P., Osteras, O., Simensen, E. (2005): Description of herd level criteria for good and poor udder health in Norwgian dairy cows. J. Dairy Sci. 88:86-92. 
VIT - Vereinigte Informationssysteme Tierhaltung w. V. (2005): Jahresbericht 2005. https://service.vit.de/Jahresbericht_2005.html, VITJB2005_4_ZWS.pdf, 15.05.2006.

VIT - Vereinigte Informationssysteme Tierhaltung w. V. (2010): Rasseverteilung in niedersächsischen MLP Betrieben, Jahresabschluss 2009/2010 Interne Statistik.

Volling, O., Poddey, E., Krömker, V. (2010): Ökonomischer Gewinn und Indikatoren der Tiergesundheit in ökologisch wirtschaftenden Milchviehbetrieben. Tierärztl. Prax., akzeptiert.

Vries, de T.J., von Keyserlingk, M.A.G., Beauchemin, K.A. (2005): Frequency of feed delivery affects the behaviour of lactating dairy cows. J. Dairy Sci. 88:35533562.

Waage, S., Sviland, S., Ødegaard, S.A. (1998): Identification of risk factors for clinical mastitis in dairy heifers. J. Dairy Sci. 81:1275-1284.

Wagner, A.M., Ruegg, P.L. (2002): The effect on manual forestripping on milking performance of Holstein dairy cows. J. Dairy Sci. 85:804-809.

Walter, K., Bockisch, F.-J., Ohrtmann, J., Thomsen, J. (2005): Entwicklung der Milchviehhaltung in der Zeit vor und nach dem Neubau des Kuhstalls. Landbauforschung Völkenrode, 2-55:107-118.

Wang, J.Y., Owen, F.G., larson, L.L. (1988): Effect of ß-carotene supplementation on reproductive performance of lactating Holstein cows. J. Dairy Sci. 71:181-186.

Watts, J.L., Owens, W.E. (1989): Prevalence of staphylococcal species in four dairy herds. Res. Vet. Sci. 46:1-4.

Weiss, W.P., Hogan, J.S., Todhunter, D.A., Smith, K.L. (1997): Effect of vitamin E supplementation in diets with a low concentration of selenium on mammary gland health of dairy cows. J. Dairy Sci. 80:1728-1737. 
Wille, S. (2009): Deutsche Milcherzeugung im europäischen Vergleich - Ergebnisse aus der allgemeinen Statistik und aus dem Produktionskostenvergleich der European Dairy Farmers. Vortrag im Rahmen der landwirtschaftlichen Woche, Nordhessen, Januar 2009, http://www.llh-hessen.de/veranstaltungen_archiv /2009/090106_Iw_woche/daten/land_forstwirtschaft/Wille\%20Steffi.pdf.

1.7.2010.

Wilson, D.J., Gonzalez, R.N., Sears, P.M. (1995): Segregation or use of separate milking units for cows infected by Staphylococcus aureus: Effects on prevalence of infection and bulk tank somatic cell count. J. Dairy Sci. 78:20832085.

Wilson, D.J., Das, H.H., Gonzalez, R.N., Sears, P.M. (1997): Association between management practices, dairy herd characteristics, and somatic cell count of bulk tank milk. J. Am. Vet. Med. A. 10:1499-1502.

Whist, A.C., Østerås, O., Sølverød, L. (2009): Association between isolation of Staphylococcus aureus one week after calving and milk yield, somatic cell count, clinical mastitis, and culling through the remaining lactation. J. Dairy Res. 76:24-35.

Zadoks, R.N., Allore, H.G., Barkema, H.W., Sampimon, O.C., Wellenberg, G.J., Gröhn, Y.T., Schukken, Y.H. (2001): Cow- and quarter-level risk factors for Streptococcus uberis and Staphylococcus aureus mastitis. J. Dairy Sci. 84:2649-2663.

Zecconi, A. (2006): Can we eradicate staphylococcus aureus mastitis?. Proc. XXIVth World Buiatrics Congress, Nice, France, 2006, 225-236.

Zube, P. (2005): Liegeboxenbeläge - Erwartungen und Realität. Ministerium für Ländliche Entwicklung, Umwelt und Verbraucherschutz des Landes Brandenburg (MLUV). Landesamt für Verbraucherschutz, Landwirtschaft und Flurneuordnung, Frankfurt (Oder), TZ 86:05. 


\section{Anhang}

Interviewleitfaden

\begin{tabular}{|c|c|c|}
\hline Frage & Mgl. Antworten & Eingabe \\
\hline Betriebsdaten & $\begin{array}{l}\text { Name } \\
\text { E-Mail Adresse }\end{array}$ & \\
\hline $\begin{array}{l}\text { Welche Bodenart } \\
\text { herrscht vor? }\end{array}$ & $\begin{array}{l}\text { Moor } \\
\text { Anmoorig } \\
\text { Sand / Geest } \\
\text { Lehm } \\
\text { Ton }\end{array}$ & \\
\hline Erwerbsform? & $\begin{array}{l}\text { Haupterwerb } \\
\text { Nebenerwerb }\end{array}$ & \\
\hline $\begin{array}{l}\text { Produktionsverfahren } \\
\text { Tierhaltung }\end{array}$ & $\begin{array}{l}\text { Färsenaufzucht } \\
\text { Bullenmast } \\
\text { Kälbermast } \\
\text { Sauenhaltung } \\
\text { Mastschweinehaltung } \\
\text { Legehennen } \\
\text { Mastgeflügel } \\
\text { Pensionspferde }\end{array}$ & \\
\hline $\begin{array}{l}\text { Produktionsverfahren } \\
\text { Ackerbau }\end{array}$ & $\begin{array}{l}\text { Getreidebau } \\
\text { Zuckerrüben } \\
\text { Kartoffeln } \\
\text { Feldgemüse } \\
\text { Spargel }\end{array}$ & \\
\hline $\begin{array}{l}\text { Flächenausstattung } \\
\text { gesamt }\end{array}$ & & ha \\
\hline Grünland & & ha \\
\hline Naturschutzflächen & & ha \\
\hline
\end{tabular}




\begin{tabular}{|c|c|c|}
\hline & & ha \\
\hline davon Mais & & ha \\
\hline davon Ackergras & & ha \\
\hline davon Futterrüben & & ha \\
\hline sonstige Futterflächen & & ha \\
\hline Futterfläche gesamt & & ha \\
\hline Rasse Milchvieh & $\begin{array}{l}\text { Deutsch Holstein sb } \\
\text { Deutsch Holstein rb } \\
\text { Alte Schwarzbunte } \\
\text { Alte Rotbunte } \\
\text { Fleckvieh } \\
\text { Jersey } \\
\text { Braunvieh }\end{array}$ & \\
\hline Milchquote & & tkg \\
\hline $\begin{array}{l}\text { Wie oft wird täglich } \\
\text { gemolken? }\end{array}$ & $\begin{array}{l}\text { Einmal } \\
\text { Zweimal } \\
\text { Dreimal } \\
\text { Viermal }\end{array}$ & \\
\hline Stallart laktierende Kühe & $\begin{array}{l}\text { Anbindestall / Liegeboxenlaufstall } \\
\text { Tretmistall / Tieflaufstall }\end{array}$ & \\
\hline Anzahl Reihen & & \\
\hline Untergrund der Laufflächen & $\begin{array}{l}\text { Planbefestigt Beton } \\
\text { Planbefestigt Gußasphalt } \\
\text { Planbefestigt mit Einstreu } \\
\text { Spaltenboden }\end{array}$ & \\
\hline $\begin{array}{l}\text { Werden die Laufflächen } \\
\text { regelmäßig gereinigt? }\end{array}$ & Ja / nein & \\
\hline
\end{tabular}




\begin{tabular}{|c|c|}
\hline \multirow[t]{2}{*}{ Reinigung der Laufflächen } & mal / Woche \\
\hline & $\begin{array}{l}\text { Art } \\
\text { ganz / halb }\end{array}$ \\
\hline $\begin{array}{l}\text { Werden die Laufflächen } \\
\text { regelmäßig desinfiziert? }\end{array}$ & Ja / nein \\
\hline \multirow[t]{2}{*}{ Desinfektion der Laufflächen } & mal / Woche \\
\hline & Art \\
\hline \multirow[t]{4}{*}{ Untergrund der Liegefläche } & Beton \\
\hline & Gummimatte \\
\hline & Komfortmatte \\
\hline & Mistmatratze \\
\hline $\begin{array}{l}\text { Werden die Liegeboxen, - } \\
\text { flächen regelmäßig } \\
\text { eingestreut / gepflegt? }\end{array}$ & Ja / nein \\
\hline \multirow{6}{*}{ Einstreuen / Boxenpflege } & Häufigkeit ___ mal/ o. Tag \\
\hline & Langstroh \\
\hline & Häckselstroh \\
\hline & Sägespähne \\
\hline & Volumen $\%$ oder Gewicht $\%$ \\
\hline & Menge __ $\mathrm{kg} /$ Kuh *Jahr \\
\hline \multirow{4}{*}{$\begin{array}{l}\text { Wo wird die Einstreu } \\
\text { gelagert? }\end{array}$} & Im Freien, dann im Kopfraum \\
\hline & Unter Dach, dann im Kopfraum \\
\hline & Im Freien, täglich frisch \\
\hline & Unter Dach, täglich frisch \\
\hline $\begin{array}{l}\text { Werden die Liegeboxen, - } \\
\text { flächen regelmäßig } \\
\text { desinfiziert? }\end{array}$ & Ja / nein \\
\hline Liegeflächendesinfektion & $\begin{array}{l}\text { Häufigkeit___ mal/Woche o. Tag } \\
\text { Brandkalk } \\
\text { Stallosan } \\
\text { Andere Mittel }\end{array}$ \\
\hline
\end{tabular}




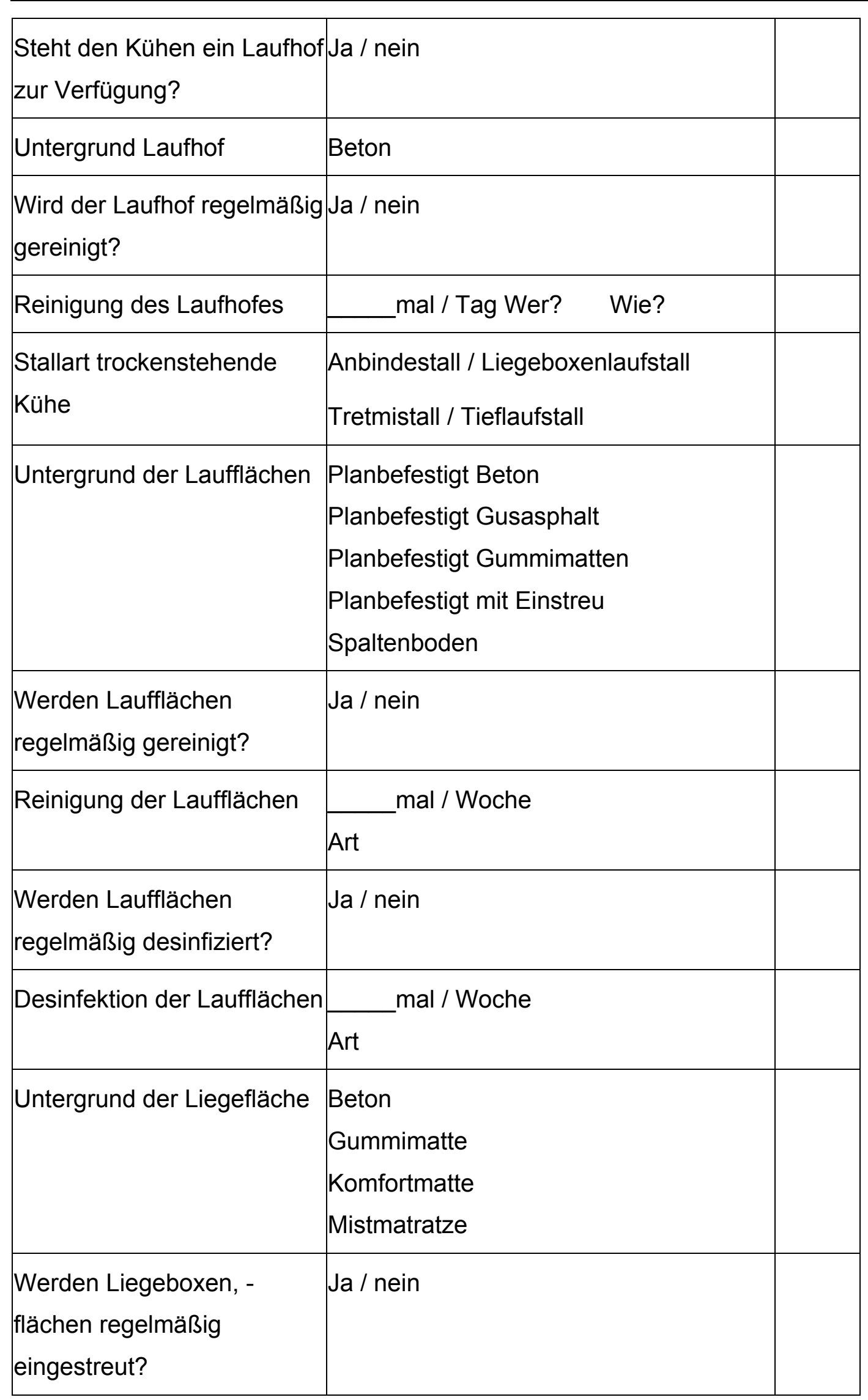




\begin{tabular}{|c|c|c|}
\hline Einstreuen / Boxenpflege & $\begin{array}{l}\text { Häufigkeit__ mal/Woche } \\
\text { Langstroh } \\
\text { Häckselstroh } \\
\text { Sägespäne } \\
\text { Volumen\% oder Gewicht\% } \\
\text { Menge __ kg/Kuh *Jahr }\end{array}$ & \\
\hline $\begin{array}{l}\text { Werden die Liegeboxen, - } \\
\text { flächen regelmäßig } \\
\text { desinfiziert? }\end{array}$ & Ja / nein & \\
\hline Liegeflächendesinfektion & $\begin{array}{l}\text { Häufigkeit___ mal/Woche } \\
\text { Brandkalk } \\
\text { Stallosan }\end{array}$ & \\
\hline $\begin{array}{l}\text { Steht den Kühen ein Laufho } \\
\text { zur Verfügung? }\end{array}$ & $\mathrm{f} / \mathrm{Ja} /$ nein & \\
\hline Untergrund Laufhof & Beton & \\
\hline $\begin{array}{l}\text { Wird der Laufhof regelmäßig } \\
\text { gereinigt? }\end{array}$ & Ja / nein & \\
\hline Reinigung des Laufhofes & Art mal / Woche & \\
\hline $\begin{array}{l}\text { Werden die Kühe im } \\
\text { Sommer im Wartehof } \\
\text { gekühlt? }\end{array}$ & & \\
\hline $\begin{array}{l}\text { Werden die Stallungen im } \\
\text { Sommer gekühlt? }\end{array}$ & & \\
\hline $\begin{array}{l}\text { Werden die Kühe } \\
\text { losgebunden? }\end{array}$ & $\begin{array}{l}\text { nein } \\
\text { ja h täglich / mal je Woche im } \\
\text { Sommer } \\
\text { ja h täglich / mal je Woche im } \\
\text { Winter }\end{array}$ & \\
\hline Durchschnittliche Anzahl & & Stk \\
\hline
\end{tabular}




\begin{tabular}{|c|c|c|}
\hline \multicolumn{3}{|l|}{ Milchkühe im Jahr } \\
\hline Anzahl Fressplätze & & Stk \\
\hline Tier:Fressplatzverhältnis & & - \\
\hline Anzahl Liegeboxen & & Stk \\
\hline Tier:Liegeplatzverhältnis & & - \\
\hline $\begin{array}{l}\text { Was ist ihrer Meinung nach } \\
\text { im Bereich der Haltung das } \\
\text { Wichtigste? }\end{array}$ & & \\
\hline $\begin{array}{l}\text { Was für einen Melkstand } \\
\text { haben Sie? }\end{array}$ & $\begin{array}{l}\text { Tandem } \\
\text { Fischgräte } \\
\text { Side by side } \\
\text { Swing over } \\
\text { Eimermelkanlage } \\
\text { Rohrmelkanlage }\end{array}$ & \\
\hline $\begin{array}{l}\text { Von welcher Firma ist die } \\
\text { Melkanlage? }\end{array}$ & $\begin{array}{l}\text { Alfa Laval } \\
\text { Westfalia } \\
\text { Fullwood }\end{array}$ & \\
\hline $\begin{array}{l}\text { von welcher Firma ist die } \\
\text { Reinigungsanlage? }\end{array}$ & $\begin{array}{l}\text { Alfa Laval } \\
\text { Westfalia } \\
\text { Fullwood }\end{array}$ & \\
\hline Wann ist dieser gebaut? & $\begin{array}{l}\text { Gebäudehülle } \\
\text { Melkmaschine } \\
\text { Pulsatoren } \\
\text { Sammelstücke }\end{array}$ & \\
\hline Morgenmelkzeit Beginn & & \\
\hline Abendmelkzeit Beginn & & \\
\hline $\begin{array}{l}\text { Wie viele dreistrichige Kühe } \\
\text { haben sie in der Herde? }\end{array}$ & \begin{tabular}{|l} 
Durch Verletzungen \\
durch Mastitis
\end{tabular} & $\%$ \\
\hline Melken Sie mit & Ja / nein & \\
\hline
\end{tabular}




\begin{tabular}{|c|c|c|}
\hline Handschuhen? & & \\
\hline $\begin{array}{l}\text { Wie werden Eutertücher } \\
\text { aufbewahrt und desinfiziert? }\end{array}$ & $\begin{array}{l}\text { DesinfektionslösungAbkochen mit } \\
\text { HaushaltswaschmaschineAbkochen mit } \\
\text { Industriewaschmaschinelm Trockner } \\
\text { trocknenMit Wasser ausspülen }\end{array}$ & \\
\hline $\begin{array}{l}\text { Welche } \\
\text { Hygienemaßnahmen } \\
\text { werden vor dem Melken, } \\
\text { bzw. wenn der Melker den } \\
\text { Melkstand verlassen hat } \\
\text { ergriffen? }\end{array}$ & $\begin{array}{l}\text { Desinfektion } \\
\text { Hände waschen }\end{array}$ & \\
\hline $\begin{array}{l}\text { Wann reagiert } \\
\text { Abnahmeautomatik? }\end{array}$ & Schaltwert & \\
\hline $\begin{array}{l}\text { Kontrollieren Sie die } \\
\text { Melkanlage regelmäßig? }\end{array}$ & Ja / nein & \\
\hline $\begin{array}{l}\text { Was kontrollieren Sie selber } \\
\text { regelmäßig? }\end{array}$ & $\begin{array}{l}\text { Ölstand } \\
\text { Vakuum } \\
\text { Pulsatoren } \\
\text { Ausmelkgrad }\end{array}$ & \\
\hline $\begin{array}{l}\text { Wird die Melkanlage } \\
\text { regelmäßig von anderen } \\
\text { kontrolliert? }\end{array}$ & Ja / nein & \\
\hline Kontrolle Melkanlage & $\begin{array}{l}\text { Monate } \\
\text { Melkmaschinenfirma } \\
\text { LKV } \\
\text { Landwirt }\end{array}$ & \\
\hline Austausch Verschleißteile & $\begin{array}{l}\text { Zitzengummis } \\
\text { Andere Gummiteile }\end{array}$ & \\
\hline $\begin{array}{l}\text { Wechsel Zitzengummis } \\
\text { nach }\end{array}$ & $\begin{array}{l}\text { Stunden } \\
\text { Monaten }\end{array}$ & h \\
\hline
\end{tabular}




\begin{tabular}{|c|c|c|}
\hline $\begin{array}{l}\text { Gibt es Besonderheiten } \\
\text { beim Reinigen der } \\
\text { Melkanlage }\end{array}$ & Ja / nein & \\
\hline $\begin{array}{l}\text { Besonderheiten beim } \\
\text { Reinigen der Melkanlage }\end{array}$ & $\begin{array}{l}\text { Temperatur } \\
\text { Mittel } \\
\text { Zeit }\end{array}$ & \\
\hline $\begin{array}{l}\text { Werden die Kühe nach dem } \\
\text { Melken im Fressgitter } \\
\text { fixiert? }\end{array}$ & Ja / nein & \\
\hline Zeit der Fixierung & & \\
\hline $\begin{array}{l}\text { Worauf muss man ihrer } \\
\text { Meinung nach beim Melken } \\
\text { besonders achten? }\end{array}$ & & \\
\hline $\begin{array}{l}\text { Wie viele verschiedene } \\
\text { Personen kümmern sich um } \\
\text { die Milchkühe? }\end{array}$ & $\begin{array}{l}\text { Familien-Ak } \\
\text { Fest angestellt-Ak } \\
\text { Aushilfen }\end{array}$ & Anz \\
\hline $\begin{array}{l}\text { Mit welchem zeitlichen } \\
\text { Aufwand kümmern sich } \\
\text { diese Personen um die } \\
\text { Kühe? }\end{array}$ & $\begin{array}{l}\text { Familien-Ak } \\
\text { Fest angestellt-Ak } \\
\text { Aushilfen }\end{array}$ & Akh \\
\hline $\begin{array}{l}\text { Wie viele Akh } \\
(2500 h / F a m A K) \text { werden für } \\
\text { die Milchkühe ohne } \\
\text { Futterbau benötigt? }\end{array}$ & & \\
\hline $\begin{array}{l}\text { Wie viele verschiedene } \\
\text { Personen melken? (Anzahl } \\
\text { mit \%-Angaben) }\end{array}$ & $\begin{array}{l}\text { Familien-Ak } \\
\text { Fest angestellt-Ak } \\
\text { Aushilfen }\end{array}$ & Anz \\
\hline $\begin{array}{l}\text { Gibt es eine feste Person für } \\
\text { Urlaubs- oder } \\
\text { Wochenendvertretung? }\end{array}$ & rJa / nein & \\
\hline
\end{tabular}




\begin{tabular}{|l|l|l|}
\hline $\begin{array}{l}\text { Wie lange dauert das } \\
\text { tägliche Melken Licht an bis } \\
\text { Licht aus? }\end{array}$ & h \\
\hline $\begin{array}{l}\text { Wie viele Akh dauert das } \\
\text { tägliche Melken Licht an bis } \\
\text { Licht aus? }\end{array}$ & & Akh \\
\hline $\begin{array}{l}\text { Wie lange dauert die reine } \\
\text { Melkzeit tgl? }\end{array}$ & & \\
\hline $\begin{array}{l}\text { Wie viele Akh werden für } \\
\text { das Jungvieh benötigt? }\end{array}$ & & Akh \\
\hline $\begin{array}{l}\text { Wie viele Akh werden für } \\
\text { das tägliche Füttern } \\
\text { benötigt? }\end{array}$ & Akh \\
\hline $\begin{array}{l}\text { Wie viele Akh werden } \\
\text { zusätzlich zu den täglichen } \\
\text { Arbeiten für das Füttern je } \\
\text { Woche benötigt? }\end{array}$ & & Akh \\
\hline $\begin{array}{l}\text { Wie viele Akh dauert die } \\
\text { Boxenpflege / Einstreuen je } \\
\text { Tag? }\end{array}$ & & Akh \\
\hline $\begin{array}{l}\text { Wie viele Akh dauert } \\
\text { Spaltenabschieben? }\end{array}$ & Jahre \\
\hline $\begin{array}{l}\text { Sind Betriebsleiter und } \\
\text { Hauptverantwortlicher für } \\
\text { die Milchkühe ein und die } \\
\text { selbe Person? }\end{array}$ & Ja / nein & \\
\hline $\begin{array}{l}\text { Alter des } \\
\text { Hauptverantwortlichen für } \\
\text { die Kühe? }\end{array}$ & & \\
\hline Familienstand & \\
\hline
\end{tabular}




\begin{tabular}{|c|c|c|}
\hline $\begin{array}{l}\text { Jahre im Beruf } \\
\text { Hauptverantwortlicher }\end{array}$ & & Jahre \\
\hline $\begin{array}{l}\text { Jahre in leitender Funktion } \\
\text { Hauptverantwortlicher }\end{array}$ & & Jahre \\
\hline $\begin{array}{l}\text { Welche Ausbildung hat der } \\
\text { Betriebsleiter? }\end{array}$ & $\begin{array}{l}\text { Lehre Landwirt } \\
\text { Einjährige Fachschule } \\
\text { Zweijährige Fachschule } \\
\text { Gehilfenjahre } \\
\text { Studium FH Landwirtschaft } \\
\text { Studium Uni Landwirtschaft }\end{array}$ & \\
\hline $\begin{array}{l}\text { Welche Ausbildung hat der } \\
\text { Hauptverantwortliche? }\end{array}$ & $\begin{array}{l}\text { Lehre Landwirt } \\
\text { Einjährige Fachschule } \\
\text { Zweijährige Fachschule } \\
\text { Gehilfenjahre } \\
\text { Studium FH Landwirtschaft } \\
\text { Studium Uni Landwirtschaft }\end{array}$ & \\
\hline $\begin{array}{l}\text { Nimmt der } \\
\text { Hautverantwortliche } \\
\text { regelmäßig an } \\
\text { Weiterbildungen teil? }\end{array}$ & Ja / nein & \\
\hline $\begin{array}{l}\text { Wie oft macht die } \\
\text { verantwortliche Person } \\
\text { Weiterbildungen? }\end{array}$ & & $d / a$ \\
\hline $\begin{array}{l}\text { Welche Art von } \\
\text { Weiterbildung macht die } \\
\text { verantwortliche Person? }\end{array}$ & $\begin{array}{l}\text { Kongresse } \\
\text { Vorträge LWK } \\
\text { Vorträge Molkerei } \\
\text { Vorträge Beratungsring } \\
\text { DLG Tagung }\end{array}$ & \\
\hline
\end{tabular}




\begin{tabular}{|c|c|}
\hline $\begin{array}{l}\text { Welche Fachzeitung liest die } \\
\text { verantwortliche Person? }\end{array}$ & $\begin{array}{l}\text { Land und Forst } \\
\text { Topagrar } \\
\text { DLZ } \\
\text { DLG Mitteilungen } \\
\text { Milchpraxis } \\
\text { Milchrind } \\
\text { Elite }\end{array}$ \\
\hline $\begin{array}{l}\text { Bekommt der } \\
\text { Hauptverantwortliche } \\
\text { regelmäßig Beratung? }\end{array}$ & Ja / nein \\
\hline Regelmäßig Beratung durch & $\begin{array}{l}\text { Tierarzt } \\
\text { Bestandsbetreuender Tierarzt } \\
\text { Ringberater } \\
\text { Kammerberater } \\
\text { Milchviehspezialberater } \\
\text { Futtermittelvertreter }\end{array}$ \\
\hline $\begin{array}{l}\text { Von wem bekommt er } \\
\text { Kriesenberatung? }\end{array}$ & $\begin{array}{l}\text { Tierarzt } \\
\text { Bestandsbetreuender Tierarzt } \\
\text { Ringberater } \\
\text { Kammerberater } \\
\text { Milchviehspezialberater } \\
\text { Futtermittelvertreter }\end{array}$ \\
\hline $\begin{array}{l}\text { Was ist ihrer Meinung nach } \\
\text { im Bereich Management / } \\
\text { Arbeitskräfte das } \\
\text { Wichtigste? }\end{array}$ & \\
\hline $\begin{array}{l}\text { Gibt es unterschiedliche } \\
\text { Gruppen in der Fütterung? }\end{array}$ & Ja / nein \\
\hline
\end{tabular}




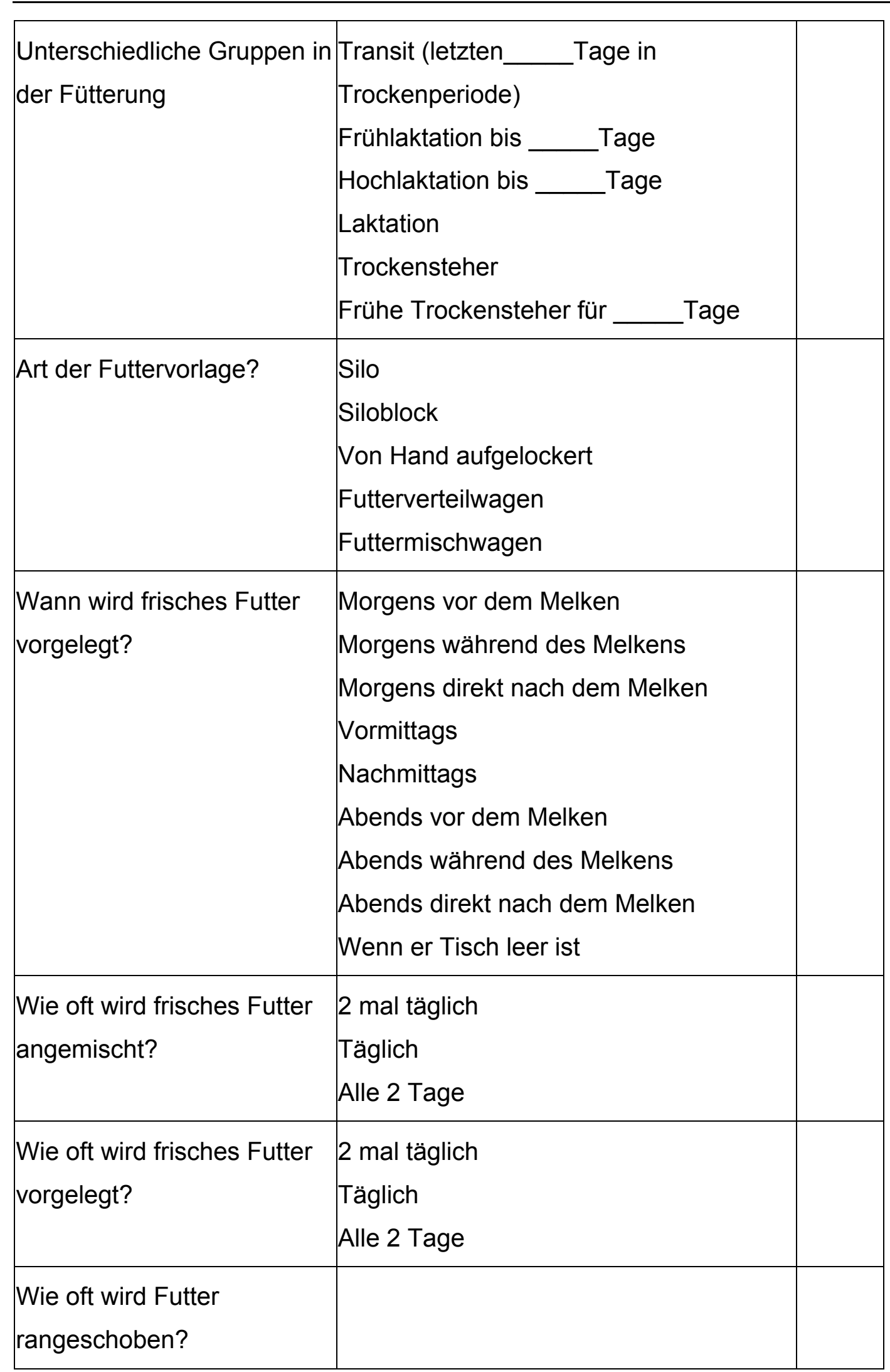




\begin{tabular}{|c|c|c|}
\hline $\begin{array}{l}\text { Wie oft wird der Futtertisch } \\
\text { gereinigt? }\end{array}$ & $\begin{array}{l}\text { Nie } \\
\text { Täglich } \\
\text { Alle } 2 \text { Tage } \\
\text { Wöchentlich }\end{array}$ & \\
\hline $\begin{array}{l}\text { Wie viel Futterreste werden } \\
\text { entfernt? }\end{array}$ & $\begin{array}{l}\text { Keine } \\
\text { Kg } \\
\text { Schubkarren } \\
\%\end{array}$ & \\
\hline $\begin{array}{l}\text { Wird regelmäßig eine } \\
\text { Rationsberechnung erstellt? }\end{array}$ & Ja / nein & \\
\hline $\begin{array}{l}\text { Für wen machen Sie } \\
\text { Rationsberechnung }\end{array}$ & $\begin{array}{l}\text { Laktierende KüheTrockenstehende } \\
\text { KüheFärsen }\end{array}$ & \\
\hline $\begin{array}{l}\text { Ermitteln Sie regelmäßig die } \\
\text { Trockenmasseaufnahme? }\end{array}$ & Ja / nein & \\
\hline TM-Aufnahme gesamt & $\begin{array}{l}\text { Gewogen } \\
\text { Geschätzt } \\
\text { Unbekannt }\end{array}$ & $\mathrm{kg}$ \\
\hline $\begin{array}{l}\text { Welche Komponenten } \\
\text { werden zu welchen Anteilen } \\
\text { im Winter eingesetzt? }\end{array}$ & $\begin{array}{l}\text { Grassilage } \\
\text { Maissilage } \\
\text { Biertreber } \\
\text { Kartoffelpülpe } \\
\text { Pressschnitzel } \\
\text { Kraftfutter } \\
\text { Getreide } \\
\text { Leguminosen } \\
\text { Sojaextraktionsschrot }\end{array}$ & \\
\hline
\end{tabular}




\begin{tabular}{|c|c|}
\hline $\begin{array}{l}\text { Welche Komponenten } \\
\text { werden zu welchen Anteilen } \\
\text { im Sommer eingesetzt? }\end{array}$ & $\begin{array}{l}\text { Weidegras } \\
\text { Frischgras } \\
\text { Grassilage } \\
\text { Maissilage } \\
\text { Biertreber } \\
\text { Kartoffelpülpe } \\
\text { Pressschnitzel } \\
\text { Kraftfutter } \\
\text { Getreide } \\
\text { Leguminosen } \\
\text { Sojaextraktionsschrot }\end{array}$ \\
\hline Liegen Futteranalysen vor & \\
\hline $\begin{array}{l}\text { Wann wurde der Schnitt } \\
1 / 05 \text { gemacht? }\end{array}$ & \\
\hline $\begin{array}{l}\text { Wie viele Schnitte im Jahr } \\
\text { Grünland? }\end{array}$ & \\
\hline $\begin{array}{l}\text { Wie viele Schnitte im Jahr } \\
\text { Ackergras? }\end{array}$ & \\
\hline $\begin{array}{l}\text { Wie viele Zeit liegt zwischen } \\
\text { den Schnitten? }\end{array}$ & \\
\hline $\begin{array}{l}\text { Woraus besteht der } \\
\text { Untergrund des Siloplatzes? }\end{array}$ & $\begin{array}{l}\text { gewachsener Boden } \\
\text { Sand } \\
\text { Alte Förderbänder } \\
\text { Stroh } \\
\text { Beton }\end{array}$ \\
\hline Wird Kraftfutter gefüttert? & Ja / nein \\
\hline $\begin{array}{l}\text { Wie wird das Kraftfutter } \\
\text { zugeteilt? }\end{array}$ & $\begin{array}{l}\text { Von Hand } \\
\text { Transponderstation } \\
\text { Beim Melken } \\
\text { Mischration }\end{array}$ \\
\hline
\end{tabular}




\begin{tabular}{|c|c|}
\hline $\begin{array}{l}\text { Was für ein Kraftfutter wird } \\
\text { in der Futtermischung } \\
\text { eingesetzt? }\end{array}$ & $\begin{array}{l}16 / 3 \mathrm{er} \\
18 / 3 \mathrm{er} \\
18 / 4 \mathrm{er} \\
20 / 3 \mathrm{er} \\
20 / 4 \mathrm{er} \\
\text { Getreide } \\
\text { Leguminosen }\end{array}$ \\
\hline $\begin{array}{l}\text { Was für ein Kraftfutter wird } \\
\text { in der Einzeltierzuteilung } \\
\text { eingesetzt? }\end{array}$ & $\begin{array}{l}16 / 3 \mathrm{er} \\
18 / 3 \mathrm{er} \\
18 / 4 \mathrm{er} \\
20 / 3 \mathrm{er} \\
20 / 4 \mathrm{er} \\
\text { Getreide } \\
\text { Leguminosen }\end{array}$ \\
\hline $\begin{array}{l}\text { Nach welchen Kriterien wird } \\
\text { das Kraftfutter zugeteilt? }\end{array}$ & $\begin{array}{l}\text { Letzter Kalbetermin } \\
\text { Trächtigkeitszustand } \\
\text { Trockenstelltermin } \\
\text { Milchleistung } \\
\text { Körperkondition }\end{array}$ \\
\hline $\begin{array}{l}\text { In welcher Höhe wird das } \\
\text { Kraftfutter im Winter } \\
\text { zugeteilt? }\end{array}$ & $\begin{array}{l}10 \text { kg Milch } \\
15 \text { kg Milch } \\
20 \text { kg Milch } \\
25 \text { kg Milch } \\
30 \text { kg Milch } \\
35 \text { kg Milch } \\
40 \text { kg Milch } \\
45 \text { kg Milch } \\
50 \text { kg Milch }\end{array}$ \\
\hline
\end{tabular}




\begin{tabular}{|c|c|c|}
\hline $\begin{array}{l}\text { In welcher Höhe wird das } \\
\text { Kraftfutter im Sommer } \\
\text { zugeteilt? }\end{array}$ & $\begin{array}{l}10 \text { kg Milch } \\
15 \text { kg Milch } \\
20 \text { kg Milch } \\
25 \text { kg Milch } \\
30 \text { kg Milch } \\
35 \text { kg Milch } \\
40 \text { kg Milch } \\
45 \text { kg Milch } \\
50 \text { kg Milch }\end{array}$ & \\
\hline $\begin{array}{l}\text { Wie viele Kraftfutter wird } \\
\text { maximal je Kuh und Tag } \\
\text { verfüttert? }\end{array}$ & & $\begin{array}{l}\mathrm{kg} / \text { Kuh } \\
\text { und } \\
\text { Tag }\end{array}$ \\
\hline $\begin{array}{l}\text { Wie hoch ist die } \\
\text { Kraftfuttergabe ums Kalben? }\end{array}$ & & $\mathrm{kg} / \mathrm{Tag}$ \\
\hline $\begin{array}{l}\text { Wann beginnen Sie die KF- } \\
\text { Mengen hoch zu setzen? }\end{array}$ & & \\
\hline $\begin{array}{l}\text { Bis zu welchem } \\
\text { Laktationstag wird die } \\
\text { Kraftfuttermenge gesteigert? }\end{array}$ & & d \\
\hline $\begin{array}{l}\text { Um Wie viele kg/Tag wird } \\
\text { das Kraftfutter raufgesetzt? }\end{array}$ & & $\mathrm{kg}$ \\
\hline $\begin{array}{l}\text { Maximale Kraftfuttermenge } \\
\text { je Einzelgabe ohne } \\
\text { Grundfutter? }\end{array}$ & & Gramm \\
\hline $\begin{array}{l}\text { Wird der Kraftfutterautomat } \\
\text { regelmäßig kalibriert? }\end{array}$ & Ja / nein & \\
\hline $\begin{array}{l}\text { Wie oft wird der } \\
\text { Kraftfutterautomat kalibriert? }\end{array}$ & $\begin{array}{l}\text { Mit jeder neuen Lieferung } \\
\text { Halbjährlich } \\
\text { Jährlich }\end{array}$ & \\
\hline
\end{tabular}




\begin{tabular}{|c|c|}
\hline $\begin{array}{l}\text { Woher stammt das } \\
\text { Tränkewasser der Kühe? }\end{array}$ & $\begin{array}{l}\text { Brunnen } \\
\text { Stadtwasser }\end{array}$ \\
\hline $\begin{array}{l}\text { Hat das Wasser } \\
\text { Trinkwasserqualität? }\end{array}$ & Ja / nein \\
\hline $\begin{array}{l}\text { Werden die Tränken } \\
\text { regelmäßig gereinigt? }\end{array}$ & Ja / nein \\
\hline $\begin{array}{l}\text { Wie oft werden die Tränken } \\
\text { gereinigt? }\end{array}$ & mal / Woche \\
\hline $\begin{array}{l}\text { Werden Mineralstoffe } \\
\text { ergänzt? }\end{array}$ & Ja / nein \\
\hline $\begin{array}{l}\text { Werden Mineralstoffe } \\
\text { ganzjährig ergänzt? }\end{array}$ & $\begin{array}{l}\text { Sommer } \\
\text { Winter }\end{array}$ \\
\hline $\begin{array}{l}\text { Auf welcher Grundlage } \\
\text { werden Mineralstoffe } \\
\text { ergänzt? }\end{array}$ & $\begin{array}{l}\text { Pauschal } \\
\text { Nach Bedarf + Grundfutteranalysen } \\
\text { Nach Empfehlung von }\end{array}$ \\
\hline $\begin{array}{l}\text { Welche Mineralstoffe } \\
\text { werden in welcher Höhe } \\
\text { ergänzt? }\end{array}$ & $\begin{array}{l}\text { Futterkalk } \\
\text { Viehsalz } \\
\text { Mineralfutter (Firma, Bezeichnung) }\end{array}$ \\
\hline Werden Vitamine ergänzt? & Ja / nein \\
\hline $\begin{array}{l}\text { Wie werden Vitamine } \\
\text { ergänzt? }\end{array}$ & $\begin{array}{l}\text { Pauschal } \\
\text { Nach Bedarf + Grundfutteranalysen } \\
\text { Nach Empfehlung von }\end{array}$ \\
\hline $\begin{array}{l}\text { Welche Vitamine werden in } \\
\text { welcher Höhe ergänzt? }\end{array}$ & $\begin{array}{l}\text { Einzelpräparate } \\
\text { Mineralfutter (Firma, Bezeichnug) }\end{array}$ \\
\hline $\begin{array}{l}\text { Werden Sonderfuttermittel } \\
\text { eingesetzt? }\end{array}$ & Ja / nein \\
\hline $\begin{array}{l}\text { Wird Propylenglykol } \\
\text { eingesetzt? }\end{array}$ & Ja / nein \\
\hline
\end{tabular}




\begin{tabular}{|c|c|}
\hline Propylenglykol & $\begin{array}{l}\text { Tier } \\
\text { Zeitraum } \\
\text { Menge } \\
\text { Häufigkeit }\end{array}$ \\
\hline $\begin{array}{l}\text { Wird Natriumbicarbonat } \\
\text { eingesetzt? }\end{array}$ & Ja / nein \\
\hline Natriumbicarbonat & $\begin{array}{l}\text { Tier } \\
\text { Zeitraum } \\
\text { Menge } \\
\text { Häufigkeit }\end{array}$ \\
\hline $\begin{array}{l}\text { Werden geschützte Fette } \\
\text { eingesetzt? }\end{array}$ & Ja / nein \\
\hline Geschützte Fette & $\begin{array}{l}\text { Tier } \\
\text { Zeitraum } \\
\text { Menge } \\
\text { Häufigkeit }\end{array}$ \\
\hline $\begin{array}{l}\text { Welche anderen } \\
\text { Sonderfuttermittel werden } \\
\text { eingesetzt? }\end{array}$ & \\
\hline $\begin{array}{l}\text { Bekommen die Milchkühe } \\
\text { Weidegang? }\end{array}$ & Ja / nein \\
\hline $\begin{array}{l}\text { Welche Kühe gehen auf die } \\
\text { Weide? }\end{array}$ & $\begin{array}{l}\text { Trockensteher } \\
\text { Frischlaktierende } \\
\text { Altmelkende } \\
\text { Alle }\end{array}$ \\
\hline $\begin{array}{l}\text { Welche Art der } \\
\text { Weideführung machen Sie? }\end{array}$ & $\begin{array}{l}\text { Joggingweide } \\
\text { Standweide } \\
\text { Intensive Standweide } \\
\text { Portionsweide } \\
\text { Umtriebsweide }\end{array}$ \\
\hline
\end{tabular}




\begin{tabular}{|c|c|c|}
\hline $\begin{array}{l}\text { Wann wird mit dem } \\
\text { Anweiden begonnen? }\end{array}$ & Monat & \\
\hline $\begin{array}{l}\text { Wie lange sind die Kühe } \\
\text { beim Anweiden täglich auf } \\
\text { der Weide? }\end{array}$ & & h \\
\hline $\begin{array}{l}\text { Wann beginnt die } \\
\text { eigentliche Weideperiode? }\end{array}$ & Monat & \\
\hline $\begin{array}{l}\text { Weidedauer zwischen } 6 \text { Uhr } \\
\text { und } 18 \text { Uhr? }\end{array}$ & & r \\
\hline $\begin{array}{l}\text { Weidedauer zwischen } 18 \\
\text { Uhr und } 6 \text { Uhr? }\end{array}$ & & r \\
\hline $\begin{array}{l}\text { Wird das } \\
\text { Weidemanagement bei } \\
\text { Hitzeperioden geändert? }\end{array}$ & Ja / nein & \\
\hline $\begin{array}{l}\text { Wie wird das } \\
\text { Weidemanagement bei } \\
\text { Hitzeperioden geändert? }\end{array}$ & Nur noch NachtweideKein Weidegang & \\
\hline $\begin{array}{l}\text { Wann wird mit dem } \\
\text { Abweiden begonnen? }\end{array}$ & Monat & \\
\hline $\begin{array}{l}\text { Wie lange sind die Kühe } \\
\text { beim Abweiden täglich auf } \\
\text { der Weide? }\end{array}$ & & th \\
\hline $\begin{array}{l}\text { Wann endet die } \\
\text { Weideperiode? }\end{array}$ & Monat & \\
\hline $\begin{array}{l}\text { Wie wird die Weide } \\
\text { gepflegt? }\end{array}$ & $\begin{array}{l}\text { Nachsaat } \\
\text { Walzen } \\
\text { Schleppen } \\
\text { Nachmahd }\end{array}$ & \\
\hline
\end{tabular}




\begin{tabular}{|c|c|c|}
\hline $\begin{array}{l}\text { Wie viele TM nehmen die } \\
\text { Kühe von der Weide auf? }\end{array}$ & $\begin{array}{l}\text { Gewogen } \\
\text { Geschätzt } \\
\text { Unbekannt }\end{array}$ & $\mathrm{kg}$ \\
\hline $\begin{array}{l}\text { Wie weit müssen die Kühe } \\
\text { maximal laufen? }\end{array}$ & & $\mathrm{m}$ \\
\hline $\begin{array}{l}\text { Wird den Kühen auf der } \\
\text { Weide Wasser angeboten? }\end{array}$ & Ja / nein & \\
\hline Tränke Weide & $\begin{array}{l}\text { Oasetränke } \\
\text { Trogtränke } \\
\text { Schalentränke }\end{array}$ & \\
\hline $\begin{array}{l}\text { Wo sind die Tränken auf der } \\
\text { Weide positioniert? }\end{array}$ & $\begin{array}{l}\text { Anfang } \\
\text { Mitte } \\
\text { Ende }\end{array}$ & \\
\hline $\begin{array}{l}\text { Weiteste Entfernung zur } \\
\text { Tränke auf der Weide? }\end{array}$ & & $\mathrm{m}$ \\
\hline $\begin{array}{l}\text { Gibt es auf allen } \\
\text { Weideflächen Schatten für } \\
\text { die Kühe? }\end{array}$ & $\begin{array}{l}\text { Ja } \\
\text { Nein } \\
\text { Zeitweise }\end{array}$ & \\
\hline $\begin{array}{l}\text { Werten sie die MLP-Daten } \\
\text { aus, um eine } \\
\text { Rationskontrolle } \\
\text { durchzuführen? }\end{array}$ & Ja / nein & \\
\hline $\begin{array}{l}\text { Welche Daten werten sie } \\
\text { monatlich in der MLP aus, } \\
\text { um die Fütterung zu } \\
\text { kontrollieren? }\end{array}$ & $\begin{array}{l}\text { Milchleistung } \\
\text { Eiweiß \% } \\
\text { Fett \% } \\
\text { F-E-Quotient } \\
\text { Harnstoffgehalt }\end{array}$ & \\
\hline $\begin{array}{l}\text { Was ist ihrer Meinung nach } \\
\text { im Bereich der Fütterung } \\
\text { das Wichtigste? }\end{array}$ & & \\
\hline
\end{tabular}




\begin{tabular}{|c|c|}
\hline $\begin{array}{l}\text { Werden die Kühe vor einer } \\
\text { Kalbung trockengestellt? }\end{array}$ & Ja / nein \\
\hline $\begin{array}{l}\text { Wie lange sollen die Kühe } \\
\text { trockenstehen? }\end{array}$ & Wochen \\
\hline $\begin{array}{l}\text { Nach welchen Kriterien wird } \\
\text { trockengestellt? }\end{array}$ & MilchleistungGeplante Trockenstehzeit \\
\hline $\begin{array}{l}\text { Wird etwas unternommen, } \\
\text { um die Milchmenge vor dem } \\
\text { Trockenstellen zusätzlich zu } \\
\text { reduzieren? }\end{array}$ & Ja / nein \\
\hline $\begin{array}{l}\text { Ab welcher Milchmenge wird } \\
\text { trockengestellt? }\end{array}$ & $\begin{array}{l}\text { Egal } \\
\text { Milchmenge wird auf ____reduziert } \\
\text { Wenn die Milchmenge >__ dann wird } \\
\text { durchgemolken }\end{array}$ \\
\hline $\begin{array}{l}\text { Was wird unternommen, } \\
\text { damit die Kühe vor dem } \\
\text { Trockenstellen weniger } \\
\text { Milch geben? }\end{array}$ & \begin{tabular}{|l} 
Tage Kraftfutterreduzierung \\
auf_ $\mathrm{kg}$ \\
Tage Kraftfutterentzug \\
Tage reduzierte Grundfuttermenge \\
Tage nur Heu \\
Tage kein Wasser
\end{tabular} \\
\hline $\begin{array}{l}\text { Wird der Melkrhythmus vor } \\
\text { dem Trockenstellen } \\
\text { geändert? }\end{array}$ & $\begin{array}{l}\text { Nein } \\
1 \text { mal täglich } \\
\text { alle } 2 \text { Tage } \\
\text { Zeit der Änderung }\end{array}$ \\
\hline $\begin{array}{l}\text { Werden Trockensteller } \\
\text { eingesetzt? }\end{array}$ & Ja / nein \\
\hline $\begin{array}{l}\text { Wann werden Trockensteller } \\
\text { eingesetzt? }\end{array}$ & $\begin{array}{l}\text { Schalmtest positiv } \\
\text { Zellzahlen >__ in der letzten MLP } \\
\text { Bakt. Befunde } \\
\text { Mastitis in letzter Laktation } \\
\text { Generell }\end{array}$ \\
\hline
\end{tabular}




\begin{tabular}{|c|c|}
\hline $\begin{array}{l}\text { Welche Trockensteller } \\
\text { werden eingesetzt? }\end{array}$ & $\begin{array}{l}\text { Orbeseal } \\
\text { Orbenin } \\
\text { Benestermycin } \\
\text { Cobactan }\end{array}$ \\
\hline $\begin{array}{l}\text { Wird der Trockensteller } \\
\text { regelmäßig gewechselt? }\end{array}$ & Ja / nein \\
\hline $\begin{array}{l}\text { Häufigkeit } \\
\text { Trockenstellerwechsel }\end{array}$ & $\begin{array}{l}\text { Halbjährlich } \\
\text { Jährlich }\end{array}$ \\
\hline $\begin{array}{l}\text { Wird mit Kühen, die Flocken } \\
\text { haben, anders verfahren? }\end{array}$ & \\
\hline $\begin{array}{l}\text { Wird mit Kühen, die erhöhte } \\
\text { Zellgehalte haben, anders } \\
\text { verfahren? }\end{array}$ & \\
\hline $\begin{array}{l}\text { Werden die Zitzen zum } \\
\text { Trockenstellen versiegelt? }\end{array}$ & Ja / nein \\
\hline Zitzenversiegelung mit & $\begin{array}{l}\text { Dryflex } \\
\text { Anderes Dippmittel }\end{array}$ \\
\hline $\begin{array}{l}\text { Werden die Euter der Kühe } \\
\text { nach dem Trockenstellen } \\
\text { regelmäßig kontrolliert? }\end{array}$ & Ja / nein \\
\hline $\begin{array}{l}\text { Von wem werden die Euter } \\
\text { nach dem Trockenstellen } \\
\text { kontrolliert? }\end{array}$ & $\begin{array}{l}\text { Hauptverantwortliche } \\
\text { Melker } \\
\text { Tierarzt }\end{array}$ \\
\hline $\begin{array}{l}\text { Wie Kontrollieren Sie die } \\
\text { Euter der Trockensteher? }\end{array}$ & $\begin{array}{l}\text { Mit dem Auge } \\
\text { Abtasten } \\
\text { Abtasten, wenn das Euter unförmig }\end{array}$ \\
\hline $\begin{array}{l}\text { Kontrolle der Trockensteher } \\
\text { zum Beginn der } \\
\text { Trockenstehzeit }\end{array}$ & $\begin{array}{l}\text { _Tage täglich } \\
\text { Nach__ Tagen }\end{array}$ \\
\hline
\end{tabular}




\begin{tabular}{|c|c|c|}
\hline $\begin{array}{l}\text { Lassen die Kühe zu Beginn } \\
\text { der Trockenstehzeit die } \\
\text { Milch laufen? }\end{array}$ & Ja / nein & \\
\hline Wie lange? & & \\
\hline Wenn ja, Anteil? & & \\
\hline $\begin{array}{l}\text { Wie wird mit Kühen } \\
\text { umgegangen, die nach dem } \\
\text { Trockenstellen die Milch } \\
\text { laufen lassen? }\end{array}$ & $\begin{array}{l}\text { Erneut melken nach___ Tagen } \\
\text { Nach Anmelken wieder trockenstellen } \\
\text { Nichts } \\
\text { Tropfen rausmelken }\end{array}$ & \\
\hline $\begin{array}{l}\text { Werden die Trockensteher } \\
\text { besonders gefüttert / } \\
\text { behandelt, zur } \\
\text { Milchfieberprophyaxe? }\end{array}$ & Ja / nein & \\
\hline $\begin{array}{l}\text { Welches } \\
\text { Trockenstehermineral wird } \\
\text { gefüttert? }\end{array}$ & $\begin{array}{l}\text { Saure Salze } \\
\text { Enges Ca-P Verhältnis } \\
\text { Reines Phosphor } \\
\text { Ca-Boli }\end{array}$ & \\
\hline $\begin{array}{l}\text { Wie lange werden die } \\
\text { Trockensteher angefüttert? }\end{array}$ & & d \\
\hline $\begin{array}{l}\text { Mi-Fi-Prophyaxe in } \\
\text { Anfütterungszeit? }\end{array}$ & & \\
\hline $\begin{array}{l}\text { Werden die Euter der Kühe } \\
\text { vor der Kalbung regelmäßig } \\
\text { kontrolliert? }\end{array}$ & Ja / nein & \\
\hline $\begin{array}{l}\text { Wie werden die Euter vorm } \\
\text { Kalben kontrolliert? }\end{array}$ & $\begin{array}{l}\text { Mit dem Auge } \\
\text { Abtasten } \\
\text { Abtasten, wenn das Euter unförmig }\end{array}$ & \\
\hline Kontrolle der Trockensteher & Tage täglich & \\
\hline
\end{tabular}




\begin{tabular}{|c|c|}
\hline zum Kalben & Nach__ Tagen \\
\hline $\begin{array}{l}\text { Lassen die Kühe vor dem } \\
\text { Kalben die Milch laufen? }\end{array}$ & Ja / nein \\
\hline Wenn ja, Anteil? & \\
\hline Wenn ja, wie lange? & \\
\hline $\begin{array}{l}\text { Wie wird mit Kühen } \\
\text { umgegangen, die vor der } \\
\text { Kalbung die Milch laufen } \\
\text { lassen? }\end{array}$ & $\begin{array}{l}\text { Antibiotisch behandelt } \\
\text { Angemolken } \\
\text { Nicht anmelken }\end{array}$ \\
\hline $\begin{array}{l}\text { Werden die Kühe vor dem } \\
\text { Abkalben gedippt? }\end{array}$ & Ja / nein \\
\hline Dippen vor dem Kalben & $?$ \\
\hline $\begin{array}{l}\text { Was ist Ihrer Meinung nach } \\
\text { das Wichtigste bei den } \\
\text { trockenstehenden Kühen? }\end{array}$ & \\
\hline $\begin{array}{l}\text { Wird Wasser direkt noch } \\
\text { dem Kalben getränkt? }\end{array}$ & Ja / nein \\
\hline Tränke nach Kalbung & $\begin{array}{l}\text { Ad libitum } \\
\qquad \begin{array}{l}\text { Temperatur } \\
\text { Zusätze }\end{array}\end{array}$ \\
\hline $\begin{array}{l}\text { Bleiben die Kälber nach der } \\
\text { Geburt bei der Kuh? }\end{array}$ & Ja / nein \\
\hline $\begin{array}{l}\text { Wie lange bleiben die } \\
\text { Kälber nach der Geburt bei } \\
\text { der Kuh? }\end{array}$ & $\begin{array}{l}0,5 \text { Tage } \\
1 \text { Tag } \\
2 \text { Tage } \\
3 \text { Tage }\end{array}$ \\
\hline $\begin{array}{l}\text { Wird Milch mit hohen Zellen } \\
\text { an weibliche Kälber }\end{array}$ & Ja / nein \\
\hline
\end{tabular}




\begin{tabular}{|c|c|c|}
\hline vertränkt? & & \\
\hline $\begin{array}{l}\text { Wie werden die Kälber } \\
\text { getränkt? }\end{array}$ & $\begin{array}{l}\text { Nuckeleimer } \\
\text { Eimer } \\
\text { Rinne } \\
\text { Tränkeautomat }\end{array}$ & \\
\hline $\begin{array}{l}\text { Womit werden Kälber } \\
\text { getränkt? }\end{array}$ & $\begin{array}{l}\text { Biestmilch___ Tage } \\
\text { Vollmilch mit___ } \\
\text { Milchaustauscher }\end{array}$ & \\
\hline $\begin{array}{l}\text { Wie lange werden die } \\
\text { Kälber in Einzelboxen } \\
\text { gehalten? }\end{array}$ & $\begin{array}{r}7 \text { Tage } \\
14 \text { Tage } \\
\text { Wochen }\end{array}$ & \\
\hline $\begin{array}{l}\text { Gibt es manchmal Sauger } \\
\text { bei ihren Kälbern? }\end{array}$ & Ja / nein & \\
\hline $\begin{array}{l}\text { Was unternehmen Sie } \\
\text { gegen die Sauger? }\end{array}$ & $\begin{array}{l}\text { Nichts } \\
\text { Extra sperren } \\
\text { Nasenring } \\
\text { Andere Maßnahme }\end{array}$ & \\
\hline $\begin{array}{l}\text { Wie lange bleiben die Euter } \\
\text { nach dem Kalben } \\
\text { geschwollen? }\end{array}$ & $\begin{array}{l}1 \text { Tag } \\
3 \text { Tage } \\
1 \text { Woche } \\
2 \text { Wochen }\end{array}$ & \\
\hline $\begin{array}{l}\text { Haben Sie dreistrichige } \\
\text { Färsen im Bestand? }\end{array}$ & Ja / nein & \\
\hline $\begin{array}{l}\text { Wie hoch ist der Anteil an } \\
\text { dreistrichigen Färsen? }\end{array}$ & & $\%$ \\
\hline $\begin{array}{l}\text { Wann werden die Färsen in } \\
\text { die Herde integriert? }\end{array}$ & $\begin{array}{l}\text { Vor der Geburt } \\
\text { Nach der Geburt }\end{array}$ & \\
\hline Integration der Färsen & $\begin{array}{l}\text { Tage vor der Geburt } \\
\text { Einzeln } \\
\text { Als Gruppe von ___ Tieren }\end{array}$ & \\
\hline
\end{tabular}




\begin{tabular}{|c|c|}
\hline $\begin{array}{l}\text { Werden die Färsen vor dem } \\
\text { Abkalben gedippt? }\end{array}$ & Ja / nein \\
\hline $\begin{array}{l}\text { Dippen der Färsen vor dem } \\
\text { Abkalben mit }\end{array}$ & $\begin{array}{l}\text { Dryflex } \\
\text { Spezielles Dippmittel } \\
\text { Beim Melken }\end{array}$ \\
\hline $\begin{array}{l}\text { Werden die Färsen vor der } \\
\text { Kalbung behandelt? }\end{array}$ & Ja / nein \\
\hline $\begin{array}{l}\text { Behandlung der Färsen vor } \\
\text { der Kalbung }\end{array}$ & $\begin{array}{l}\text { Orbeseal } \\
\text { Dryflex } \\
\text { Orbenin } \\
\text { Benestermycin } \\
\text { Cobactan } \\
\text { Laktations Antibiotikum } \\
\text { Angemolken }\end{array}$ \\
\hline $\begin{array}{l}\text { Werden die Euter der } \\
\text { Färsen vor der Kalbung } \\
\text { regelmäßig kontrolliert? }\end{array}$ & Ja / nein \\
\hline $\begin{array}{l}\text { Kontrolle der Euter der } \\
\text { Färsen vor der Kalbung }\end{array}$ & $\begin{array}{l}\text { Beginn__ Tage vor der Geburt } \\
\text { jeden__ Tag }\end{array}$ \\
\hline $\begin{array}{l}\text { Lassen die Färsen vor dem } \\
\text { Kalben die Milch laufen? }\end{array}$ & Ja / nein \\
\hline Wenn ja, Anteil? & \\
\hline $\begin{array}{l}\text { Wie wird mit Färsen } \\
\text { umgegangen, die vor der } \\
\text { Kalbung die Milch } \\
\text { laufenlassen? }\end{array}$ & $\begin{array}{l}\text { Keine besondere Behandlung } \\
\text { Antibiotisch behandelt } \\
\text { Angemolken }\end{array}$ \\
\hline $\begin{array}{l}\text { Was ist ihrer Meinung nach } \\
\text { im Bereich der } \\
\text { Färsenaufzucht besonders } \\
\text { zu beachten? }\end{array}$ & \\
\hline
\end{tabular}




\begin{tabular}{|c|c|c|}
\hline $\begin{array}{l}\text { Wird künstliche Besamung } \\
\text { durchgeführt? }\end{array}$ & Ja / nein & \\
\hline $\begin{array}{l}\text { Wer wählt die Bullen zur } \\
\text { Zucht aus? }\end{array}$ & $\begin{array}{l}\text { Hauptverantwortlicher } \\
\text { Melker } \\
\text { Zuchtinspektor } \\
\text { Besamungstechniker }\end{array}$ & \\
\hline $\begin{array}{l}\text { Von welchem Verband } \\
\text { werden Bullen eingesetzt? }\end{array}$ & $\begin{array}{l}\text { Nordrind } \\
\text { Osnabrücker Herdbuch } \\
\text { ARL } \\
\text { Ostfriesische Stammviehzüchter }\end{array}$ & \\
\hline $\begin{array}{l}\text { Wonach werden Bullen zur } \\
\text { Zucht ausgewählt? }\end{array}$ & $\begin{array}{l}\text { Milchleistung } \\
\text { Inhaltsstoffe } \\
\text { Melkbarkeit }\end{array}$ & \\
\hline $\begin{array}{l}\text { Welches sind zur Zeit die } \\
\text { am meisten eingesetzten } \\
\text { Bullen? }\end{array}$ & & \\
\hline $\begin{array}{l}\text { Wonach werden die Färsen } \\
\text { ausgewählt, die zur } \\
\text { Bestandsergänzung im } \\
\text { Betrieb bleiben? }\end{array}$ & $\begin{array}{l}\text { Einsatzleistung } \\
\text { Abstammung } \\
\text { Leistung der Mutter } \\
\text { Euterform } \\
\text { Melkbarkeit }\end{array}$ & \\
\hline $\begin{array}{l}\text { Wie lange wird diese } \\
\text { Zuchtrichtung im Betrieb } \\
\text { angewendet? }\end{array}$ & & Jahre \\
\hline $\begin{array}{l}\text { Was ist ihrer Meinung nach } \\
\text { im Bereich der Zucht } \\
\text { besonders zu beachten, um } \\
\text { eine gute Eutergesundheit } \\
\text { zu erlangen? }\end{array}$ & & \\
\hline Werden Managementhilfen & Ja / nein & \\
\hline
\end{tabular}




\begin{tabular}{|c|c|c|}
\hline $\begin{array}{l}\text { im Bereich der } \\
\text { Tiergesundheit benutzt? }\end{array}$ & & \\
\hline $\begin{array}{l}\text { Managementhilfen im } \\
\text { Bereich der Tiergesundheit }\end{array}$ & $\begin{array}{l}\text { Behandlungsbuch } \\
\text { Auswertung des Behandl.buch nach } \\
\text { Einzeltieren } \\
\text { Auswertung des Behandl.buch nach } \\
\text { Krankheiten } \\
\text { Andere Aufzeichungen }\end{array}$ & \\
\hline $\begin{array}{l}\text { Werden Impfprogramme } \\
\text { durchgeführt? }\end{array}$ & $\begin{array}{l}\text { IBR } \\
\text { BVD } \\
\text { Roter Korona }\end{array}$ & \\
\hline $\begin{array}{l}\text { Haben Sie BVD im } \\
\text { Bestand? }\end{array}$ & $\begin{array}{l}\text { Status unbekannt } \\
\text { BVD vorhanden } \\
\text { BVD geimpft } \\
\text { BVD frei }\end{array}$ & \\
\hline Haben Sie IBR im Bestand? & $\begin{array}{l}\text { Status unbekannt } \\
\text { IBR vorhanden } \\
\text { IBR geimpft } \\
\text { IBR frei }\end{array}$ & \\
\hline $\begin{array}{l}\text { Anzahl der Erkrankungen } \\
\text { der Kühe im letzten Jahr: }\end{array}$ & $\begin{array}{l}\text { Eutergesundheit Zellen } \\
\text { Eutergesundheit Flocken } \\
\text { Euterge Flocken + Schwellung } \\
\text { Euterge Flo + Schwel + Fieber } \\
\text { Eutergesundheit Strichverletzungen } \\
\text { Nachgeburtsverhaltungen } \\
\text { Gebärmutterbehandlungen } \\
\text { Fruchtbarkeit } \\
\text { Milchfieber } \\
\text { Labmagen } \\
\text { Stoffwechsel } \\
\text { Panaritium } \\
\text { Mortellaro }\end{array}$ & Stk \\
\hline
\end{tabular}




\begin{tabular}{|c|c|c|}
\hline & $\begin{array}{l}\text { Lahmheiten } \\
\text { Sonstige }\end{array}$ & \\
\hline Stallbuch & & Stk \\
\hline $\begin{array}{l}\text { Gibt es ein standardisiertes } \\
\text { Fruchtbarkeitsmanagement? }\end{array}$ & Ja / nein & \\
\hline $\begin{array}{l}\text { Standard } \\
\text { Fruchtbarkeitsmanagement }\end{array}$ & $\begin{array}{l}\text { Temperaturkontrolle pp } \\
\text { Unters., ob Kuh aufnahmebereit } \\
\text { Anspritzen } \\
\text { 1x Besamen } \\
\text { Doppelbesamung } \\
\text { Trächtigkeitsuntersuchungen }\end{array}$ & \\
\hline $\begin{array}{l}\text { Welche Managementhilfen } \\
\text { werden im Bereich der } \\
\text { Fruchtbarkeit benutzt? }\end{array}$ & $\begin{array}{l}\text { Brunstkalender } \\
\text { Besamungskarten } \\
\text { Besamungskarten mit Karteikasten } \\
\text { Herdenführungsprogramm } \\
\text { Schrittzähler der Kühe } \\
\text { Kontaktfenster zu Bullen }\end{array}$ & \\
\hline $\begin{array}{l}\text { Wird regelmäßig } \\
\text { Klauenpflege gemacht? }\end{array}$ & Ja / nein & \\
\hline Häufigkeit Klauenpflege & $\begin{array}{l}\text { Halbjährlich } \\
\text { Jährlich }\end{array}$ & \\
\hline $\begin{array}{l}\text { Wer macht die Klauenpflege } \\
\text { routinemäßig? }\end{array}$ & $\begin{array}{l}\text { Verantwortlich für das Melken } \\
\text { Professioneller Klauenpfleger } \\
\text { Tierarzt }\end{array}$ & \\
\hline $\begin{array}{l}\text { Wer macht die Klauenpflege } \\
\text { bei Bedarf? }\end{array}$ & $\begin{array}{l}\text { Hauptverantwortlicher } \\
\text { Professioneller Klauenpfleger } \\
\text { Tierarzt }\end{array}$ & \\
\hline $\begin{array}{l}\text { Wo treten Lahmheiten } \\
\text { vornehmlich auf? }\end{array}$ & $\begin{array}{l}\text { Vorne } \\
\text { Hinten } \\
\text { Vorne und Hinten }\end{array}$ & $\%$ \\
\hline
\end{tabular}




\begin{tabular}{|c|c|}
\hline $\begin{array}{l}\text { Haben sie Tiere mit } \\
\text { Mortellaro? }\end{array}$ & Ja / nein \\
\hline $\begin{array}{l}\text { Haben sie Tiere mit } \\
\text { Panaritium }\end{array}$ & Ja / nein \\
\hline $\begin{array}{l}\text { Wie lange haben sie schon } \\
\text { eine so gute } \\
\text { Eutergesundheit? }\end{array}$ & 1 Jahr2 Jahre3 Jahre \\
\hline $\begin{array}{l}\text { Was haben Sie } \\
\text { unternommen, um einen so } \\
\text { guten } \\
\text { Eutergesundheitsstatus zu } \\
\text { erlangen? }\end{array}$ & \\
\hline $\begin{array}{l}\text { Ab welchem Zellgehalt } \\
\text { sprechen sie bei einer Kuh } \\
\text { von erhöhter Zellzahl? }\end{array}$ & $\begin{array}{l}\text { Milchkühe } \\
\text { Färsen } \\
\text { Zum Ende der Laktation }\end{array}$ \\
\hline $\begin{array}{l}\text { Gibt es eine Extragruppe für } \\
\text { euterkranke Tiere? }\end{array}$ & Ja / nein \\
\hline Gründe für Krankengruppe & $\begin{array}{l}\text { Bestimmte Erreger } \\
\text { Hohe Zellen } \\
\text { Chronische Tiere }\end{array}$ \\
\hline Wo ist die Krankengruppe? & $\begin{array}{l}\text { Direkter Kontakt } \\
\text { Im gleichen Stall } \\
\text { Im anderen Stall }\end{array}$ \\
\hline $\begin{array}{l}\text { Wann wird die } \\
\text { Krankengruppe gemolken? }\end{array}$ & $\begin{array}{l}\text { Vor den anderen } \\
\text { Mit den anderen } \\
\text { Nach den anderen }\end{array}$ \\
\hline $\begin{array}{l}\text { Wenn Krankengruppe } \\
\text { vorher oder mittendrin } \\
\text { gemolken wird, gibt es eine } \\
\text { Desinfektion? }\end{array}$ & Ja / nein \\
\hline
\end{tabular}




\begin{tabular}{|c|c|c|}
\hline $\begin{array}{l}\text { Ist mangelhafte } \\
\text { Eutergesundheit ein Grund, } \\
\text { Kühe zum Schlachter zu } \\
\text { geben? }\end{array}$ & Ja / nein & \\
\hline $\begin{array}{l}\text { Wann muss eine Kuh mit } \\
\text { mangelhafter } \\
\text { Eutergesundheit den Betrieb } \\
\text { verlassen? }\end{array}$ & $\begin{array}{l}\text { Erregernachweis mit } \\
\text { Aktueller Zellgehalt } \\
\begin{array}{l}\text { ab_Zellen } \\
\text { Wiederholt Zellgehalte > } \\
\text { mal }\end{array} \\
\text { Zusätzlich nicht tragend } \\
\text { Zusätzlich lahmend } \\
\text { Zusätzlich schwer melkend }\end{array}$ & \\
\hline $\begin{array}{l}\text { Anzahl laktierender Kühe im } \\
\text { letzten Monat }\end{array}$ & & \\
\hline $\begin{array}{l}\text { Wie hoch war die klinische } \\
\text { Infektionsrate für Mastitis im } \\
\text { letzten Monat? }\end{array}$ & \begin{tabular}{|l} 
Neu erkrank. Tiere, kl. Flocken \\
Neu erkr T., kl. Flo + Schw \\
N. er T., kl. Flo + Schw + Fieber \\
Neu erkrankte Tiere, eitrig \\
Chronisch erkrankte Tiere \\
mal/Monat
\end{tabular} & Stk \\
\hline $\begin{array}{l}\text { Wie hoch war die klinische } \\
\text { Infektionsrate für Mastitis in } \\
\text { den letzten } 12 \text { Monaten? }\end{array}$ & \begin{tabular}{|l} 
Neu erkrank. T., kl. Flocken \\
Neu erkr T., kl. Flo + Schw \\
N. er T., kl. Flo + Schw + Fieber \\
Neu erkrankte Tiere, eitrig \\
Chronisch erkrankte Tiere \\
mal/Monat
\end{tabular} & Stk \\
\hline $\begin{array}{l}\text { Werten sie die MLP-Daten } \\
\text { aus, um eine Überblick über } \\
\text { die Eutergesundheit zu } \\
\text { bekommen? }\end{array}$ & Ja / nein & \\
\hline
\end{tabular}




\begin{tabular}{|c|c|}
\hline $\begin{array}{l}\text { MLP im Bezug auf die } \\
\text { Eutergesundheit }\end{array}$ & $\begin{array}{l}\text { Zellgehalt nach Laktationsgruppen } \\
\text { Zellgehalt von Einzeltieren } \\
\text { Entwicklung Zellgehalt von Einzeltieren }\end{array}$ \\
\hline $\begin{array}{l}\text { Gibt es ein festes Schema } \\
\text { für Milchkühe, die erstmalig } \\
\text { Flocken haben? }\end{array}$ & Ja / nein \\
\hline $\begin{array}{l}\text { Verfahren für Tiere, die } \\
\text { erstmalig "Flocken" haben }\end{array}$ & $\begin{array}{l}\text { Es wird nichts unternommen } \\
\text { MLP abwarten } \\
\text { Ab welchem Zellgehalt werden sie tätig? } \\
\text { Viertelgemelksprobe einsenden } \\
\text { Labor: } \\
\text { Von Hand ausmelken } \\
\text { Temperatur messen } \\
\text { Schalmtest } \\
\text { Äußerlich behandeln mit } \\
\text { Innerlich Behandeln mit } \\
\text { Im Euter behandeln mit } \\
\text { Euter abtasten } \\
\text { Zuletzt melken } \\
\text { Melkzeug reinigen mit }\end{array}$ \\
\hline $\begin{array}{l}\text { Gibt es ein standardisiertes } \\
\text { Verfahren für Milchkühe, die } \\
\text { erstmalig über } 100.000 \\
\text { Zellen in der MLP haben? }\end{array}$ & Ja / nein \\
\hline $\begin{array}{l}\text { Verfahren für Tiere, die } \\
\text { erstmalig eine subklinische } \\
\text { Infektion haben }\end{array}$ & $\begin{array}{l}\text { Es wird nichts unternommen } \\
\text { Ab welchem Zellgehalt werden sie tätig? } \\
\text { Viertelgemelksprobe einsenden } \\
\text { Labor: } \\
\text { Von Hand ausmelken } \\
\text { Temperatur messen } \\
\text { Schalmtest } \\
\text { Äußerlich behandeln mit }\end{array}$ \\
\hline
\end{tabular}




\begin{tabular}{|c|c|}
\hline & $\begin{array}{l}\text { Innerlich Behandeln mit } \\
\text { Im Euter behandeln mit } \\
\text { Euter abtasten } \\
\text { Zuletzt melken } \\
\text { Melkzeug reinigen mit }\end{array}$ \\
\hline $\begin{array}{l}\text { Gibt es ein standardisiertes } \\
\text { Verfahren für Milchkühe, die } \\
\text { immer wieder Flocken } \\
\text { haben? }\end{array}$ & Ja / nein \\
\hline $\begin{array}{l}\text { Verfahren für Tiere, die } \\
\text { chronisch klinische } \\
\text { Infektionen haben }\end{array}$ & $\begin{array}{l}\text { Es wird nichts unternommen } \\
\text { MLP abwarten } \\
\text { Ab welchem Zellgehalt werden sie tätig? } \\
\text { Viertelgemelksprobe einsenden } \\
\text { Labor: } \\
\text { Von Hand ausmelken } \\
\text { Temperatur messen } \\
\text { Schalmtest } \\
\text { Äußerlich behandeln mit } \\
\text { Innerlich Behandeln mit } \\
\text { Im Euter behandeln mit } \\
\text { Euter abtasten } \\
\text { Zuletzt melken } \\
\text { Melkzeug reinigen mit }\end{array}$ \\
\hline $\begin{array}{l}\text { Gibt es ein standardisierte } \\
\text { Verfahren für Milchkühe, die } \\
\text { regelmäßig über } 100.000 \\
\text { Zellen in der MLP haben? }\end{array}$ & Ja / nein \\
\hline $\begin{array}{l}\text { Verfahren für Tiere, die } \\
\text { chronisch subklinische } \\
\text { Infektionen haben }\end{array}$ & $\begin{array}{l}\text { Es wird nichts unternommen } \\
\text { MLP abwarten } \\
\text { Ab welchem Zellgehalt werden sie tätig? } \\
\text { Bakt. Befund einsenden } \\
\text { Labor: }\end{array}$ \\
\hline
\end{tabular}




\begin{tabular}{|c|c|}
\hline & $\begin{array}{l}\text { Von Hand ausmelken } \\
\text { Temperatur messen } \\
\text { Schalmtest } \\
\text { Äußerlich behandeln mit } \\
\text { Innerlich Behandeln mit } \\
\text { Im Euter behandeln mit } \\
\text { Euter abtasten } \\
\text { Zuletzt melken } \\
\text { Melkzeug reinigen mit }\end{array}$ \\
\hline $\begin{array}{l}\text { Wird regelmäßig ein } \\
\text { Schalmtest durchgeführt? }\end{array}$ & Ja / nein \\
\hline Häufigkeit Schalmtest & $\begin{array}{l}\text { monatlich } \\
\text { halbjährlich } \\
\text { jährlich }\end{array}$ \\
\hline $\begin{array}{l}\text { Von welchen Tiere wird } \\
\text { regelmäßig ein Schalmtest } \\
\text { gemacht? }\end{array}$ & $\begin{array}{l}\text { Färsen }>\_ \text {Zellen } \\
\text { Kühe }>\_ \text {Zellen } \\
\text { Chronisch mit Flocken } \\
\% \text { der Herde } \\
\text { Immer vor dem Trockenstellen } \\
\text { Immer nach dem Kalben }\end{array}$ \\
\hline $\begin{array}{l}\text { Werden regelmäßig bakt. } \\
\text { Befunde erhoben? }\end{array}$ & Ja / nein \\
\hline Häufigkeit bakt. Befunde & $\begin{array}{l}\text { monatlich } \\
\text { halbjährlich } \\
\text { jährlich } \\
\text { immer vor dem Trockenstellen }\end{array}$ \\
\hline $\begin{array}{l}\text { Von welchen Tiere werden } \\
\text { regelmäßig bakt. Befunde } \\
\text { erhoben? }\end{array}$ & $\begin{array}{c}>\quad \text { Zellen } \\
\text { Chronisch mit Flocken } \\
\% \text { der Herde }\end{array}$ \\
\hline $\begin{array}{l}\text { Gibt es ein "Standard- } \\
\text { Antibiotikum"? }\end{array}$ & Ja / nein \\
\hline
\end{tabular}




\begin{tabular}{|c|c|}
\hline $\begin{array}{l}\text { Wird das "Standard- } \\
\text { Antibiotikum" regelmäßig } \\
\text { gewechselt? }\end{array}$ & $\begin{array}{l}\text { nein } \\
\text { halbjährlich } \\
\text { jährlich }\end{array}$ \\
\hline $\begin{array}{l}\text { Welche Mastitiserreger } \\
\text { wurden in den letzten } 12 \\
\text { Monaten nachgewiesen? }\end{array}$ & $\begin{array}{l}\text { Staph. aureus } \\
\text { Strept. agalactiae } \\
\text { Strept. dysgalactiae } \\
\text { Strept. uberis } \\
\text { Enterokokken } \\
\text { Coliforme Keime } \\
\text { Koagulase negative Staph. }\end{array}$ \\
\hline $\begin{array}{l}\text { Welche Mastitiserreger } \\
\text { wurden in den letzten } 3 \\
\text { Jahren nachgewiesen? }\end{array}$ & $\begin{array}{l}\text { Staph. aureus } \\
\text { Strept. agalactiae } \\
\text { Strept. dysgalactiae } \\
\text { Strept. uberis } \\
\text { Enterokokken } \\
\text { Coliforme Keime } \\
\text { Koagulase negative Staph. }\end{array}$ \\
\hline $\begin{array}{l}\text { Wie wird mit Infektionen } \\
\text { durch kuhassoziierte } \\
\text { Erreger verfahren? }\end{array}$ & $\begin{array}{l}\text { Extra Gruppe } \\
\text { Behandlung mit } \\
\text { Extra melken }\end{array}$ \\
\hline $\begin{array}{l}\text { Wie wird mit Infektionen } \\
\text { durch umweltassoziierten } \\
\text { Erreger verfahren? }\end{array}$ & $\begin{array}{l}\text { Extra Gruppe } \\
\text { Behandlung mit } \\
\text { Extra melken }\end{array}$ \\
\hline $\begin{array}{l}\text { Was hat Ihrer Meinung nach } \\
\text { das Wichtigste im Bereich } \\
\text { der Euterbehandlung, um } \\
\text { eine gute Eutergesundheit } \\
\text { zu erlangen? }\end{array}$ & \\
\hline $\begin{array}{l}\text { Wird jährlich eine } \\
\text { Betriebszweigauswertung } \\
\text { gemacht? }\end{array}$ & Ja / nein \\
\hline
\end{tabular}




\begin{tabular}{|c|c|c|}
\hline $\begin{array}{l}\text { Tierarztkosten } \\
\text { Milchkühe/Jahr }\end{array}$ & $<50,<100,<150,<200$ & Euro \\
\hline Tierarztkosten Rinder/Jahr & & Euro \\
\hline $\begin{array}{l}\text { Gewinn Betriebszweig } \\
\text { Milchviehhaltung? }\end{array}$ & & Euro \\
\hline DB/ Kuh & & Euro \\
\hline $\begin{array}{l}\text { Was ist ihrer Meinung nach } \\
\text { ihr Erfolgsrezept für die gute } \\
\text { Eutergesundheit? }\end{array}$ & & \\
\hline Futteranalysen & & \\
\hline Rationsberechnung & & \\
\hline Stallbuch & LDW & \\
\hline Stallbuch & Tierarzt & \\
\hline Baktbefunde & & \\
\hline Tierarztkosten & & \\
\hline Unterschrift EV-Erklärung & & \\
\hline $\begin{array}{l}\text { Anzahl Kühe mit wenigstens } \\
1 \text { Gliedmaße in der } \\
\text { Liegebox nicht liegend } 2 \mathrm{~h} \\
\text { nach dem Melken }\end{array}$ & & \\
\hline $\begin{array}{l}\text { Anzahl liegender Kühe nicht } \\
\text { kauend } 2 \mathrm{~h} \text { nach dem } \\
\text { Melken }\end{array}$ & & \\
\hline $\begin{array}{l}\text { Liegende und } \\
\text { wiederkauende Kühe } 2 \mathrm{~h} \\
\text { nach dem Melken }\end{array}$ & & \\
\hline $\begin{array}{l}\text { Kauschläge pro Bissen } 2 \mathrm{~h} \\
\text { nach dem Melken }\end{array}$ & & Anz \\
\hline
\end{tabular}


Vor dem Melken

\begin{tabular}{|c|c|}
\hline $\begin{array}{l}\text { Anzahl Kühe mit } \\
\text { wenigstens } 1 \text { Gliedmaße } \\
\text { in der Liegebox nicht } \\
\text { liegend }\end{array}$ & \\
\hline $\begin{array}{l}\text { Anzahle liegender Kühe } \\
\text { nicht kauend }\end{array}$ & \\
\hline $\begin{array}{l}\text { Liegende und } \\
\text { Wiederkauende Kühe vor } \\
\text { dem melken? }\end{array}$ & \\
\hline Melkzeit & \\
\hline $\begin{array}{l}\text { Beginn der besuchten } \\
\text { Melkzeit Licht an? }\end{array}$ & \\
\hline Evakuierzeit & Ventile offen \\
\hline $\begin{array}{l}\text { (Zeit von Anschalten bis } \\
\text { Betriebsvakuum) }\end{array}$ & Ventile geschlossen \\
\hline $\begin{array}{l}\text { Melkvakuum nach } \\
\text { Anzeige }\end{array}$ & \\
\hline Nummer Lactocorder & \\
\hline Beginn des Melkens? & \\
\hline $\begin{array}{l}\text { Was passiert bis zum } \\
\text { Ansetzen des } \\
\text { Melkzeuges in welcher } \\
\text { Reihenfolge? }\end{array}$ & $\begin{array}{l}\text { Vormelken } \\
\text { Reinigen } \\
\text { Warten } \\
\text { Ansetzen }\end{array}$ \\
\hline Wie wird vorgemolken? & $\begin{array}{l}\text { Kontrolle im Vormelkbecher } \\
\text { Vorgemelk auf Boden }\end{array}$ \\
\hline Womit wird vorgereinigt? & $\begin{array}{l}\text { Pre-Dipp (Marke) } \\
\text { Trockene Tücher } \\
\text { feuchte Tücher }\end{array}$ \\
\hline
\end{tabular}




\begin{tabular}{|c|c|}
\hline $\begin{array}{l}\text { Für wie viele Tiere wird } \\
\text { ein Eutertuch verwand? }\end{array}$ & $\begin{array}{l}\text { Einmalig } \\
\text { Zweimalig } \\
\text { Mehrmals }\end{array}$ \\
\hline $\begin{array}{l}\text { Luftsaugen beim } \\
\text { Ansetzen }\end{array}$ & $\begin{array}{l}\text { Ohne Luft (<1 sec) } \\
\text { mit Luft }(2 \mathrm{sec}) \\
\text { mit viel Luft (>2 se }\end{array}$ \\
\hline $\begin{array}{l}\text { Abnahme des } \\
\text { Melkzeuges }\end{array}$ & $\begin{array}{l}\text { Kontrollgriff } \\
\text { Abschalten des Vakuums } \\
\text { Belüften des Sammelstücks } \\
\text { sanftes Abnehmen des Melkzeuges }\end{array}$ \\
\hline $\begin{array}{l}\text { Welche Pflege- und oder } \\
\text { Desinfektionsmaßnahmen } \\
\text { finden nach der Abnahme } \\
\text { des Melkzeuges statt? } \\
\text { (Mittel angeben) }\end{array}$ & $\begin{array}{l}\text { Nichts } \\
\text { Desinfizieren } \\
\text { Pflegen } \\
\text { Desinfizieren und Pflegen }\end{array}$ \\
\hline $\begin{array}{l}\text { Wie wird gepflegt / } \\
\text { desinfiziert? }\end{array}$ & $\begin{array}{l}\text { Einschmieren } \\
\text { Dippen } \\
\text { Sprühen }\end{array}$ \\
\hline
\end{tabular}


Datenaufnahme Melkzeit

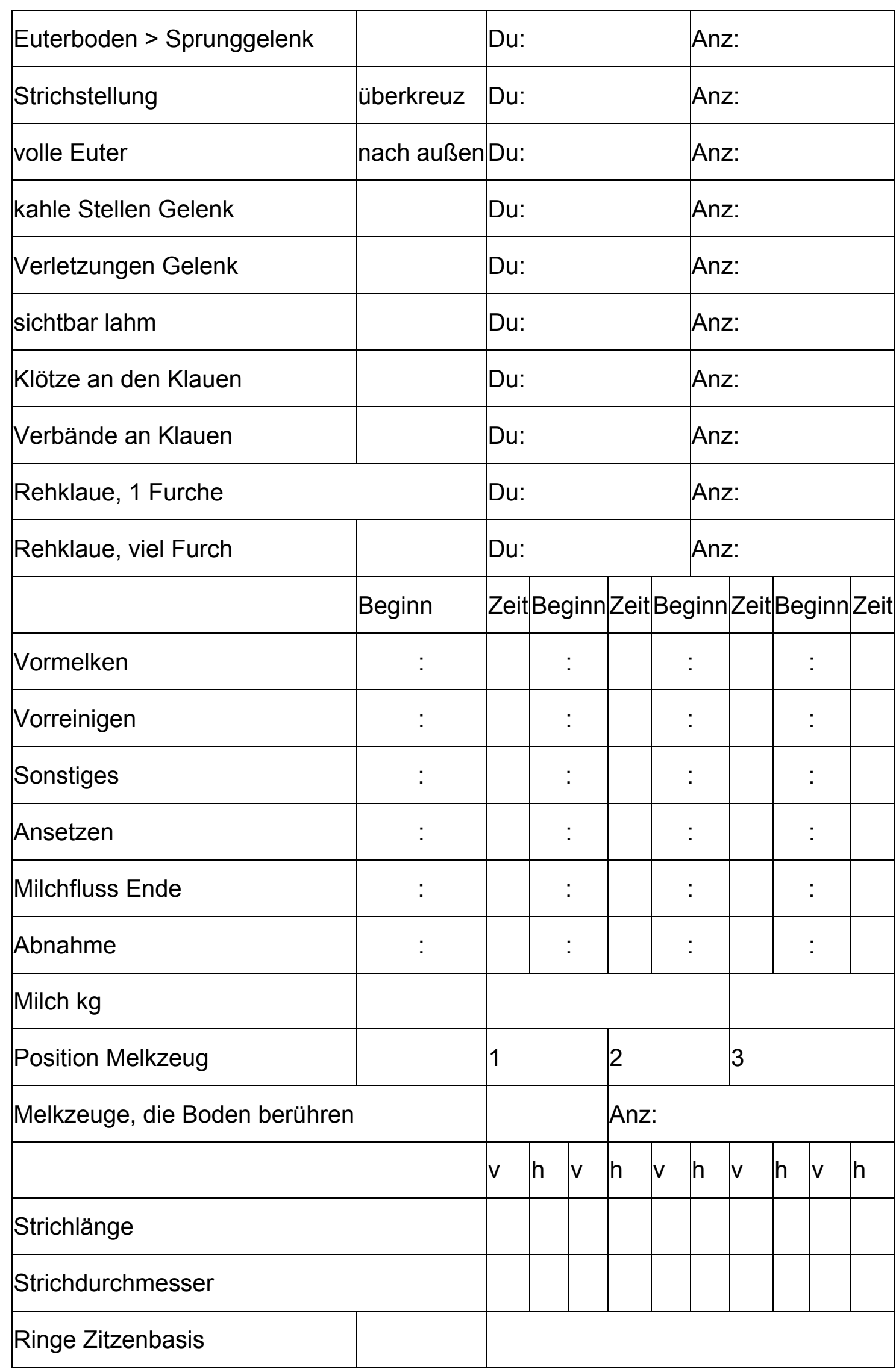




\begin{tabular}{|c|c|c|c|}
\hline Hyper- & 1 nor & & \\
\hline \multirow[t]{3}{*}{ keratosen } & $2 \mathrm{kl} \mathrm{w}$ & & \\
\hline & $3 \mathrm{kl} \mathrm{Fr}$ & & \\
\hline & 4 r Fr & & \\
\hline \multicolumn{4}{|l|}{ blaue Zitzen } \\
\hline \multicolumn{4}{|l|}{ Blutungen Striche } \\
\hline Restmilch & $\mathrm{ml}$ & & \\
\hline \multicolumn{4}{|l|}{ Koten beim Melken } \\
\hline \multicolumn{4}{|l|}{ Harnen beim Melken } \\
\hline \multicolumn{4}{|l|}{ Abwehr Ansetzen } \\
\hline Wiederk. b. Melken & & Du: & Anz: \\
\hline \multicolumn{4}{|l|}{ Strichverletzungen } \\
\hline \multicolumn{4}{|l|}{ Warzen Striche } \\
\hline \multicolumn{4}{|l|}{ Abfallen Melkzeuge } \\
\hline \multicolumn{4}{|l|}{ Abgetretene Melkzeug } \\
\hline \multicolumn{4}{|l|}{ Slippen Melkzeug } \\
\hline \multicolumn{4}{|l|}{ V. Hand nachgemolken } \\
\hline Mit Bügel gemolken & & & \\
\hline
\end{tabular}


Datenaufnahme Melkzeit

\begin{tabular}{|c|c|c|c|c|c|c|c|c|c|c|c|c|c|c|}
\hline & Beginn & Zeit & Beginn & n'Zeit & Beginn & Zeit & Beginn & nZeit & Beginn & Zeit E & Beginn & Zeit|E & Beginn & Zeit \\
\hline Vormelken & : & & : & & : & & : & & : & & : & & : & \\
\hline Vorreinigen & : & & : & & : & & : & & : & & : & & : & \\
\hline Sonstiges & : & & : & & : & & : & & : & & : & & : & \\
\hline Ansetzen & : & & : & & : & & : & & : & & : & & : & \\
\hline Milchfl Ende & : & & : & & : & & : & & : & & : & & : & \\
\hline Abnahme & : & & : & & : & & : & & : & & : & & : & \\
\hline Milch kg & : & & : & & : & & : & & : & & : & & : & \\
\hline
\end{tabular}

\begin{tabular}{|c|c|c|c|c|c|c|c|c|c|c|c|c|c|c|}
\hline & Beginn & Zeit & Beginn & Zeit & Beginn & Zeit & Beginn & Zeit & Beginn & Zeit & Beginn & Zeit & Beginn & Zeit \\
\hline Vormelken & : & & : & & : & & : & & : & & : & & : & \\
\hline Vorreinigen & : & & : & & : & & : & & : & & : & & : & \\
\hline Sonstiges & : & & : & & : & & : & & : & & $:$ & & : & \\
\hline Ansetzen & : & & : & & : & & : & & : & & : & & : & \\
\hline Milchfl Ende & : & & : & & : & & : & & : & & : & & : & \\
\hline Abnahme & : & & : & & : & & : & & : & & : & & : & \\
\hline Milch kg & : & & . & & : & & : & & : & & . & & : & \\
\hline
\end{tabular}


Datenaufnahme Melkzeit

\begin{tabular}{|c|c|c|}
\hline Sind die Tiere überwiegend sauber? & ja / nein & \\
\hline \multicolumn{3}{|l|}{ Euter (1-6) } \\
\hline \multicolumn{3}{|l|}{ Klauen (1-6) } \\
\hline \multicolumn{3}{|l|}{ Beine bis Sprunggelenk (1-6) } \\
\hline \multicolumn{3}{|l|}{ Schwanz (1-6) } \\
\hline \multicolumn{3}{|l|}{ Flanken (1-6) } \\
\hline Sind die Euterhaare abgeschoren? & ja / nein & \\
\hline Lautstärke beim Melken & $\mathrm{db}$ & \\
\hline Läuft das Radio beim Melken? & ja / nein & \\
\hline Helligkeit im Melkstand am Euter der Kuh & lux & \\
\hline Helligkeit in Melkgrube & lux & \\
\hline \multirow[t]{2}{*}{ Vakuum messen nass } & kPA & mitte \\
\hline & kPA & schwanku \\
\hline \multirow[t]{4}{*}{ Pulsation } & Takte & \\
\hline & simultan & wechsel \\
\hline & $E$ & M \\
\hline & $\mathrm{F}$ & \\
\hline \multirow[t]{2}{*}{4 Werte } & 1 & 3 \\
\hline & 2 & 4 \\
\hline Milchflusscharakteristik & $\begin{array}{l}\text { Abscheider } \\
\text { Leitung }\end{array}$ & \\
\hline $\begin{array}{l}\text { Treten die ersten Kühe eines j } \\
\text { Durchganges flott in den Melkstand? }\end{array}$ & ja / nein & \\
\hline
\end{tabular}




\begin{tabular}{|l|l|l|}
\hline Euterform & $\begin{array}{l}\text { Stufeneuter } \\
\text { Ziegeneuter } \\
\text { Normal }\end{array}$ & \\
\hline $\begin{array}{l}\text { Wird Luftsaugen während des Melkens } \\
\text { korrigiert? }\end{array}$ & ja / nein & \\
\hline Sind die Arbeitsabläufe für jede Kuh gleich? & ja / nein & \\
\hline Handschuhe beim Melken? & Abweichungen: & \\
\hline Zwischendesinfektion? & & \\
\hline Reinigung Standfläche der Kühe im Melkstand & & \\
\hline Helligkeit Weg der Kuh? & lux & \\
\hline Winkel von Wartehof zu Melkstand? & & \\
\hline Gerade Strecke vor dem Melkstand? & & \\
\hline Winkel, bis 3 Kühe nebeneinander stehen ? & & \\
\hline Ende des Melkens? & & \\
\hline Ende der besuchten Melkzeit Licht aus? & & \\
\hline Ist immer eine Person im Melkstand? & & \\
\hline Personen von Anfang bis Ende am Melken? & & \\
\hline Personen sind nur zeitweise am Melken? & & \\
\hline Personen sind maximal zeitgleich am Melken? & & \\
\hline Melker verlässt den Melkstand für wie lange? & & \\
\hline
\end{tabular}




\begin{tabular}{|c|c|}
\hline Wie wird nachgetrieben? & $\begin{array}{l}\text { Mechanisch } \\
\text { Ketten mit Strom } \\
\text { Ketten ohne Strom } \\
\text { Melker mit } \\
\text { zwischendrin } \\
\text { abtrennen } \\
\text { Andere Person mit } \\
\text { abtrennen } \\
\text { Hund }\end{array}$ \\
\hline Art Melkstand, Anzahl Plätze & $\begin{array}{l}\text { Tandem } \\
\text { Fischgräte } \\
\text { Side by side } \\
\text { Swing over } \\
\text { Eimermelkanlage } \\
\text { Rohrmelkanlage }\end{array}$ \\
\hline Zitzengummis & $\begin{array}{l}\text { Hersteller } \\
\text { Weite } \\
\text { Länge }\end{array}$ \\
\hline Melkbecher & $\begin{array}{l}\text { Hersteller } \\
\text { Größe }\end{array}$ \\
\hline Sammelstück & $\begin{array}{l}\text { Hersteller } \\
\text { Größe }\end{array}$ \\
\hline Langer Milchschlauch & $\begin{array}{l}\text { Durchmesser } \\
\text { Material }\end{array}$ \\
\hline Milchleitung Durchmesser & $\begin{array}{l}\text { Hersteller } \\
\text { Größe } \\
\text { Material }\end{array}$ \\
\hline Art der Milchleitung & $\begin{array}{l}\text { Ringleitung } \\
\text { Stichleitung }\end{array}$ \\
\hline Pulsator & $\begin{array}{l}\text { Hersteller } \\
\text { Fabrikat }\end{array}$ \\
\hline
\end{tabular}




\begin{tabular}{|l|l|l|}
\hline Pumpenleistung & $\begin{array}{l}\text { Hersteller } \\
\text { Typ } \\
\text { Leistung }\end{array}$ & \\
\hline Regelventil & $\begin{array}{l}\text { Hersteller } \\
\text { Typbezeichnung }\end{array}$ & \\
\hline Nachmelkautomatik & ja / nein & \\
\hline Abnahmeautomatik & $\begin{array}{l}\text { Nein } \\
\text { Typ }\end{array}$ & \\
\hline Servicearm Melkanlage & Keinen & \\
\hline Reinigungsmittel & sauer \\
alkalisch & \\
\hline Tankmilch an Kontrolldatum & & \\
\hline Kälbermilch an Kontrolldatum & & \\
\hline Typbez. Dippmittel & & \\
\hline
\end{tabular}




\section{Datenaufnahme Stall}

\begin{tabular}{|c|c|c|c|}
\hline Sind die Tränken sauber? & $\begin{array}{l}\text { Klares Wasser } \\
\text { Wenig Ablagerungen } \\
\text { Der Boden ist nicht mehr zu } \\
\text { erkennen }\end{array}$ & & \\
\hline Anzahl Tränken im Kuhstall & $\begin{array}{l}\text { Kleine Schalentränken } \\
\text { Große Schalentränken } \\
\text { Klappentränken } \\
\text { Balltränken } \\
\text { Meter Trogtränke }\end{array}$ & & \\
\hline $\begin{array}{l}\text { Wassernachfluss bei Schalen- und } \\
\text { Klappentränken }\end{array}$ & $\begin{array}{l}\text { Langsam } \\
\text { Mitte } \\
\text { Schnell }\end{array}$ & & \\
\hline \multicolumn{4}{|l|}{ Höhe der Tränken } \\
\hline Wo sind die Tränken platziert? & $\begin{array}{l}\text { Melkstand } \\
\text { Nach dem Melkstand } \\
\text { Zentral } \\
\text { In Sackgassen }\end{array}$ & & \\
\hline Höhe Futtertisch & & $\mathrm{cm}$ & $\mathrm{cm}$ \\
\hline $\begin{array}{l}\text { Ist das Fressgitter zum Futtertisch } \\
\text { geneigt? }\end{array}$ & $\begin{array}{l}0^{\circ} \\
5^{\circ} \\
10^{\circ} \\
15^{\circ}\end{array}$ & & \\
\hline Fressplatzbreite & & $\mathrm{cm}$ & $\mathrm{cm}$ \\
\hline \multicolumn{4}{|l|}{ Breite des Fressgangs } \\
\hline Art der Liegeboxen & $\begin{array}{l}\text { Hochbox } \\
\text { Tiefbox }\end{array}$ & & \\
\hline Boxenbreite / Liegeflächenbreite & & & \\
\hline
\end{tabular}




\begin{tabular}{|c|c|c|}
\hline Boxenlänge & $\begin{array}{l}\text { Gegenständig } \\
\text { Wandständig }\end{array}$ & \\
\hline \multicolumn{3}{|l|}{ Nackenriegelhöhe } \\
\hline \multicolumn{3}{|l|}{ Nackenriegellage } \\
\hline \multicolumn{3}{|l|}{ Diagonale Nackenriegellage } \\
\hline \multicolumn{3}{|l|}{ Bugschwellenabstand } \\
\hline \multicolumn{3}{|l|}{ Bugschwellenhöhe } \\
\hline \multicolumn{3}{|l|}{ Seitenbügelhöhe } \\
\hline \multicolumn{3}{|l|}{ Höhe der Liegebox } \\
\hline \multicolumn{3}{|l|}{ Höhe Streuschwelle } \\
\hline \multicolumn{3}{|l|}{ Zu überwindende Kante? } \\
\hline \multicolumn{3}{|l|}{ Höhe der Einstreu (Menge) } \\
\hline Wie weich ist die Liegefläche? & $\begin{array}{l}\text { Sehr weich (angenehm) } \\
\text { Weich (unangenehm) } \\
\text { Hart (schmerzt) }\end{array}$ & \\
\hline $\begin{array}{l}\text { Ist die Liegefläche im Euterbereich } \\
\text { trocken? }\end{array}$ & $\begin{array}{l}\text { Trocken } \\
\text { Feucht } \\
\text { Nass }\end{array}$ & \\
\hline $\begin{array}{l}\text { Ist die Liegefläche im Euterbereich } \\
\text { sauber? }\end{array}$ & $\begin{array}{l}\text { Frische Einstreu } \\
\text { Trockene Kotreste } \\
\text { Nasse Kotreste }\end{array}$ & \\
\hline Vermessung der 3 größten Kühen & $\begin{array}{l}\text { Widerristhöhe } \\
\text { Schräge Rumpflänge } \\
\text { (Sitzbeinhöcker - Buggelenk) }\end{array}$ & \\
\hline Breite des schmalsten Laufgangs & & \\
\hline Breite der Durchgänge & & \\
\hline Sauberkeit der Laufflächen & & \\
\hline
\end{tabular}




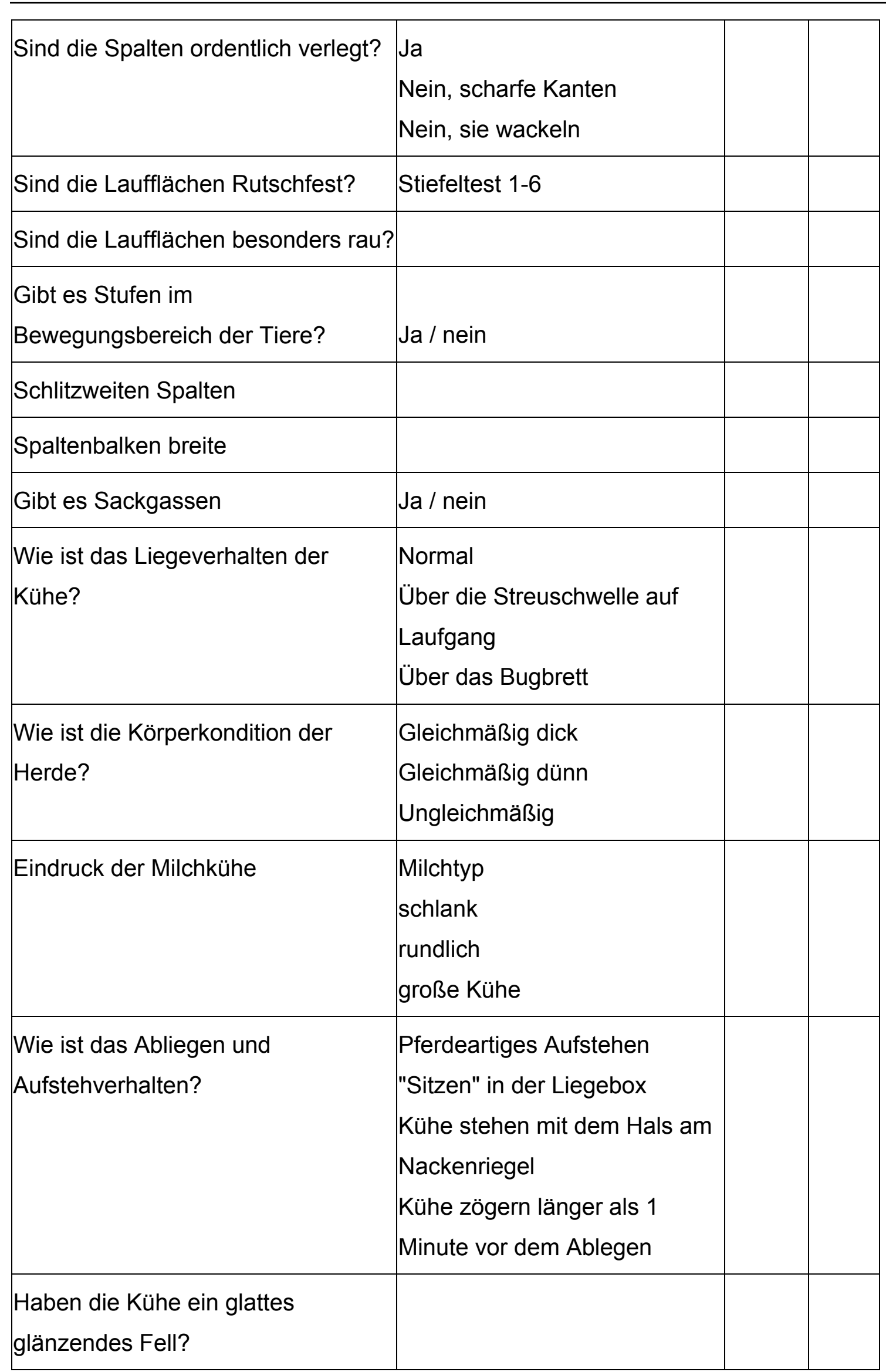




\begin{tabular}{|c|c|c|}
\hline $\begin{array}{l}\text { Haben die Kühe Verletzungen an } \\
\text { der Wirbelsäule? }\end{array}$ & & $\%$ \\
\hline $\begin{array}{l}\text { Zeigen die Kühe aufmerksames } \\
\text { Ohrenspiel? }\end{array}$ & & \\
\hline Individualdistanz & & \\
\hline $\begin{array}{l}\text { Wie ist die Luftqualität im } \\
\text { Liegebereich der Kühe? }\end{array}$ & & \\
\hline$m^{2}$ Laufhof je Kuh & & \\
\hline Ist der Laufhof attraktiv gestaltet? & $\begin{array}{l}\text { Tränke } \\
\text { Kraftfutterautomat } \\
\text { Grünfutterangebot } \\
\text { Putzgeräte }\end{array}$ & \\
\hline Art der Anbindung & $\begin{array}{l}\text { Grabner-Kette } \\
\text { Fangrahmen } \\
\text { Riemen } \\
\text { Kugelfang } \\
\text { Halsrahmen }\end{array}$ & \\
\hline Lüftungssystem im Stall & $\begin{array}{l}\text { Trauf-First-Lüftung } \\
\text { Querlüftung }\end{array}$ & \\
\hline Dach & $\begin{array}{l}\text { Isoliert } \\
\text { Dachplatten } \\
\text { Dachplatten mit Schlitzen } \\
\text { verlegt }\end{array}$ & \\
\hline Wandaufbau & $\begin{array}{l}\text { links } \\
\text { rechts } \\
\text { Stirn a } \\
\text { Stirn b }\end{array}$ & \\
\hline Tierbesatz im Stall & $\begin{array}{l}\text { Kühe } \\
1-2 \text { Jahr } \\
0-1 \text { Jahr }\end{array}$ & \\
\hline
\end{tabular}




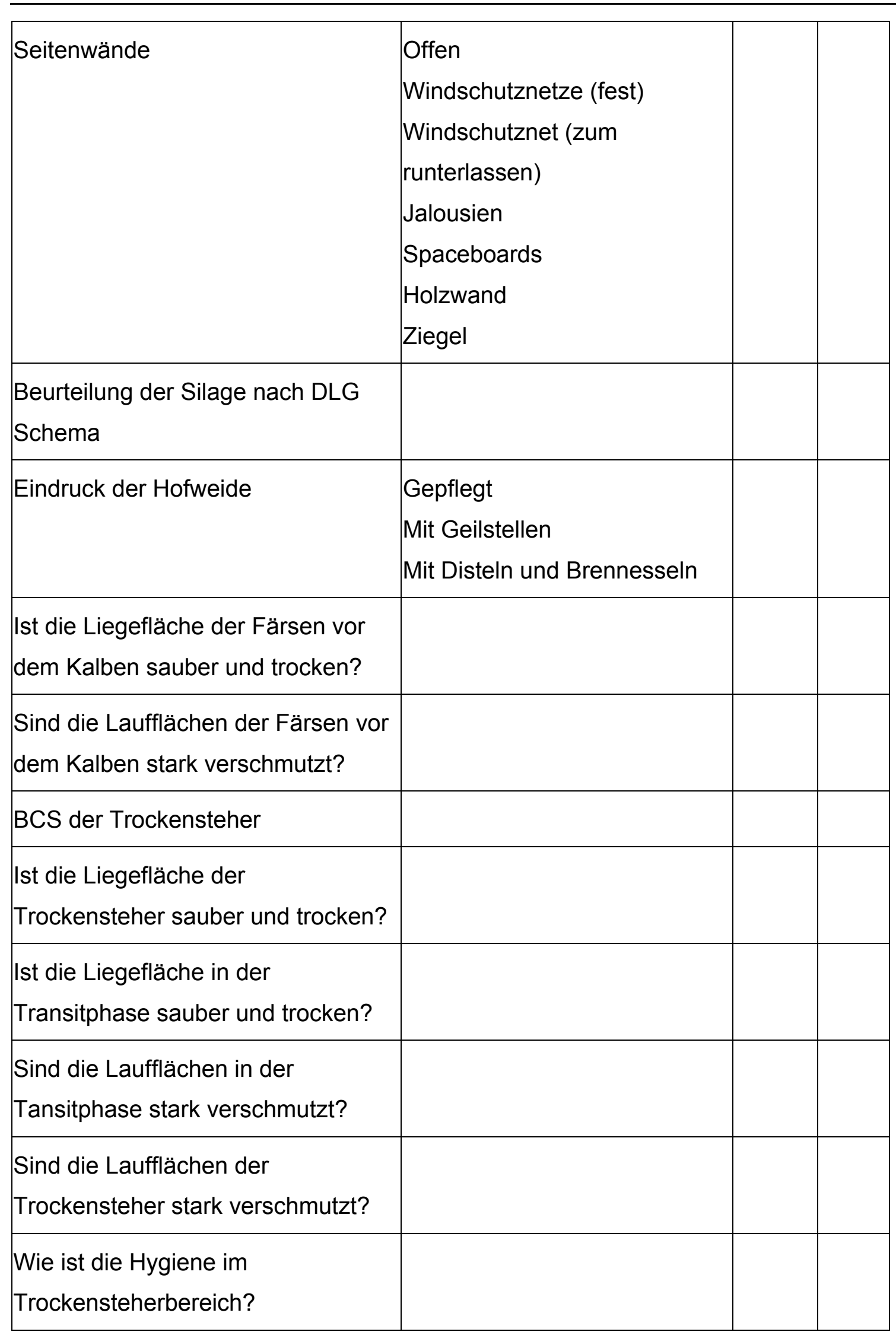




\begin{tabular}{|l|l|l|l|}
\hline Allgemeine Hygienebewertung (1-6) & Melkstand & & \\
& Milchkammer & & \\
& Stall & & \\
Futtertisch & Melken & & \\
\hline Persönlicher Eindruck & Futter & & \\
& Umgang mit Tieren & & \\
& Eindruck der Tiere & & \\
& Haltung & & \\
Besonderheiten & Hygiene & & \\
\hline Bas ist das Geheimnis des & Menschen & & \\
\hline
\end{tabular}


Datenaufnahme Stallbuch

\begin{tabular}{|c|c|c|c|}
\hline Stallbuch & Prophylaxe & Therapie & Mittel \\
\hline \multicolumn{4}{|l|}{ Mastitis } \\
\hline \multicolumn{4}{|l|}{ Verletzung } \\
\hline \multicolumn{4}{|l|}{ hochzellig } \\
\hline \multicolumn{4}{|l|}{ Flocken } \\
\hline \multicolumn{4}{|l|}{$\mathrm{FI}+$ Schwellung } \\
\hline \multicolumn{4}{|l|}{$\mathrm{Fl}+$ Schw+Fieber } \\
\hline \multicolumn{4}{|l|}{ Stoffwechsel } \\
\hline \multicolumn{4}{|l|}{ Rest } \\
\hline \multicolumn{4}{|l|}{ Labmagen } \\
\hline \multicolumn{4}{|l|}{ Milchfieber } \\
\hline \multicolumn{4}{|l|}{ Lahmheiten } \\
\hline \multicolumn{4}{|l|}{ Lahmheit } \\
\hline \multicolumn{4}{|l|}{ Panaritium } \\
\hline \multicolumn{4}{|l|}{ Mortellaro } \\
\hline \multicolumn{4}{|l|}{ Fruchtbarkeit } \\
\hline \multicolumn{4}{|l|}{ Nachgeb.verhaltung } \\
\hline \multicolumn{4}{|l|}{ Gebärmutterentz. } \\
\hline \multicolumn{4}{|l|}{ Spirale } \\
\hline \multicolumn{4}{|l|}{ Hormone } \\
\hline \multicolumn{4}{|l|}{ Sonstige } \\
\hline \multicolumn{4}{|l|}{ Lungenentzündung } \\
\hline \multicolumn{4}{|l|}{ Fremdkörper } \\
\hline \multicolumn{4}{|l|}{ Durchfall } \\
\hline Verstopfung & & & \\
\hline
\end{tabular}




\section{Danksagung}

Zuerst möchte ich all denen danken, die zum Gelingen dieser Arbeit beigetragen haben.

Bedanken möchte ich mich bei Herrn Prof. Dr. Gauly für die Übernahme des Referats. Außerdem danke ich Prof. Dr. Krömker für die Überlassung des Themas, die Übernahme des Korreferats und die Bereitstellung der Daten für die Vergleichsgruppe. Herrn Prof. Dr. Isselstein und Herrn Prof. Dr. Abel möchte ich dafür danken, dass sie die Tätigkeit des 3. Prüfers und 4. Prüfers übernommen haben.

Darüber hinaus möchte ich allen Betriebsleiter/innen herzlich danken, die diese Studie erst ermöglicht haben, indem sie ihre Daten zur Verfügung gestellt und sich sehr viel Zeit für die Beantwortung der Fragen und die Erhebung der Daten während der Betriebsbesuche genommen haben.

Die Studie wurde dankenswerter Weise von der Landwirtschaftskammer Niedersachsen, den Vereinigten Informationssystemen Tierhaltung und den Landeskontrollverbänden Weser-Ems und Hannover gefördert und in Zusammenarbeit mit ihnen durchgeführt.

Mein herzlicher Dank gilt ganz besonders meiner Frau, die mir während der Promotionszeit immer zur Seite standen und mich in all meinen Entscheidungen unterstützt hat. 


\section{Lebenslauf}

Personalien

Name: $\quad$ Otto Volling

Geburtsdatum: $\quad 9.6 .1972$

Geburtsort: $\quad$ Soltau, Niedersachsen

Familienstand: Verheiratet

Werdegang

08/78 - 07/82 Grundschule, Pattensen, Niedersachsen

08/82 - 07/84 Orientierungsstufe Pattensen, Niedersachsen

08/84-07/91 Gymnasium Sarstedt, Niedersachsen

10/91 - 12/92 Zivildienst beim Kreisjugenddienst Laatzen/Pattensen

01/93 - 07/94 Ausbildung zum Landwirt auf 2 Milchviehbetrieben

08/94 - 06/96 Landwirtschaftlicher Gehilfe bei Betrieb F. Maage

Ab 04/96 Studium der Agrarwirtschaft, Schwerpunkt Ökologischer Landbau, Gesamthochschule Kassel, Außenstelle Witzenhausen

08/96 - 06/97 Aberdeen, Schottland

04/99 - 06/99 Praktikum: Demeter Erzeugergemeinschaft Berlin-Brandenburg

$02 / 00$ Abschluss Studium der Agrarwirtschaft, Gesamthochschule Kassel

06/00 - 05/01 Berateranwärter,

Beratungsring für ökologischen Landbau Niedersachsen e.V.

06/01 - heute Landwirtschaftlicher Unternehmensberater,

Beratungsring für ökologischen Landbau Niedersachsen e.V.

01/02- 06-10 Agraringenieur, Kompetenzzentrum Ökolandbau Nieders. GmbH

7-10 - heute Landwirtschaftlicher Fachberater beim Bioland e.V. 


\section{Selbstständigkeitserklärung}

Hiermit versichere ich, dass ich die vorliegende Dissertation selbstständig und nur unter Zuhilfenahme der angegebenen Quellen erstellt habe.

Otto Volling

Visselhövede, den 16.12.2010 